\title{
HIV/AIDS : stigma as a factor that affects care seeking, care and support of persons with HIV/AIDS in Port Harcourt Nigeria
}

Citation for published version (APA):

Mbonu, N. C. (2010). HIVIAIDS : stigma as a factor that affects care seeking, care and support of persons with HIVIAIDS in Port Harcourt Nigeria. [Doctoral Thesis, Maastricht University]. Datawyse / Universitaire Pers Maastricht. https://doi.org/10.26481/dis.20101015nm

Document status and date:

Published: 01/01/2010

DOI:

10.26481/dis.20101015nm

Document Version:

Publisher's PDF, also known as Version of record

Please check the document version of this publication:

- A submitted manuscript is the version of the article upon submission and before peer-review. There can be important differences between the submitted version and the official published version of record.

People interested in the research are advised to contact the author for the final version of the publication, or visit the DOI to the publisher's website.

- The final author version and the galley proof are versions of the publication after peer review.

- The final published version features the final layout of the paper including the volume, issue and page numbers.

Link to publication

\footnotetext{
General rights rights.

- You may freely distribute the URL identifying the publication in the public portal. please follow below link for the End User Agreement:

www.umlib.nl/taverne-license

Take down policy

If you believe that this document breaches copyright please contact us at:

repository@maastrichtuniversity.nl

providing details and we will investigate your claim.
}

Copyright and moral rights for the publications made accessible in the public portal are retained by the authors and/or other copyright owners and it is a condition of accessing publications that users recognise and abide by the legal requirements associated with these

- Users may download and print one copy of any publication from the public portal for the purpose of private study or research.

- You may not further distribute the material or use it for any profit-making activity or commercial gain

If the publication is distributed under the terms of Article $25 \mathrm{fa}$ of the Dutch Copyright Act, indicated by the "Taverne" license above, 


\section{HIV/AIDS}

STIGMA as a factor that affects care seeking, care and support of PERSONS with HIV/AIDS in Port Harcourt Nigeria 
ISBN 9789052789651

(C) Copyright Ngozi C Mbonu, Maastricht 2010

All right reserved. No parts of this book may be reproduced without the prior written permission Of the copyright holder

Production Datawyse / Universitaire Pers Maastricht 


\title{
HIV/AIDS
}

\section{STIGMA as a factor that affects care seeking, care and support of PERSONS with HIV/AIDS in Port Harcourt Nigeria}

\author{
DISSERTATION \\ to obtain the degree of Doctor \\ at the Maastricht University, \\ on the authority of the Rector Magnificus, \\ Prof. dr. G.P.M.F. Mols, \\ in accordance with the decision of the Board of Deans, \\ to be defended in public on Friday 15 October 2010, at 10:00 hours \\ by
}

Ngozika Chinwe Mbonu

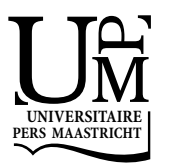




\section{Supervisors}

Prof. dr. N.K. de Vries

Prof. dr. H.W. van den Borne

\section{Assessment Committee}

Prof. dr. G.J. Kok (Chairman)

Dr. A. Dijker

Prof. dr. S. van der Geest (Emeritus) University of Amsterdam

Prof. dr. R.A. Knibbe

Dr. A. Krumeich

Acknowledgements

I gratefully acknowledge the financial support of the the Department of Health Promotion, School of Public Health and primary care (CAPHRI), Faculty of Health, Medicine and Life Sciences, Maastricht University, The Netherlands and the financial assitance from the Department of Dermatology, Phlebology and Laser Therapy, Medical Centre Maastricht, The Netherlands in the printing of the thesis book. 
Courage and perseverance have a magical talisman, before which difficulties disappear and obstacles vanish into air (John Quincy Adams 1767-1848)

To God be the glory

All human actions have one or more of these seven causes: chance, nature, compulsion, habit, reason, passion, and desire (Aristotle 384BC-322BC)

To my father O.C. Umeh 



\section{Contents}

Chapter 1: Introduction.

Chapter 2: Stigma of people with HIV/AIDS in Sub-Saharan

Africa: a literature review.

J Tropical Med. 2009; doi:10.1155/2009/145891.

Chapter 3: A model for understanding the relationship between stigma and healthcare-seeking behavior among people living with HIV/AIDS in Sub-Saharan Africa.

AJAR 2009; 8 (2), 201-212.

Chapter 4: Societal beliefs and reactions about people living with HIV/AIDS in Port Harcourt, Nigeria.

Submitted

Chapter 5: Professional health care delivery problems associated with HIV/AIDS in Port Harcourt, Nigeria.

\section{Submitted}

Chapter 6: The experiences and complexities of care seeking behavior of people living with HIV/AIDS in Port Harcourt, Nigeria.

Submitted

Chapter 7: Gender-related power differences, beliefs and reactions towards people living with HIV/AIDS: An urban city study in Nigeria.

BMC Public health 2010; 10:334.

Chapter 8: Discussion.

Summary

Samenvatting (Summary in Dutch)

Appendix

Curriculum Vitae

List of publications 



\section{Chapter One}

\section{Introduction}

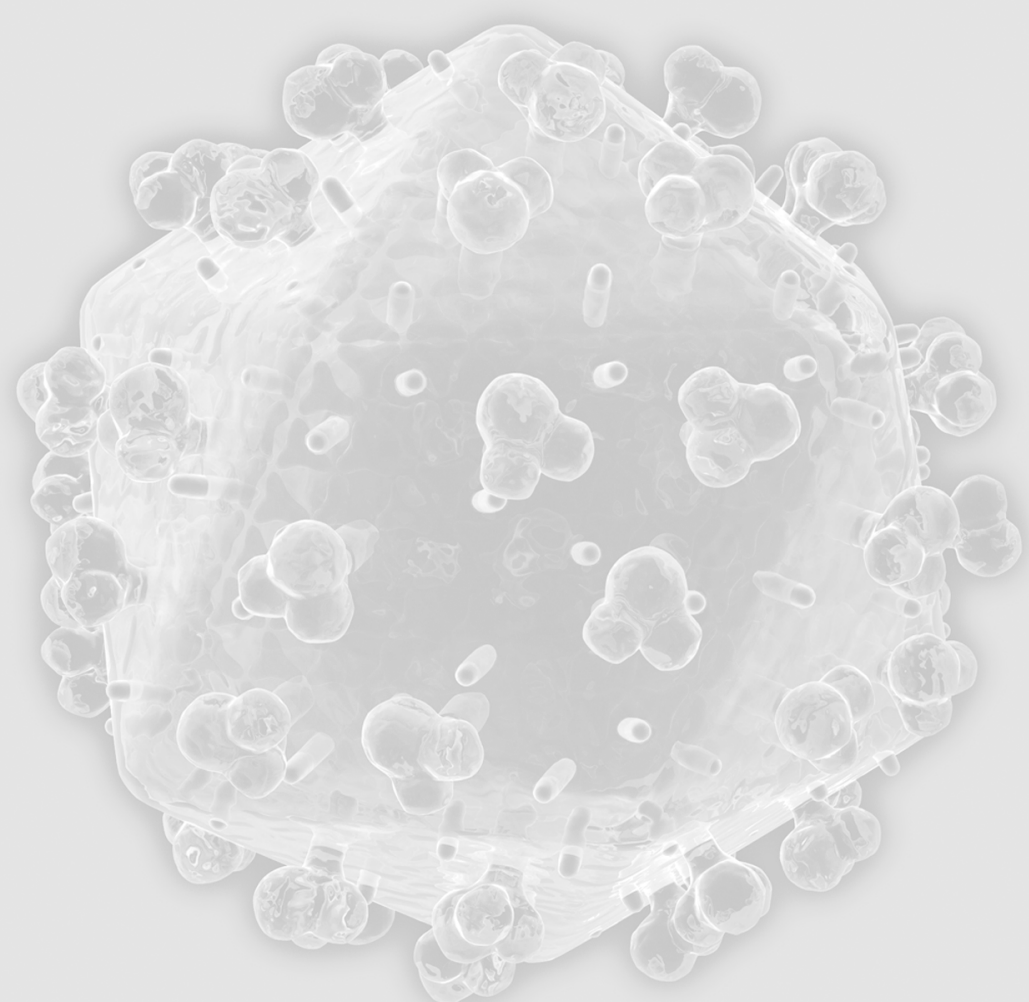




\section{Introduction}

This thesis is about the stigma and effects of stigma on care seeking, care and support of persons with HIV/AIDS. The interest and justification for this research lies in the fact that, despite an increasing awareness of and publicity given to HIV/AIDS, many problems have continued, especially for people living with HIV/AIDS (PLWHA) in developing countries such as Nigeria. The goal is to investigate the problems PLWHA in Port Harcourt, Nigeria, face in society. These include the problems in health care institutions that prevent PLWHA from receiving a good quality and standard of care in hospitals, and that prevent them from being cared for and supported by their communities.

HIV/AIDS has been identified as one of the major problems facing the global community. The HIV/AIDS epidemic is having a profound impact on society which cannot be overemphasized. Globally, 2.7 million new HIV infections and 2 million HIV-related deaths occurred in 2008 (UNAIDS, 2009). Two-thirds (67\%) of the global total of 32.9 million people with HIV live in Sub-Saharan Africa and close to three-quarters (72\%) of all AIDS deaths in 2008 occurred in this region (UNAIDS, 2009). An estimated 1.9 million (1.6 million-2.2 million) people were newly infected with HIV in 2008 in Sub-Saharan Africa. In Nigeria, 2.6 million adults and children were living with HIV/AIDS in 2007 and an estimated 170,000 adults and children died of AIDS in 2007 (World Health Organization [WHO], 2008). Furthermore, in 2007, 1.2 million children under 17 years had been orphaned due to AIDS. Although the infection rate is lower than in neighboring countries, Nigeria has the third highest number of HIV-infected adults in the world after India and South Africa (UNAIDS, 2008). The development over time offers no comfort and the effects will last for decades.

HIV/AIDS cannot yet be cured. Although the current antiretroviral therapy (ART) gives a good prognostic outcome in terms of increased survival and reduced morbidity, still, the lack of a cure for HIV/AIDS affects the way in which society views PLWHA (Carlisle, 2001). Because of the complexity of the HIV/AIDS disease, many afflicted persons are subject to political, social and legal effects (Dhai, 2008). The major risk groups such as sex workers and homosexuals are vulnerable to social and private discrimination, posing particular problems. PLWHA are in an unusual position in society. They are not only suffering from a disease that is a medical challenge, but their social lives are affected as well. Obviously, one of the important aspects of HIV/AIDS is the socio-cultural environment in which PLWHA live and interact.

It is important to understand the health care system in Nigeria to know the care options PLWHA have. Nigeria has a three tier system of health care; the primary, the secondary and the tertiary health care. The primary health care deals with the provision of health care at the local level with the support of the state ministries of health and within the national health policy. Private medical practitioners all 
provide health care at this level. The secondary health care deals with the provision of specialized services to patients referred by the primary health care level to outpatient and in-patient services of hospitals, such as general medical, surgical, pediatric and community health services. This secondary health care is available at the district divisional and zonal levels of the states. Supportive services such as laboratory, diagnostic facilities, blood bank, rehabilitation and physiotherapy are also offered. The tertiary health care consists of highly specialized services provided by teaching hospitals and other specialist hospitals, including orthopaedic, ophthalmology, psychiatric, infectious diseases, maternity and paediatric medicine (Motherland Nigeria, 2009). The private sector provides $65.7 \%$ of health care delivery in Nigeria (WHO, 2009). PLWHA need health services in all three tiers of the health system.

Economically, Nigeria is the sixth largest oil producer in the world and the second largest economy in Sub-Saharan Africa (World Bank, 2009), yet it ranks number 114 in the global human poverty index (computed in 2007: Human Development Report, 2009). Nigeria has a gross national income per capita of 1,410 naira (approximately 60 euros) (World Bank, 2009) and life expectancy at birth for males is 48 years and 49 years for females (WHO, 2009). Furthermore, about $54 \%$ of the population live on less than one dollar per day (World Bank, 2009) creating a large economic inequality in the country. In general, although Nigeria has lots of wealth from natural resources such as crude oil, there is a very large number of very poor people. There is no health insurance that is accessible to all Nigerians. The current national health insurance scheme was conceptualized in 1999 (WHO, 2009), and launched in 2005 with the ambitious aim of covering all Nigerians by 2015 (Ogundipe, 2008). In 2009, this health insurance scheme covered only 4.5 million people (Iroegbu, 2009) out of a population officially estimated to be around 145 million (WHO, 2009).

The World Health Organization (WHO) has been calling for better access to care for people living with HIV/AIDS in developing nations. The Nigerian government has made considerable efforts to curtail the HIV epidemic with a multisector AIDS programme. Among the strategies developed by the Nigerian government is a national policy on HIV/AIDS control, formulated in 1997 (National HIV Policy, 2003). In 2000, the government established two key institutions, namely, the Presidential Committee on AIDS and the National Action Committee on AIDS (NACA), to coordinate the various HIV/AIDS prevention, treatment and care activities in Nigeria (National HIV Policy, 2003). The main responsibility of NACA was the execution and implementation of activities under the HIV/AIDS emergency action plan (HEAP), which was introduced as a bridge to a long-term strategic plan covering up to 2004 (UNAIDS, 2008). HEAP had two main components: first, to break down barriers to HIV prevention such as stigma and discrimination and to support community-based responses; and second, to provide direct prevention, care and support interventions. The much-needed and 
recommended government intervention failed to initiate the wave of behavioral change that was anticipated. So far, there was some progress towards achieving the goals of HEAP but there are still huge gaps in HIV prevention, treatment and care services, particularly at community level (Partner for Health, 2004; Abdulsalami \& Tekena, 2004). Since 2007, NACA became legally the agency for the control of AIDS in Nigeria (UNAIDS, 2008). NACA currently provides leadership and monitor the progression of HIV epidemic (NACA, 2010). In addition, NACA oversees policies, programmes and projects directed at the AIDS issue.

The Nigerian government also began importing some antiretroviral therapy (ART) (World Health Organization, 2009), but not in sufficient quantity for the number of PLWHA (Uzochukwu et al., 2009; WHO, 2009). The proportion of people with advanced HIV in Nigeria receiving ART increased from 2\% in 2004 to $26 \%$ in 2007; still, only $7 \%$ of pregnant women with HIV/AIDS received ART for prevention of mother-to-child transmission (PMTCT) in 2007 (UNAIDS, 2008). The most important reason cited for the lack of participation in the Nigerian government's ART programme was reported to be the cost of diagnosis and treatment, amplified by disease-associated stigma (Adeneye et al., 2006; Uzochukwu et al., 2009). Antiretroviral therapy is just one of the many needs of PLWHA, however. Each hospital is bound to have HIV patients in its care at any time and should give them the same attention as they would in any other class of patients. But PLWHA have concerns and needs beyond accurate diagnosis and medical treatment in hospitals; they also have a need for care from people around them in society. Unfortunately, PLWHA are not like others in that they are highly stigmatized by the society and this includes health care professionals (HCPs).

One of the major problems that PLWHA face is stigma. Stigma has a large impact on PLWHA, their behavior, the health care system and society. Until now there has been limited research on HIV-related stigma in Nigeria. Due to the scarcity of research on this topic, there is a need for the problems of PLWHA to become clear. For this to be achieved, understanding HIV-related stigma, its determining causes, processes and effects in society including in health care institutions, remains one of the key factors as well as the basis for introducing mechanisms and strategies that address the underlying conditions that support it. This approach should be bolstered by sufficient legal and policy mechanisms to protect PLWHA who are subject to stigma. The mechanisms should be functional and accessible to all. The main aim of the studies reported in this dissertation is to contribute to understanding of HIV-related stigma, its causes and effects.

\section{Study area}

The study was performed in Port Harcourt city, Rivers State, Nigeria. Port Harcourt is located in the southern part of Nigeria, in the Niger delta. It lies along the Bonny River (an eastern tributary of the Niger), 66km upstream from the Gulf of Guinea 
(Port Harcourt, 2009). Port Harcourt was founded by the British in an area originally inhabited by Ikwerre-Igbo people and Okrika people. There is a huge inflow of people from different parts of Nigeria and from outside Nigeria who live and work in the city. Oil being one of Nigeria's most important commodities and the main foreign exchange earner, Port Harcourt is the chief oil refining city in Nigeria, with the presence of many multinational firms. The official population of Rivers State in 1991 was 3,187,864 (Rivers State Government, 2010), and according to the 2005 census the population was 5, 689, 087 (Nigeria exchange, 2010). Families have a median of six persons per household (Obinna, Owei, Ayodele \& Okwakpam, 2009). There are three main types of religions; namely Christianity, Islam and traditional religions. Figure 1 is the map of Nigeria showing Port Harcourt and some major cities.

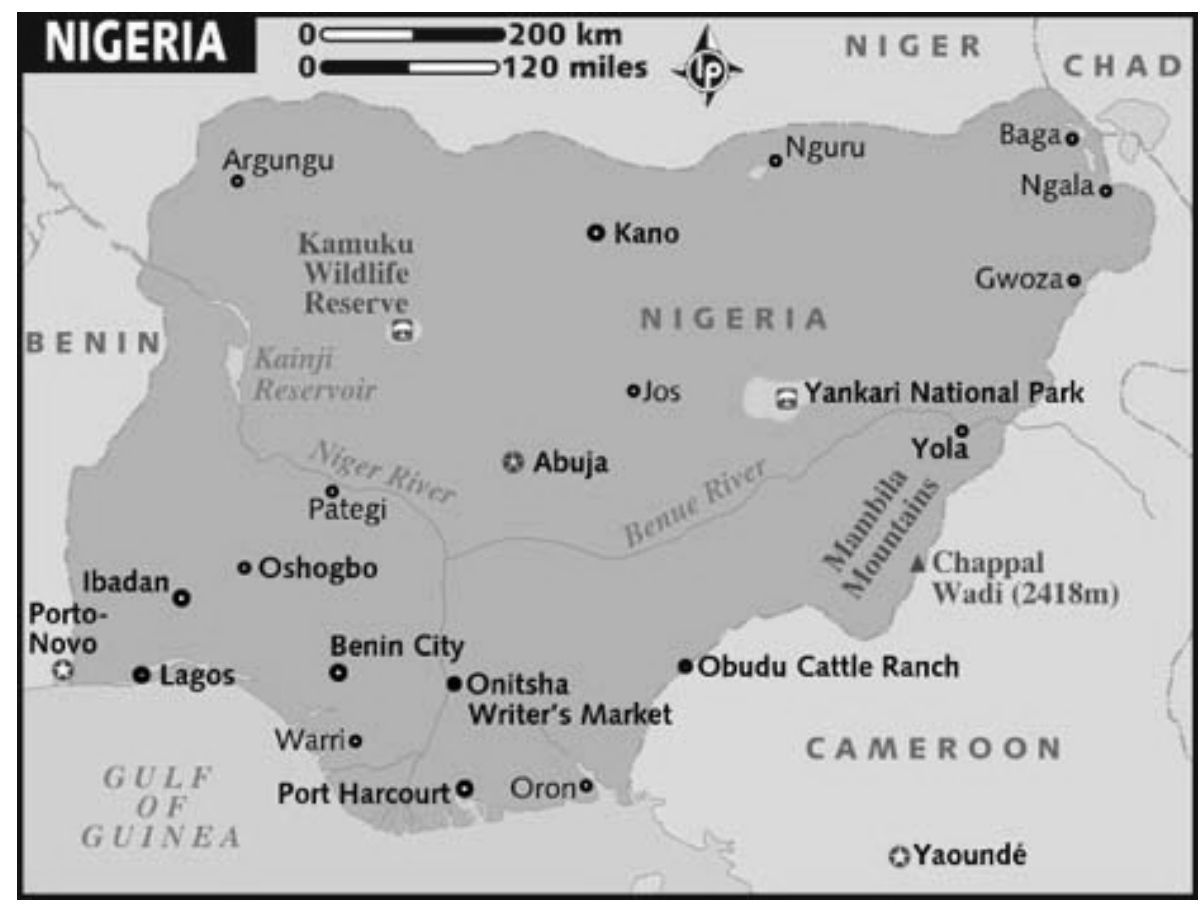

Figure 1. Map of Nigeria showing Port-Harcourt and some major cities

\section{Thesis aims}

The general aims of the research reported in this thesis are threefold:

1. To investigate the problems of PLWHA associated with seeking and receiving care.

2. To understand the role of stigma in care seeking and receiving care.

3. To explore how this affects the HCPs caring for PLWHA. 
The studies reported in this thesis focus on the following specific research questions:

1. What are the underlying factors that allow stigma to occur in society?

2. What makes PLWHA refrain from seeking timely and proper care in health care institutions?

a. What is the role of stigma in care seeking behavior of PLWHA?

b. What are the determinants of care seeking?

3. What role does gender play with regard to stigmatization of PLWHA?

4. What is the current situation of the care of patients with HIV/AIDS in health care institutions?

5. What are the coping mechanisms that PLWHA use?

6. What are the consequences of HIV stigma in society?

This thesis presents qualitative studies investigating and exploring these questions, while drawing upon a variety of research findings to illustrate ways in which PLWHA experience stigmatization which affects their quality of life. The thesis discusses the implications for future research as well as recommendations for health care, health care institutions and health promotion interventions. The thesis is organized in eight chapters which examines from different perspectives how stigmatization has a profound effect on PLWHA. We first give an outline of the study followed by a brief description of the chapters.

\section{Outline of the study}

We started out by doing a comprehensive literature review (Chapters 2 and 3) followed by three interrelated qualitative studies among the general public, health care professionals and PLWHA. The results and outcomes of the four qualitative studies are shown in chapters 4 to 7 . Figure 2 shows the outline of the study.
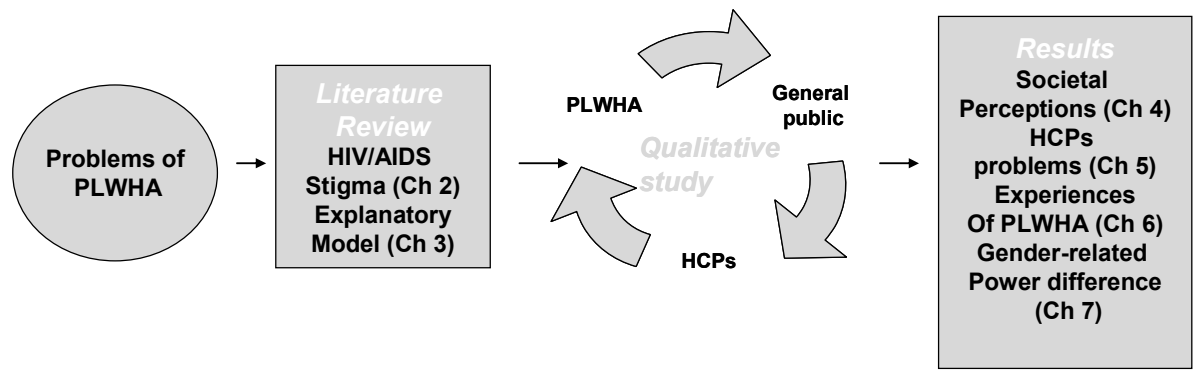

Figure 2 showing Outline of the study 


\section{Chapter 2 A literature review of HIV/AIDS stigma in Sub-Saharan Africa}

This chapter reviews empirical work from previous studies that highlight the problems of HIV/AIDS stigma and its processes. We discuss some well documented issues that contribute to stigmatization in Sub-Saharan Africa. For example, we describe how beliefs about contamination, sexuality and religion contribute to stigmatization. Second, we explore how the cultural construction of HIV, stereotypes and specific beliefs in society influence the denial and acceptance of HIV/AIDS. Finally, we discuss the consequences of HIV/AIDS and discrimination against PLWHA.

Chapter 3 A model for understanding the care-seeking behavior of PLWHA in Sub-Saharan Africa

In this chapter, we present a conceptual model developed to explain the careseeking behavior of PLWHA. We draw information from existing scientific research to answer a number of questions about the non-utilization of health care institutions by PLWHA. The model provides a representation of factors affecting the care-seeking behavior of PLWHA and their coping mechanisms. This model offers a framework for the design and analysis of the research carried out in Chapter 6. Moreover, the model emerged useful for predictions to be derived from the specific research questions posed in Chapter 8. Finally, the model may guide researchers in their research and analysis of help and care seeking behaviour of PLWHA and accommodate modifications.

\section{Chapter 4 Societal beliefs and reactions towards PLWHA in Port Harcourt, Nigeria}

This chapter examines the societal beliefs and reactions towards PLWHA. We focus particularly on public opinion about PLWHA with regard to caring for them. We address the various determining factors that allow stigma to become manifest in society and present both the overt and subtle manifestations of stigma. In addition, this study identifies the conditions in which some people do not stigmatize PLWHA and are prepared to care for them.

\section{Chapter 5 Professional health care delivery problems associated with HIV/AIDS in Port Harcourt, Nigeria}

This chapter deals with problems associated with caring for PLWHA in health care institutions. We examine factors contributing to problems health care professionals ( $\mathrm{HCPs})$ experience in care delivery. We investigate differences between private and government hospitals with regard to care of PLWHA, and the effects of problems of delivery of care by HCPs to PLWHA. We provide a number of suggestions to improve the care PLWHA receive in health care institutions. 
Chapter 6 Experiences and complexities of care seeking behavior of PLWHA in Port Harcourt, Nigeria

This chapter addresses the ways in which stigmatization affects care-seeking behavior of PLWHA in Port Harcourt, Nigeria. We begin by using our explanatory model, depicted in the previous research (Chapter 3) to organize the findings. This research suggests that a number of factors contribute to problems in care seeking, but also identifies the coping mechanisms used by PLWHA in Port Harcourt, Nigeria in dealing with HIV/AIDS. On the whole, specific recommendations are given to support PLWHA in coping with their specific situations.

Chapter 7 Gender-related power differences, beliefs and reactions towards people living with HIV/AIDS: An urban city study in Nigeria

This chapter examines gender-related differences in beliefs and reactions towards PLWHA. In order to highlight the differences in negative reactions based on societal beliefs, we compare data from three groups; the general public, HCPs and PLWHA. Furthermore, we use Connell's (1987) theory of gender and power to analyze our findings (Connell, 1987). On the basis of this theory, the causes of gender-related differences in beliefs and reactions towards PLWHA are identified. We discuss the unique situation in which women living with HIV/AIDS find themselves in family, society and health care institutions.

\section{Chapter 8 Discussion}

In this concluding chapter, we discuss the implications of the results from all the chapters pertaining to the problems of PLWHA, the methodological considerations and the limitations of the research. While recognizing the many problems of PLWHA, some of which we highlight, we conclude by offering recommendations that may help health care professionals and policy makers to improve the quality of life of PLWHA.

\section{References}

Abdulsalami, N., \& Tekena, O.H. (2004). The epidemiology of HIV/AIDS in Nigeria. Retrieved 12 March, 2010 from Harvard website: http://www.apin.harvard.edu/chapter2.pdf.

Adeneye, A.K., Adewole, T.A., Musa, A.Z., Onwujekwe, D., Odunukwe, N.N., Araoyinbo, I.D., Gbajabiamila, T.A., Ezeobi, P.M., \& Idigbe, E.O. (2006). Limitations to access and use of antiretroviral therapy (ART) among HIV positive persons in Lagos, Nigeria. World Health and Population, 8 (2), 46-56.

Carlisle, C. (2001). HIV/AIDS. In Mason, T., Carlisle, C., Watkins, C \& Whitehead (Eds.), HIV and AIDS. (Pg 117-125). New York: Routledge publishers.

Connell, R.W. (1987). Gender and power: society, the person and sexual politics. United Kingdom: Blackwell publishers.

Dhai, A. (2008). HIV and AIDS in Africa: social, political and economic realities. Theoretical Medicine and Bioethics, 29 (5), 293-296. 
Human Development Report, (2009). 1-I Human and Income Poverty: Human poverty index (HPI-I) rank. Retrieved 1 March 2010 from UNDP website: http:/hdrstats.undp.org/en/indicators $/ 96 . h \mathrm{html}$.

Iroegbu, O. (2009). International Finance Corporation (IFC) and the National Health Insurance Scheme (NHIS) to expand insurance coverage. Retrieved 27 October 2009 from thenationonline website: www.thenationonlineng.net/web2/articles/23251/1/IFC-NHIS-toexpand-insurance.

Motherland Nigeria, (2009). Current health policy: National health policy in Nigeria. Retrieved 6 October 2009 from Motherland Nigeria website: www.motherland Nigeria.com/health.html.

National agency for the control of AIDS (NACA) (2010). Welcome to the National agency for the control of AIDS. Retrieved 16 March 2010 from NACA website: http://www.naca.gov.ng/index.php?options $=$ com_frontpage\&itemid $=1$.

National HIV Policy, (2003). Federal Government of Nigeria: National Policy on HIV/AIDS 2003. Retrieved 1 March 2010 from Nigeriaaids website: http://www.nigeria-aids.org/documents/NationalHIVPolicy.pdf.

Nigeria Exchange, (2010). Rivers State. Retrieved 2 March 2010 from Nigeria Exchange website: www.ngex.com/nigeria/placses/states/rivers.htm.

Obinna, V., Owei, O., Ayodele, A., \& Okwakpam, I. (2009). Patterns and determinants of recreational behavior in Port Harcourt, Rivers State, Nigeria. Theoretical and Empirical Researches in Urban Management, 3 (12), 150-165.

Ogundipe, S. (2008). Nigerians should expect universal health insurance coverage by 2015 . Retrieved 8 January 2010 from AllAfrica.com website: www.allafrica.com/ stories/200809230539.html.

Partners for health, (2004). Nigeria: Rapid assessment of HIV/AIDS care in the public and private sectors. Retrieved 1 March 2010 from Population and health inforshare Nigeria website: www://phishare.org/documents/phrplus/2708.

Port Harcourt, (2009). Port Harcourt Nigeria. Retrieved 8 December 2009 from Port Harcourt website: www.portharcourt.com.

Rivers State Government, (2010). About Rivers State. Retrieved 2 March 2010 from Rivers State Government website: www.riversstate.gov.ng.

The Joint United Nations Programme on HIV/AIDS (UNAIDS), 2008. Nigeria UNGASS 2007 Report. Retrieved 12 March 2010 from UNAIDS website: http://data.unaids.org/pub/report/2008/nigeria_2008_country_progress_report_en.pdf.

The Joint United Nations Programme on HIV/AIDS (UNAIDS), 2008. Treatment and Care: 2008 report on the global AIDS epidemic. Retrieved 16 July 2009 from UNAIDS website: http://data.unaids.org/pub/GlobalReport/2008/jc1510_2008_global_report_pp129_158_en.pdf.

The Joint United Nations Programme on HIV/AIDS (UNAIDS), (2009). AIDS epidemic update December 2009. Retrieved 22 January 2010 from UNAIDS website: http://data.unaids.org/pub/Report/2009/JC1700_EPI_Update_2009_en.pdf.

Uzochukwu, B.S.C., Onwujekwe, O.E., Onoka, A.C., Okoli, C., Uguru, N.P., \& Chukwuogo, O.I. (2009). Determinants of non-adherence to subsidized anti-retroviral treatment in South East Nigeria. Health Policy and Planning, 24(3), 189-196.

World Health Organization, (2008). Epidemiological fact sheet on HIV and AIDS: Core data on epidemiology and response, Nigeria 2008 update. Retrieved 26 August 2009 from WHO website: http://apps.who.int/globalatlas/predefinedReports/EFS2008/full/EFS2008_NG.pdf.

World Health Organization, (2009). Health systems policies and service delivery. Retrieved 6 October 2009 from WHO African Region Nigeria website: http://www.who.int/countries/nga/areas/healthsystems/en/index.html.

World Health Organization, (2009). HIV/AIDS treatment. Retrieved 29 October 2009 from WHO website: www.who.int/hiv/HIVCP_NGA.pdf.

World Bank, (2009). Country brief. Retrieved 8 January 2010 from World bank Nigeria website:www.web.worldbank.org/WBSITE/EXTERNAL/countries/Africaext/Nigeriaextn/o, menuspk:368906. 



\section{Chapter Two}

\section{Stigma of people with HIV/AIDS in Sub-Saharan Africa: a literature review}

Journal of Tropical Medicine, (2009) doi:10.1155/2009/145891

Authors

Ngozi C. Mbonu

Bart van den Borne

Nanne K. De Vries 


\section{Abstract}

Objective: The aim of this literature review is to elucidate what is known about HIV/AIDS and stigma in Sub-Saharan Africa.

Methods: Literature about HIV/AIDS and stigma in Sub-Saharan Africa was systematically searched in Pubmed, Medscape, and Psycinfo up to March 31, 2009. No starting date limit was specified. The material was analyzed using Gilmore and Somerville's (1994) four processes of stigmatizing responses: the definition of the problem HIV/AIDS, identification of people living with HIV/AIDS (PLWHA), linking HIV/AIDS to immorality and other negative characteristics, and finally behavioural consequences of stigma (distancing, isolation, discrimination in care).

Results: It was found that the cultural construction of HIV/AIDS, based on beliefs about contamination, sexuality and religion, plays a crucial role and contributes to the strength of distancing reactions and discrimination in society.

Conclusion: Stigma prevents the delivery of effective social and medical care (including taking antiretroviral therapy), and also enhances the number of HIV infections. More qualitative studies on HIV/AIDS stigma including stigma in health care institutions in Sub-Saharan Africa are recommended. 


\section{Introduction}

Although the current data show that the global HIV/AIDS epidemic is stabilizing, statistics still report an unacceptably high level of infection and progress is uneven in many countries (UNAIDS, 2008). In 2007, approximately 33 million people worldwide were infected with the human immunodeficiency virus (HIV) (UNAIDS, 2008). Sub-Saharan Africa remains the most affected region in the world and it is home to almost $67 \%$ of all people living with HIV (an estimated 22.5 million) (UNAIDS, 2008). In 2007, an estimated 1.7 million adults and children in this region became newly infected, while 1.6 million died of acquired immune deficiency syndrome (AIDS).

People living with HIV/AIDS (PLWHA) face not only medical problems but also social problems associated with the disease. One of the barriers to reaching those who are at risk or infected with HIV/AIDS is stigma (Greeff et al., 2008). Stigma enhances secrecy and denial, which are also catalysts for HIV transmission (Rankin, Brennan, Schell, Laviwa \& Rankin, 2005). Although the reaction to PLWHA varies, with some PLWHA receiving support which positively affects them, HIV/AIDS stigma negatively affects seeking HIV testing, seeking care after diagnosis, quality of care given to HIV patients, and finally the negative perception and treatment of PLWHA by their communities and families, including partners (Herek \& Glunt, 1988; Gerbert, Sumser \& Maguire, 1991). It isolates people from the community and affects the overall quality of life of HIV patients (Rankin et al., 2005; Campbell, Nair, Maimane \& Nicholson, 2007; Miller \& Rubin, 2007; Greeff et al., 2008).

Currently, there is increasing number of researches on HIV-related stigma in Sub-Saharan Africa. It is being increasingly acknowledged; however, that effective treatment and care strategies require an understanding of the cultural context (Goldin, 1994; Campbell et al., 2007) in which stigma exists. The aim of this literature review is to elucidate what is known about HIV/AIDS stigma in SubSaharan Africa, the origins and contents of stigma, contributing factors and the gender dimension of stigma.

\section{Methodology}

The analyses in this review paper were based on Gilmore and Somerville's (1994) (Gilmore \& Somerville, 1994) classification of stigmatization in sexuallytransmitted diseases, which for this paper was applied to the various factors that affect stigmatization of PLWHA. 


\section{Materials}

Literature about HIV/AIDS stigma in Sub-Saharan Africa was systematically searched in Pubmed, Medscape, and Psycinfo up to March 31, 2009. No starting date was specified.

A first search in Medline, PsycInfo and Pubmed with 'HIV/AIDS', 'stigma' and 'Africa' as key words gave 292 abstracts, of which 91 abstracts came from Medline, 57 from PsycInfo, and 144 from Pubmed; another search with 'HIV/AIDS', 'discrimination' and 'Africa' gave an additional 192 abstracts (Medline 73, PsycInfo 15, and Pubmed 104). A total of 484 abstracts were examined. From this list, papers relevant to the aim of this review were selected on the basis of their abstracts; uncertainties were reconciled through discussion with all the authors of this paper. The completeness of the search was checked by means of the reference lists of reviewed articles. Books or book chapters were included whenever applicable. Exclusion criteria included newspaper articles, campaign posters, articles not in the English language and articles not related to the topic. On the basis of this selection, 65 original articles were critically evaluated.

\section{Outcome selection}

HIV stigma as a phenomenon was considered to be the major topic of the review and was not limited to any geographical region. Although HIV/AIDS stigma is a general phenomenon which affects PLWHA in all parts of the world, in this paper, we focused on an analysis of the factors contributing to stigma identified from empirical studies in Sub-Saharan Africa, books, theoretical, and review papers. The factors include cultural constructions, stereotypes and specific beliefs, access to and the role of antiretroviral therapy, religion, and gender.

\section{Results and discussion}

Figure 1 shows the flow chart of the search results. A total of 65 articles were selected. Twenty of these articles were theoretical papers, review papers and articles on stigma not limited to any geographical location while 45 articles were empirical studies from Sub-Saharan Africa. For the analysis of the contributing factors to HIV/AIDS stigma, 45 articles from empirical studies within Sub-Saharan Africa were used. In addition, books, theoretical papers and review papers were also used. Table 1 shows the method, study objectives, study population and country of study of these papers; 21 articles addressed origin and contents of stigma, 30 articles addressed cultural constructions of HIV, stereotypes and specific beliefs, 25 articles addressed access to and the role of ART, 15 articles addressed religion, 30 articles addressed gender and 20 articles addressed consequences of stigma. 


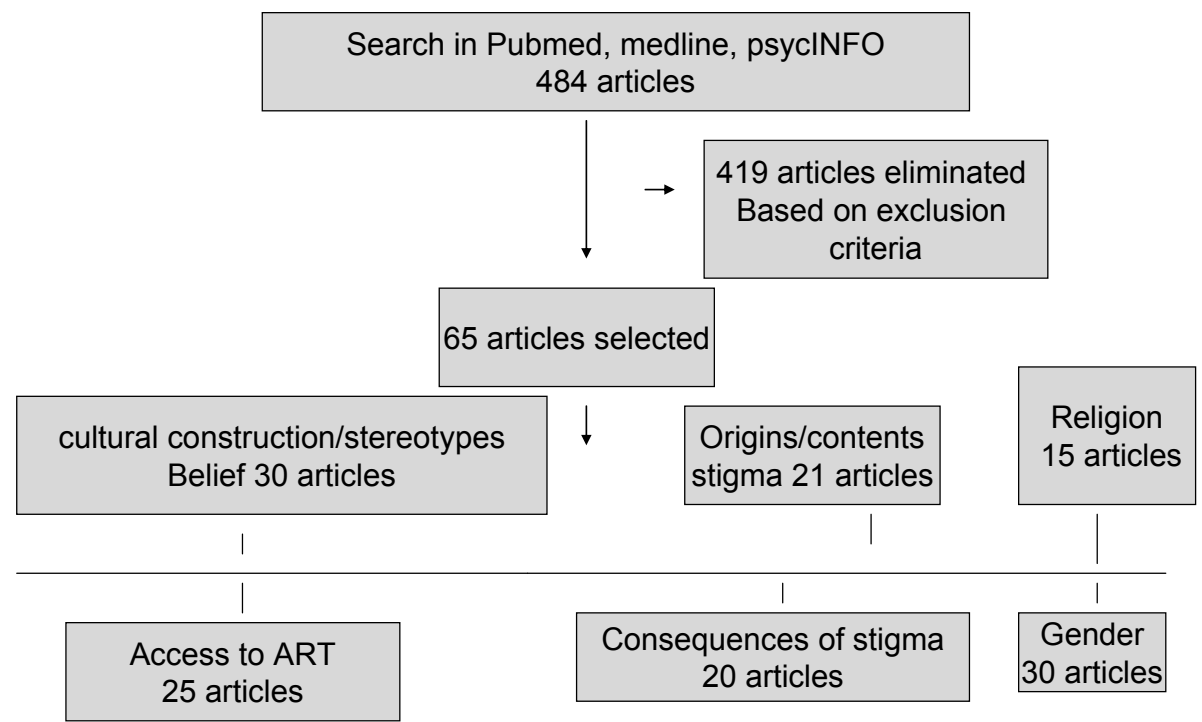

Figure 1 showing the flow chart of search results 


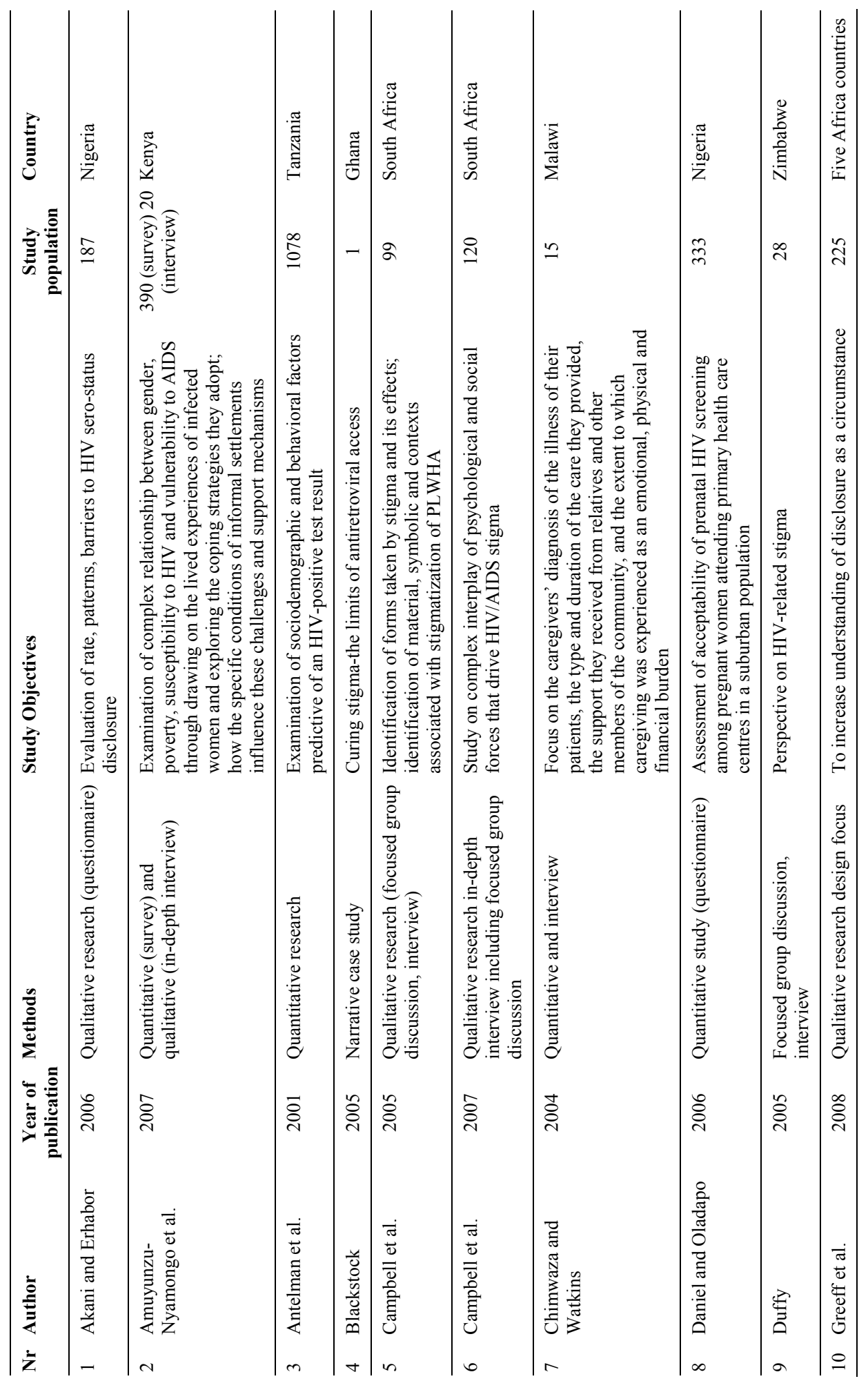




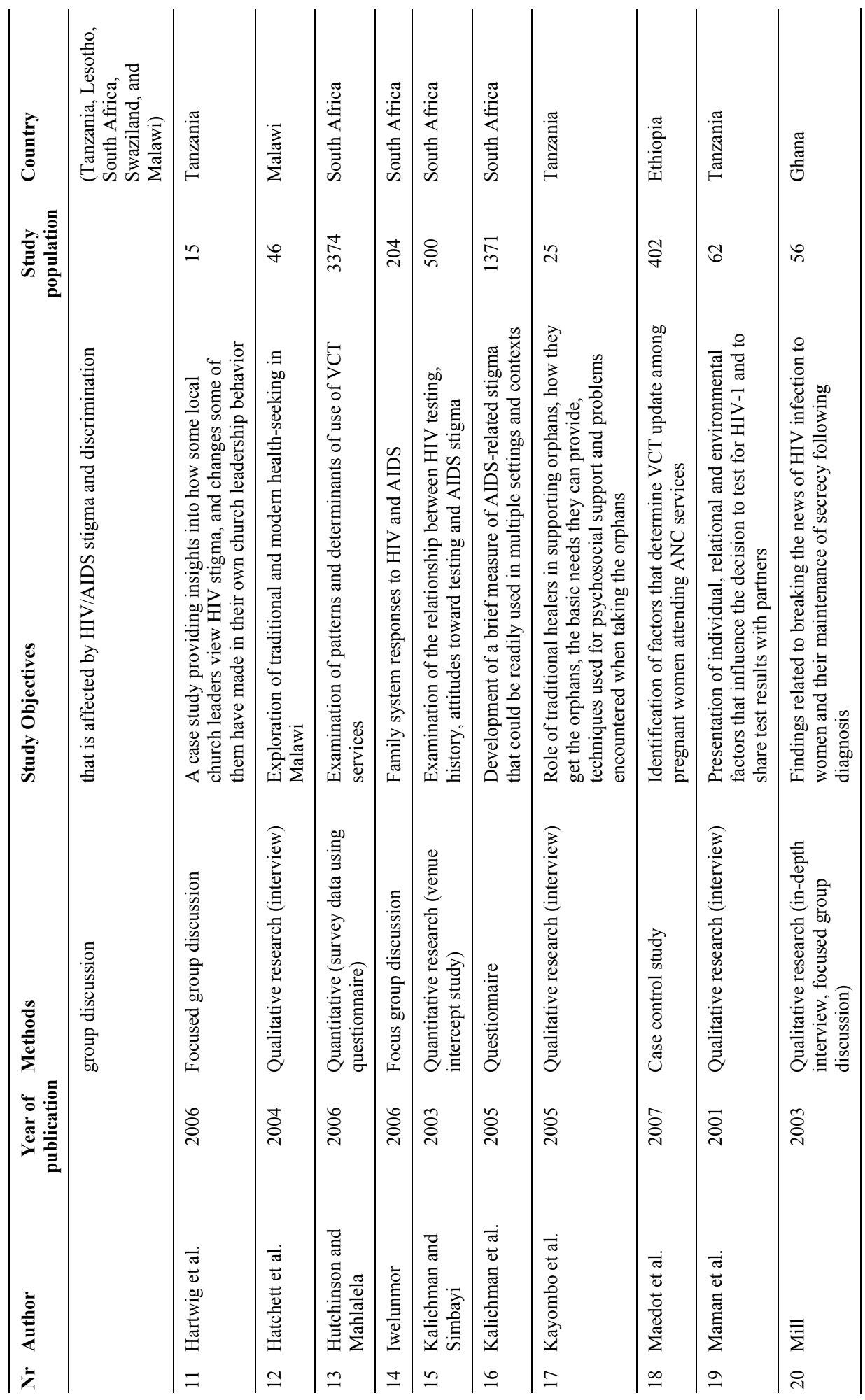




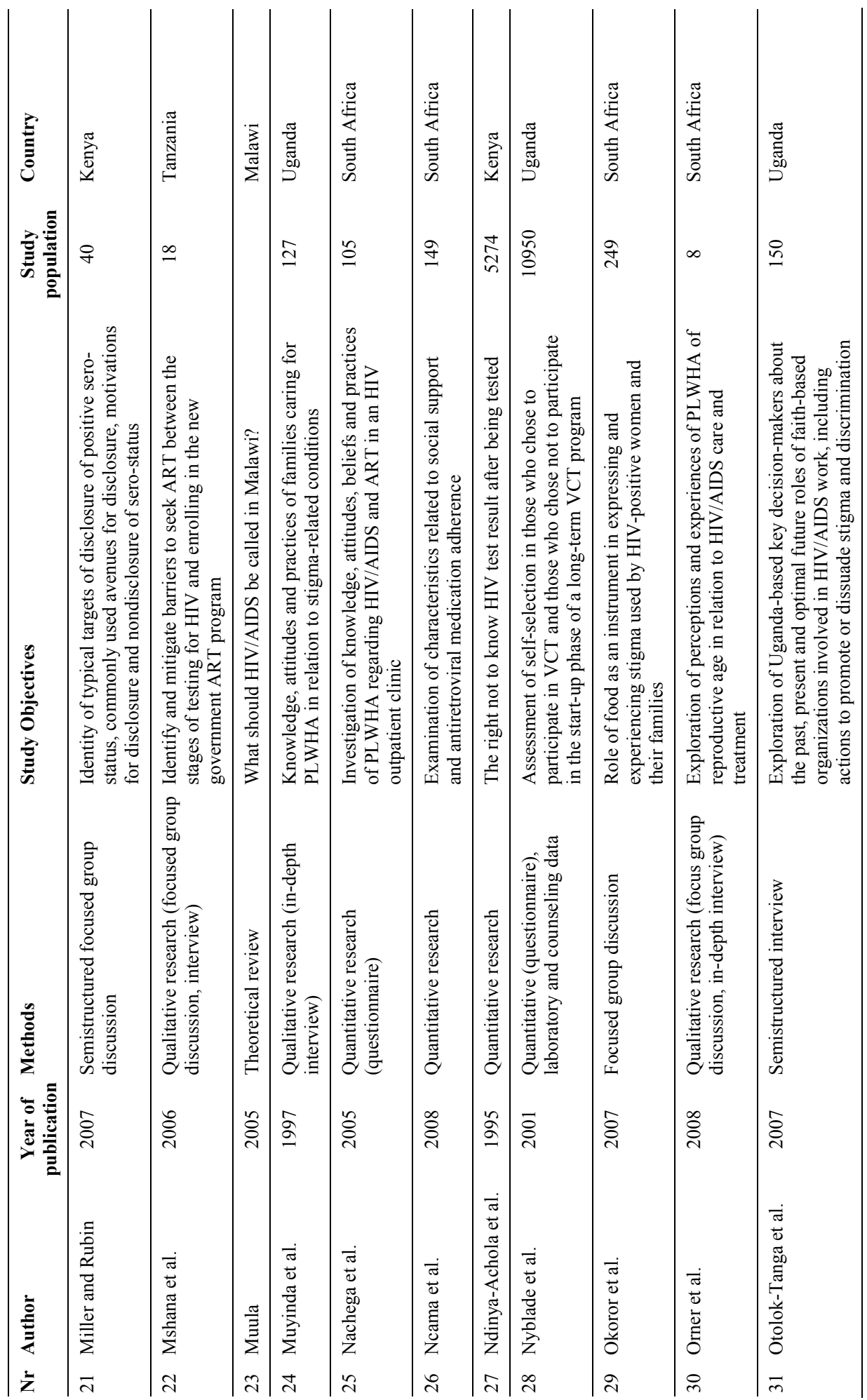




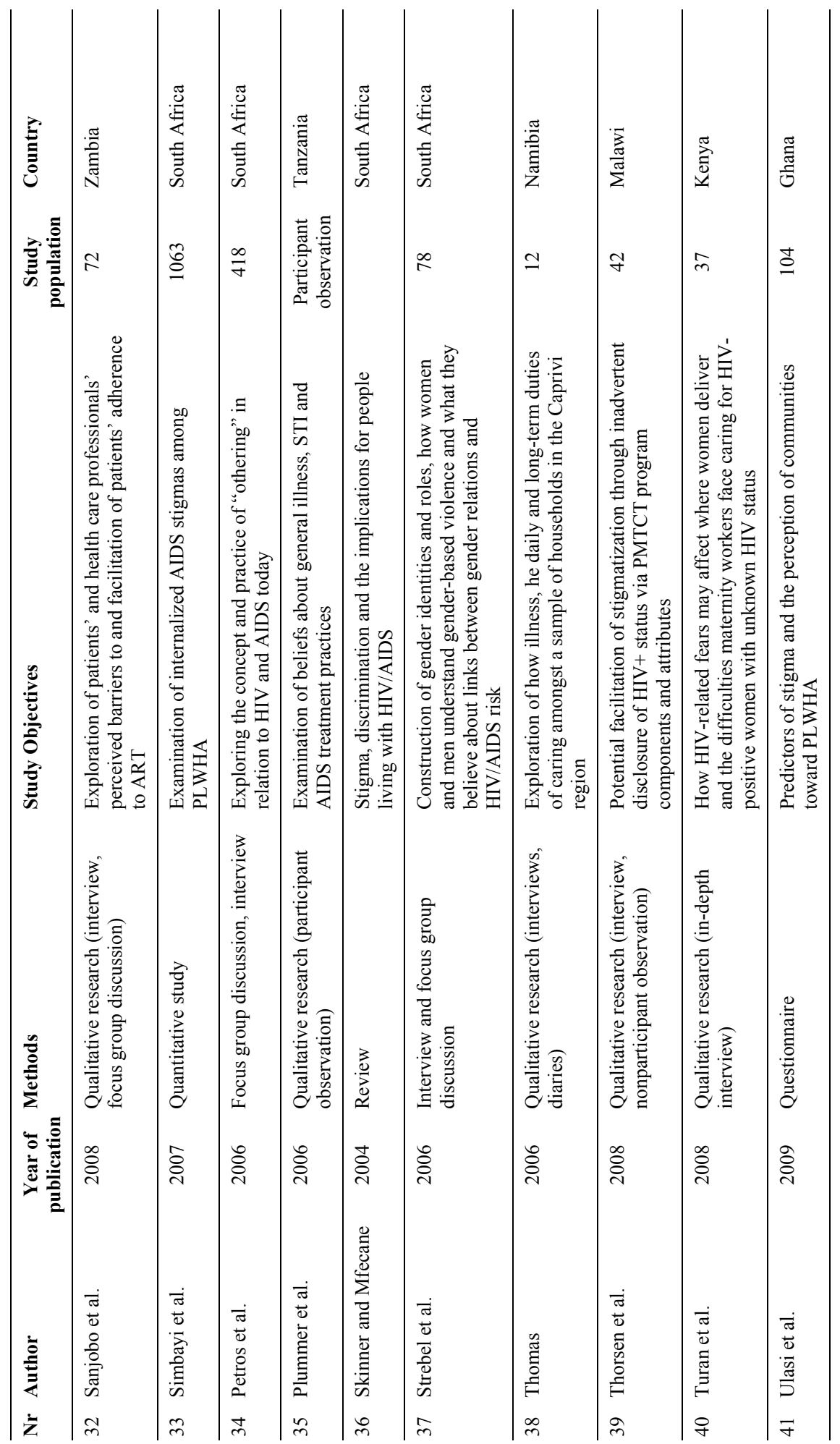




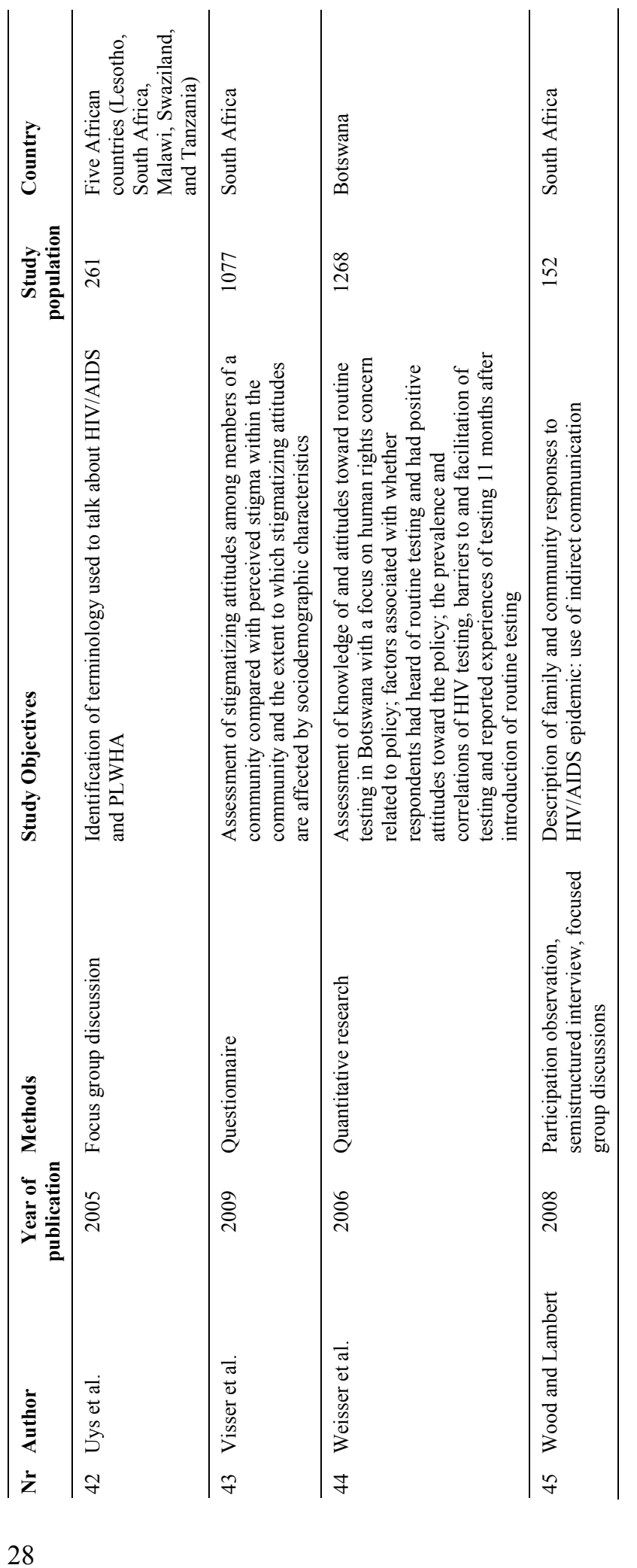




\section{Origins and Contents of Stigma}

Etymologically, the concept of 'stigma' derives from a Greek word referring to a tattoo mark. It generally has two meanings. One derived from Christianity and denotes bodily marks which resemble those of the crucifixion of Jesus Christ - they are attributed to divine favour. The second meaning is secular, namely marks of disgrace, discredit or infamy (Gilmore \& Somerville, 1994). Today, the term 'stigma' is applied more to social disgrace than to any bodily signs (Hardon et al., 1995). Stigma is generally recognized as an 'attribute that is deeply discrediting' that reduces the bearer 'from a whole and usual person to a tainted, discounted one' (Goffman, 1963). Stigma is also used to set the affected persons or groups apart from the normalized social order ('us' against 'them') and this separation implies devaluation (Gilmore \& Somerville, 1994; Mawar, Saha, Pandit \& Muhajan, 2005; Strebel et al., 2006; Greeff et al., 2008). HIV stigma is shaped not only by individual perceptions and interpretations of micro-level interactions but also by larger social and economic forces (Campbell et al., 2007). It is a social construct, which has significant impact on the life experiences of individuals both infected and affected by HIV (Taylor, 2001). Stigma includes prejudice and can lead to active discrimination directed towards persons either perceived to be or actually infected with HIV and the social groups and persons with whom they are associated (CDC, 2000). Since not all stigmatizing attitudes result in overtly discriminatory behaviours, Campbell and colleagues (2007) described discrimination as negative behaviour and stigmatization as any negative thoughts, feelings or actions towards PLWHA irrespective of whether people are discriminated because they know they are devalued (Campbell et al., 2007). In other words, discrimination has to be acted out externally while stigmatization can be overt or constitute libel, slander or defamation of persons who are stigmatized (Gilmore \& Somerville, 1994).

Stigma can be external or internal (Rankin et al., 2005). External stigma refers to the actual experience of discrimination (Siyam Kela, 2004). Internal stigma (felt or imagined stigma) is the shame associated with HIV/AIDS and PLWHAs' fear of being discriminated against (The Policy project, 2003; Greef et al., 2008). Internal stigma is a powerful survival mechanism aimed at protecting oneself from external stigma and often results in thoughts or behaviour such as the refusal or reluctance to disclose a positive HIV status, denial of HIV/AIDS and unwillingness to accept help (Miller \& Rubin, 2007; Simbayi et al., 2007; Greeff et al., 2008; Wood \& Lambert, 2008). This collective public denial in societies is reflected by avoidance of mentioning any terminal illness including HIV/AIDS, a need to keep hope alive for therapeutic success, stigma attached to HIV/AIDS, and unwillingness to confront matters related to sexuality (Wood \& Lambert, 2008). Many authors have theorized and produced models of stigmatization, but this paper will apply Gilmore and Somerville's (1994) (Gilmore \& Somerville, 1994) categorization of 
stigmatization in sexually transmitted diseases. They argued that any stigmatizing response has at least four processes (Gilmore \& Somerville, 1994).

(1) The problem. The problem (in the context of this paper, HIV/AIDS) which Goffman (1963) (Goffman, 1963) describes as the discredited attribute and Link and Phelan (2001) (Link \& Phelan, 2001) describe in the component of conceptualizing stigma as distinguishing and labellizing, has to be such that the response in some way permits the stigmatizer to be spared, saved or gives power to control the problem.

(2) Identification of the person or group who are targeted for stigmatization. This means PLWHA must be recognizable and therefore have some identifying characteristics that can be used to recognise them correctly or erroneously, for example, loss of weight, skin rash, and so forth (Goldin, 1994; Muula, 2005; Uys et al., 2005; Mosam \& Dlova, 2006; Miller \& Rubin, 2007; Greeff et al., 2008; Wood \& Lambert, 2008). This process was also described by Link and Phelan (2001) in the component of conceptualizing stigma as distinguishing and labellizing.

(3) Application of stigma to the target person. Here specific persons are labelled with stigma. The stigma and the negative characteristics associated with it are perceived as belonging to them, for example, someone who is stigmatized is perceived as immoral (Campbell et al., 2007; Greeff et al., 2008; Visser, Makin, Vandormael, Sikkema \& Forsyth, 2009). This according to Link and Phelan (2001) (Link \& Phelan, 2001) in the component of conceptualizing stigma relates to negative stereotyping.

(4) The outcome is usually a response to the stigmatized person such that they are distanced, disempowered or controlled by the stigmatizer. In this process, there is a change in the relationship or interaction between stigmatizer and the stigmatized (Campbell et al., 2007).

In this literature review, these four processes of stigmatization will be illustrated in an analysis of the various factors that affect HIV/AIDS stigma.

\section{Factors in HIV/AIDS stigma}

Everywhere HIV/AIDS has been accompanied by stigma and discrimination but stigma in Sub-Saharan Africa seems to be particularly common (Miller \& Rubin, 2007; Greeff et al., 2008; Ncama et al., 2008). What happens to one person concerns the whole community (Muula \& Mfutso-Bengo, 2005; Rankin et al., 2005; Iwelunmor et al., 2006; Campbell et al., 2007; Miller \& Rubin, 2007; Greef et al., 2008; Wood \& Lambert, 2008; Ulasi et al., 2009). The communal life in itself poses a dilemma because, on the one hand, it can bring about stigmatization when PLWHA are not able to interact owing to fear of being exposed (Skinner \& Mfecane, 2004; Hartwig, Kissioki \& Hartwig, 2006; Iwelunmor et al., 2006; Strebel et al., 2006; Campbell et al., 2007; Greeff et al., 2008; Ncama et al., 2008; Wood \& Lambert, 2008), but, on the other hand, communal life also ensures help and care 
for sick people (Iwelunmor et al., 2006; Campbell et al., 2007; Miller \& Rubin, 2007; Okoror et al., 2007; Greeff et al., 2008; Ulasi et al., 2009). It is important to understand how stigma is used by individuals and communities, in cultures where communal life is common, to produce and reproduce inequality (Parker \& Aggleton, 2003).

Stigmatization is part of a conservative reassertion of power relations, poverty or moral authority resting on the ability to control sexuality (Campbell et al., 2007). Because PLWHA are labelled as the 'other' by the community, people try to secure the social structure, safety and solidarity by casting out offenders or reaffirming societal values (Gilmore \& Somerville, 1994). PLWHA are assumed not to be able to contribute to the societal development (Greeff et al., 2008). For instance, some studies show that women will not disclose their HIV status to avoid being isolated from participating in the socio-cultural aspect of food preparation since food is regarded as an expression of support and acceptance (Iwelunmor et al., 2006; Okoror et al., 2007), or people refuse to buy food from PLWHA (Simbayi et al., 2007). Other studies show that family members of a person who died of HIV/AIDS or family members who live with PLWHA are stigmatized; therefore family members encourage PLWHA to remain silent to avoid social rejection (Wood \& Lambert, 2008; Ulasi et al., 2009). In some instances, receiving food assistance from the government also enhances a perception of difference from other members of the community since it is assumed that only PLWHA are offered such support in a community where almost everybody is poor and needs support (Siyam kela, 2004; Greeff et al., 2008). People from highly collectivist communities are more likely to be concerned with harmony and equality in the group (Miller \& Rubin, 2007). We also need to further understand whether stigma is more or less likely to manifest itself in cultures with an extensive communal life and how stigma finds its origins in sub-cultural beliefs, religion, or individually conceived causal processes (Alonzo, 1984; Campbell et al., 2007; Wood \& Lambert, 2008).

Factors that seem to mediate stigma include:

- Cultural Constructions, Stereotypes and Specific Beliefs

- Access to and the Role of Antiretroviral Therapy

- Religion

- Gender

\section{Cultural Constructions of HIV, Stereotypes and Specific Beliefs}

The association with specific sexual behaviour that is considered socially unacceptable by many people contributes to the stigma associated with HIV infection (Campbell et al., 2007; Otolok-Tanga, Atuyambe, Murphy, Ringheim \& Woldehanna, 2007; Wood \& Lambert, 2008; Ulasi et al., 2009). HIV/AIDS provides an example of how illness, despite the biological characteristics of its signs 
and symptoms, always carries a second reality expressed in cultural images and metaphors (Gilmore \& Somerville, 1994; Goldin, 1994; Hardon et al., 1995; Chimwaza \& Watkins, 2004; Muula \& Mfutso-Bengo, 2005; Uys et al., 2005; Wood \& Lambert, 2008). Campbell and colleagues (2007) argue that even when ART is available and the outcome of HIV/AIDS not always fatal, the link between HIV/AIDS and bad (sexual) behaviour is still a concern for PLWHA because of shame and embarrassment (Campbell et al., 2007). The second and third processes (identification and linking to immorality) apply here. Fears associated with illness, disease and sex therefore need to be viewed in their broader social and cultural context (Malcolm et al., 1998; Campbell et al., 2007). To illustrate the unacceptability associated with the disease, terms such as 'a long illness' or 'a short illness' are deemed culturally acceptable in the obituary of someone who dies from HIV/AIDS rather than mention of the real cause of death (Duffy, 2005; Muula \& Mfutso-Bengo, 2005; Greeff et al., 2008; Wood \& Lambert, 2008; Visser et al., 2009). There is also reluctance to mention the name 'AIDS' while the illness is ongoing (Chimwaza \& Watkins, 2004; Uys et al., 2005; Campbell et al., 2007). This process can be a way of denying HIV/AIDS or simple avoidance of explicitness or specificity as a way of coping with the serious threat of HIV/AIDS (Uys et al., 2005; Hartwig, Kissioki \& Hartwig, 2006; Strebel et al., 2006; Campbell et al., 2007; Greeff et al., 2008; Wood \& Lambert, 2008). Since society acts strongly against threats to tangible assets such as life, safety, property or values, it tries to sanctify the problem to protect its self-identity or reduce the negative effect (Gilmore \& Somerville, 1994). The fourth process (distancing, disempowerment or control) apply here. The practice of indirection has also been noted in areas outside HIV/AIDS, such as the use of coded language in relation to certain subjects in the presence of children (Campbell et al., 2007; Wood \& Lambert, 2008). Furthermore, mentioning HIV/AIDS can be viewed as disrespectful to the deceased (Muula \& Mfutso-Bengo, 2005; Campbell et al., 2007). In some cases, acknowledging the death of a relative as due to AIDS could put the family at risk of losing the financial benefits from insurance companies since some insurance companies may not pay out benefits resulting from death due to AIDS (Muula \& Mfutso-Bengo, 2005). Yet not acknowledging the cause of death to insurance companies can be viewed as a moral hazard thereby complicating the rights of dead persons who are seen as vulnerable (Muula \& Mfutso-Bengo, 2005). Furthermore, in a qualitative study in Zimbabwe, denial and miss-attributions of HIV/AIDS causes (e.g witches, unhappy ancestors etc.) were common (Duffy, 2005). Less than exact terms are also used by people, including health care professionals (Duffy, 2005) to describe HIV/AIDS to avoid insensitivity to culturally sensitive issues but not necessarily denying HIV/AIDS: for example, health care professionals in Malawi calling it ELISA disease, immunosuppression, and so forth, or lay people calling it Kaliwondewonde (slim disease), Ntengano (the disease that leads to wife and husband dying together or one after the other) (Muula 
\& Mfutso-Bengo, 2005) or other indirect descriptions (Duffy, 2005; Campbell, et al., 2007; Wood \& Lambert, 2008). Denial is also a way of reinforcing that HIV/AIDS is a disease of others not of the self (Petros, Airhihenbuwa, Simbayi, Ramlagan \& Brown, 2006) and one of the ways people as individual, group or society respond to a frightening or intolerable situation (Gilmore \& Somerville, 1994). This fits with the first and second processes.

HIV/AIDS is stigmatizing because it carries many symbolic associations with danger. Attribution of contagion, incurability, immorality and punishment for sinful acts is common in many societies (Gilmore \& Somerville, 1994; Hardon et al., 1995; Uys et al., 2005; Campbell et al., 2007; Otolok-Tanga et al., 2007; Simbayi et al., 2007; Ulasi et al., 2009). In terms of the third process, any person diagnosed with HIV is perceived to be immoral. Quam argues that beliefs about AIDS as a 'polluted disease' reflect people's negative evaluations of the routes through which HIV enters the body (Quam, 1990). Sexually-transmitted infections are considered to be agents of contamination or pollution in a study about HIV/AIDS prevention among African traditional healers (Kalichman et al., 2005). This polluting quality of AIDS and fear of the disease are translated into stigmatizing responses such as avoidance and isolation which is where the fourth process applies (distancing).

Self-diagnosis and self-treatment remain widespread (Chinwaza \& Watkins, 2004; Plummer et al., 2006) owing to stigmatization. The pursuit of different therapeutic options is sometimes a result of the problematic social complexity linked to AIDS (Wood \& Lambert, 2008). Witches and witchcraft remain an option for self-diagnosis of illnesses (Chimwaza \& Watkins, 2004; Hartwig, Kissioki \& Hartwig, 2006) as well as for diagnosis by traditional healers (Campbell et al., 2007). This fits with the first and second processes. Commonly, people say HIV/AIDS hides behind witcheraft since it is more culturally acceptable and it avoids personal shame (Duffy, 2005). People prefer to claim they are bewitched or have (normal) tuberculosis rather than accept they have HIV/AIDS (Muyinda, Seeley, Pickering \& Barton, 1997; Hatchett et al., 2004; Campbell et al., 2007; Wood \& Lambert, 2008).

Stigmatization is a stereotyping response to negatively perceived characteristics of a person or group (Simbayi et al., 2007). The stereotyped individuals, the context of this paper are PLWHA; often look, act or live differently and do not fit into the societal norms (Gilmore \& Somerville, 1994). As regards the second process, identification of PLWHA, and the third process, linking HIV/AIDS to immoral behaviour, the different languages used to describe PLWHA send clear messages (Rankin et al., 2005; Uys et al., 2005). Examples are as follows: he is a walking corpse (Rankin et al., 2005) or Kakokoolo (scarecrow), or Kamuyoola (was caught in a trap) in Uganda (Muyinda et al., 1997) and ashawo (prostitute) in Nigeria. An individual's past social history may also be recalled to justify why they have AIDS (Muyinda et al., 1997). PLWHA are seen as a reflection of evil and sin, leading to powerful stigma against those who have contracted the disease. In a study carried 
out in Tanzania, a distinction between 'true' AIDS and 'false' AIDS emerged, of which the former is more stigmatized and regarded as more hopeless than the latter, which is attributed to malice such as witchcraft (Plummer et al., 2006). Fear of stigma limits the efficacy of HIV-testing programmes across Sub-Saharan Africa (Daniel \& Oladapo, 2006; Hutchinson \& Mahlalela, 2006; Thorsen, Sundby \& Martinson, 2008) because in most communities everyone knows sooner or later who visits test centres (Muyinda et al., 1997; Nyblade et al., 2001). The process of identification applies here. For some individuals, not knowing one's HIV serostatus is far preferable to being tested. For example, a study carried out in Botswana on attitudes, practices and human right concerns of routine VCT showed that $33 \%$ of the respondents did not go for voluntary counseling and testing (VCT) because a positive HIV test result will force them to stop some of their sexual practices (Weiser et al., 2006). The belief is that it is better to suffer the disease quietly and hidden than to find out through HIV testing, because of the stigma associated with receiving a positive test result, in addition to the feeling that 'what you don't know can't harm you' (Skinner \& Mfecane, 2004).

\section{Access to and the Role of Antiretroviral Therapy}

Although access to antiretroviral therapy (ART) has increased more than tenfold in low- and middle-income countries including Sub-Saharan Africa in the last six years (UNAIDS, 2008), reaching the potential beneficiaries has been difficult, as the PLWHA do not identify themselves to the medical professionals (Weiser et al., 2006; Maedot et al., 2007). Individuals who were not tested for HIV demonstrated significantly greater AIDS-related stigmas ascribing greater shame, guilt and social disapproval to PLWHA (Kalichman \& Simbayi, 2003; Weiser et al., 2006). Studies have shown that many Sub-Saharan Africans are reluctant to disclose their HIV status even when they have already gone for VCT; moreover, those who do disclose it are selective in choosing their audience (Siyam Kela, 2004; Campbell et al., 2005; Nachega et al., 2005; Iwelunmor et al., 2006; Strebel et al., 2006; Campbell et al., 2007; Miller \& Rubin, 2007; Greeff et al., 2008; Orner et al., 2008; Turan et al., 2008). In a study carried out in the Niger Delta, Nigeria, 23\% of the PLWHA respondents had not disclosed their status, while of the $77 \%$ who had disclosed their status, $22.3 \%$ disclosed it to parents, $9.7 \%$ to siblings, $27.8 \%$ to pastors, $6.3 \%$ to friends, $10.4 \%$ to family members and $23.6 \%$ to sexual partners (Akani \& Erhabor, 2006). The first and second processes (HIV/AIDS as a problem and identification) apply here. Fears of stigmatization, of victimization, of confidants spreading the word, of accusation, of infidelity, and of abandonment were all noted to be barriers

to disclosure. Similar findings resulted from a study carried out in Cape Town, South Africa which showed that nearly one in four participants never talked with a friend about their HIV status (Simbayi et al., 2007). Yet a different study showed that respondents who personally knew someone infected with HIV or AIDS tended 
to report less stereotypical and less discriminatory attitudes, fewer feelings of discomfort and less intolerant attitudes (Gerbert, Sumser \& Maguire, 1991). Attempts to discuss HIV make many people withdraw or feel that the discussion should be discontinued. Some of them come up with questions about the very existence of HIV (Weiser et al., 2006; Campbell et al., 2007). Evidence also shows that non-infected people intentionally distance themselves from PLWHA (Stevenson, 1991).

A study carried out in Ghana showed that even though PLWHA regain their strength with ART and the physically devastating effect of HIV/AIDS is tempered, they still face psychological isolation and condemnation from their family, friends and society (Blackstock, 2005) because people around them are aware of their HIV status. This is linked to the first, second and fourth processes. Another problem PLWHA face is that combinations of health-seeking strategies make it difficult to know the effectiveness of ART (Kayombo, Mbwambo \& Massila, 2005). Many stop taking ART when the symptoms are gone and resort to traditional medications. In a study in Tanzania, many people consult both traditional and medical facilities when faced with AIDS (Plummer et al., 2006). Traditional healers are accessible, affordable and culturally acceptable (Kayombo, Mbwambo \& Massila, 2005). They are at the grass-roots level with sufferers and can provide psychosocial support (Kayombo, Mbwambo \& Massila, 2005).

ART has also been shown to be less effective when initiated in someone with advanced disease (Camp, 2006) so delay in care seeking should be avoided. Apart from the medical benefits, there are also psychosocial benefits associated with seeking treatment. PLWHA who opt for an ART programme can take comfort from participating because they get counselling from professionals trained to handle the psychosocial problems (Mshana et al., 2006; Orner et al., 2008). Ironically, widespread use of ART may decrease transmission concerns (Greeff et al., 2008) and increase risky behaviours (Crepaz, Hart \& Marks, 2004; Holstad, Dilorio \& Magowe, 2006). Patients and their partners may believe that because their viral load is undetectable and they feel so much better, the virus is absent or dead and they are incapable of transmitting HIV to others (Holstad, Dilorio \& Magowe, 2006; Plummer et al., 2006). Their motivation to continue condom use or other risk reduction behaviours wanes (Crepaz, Hart \& Marks, 2004).

\section{Religion}

In Sub-Saharan African, many people are religious (Petros et al., 2006; Miller \& Rubin, 2007; Wood \& Lambert, 2008; Ulasi et al., 2009). Religious institutions have been documented as playing both supportive and detrimental roles towards PLWHA (Campbell et al., 2005; Hartwig, Kissioki \& Hartwig, 2006; Iwelunmor et al., 2006; Campbell et al., 2007; Miller \& Rubin, 2007). Religious leaders have the possibility as any other leaders in position to be tempted to exercise power over 
others (Rankin et al., 2005; Campbell et al., 2007). One of the strategies used by some churches to regain their lost moral authority is vigorously linking sexual transgressions and AIDS with sin and immorality (Campbell et al., 2005; Thomas, 2006). The third process (Linking to immorality) applies here. AIDS has been targeted by some religious groups in order to enhance their own beliefs, morality and ideology (Gilmore \& Somerville, 1994; Petros et al., 2006). This is because sexual activity is both biological and socially-constructed behaviour which reflects and can challenge strong public and private religious, cultural and political values (Gilmore, 1992; Campbell et al., 2005; Otolok-Tanga et al., 2007). The religious approach warrants stigmatizing people as 'saved' or 'sinner', 'pure' or 'impure', 'us' or 'them', and it strengthens the broader social stratifications within which stigma flourishes (Gilmore \& Somerville, 1994; Rankin et al., 2005; Hartwig, Kissioki \& Hartwig, 2006; Miller \& Rubin, 2007; Otolok-Tanga, 2007). The fourth process applies here, where PLWHA are distanced, disempowered or controlled. In Zambia, churches sometimes impose mandatory HIV testing before allowing marriage and individuals with HIV have been excommunicated from churches because they were deemed 'sinners' (Muula \& Mfutso-Bengo, 2005; Campbell et al., 2007). It is also hard to find people openly critical of the religious authorities. At the same time, many people living with HIV/AIDS express faith and religion as important in coping with HIV. Religion gives people the opportunity to accept they are wrong but through prayer subsequently to have hope that they are forgiven and will go to a better place after death (Thomas, 2006); this comfort is in addition to the care and support they get, which have increased (Hartwig, Kissioki \& Hartwig, 2006; Iwelunmor et al., 2006; Amuyunzu-Nyamongo, Okeng'o, Wagura \& Mwenzwa, 2007; Miller \& Rubin, 2007; Otolok-Tanga et al., 2007; Greeff et al., 2008). Such spiritual locus-of-control beliefs are important (Greeff et al., 2008). Consultative dialogue between PLWHA and religious leaders is pivotal to a successful faith-based HIV intervention (Otolok-Tanga et al., 2007).

\section{Gender Issues in HIV in Africa}

Stigmatization has been linked with power (Gilmore \& Somerville, 1994; Parker \& Aggleton, 2003; Campbell et al., 2007). In Sub-Saharan Africa, women are traditionally expected to bear children, cook for the family (Petros et al., 2006; Okoror et al., 2007) and submit to the sexual desires of their husbands (Strebel et al., 2006; Campbell et al., 2007). Gender inequality is one of the main influential factors in women's inability to protect themselves (Duffy, 2005; AmuyunzuNyamongo et al., 2007; Campbell et al., 2007). Many cultures consider ignorance of sexual matters as a sign of purity, making women reluctant to seek reproductive health information and services (Ankrah \& Henry, 1994; Campbell et al., 2005; Campbell et al., 2007). Several means of transmission of HIV have been recognized, but in Africa, transmission by heterosexual contact is mostly 
understood to be the cause (Mosam \& Dlova, 2006; Strebel et al., 2006; Campbell et al., 2007; Miller \& Rubin, 2007; Thorsen, Sundby \& Martinson, 2008; Ulasi et al., 2009). People believe that infection must result from indecent sexual behavior (Uys et al., 2005; Petros et al., 2006; Campbell et al., 2007; Greeff et al., 2008; Wood \& Lambert, 2008; Visser et al., 2009). The third process applies here.

Society is more intolerant of females living with HIV/AIDS than of their male counterparts (Duffy, 2005; Hutchinson \& Mahlalela, 2006; Strebel et al., 2006; Simbayi et al., 2007). A study carried out in Kenya shows that $56 \%$ of women are commonly viewed to be targets of stigma compared with $12 \%$ of men (AmuyunzuNyamongo et al., 2007). Much of the social control over women's movements, voice and opportunities is based on the belief that they will become promiscuous if granted too much freedom and this could lead to contamination of the patriarchal lineage (Duffy, 2005). PLWHA have become scapegoats generally (Gilmore \& Somerville, 1994), but females experience an added intensity of this phenomenon, a double stigma with a bigger social disadvantage (Duffy, 2005; Plummer et al., 2006; Strebel et al., 2006; Campbell et al., 2007). Women are frequently blamed as vectors of HIV transmission, although contrary to the factual process (Muyinda et al., 1997; Rankin et al., 2005; Petros et al., 2006). Most societies in Africa expect their women to be monogamous but expect men to have extramarital affairs (Ankrah \& Henry, 1994; Hartwig, Kissioki \& Hartwig, 2006; Strebel et al., 2006) or to be polygamous (Strebel et al., 2006; Campbell et al., 2007). Yet a woman's monogamy does not protect her from the infection if her spouse has other sexual partners (Ankrah \& Henry, 1994). This gender aspect is even stronger in SubSaharan Africa because most women are dependent on their husbands for food, shelter and clothing (Siyam Kela, 2004; Strebel et al., 2006). In terms of all four processes, many women refrain from testing and (if positive) would rather conceal their status. A study carried out in Ghana showed that secrecy affected women's access to treatment, financial and emotional support from families (Mill, 2003). The main reasons for not disclosing HIV status were fear of stigma and divorce (Antelman et al., 2001; Amuyunzu-Nyamongo et al., 2007), fear of losing confidentiality (Antelman et al., 2001), women's low decision-making power, communication patterns between partners and male partners' attitude to voluntary counseling and testing (VCT) (Maman et al., 2001). In line with the female's sex role she may not insist on condom use when a partner refuses which is important for prevention and spread of HIV infection (Ankrah \& Henry, 1994; Antelman et al., 2001). Studies have shown that women who share HIV test results with their partners may experience a range of reactions from support and understanding to accusations, discrimination, physical violence and abandonment (Temmerman, Ndinya-Achola \& Piot, 1995; Maman et al., 2001; Iwelunmor et al., 2006; Amuyunzu-Nyamongo et al., 2007; Miller \& Rubin, 2007; Okoror et al., 2007; Greeff et al., 2008) This relates to the fourth process which is distancing, disempowerment or control. Therefore, a woman exhibiting the independence 
needed to protect her health risks the condemnation from her family and of the community (Rankin et al., 2005). Although the majority of the studies show female stigmatization, a study carried out in South Africa (Simbayi et al., 2007) showed that men were more likely than women never to have discussed AIDS with friends, were more likely to have been treated differently since testing, more likely to report experiencing internalized stigma and were more likely to have suffered loss of a place to stay or job owing to AIDS. Part of the explanation for this could be the fact that men are more likely to have been working before the sickness and are primarily responsible for providing shelter (Strebel et al., 2006; Simbayi et al., 2007).

\section{Consequences of HIV/AIDS Stigma and Discrimination}

Stigmatization can have many consequences for PLWHA and people affected by HIV/AIDS (Thomas, 2006; Campbell et al., 2007; Ulasi et al., 2009). Some of the consequences of HIV/AIDS stigma include lower uptake of maternity health services by women, fear of health workers getting infected and less provision of health care workers' services because they take into account the HIV status of patients (Mshana et al., 2006; Maedot et al., 2007; Turan et al., 2008). There is also a serious implication for prevention because people do not want to go for VCT (Duffy, 2005; Weiser et al., 2006; Greeff et al., 2008) and even those people who go for testing do not disclose their HIV status to their sexual partners owing to HIV/AIDS stigma (Ndinya-Achola, Ambani, Temmerman, \& Piot, 1995) and are more likely to engage in sexually-transmitted risk behaviours and this has implications for the spread of HIV/AIDS (Gilmore \& Somerville, 1994; Duffy, 2005) conversely, when PLWHA are shown compassion, they are likely to take protective precautions in sexual behaviour (Campbell et al., 2007) and be more open about their HIV status (Greeff et al., 2008). Some spouses end up knowing of their positive HIV status long after their partners are dead because they were not informed (Miller \& Rubin, 2007). Stigma also has ongoing effects on the adherence to ART by PLWHA thus affecting their quality of life and increasing complications (Nachega et al., 2005; Weiser et al., 2006; Campbell et al., 2007; Greeff et al., 2008; Ncama et al., 2008; Sanjobo, Frich \& Fretheim, 2008). It also leads to collective public denial of HIV/AIDS, which does not help to reduce the HIV/AIDS infection and does not help in fighting stigma (Campbell et al., 2005; Campbell et al., 2007; Wood \& Lambert, 2008). It worsens the stress PLWHA live with, as they are forced to be silent about their status, which on its own is burdensome (Blackstock, 2005; Iwelunmor et al., 2006; Greeff et al., 2008; Orner et al., 2008) especially for people who need to keep their source of livelihood by keeping their jobs (Greeff et al., 2008). It affects access to social support networks either within PLWHA that will help their psychology, sharing of experiences (Campbell et al., 2007; Greeff et al., 2008; Ncama et al., 2008) or from government that can offer them food supplements to improve their health or from their family as well as from 
their communities (Blackstock, 2005; Campbell et al., 2005; Iwelunmor et al., 2006). It hampers HIV-prevention and promotional efforts as people may not be willing to attend the educational programmes aimed at reducing the spread of HIV/AIDS.

\section{Conclusion}

Although current literature shows that stigma in some countries, for instance, the Republic of South Africa, has started to decline over the years (Strebel et al., 2006; Simbayi et al., 2007), especially when it involves a close relative (Thorsen, Sundby \& Martinson, 2008), it nevertheless is highly present (Muyinda et al., 1997; Blackstock, 2005; Duffy, 2005; Muula \& Mfutso-Bengo, 2005; Ncama et al., 2008; Ulasi et al., 2009; Visser et al., 2009). This review was based on a systematic compilation and evaluation of literature on HIV/AIDS stigma in Sub-Saharan Africa. Detailed evaluation became possible owing to selected literature of sufficient quality and the number of publications available in Pubmed, Medscape and Psycinfo. At the same time, this implies a clear restriction. Papers on HIV/AIDS not related to stigma were not considered.

Despite the current progress of good prognostic health outcomes for HIV/AIDS, the Sub-Saharan African response still stands at a crossroads. In this paper, we contend that cultural constructions of HIV/AIDS, based on beliefs about contamination, sexuality and religion, play a crucial role and contribute to the strength of distancing reactions and discrimination in Sub-Saharan Africa by enhancing inequality. The public denial of HIV/AIDS is real and stems from a cultural undertone with a view which allows the pursuit of different treatment options, although denial on its own can be relative because it can be a way of coping with the disease while still acknowledging its existence. Denial can also be further enhanced when the PLWHA do not show some of the manifestations generally associated with HIV/AIDS by the community such as weight loss especially those on ART as people do not believe they have HIV/AIDS even when they disclose their HIV status (Greeff et al., 2008).

PLWHA experience stigma throughout their lifetime. Issues of stigma, discrimination and denial are still poorly understood and often marginalised within national and international programmes and responses (Parker \& Aggleton, 2003; Duffy, 2005). Stigma prevents the delivery of effective social and medical care, enhances the number of HIV-infections and diminishes the public health effects of ART because PLWHA are not able to interact with their families and the communities which is supposed to make them feel complete and be a part of the society.

The identification of HIV patients poses a problem, because people try to hide the disease but perceivers assume that people have HIV if they are sicker than normal. Linking HIV/AIDS to immorality is common because of religious practices 
and a culture of serenity. This could be remedied by instituting programmes that allow people to discuss sexuality based on their cultural norms and beliefs during which some of the myths surrounding HIV/AIDS can be corrected. Putting people in touch with individual and collective strength is a key strategy to mobilizing them in such complex issues such as stigma (Blackstock, 2005; Campbell et al., 2005; Campbell et al., 2007; Greeff et al., 2008). More qualitative studies are needed in Sub-Saharan Africa on HIV/AIDS for better understanding of stigma given that stigma regarding HIV/AIDS is rooted in local beliefs, religion and gender.

\section{References}

Akani, C. I., \& Erhabor, O. (2006). Rate, pattern and barriers of HIV serostatus disclosure in a resource limited setting in the Niger Delta of Nigeria. Tropical Doctor, 36 (2), 87-89.

Alonzo, A. A. (1984). An illness behaviour paradigm: a conceptual exploration of a situational adaptation perspective. Social Science and Medicine, 19(5), 499-510.

Amuyunzu-Nyamongo, M., Okeng'o, L., Wagura, A., \& Mwenzwa E. (2007). Putting on a brave face: The experiences of women living with HIV and AIDS in informal settlements of Nairobi, Kenya. AIDS Care, 19 (1), S25-34.

Ankrah, E. M., \& Henry, K. (1994). Empowering women may retard HIV. Network, 15(2), 20-21.

Antelman, G., Smith-Fawzi, M. C., Kaaya, S., Mbwambo, J., Msamanga, G. I., Hunter, D. J., \& Fawzi, W.W. (2001). Predictors of HIV-1 serostatus disclosure: a prospective study among HIV-infected pregnant women in Dar es salaam, Tanzania. AIDS, 15(14), 1865-1874.

Blackstock, O. (2005). Curing stigma-The limits of antiretroviral access. The New England Journal of Medicine, 353(8), 752.

Camp, R. Antiretroviral pipeline 2006. In Huff, B. ed. What's in the pipeline: New drugs, vaccines, Microbicides, HCV and TB Therapies in Clinical Trials 2006; (pp. 2-20). New York: Treatment action group.

Campbell, C., Foulis, C. A., Maimane, S., \& Sibiya, Z. (2005). I have an evil child at my house. Stigma and HIV/AIDS management in a South African community. American Journal of Public Health, 95(5), 808-815.

Campbell, C., Nair, Y., Maimane, S., \& Nicholson, J. (2007). Dying twice: a multi-level model of the roots of AIDS stigma in two South African communities. Journal of Health Psychology, 12 (3), 403-416.

Centre for disease control (CDC). (2000). HIV related knowledge and stigma-United States, MMWR weekly, 49 (47): 1062-1064 (accessible at Http://www.cdc.gov/mmwr/preview/mmwrhtmlmm4947a2.htm).

Chimwaza, A. F., \& Watkins, S. C. (2004). Giving care to people with symptoms of AIDS in rural SubSaharan Africa. AIDS Care, 16(7), 795-807.

Crepaz, N., Hart, T. A., \& Marks, G. (2004). Highly active anti retroviral therapy and sexual risk behaviour. A meta analytic review. The Journal of the American Medical Association (JAMA), 292(2), 224-236.

Daniel, O. J., \& Oladapo, O. T. (2006). Acceptability of prenatal HIV screening at the primary care level in Nigeria. Journal of Obstetric and Gynaecology, 26(3), 191-194.

Duffy, L. (2005). Suffering, shame and silence: The stigma of HIV/AIDS. The Journal of Association of Nurses in AIDS Care, 16(1), 13-20.

Gerbert, B., Sumser, J., \& Maguire, B. T. (1991). The impact of who you know and where you live on opinions about AIDS and health care. Social Science and Medicine, 32(6), 677-681. 
Gilmore, N. (1992). Human immunodeficiency virus infection and AIDS: Concepts and constructs. In (Ed.) Jager JC, Ruitenberg EJ. AIDS impact assessment modelling and scenario analysis. Elsevier:Amsterdam p. 161-188.

Gilmore, N., \& Somerville, M, A. (1994). Stigmatization, scapegoating and discrimination in sexually transmitted disease: overcoming 'them' and 'us'. Social Science and Medicine, 39 (9), 1339-1358.

Goffman, E. (1963). Stigma: Notes on the management of spoiled identity. New York: Simon and Schuster.

Goldin, C. S. (1994). Stigmatization and AIDS: Critical issues in public health. Social Science and Medicine, 39 (9), 1359-1366.

Greeff, M., Phetlhu, R., Makoae, L.N., Dlamini, P.S., Holzemer, W.L., Naidoo, J.R., Kohi, T.W., Uys, L.R., \& Chirwa, M.L. (2008). Disclosure of HIV status: experiences and perceptions of persons living with HIV/AIDS and nurses involved in their care in Africa. Qualitative Health Research, 18(3), 311-324.

Hardon, A., Boonmongkon, P., Streefland, P., Tan, M. L., Hongvivatana, T., Van der Geest, S., \& Varkevisser, C. (1995). Applied Health Research Manual Anthropology of Health and Health Care. The Hague: CIP-Data Konkinklijke Bibliotheek.

Hartwig, K.A., Kissioki, S., \& Hartwig, C.D. (2006). Church leaders comfort HIV/AIDS and stigma: A case study from Tanzania. Journal of Community and Applied Social Psychology, 16, 492-497.

Hatchett, L. A., Kaponda, C. P., Chihana, C. N., Chilemba, E., Nyando, M., Simwaka, A., \& Levi, J. (2004). Health seeking patterns for AIDS in Malawi. AIDS Care, 16(7), 827-833.

Herek, G. M., \& Glunt, E. K. (1988). An epidemic of stigma: public reactions to AIDS. The American Psychologist, 43(11), 886-891.

Holstad, M. M., Dilorio, C., \& Magowe, M. K. (2006). Motivating HIV positive women to adhere to antiretroviral therapy and risk reduction behaviour: the KHARMA project. Online Journal of Issues in Nursing, 11(1), 5.

Hutchinson, P. L., \& Mahlalela, X. (2006). Utilization of voluntary counselling and testing services in the Eastern Cape, South Africa. AIDS Care, 18(5), 446-455.

Iwelunmor, J., Airhihenbuwa, C.O., Okoror, T,A., Brown, D.C., \& Belue, R. (2006) Family systems and HIV/AIDS IN South Africa. International Quarterly of Community Health Education, 27(4), 321-325.

Kalichman, S. C., \& Simbayi, L. C. (2003). HIV testing attitudes, AIDS stigma and voluntary HIV counselling and testing in a black township in Capetown, South Africa. Sexually Transmitted Infections, 79(6), 442-447.

Kalichman, S. C., Simbayi, L. C., Jooste, S., Toefy, Y., Cain, D., Cherry, C., \& Kagee, A. (2005). Development of a brief scale to measure AIDS-related stigmas in South Africa. AIDS and Behavior, 9(2), 135-143.

Kayombo, E. J., Mbwambo, Z. H., \& Massila, M. (2005). Role of traditional healers in psychosocial support in caring for the orphans: a case of Dar-es Salaam city, Tanzania. Journal of Ethnobiology and Ethnomedicine, 1, 3.

Link, B.G., \& Phelan, J.C. (2001). Conceptualizing stigma. Annual Review of Sociology, 27, 363-387.

Maedot. P, Haile, A., Lulseged, S., \& Belachew, A. (2007). Determinants of VCT uptake among pregnant women attending two ANC clinics in Addis Ababa city: unmatched case control study. Ethiopian Medical Journal, 45(4), 335-42.

Malcolm, A., Aggleton, P., Bronfman, M., Galvao, J., Mane, P., \& Verrall, J. (1998). HIV-related stigmatization and discrimination: its forms and contexts. Critical Public Health, 8(4), 347-370.

Maman, S., Mbwambo, J., Hogan, N.M., Kilonzo, G.P., \& Sweat, M. (2001). Women's barriers to HIV-1 testing and disclosure: challenges for HIV-1 voluntary counseling and testing. AIDS care, 13(5), 595-603.

Mawar, N., Saha, S., Pandit, A., \& Mahajan, U. (2005). The third phase of HIV pandemic: social consequences of HIV/AIDS stigma and discrimination and future needs. The Indian Journal of Medical Research, 122(6), 471-484. 
Mill, J. E. (2003). Shrouded in secrecy: breaking the news of HIV infection to Ghana women. Journal of Transcultural Nursing, 14(1), 6-16.

Mosam, A., \& Dlova, N.C. (2006). HIV/AIDS in Sub-Saharan Africa. Dermatologic Clinics, 24(4), 421-429.

Mshana, G. H., Wamoyi, J., Busza, J., Zaba, B., Changalucha, J., Kaluvya, S., Urassa, M. (2006). Barriers to accessing antiretroviral therapy in Kisesa, Tanzania: a qualitative study of early rural referrals to the national program. AIDS Patients Care and STDs, 20(9), 649-657.

Muula, A.S. (2005). What should HIV/AIDS be called in Malawi? Nursing Ethics, 12(2), 187-92.

Muula, A. S., \& Mfutso-Bengo, J. M. (2005). When is public disclosure of HIV seropositivity acceptable? Nursing Ethics, 12(3), 288-295.

Muyinda, H., Seeley, J., Pickering, H., \& Barton, T. (1997). Social aspects of AIDS- related stigma in rural Uganda. Health Place, 3(3), 143-147.

Nachega, J.B., Lehman, D.A., Hlatshwayo, D., Mothopeng, R., Chaisson, R.E., \& Karstaedt, A.S. (2005). HIV/AIDS and antiretroviral treatment knowledge attitudes, beliefs, and practices in HIV infected adults in Soweto, South Africa. Journal of Acquired immune deficiency syndromes, 38(2), 196-201.

Ncama, B.P., Mclnerney, P.A., Bhengu, B.R., Corless, I.B., Wantland, D.J., Nicholas, P.K., McGibbon, C.A., \& Davis, S.M. (2008). Social support and medication adherence in HIV disease in KwaZulu-Natal, South Africa. International Journal of Nursing Studies, 45(12), 1757-63.

Miller, A. N., \& Rubin, D.L. (2007). Factors leading to self-disclosure of a positive HIV diagnosis in Nairobi, Kenya: people living with HIV/AIDS in the Sub-Sahara. Qualitative Health Research, 17(5), 586-98.

Nyblade, L. C., Menken, J., Wawer, M. J., Sewankambo, N. K., Serwadda, D., Makumbi F., Lutalo, T., \& Gray, R.H. (2001). Population-based HIV testing and counselling in rural Uganda: participation and risk characteristics. Journal of Acquired Immune Deficiency Syndrome, 28(5), 463-470.

Okoror, T. A., Airhihenbuwa, C.O., Zungu, M., Makofani, D., Brown, D.C., Iwelunmor, J. (2007). "My mother told me I must not cook anymore"-food, culture, and the context of HIV-AIDS- related stigma in three communities in South Africa. International Quarterly of Community Health Education, 28(3), 201-213.

Orner, P., Cooper, D., Myer, L., Zweigenthal, V., Bekker, L.G., \& Moodley, J. (2008). Clients' perspective on HIV/AIDS care and treatment and reproductive health services in South Africa, AIDS Care, 20(10), 1217-1223.

Otolok-Tanga, E., Atuyambe, L., Murphy, C.K., Ringheim, K.E., \& Woldehanna, S. (2007). Examining the actions of faith based organizations and their influence on HIV/AIDS-related stigma: a case study of Uganda, African Health Sciences, 7(1), 55-60.

Parker. R., \& Aggleton, P. (2003). HIV and AIDS related stigma and discrimination: a conceptual framework and implications for action. Social Science Medicine, 57(1), 13-24.

Petros, G., Airhihenbuwa, C.O., Simbayi, L., Ramlagan, S., \& Brown, B. (2006). HIV/AIDS and othering in South Africa: the blame goes on. Culture, Health and Sexuality, 8(1), 67-77.

Plummer, M. L., Mshana, G., Wamoyi, J., Shigongo, Z. S., Hayes, R. J., Ross, D. A., \& Wight, D. (2006). 'The man who believed he had AIDS was cured': AIDS and sexually- transmitted infection treatment-seeking behaviour in rural Mwanza, Tanzania. AIDS Care, 18(5), 460-466.

Policy project. (2003). Center for the study of AIDS/University of Pretoria, USAID and chief directorate: HIV, AIDS and tuberculosis/ department of health. HIV/AIDS stigma indicators. A tool for measuring the progress of HIV/AIDS stigma mitigation. South Africa. Siyam'kela The policy project.

Quam, M. D. (1990). The sick role, stigma and pollution: the case of AIDS. In: Feldman DA (editor) pp. 29-44. Culture and AIDS. New York: Praeger.

Rankin, W. W., Brennan, S., Schell, E., Laviwa, J., \& Rankin, S. H. (2005). The stigma of being HIVpositive in Africa. PLoS Medicine, 2(8), e247. 
Sanjobo, N., Frich, J.C., \& Fretheim, A. (2008). Barriers and facilitators to patients adherence to antiretroviral treatment in Zambia: a qualitative study. SAHARA J: Journal of Social Aspects of HIV/AIDS Research, 5(3), 136-143.

Simbayi, L. C., Kalichman, S., Strebel, A., Cloete, A., Henda, N., \& Mqeketo, A. (2007). Internalized stigma, discrimination and depression among men and women living with HIV/AIDS in Capetown, South Africa. Social Science and Medicine, 64(9), 1823-1831.

Siyam Kela, (2004). Retrieved 23 April 2009 from: Http://www.kit.nl/exchange/html/20042_siyam_kela.asp.

Skinner, D., \& Mfecane, S. (2004). Stigma, discrimination and the implications for people living with HIV/AIDS in South Africa. Journal of Social Aspects of HIV/AIDS Research Alliance (SAHARA), 1(3), 157-64.

Stevenson, M. R. (1991). Social distance from persons with AIDS. Journal of Psychology and Human Sexuality, 4, 13-20.

Strebel, A., Crawford, M., Shefer, T., Cloete, A., Henda, N., Kaufman, M., Simbayi, L., Magome, K., \& Kalichman, S. (2006). Social construction of gender roles, gender based violence and HIV/AIDS in two communities of the Western Cape, South Africa. Journal of Social Aspects of HIV/AIDS Research Alliance (SAHARA), 3(3), 516-528.

Taylor, B. (2001). HIV, stigma and health: Integration of theoretical concepts and the lived experiences of individuals. Journal of Advanced Nursing, 35(5), 792-798.

Temmerman, M., Ndinya-Achola, J., Ambani, J., \& Piot, P. (1995). The right not to know HIV test results. Lancet, 345(8955), 969-970.

The Joint United Nations Programme on HIV/AIDS (UNAIDS), (2008). AIDS epidemic update, Retrieved 19 April 2009 from UNAIDS website: http://data.unaids.org/pub/EPIslides/2007/2007_epiupdate_en.pdf.

The Joint United Nations programme on HIV/AIDS (UNAIDS), (2008). AIDS epidemic update, Retrieved 15 April 2009 from UNAIDS website: http://data.unaids.org/pub/GlobalReport/2008/jc1510_2008_global_report_pp129_158_en.pdf.

Thomas, F. (2006). Stigma, fatigue and social breakdown: Exploring the impacts of HIV/AIDS on patient and carer well being in the Caprivi region, Namibia. Social Science and Medicine, 63(12), 3174-3187.

Thorsen, V.C., Sundby, J., \& Martinson, F. (2008). Potential initiators of HIV-related stigmatization: ethical and programmatic challenges for PMTCT programs, Developing World Bioethics, 8(1), 43-50.

Turan, J.M., Miller, S., Bukusi, E.A., Sande, J., \& Cohen, C.R. (2008). HIV/AIDS and maternity care in kenya: how fears of stigma and discrimination affect uptake and provision of labor and delivery services. AIDS Care, 20(8), 938-945.

Ulasi, C.I., Preko, P.O., Baidoo, J.A., Bayard, B., Ehiri, J.E., Jolly, C.M., \& Jolly, P.E. (2009). HIV/AIDS related stigma in Kumasi, Ghana. Health Place, 15(1), 255-62.

Uys, L., Chirwa, M., Dlamini, P., Greeff, M., Kohi, T., Holzemer, W., Makoae, L., Naidoo, J.R., \& Phetlu, R. (2005). Eating plastic, winning the lotto, joining the www...Descriptions of HIV/AIDS in Africa. The Journal of the Association of Nurses in AIDS Care, 16(3), 11-21.

Visser, M.J., Makin, J.D., Vandormael, A., Sikkema, K.J., \& Forsyth, B.W (2009). HIV/AIDS stigma in a South African community, AIDS Care, 21(2), 197-206.

Weiser, S.D., Heisler, M., Leiter, K., Percy-de Korte, F., Tlou, S., DeMonner, S., Phaladze, N., Bangsberg, D.R., \& Lacopino, V. (2006). Routine HIV testing in Botswana: a population-based study on attitudes, practices and human rights concerns. PLoS Medicine, 3(7), e261.

Wood, K., \& Lambert, H. (2008). Coded talk, scripted omissions: the micropolitics of AIDS talk in an affected community in South Africa. Medical Anthropology Quarterly, 22, 213-233. 



\section{Chapter Three}

\section{A model for understanding the relationship between stigma and healthcare-seeking behavior among people living with HIV/AIDS in Sub-Saharan Africa}

This is the unreviewed manuscript of an article originally submitted to African Journal of AIDS Research (AJAR) and whose final and definitive form has been published in African Journal of AIDS Research 2009, 8 (2), 201-212. (C) 2009 Copyright NISC (pty) Ltd.

African Journal of AIDS Research (AJAR) is available online at: http://www.informaworld.com $/ \mathrm{smpp} / \mathrm{content} \sim d b=$ all $\sim$ content $=a 921014350 \sim$ frm $=$ titlelink

Authors

Ngozi. C. Mbonu

Bart van den Borne

Nanne K. De Vries 


\begin{abstract}
Objective: People living with HIV/AIDS (PLWHA) in Sub-Saharan Africa sometimes have care-seeking behaviours which result in a suboptimal quality of life. This paper seeks to examine the role of stigma in the care-seeking behaviour of PLWHA. We hypothesize that stigma has to do with the behaviour of PLWHA themselves and with societal reactions including those of health-care professionals.

Methods: Literature about the social problems of HIV/AIDS stigma in Africa was systematically researched in the national library of medicine (PUBMED), Medscape and Psycinfo with no specified year limitation.

Results: In a literature review conducted, beliefs, knowledge and self-efficacy were identified as important correlates of care-seeking behavior. Gender, age, religion, policy and poverty were found to be moderating variables. Three coping strategies (that is, regarding the PLWHA themselves, others, and concerning HIV/AIDS infection) were also considered. An explanatory model was built to analyse role of stigma. Non-utilization of health-care institutions was the outcome variable.

Conclusions: PLWHA make different care-seeking choices as a result of selfstigma and stigmatization from others which may lead to non-utilization of healthcare institutions. More studies are needed to authenticate the precise coping strategies PLWHA employ in Sub-Saharan Africa.
\end{abstract}




\section{Introduction}

People living with HIV/AIDS (PLWHA) in Sub-Saharan Africa sometimes receive suboptimal care resulting in poor quality of life. Statistics show that the HIV/AIDS prevalence rate in 2006 was $5.9 \%$ (5.2\%-6.7\%); in addition 2.1 million (1.8-2.4 million) children and adults in this region died from AIDS in 2006 which represents $72 \%$ of global deaths due to AIDS (The Joint United Nations Programme on HIV/AIDS(UNAIDS), [2006]). This paper seeks to examine the role of stigma as a contributory factor in care-seeking behavior. We hypothesize that HIV/AIDS stigma not only has to do with reactions from society including health-care professionals (HCPs) but also with reactions among the PLWHA themselves which affect care-seeking behavior. To illustrate this, an explanatory model that may help to analyze the role of stigma in care-seeking behavior will be developed.

Stigmatization is a social process that affects care-seeking behavior. Stigma has been associated with many illnesses including leprosy, tuberculosis, mental illness, physical handicap and, importantly, the human immunodeficiency virus/acquired immune deficiency syndrome (HIV/AIDS). Soon after its very first diagnosis in the eighties, HIV/AIDS was accompanied by an epidemic of fear, ignorance and denial leading to stigmatization and discrimination against people with HIV/AIDS and their family members (Herek \& Glunt, 1988). The fear, engendered by a disease for which there is no cure, can create emotional and behavioral reactions (Sontag, 1991). Some of the reactions may be based on the desire to be protected from the infection (Shelp \& Sunderland, 1987). The fact that HIV/AIDS is also closely associated with already discriminated groups within society (such as sex workers and drug-users) led to a societal response which was based on judgmental attitudes and further discrimination.

Although antiretroviral therapy (ART) does not cure HIV/AIDS, the progressive introduction of new classes of drugs, simplified treatment regimens, reduced toxicity and adherence burdens has led to a sustained decline in rates of HIV-related morbidity and mortality in many countries (Camp, 2006). Despite the improvements in the prognostic outcome of antiretroviral therapy, stigma remains a barrier to prevention, treatment and care in Sub-Saharan Africa. There has been a documented increase in the number of people on ART in the developing world including Sub-Saharan Africa. Statistics show that by June 2006, more than 1 million (930 000 - 1150000 million) people were receiving ART which represents a tenfold increase since December 2003 (UNAIDS, 2006). Despite this increase, uptake is still relatively low. We contend that stigma contributes to this low coverage. ART also creates new problems. PLWHA who have access to ART will face problems associated with aging in the future due to the decline in mortality and morbidity. Increased life expectancy of PLWHA taking ART will mean higher need of family, friends and community support. Without the traditional caregivers 
(family, communities) in Sub-Saharan Africa, these aging PLWHA will have an immense impact on health-care delivery.

Stigma should remain at the centre of the fight against HIV/AIDS and underestimating the impact of stigma is to put the success of potentially effective prevention and care programmes at stake (Parker \& Aggleton, 2002; Valdiserri, 2002). The importance of HIV/AIDS stigma for human behaviour was also highlighted by Jonathan Mann (1988) who characterized three major phases of the HIV/AIDS epidemic. The first phase is the epidemic of infection, the second phase is the epidemic of AIDS itself and the final phase concerns the social impact marked by stigma. This third phase is part of social structures that set people up against each other (Rankin, Brennan, Schell, Laviwa, \& Rankin, 2005).

Applied health research needs to be grounded in theory and findings from previous research (Schoepf, 1995; Herek, Mitnick, Burris, Chesney, Devine, Fullilove, Fullilove, Gunther, Levi, Michaels, Novick, Pryor, Snyder \& Sweeney, 1998). Research should not only contribute to the medical and social service system but also help PLWHA in finding coping strategies and increase the practical knowledge skills for managing the disease (Adam, 1992). "Conceptual studies have a crucial role to play in ensuring that existing knowledge is constantly reviewed for its adequacy and appropriateness in the light of changing needs and circumstances as they impact upon HIV and AIDS-related stigma" (Parker \& Aggleton, 2002, p. 33). The aim of this paper is to apply theoretical knowledge and concepts about stigmatization to analyse the problems experienced by PLWHA in care-seeking behaviour. An explanatory model is presented that allows for a systematic approach in analysing problems that affect care-seeking behaviour hindered by stigma. Stigma impacts on determinants such as beliefs, knowledge and self-efficacy. Gender, age, religion, policy and poverty act as important moderating variables. To reduce the negative impact of HIV/AIDS stigma on care-seeking behaviours, a better understanding is needed of how stigma hampers PLWHA, including society and health-care professionals in effectively responding to HIV/AIDS.

\section{Methodology of the study}

Literature about the social problems of HIV/AIDS stigma in Africa was systematically researched in the national library of medicine (PUBMED), Medscape and Psycinfo with no specified year limitation. In doing so, the search terms social, behaviour, environment, HIV/AIDS, stigma, discrimination, and Africa were combined.

The building of the explanatory model is based on the Precede portion of the PRECEDE/PROCEED model (Green \& Kreuter, 1999) and empirical literature. This involves conceptual analysis of role of stigma in care-seeking behaviour of PLWHA. The model begins with analysis of the problem (which is stigma) and ends with identifying the predisposing, reinforcing and enabling factors 
(determinant and moderating variables) contributing to different coping strategies that can lead to various care-seeking behaviours. The outcome variable is nonutilization of health care institutions.

\section{Problem statement}

Many persons living with HIV/AIDS in Sub-Saharan Africa do not seek health care, which makes them have a suboptimal quality of life. This can partly be explained by the role of self-stigma in care-seeking behavior and societal reactions including health professionals.

\section{Discussions and conceptual analysis of the explanatory model}

The outcome variable in our model in figure 1 is non-utilization of health-care institutions. In the following section, we first discuss how stigma has an impact on the social structural context within which PLWHA, society and health-care professionals are embedded.

Second, we describe how stigma has an impact on different variables expected to determine care-seeking behaviour such as beliefs, knowledge, and self-efficacy. Third, the importance of moderating variables such as gender, age, religion, policy and poverty will be examined.

Finally, we analyse different coping strategies that can lead to various careseeking choices such as inappropriate self-care, traditional healers and faith houses, which result in PLWHA not utilizing the health-care institutions.

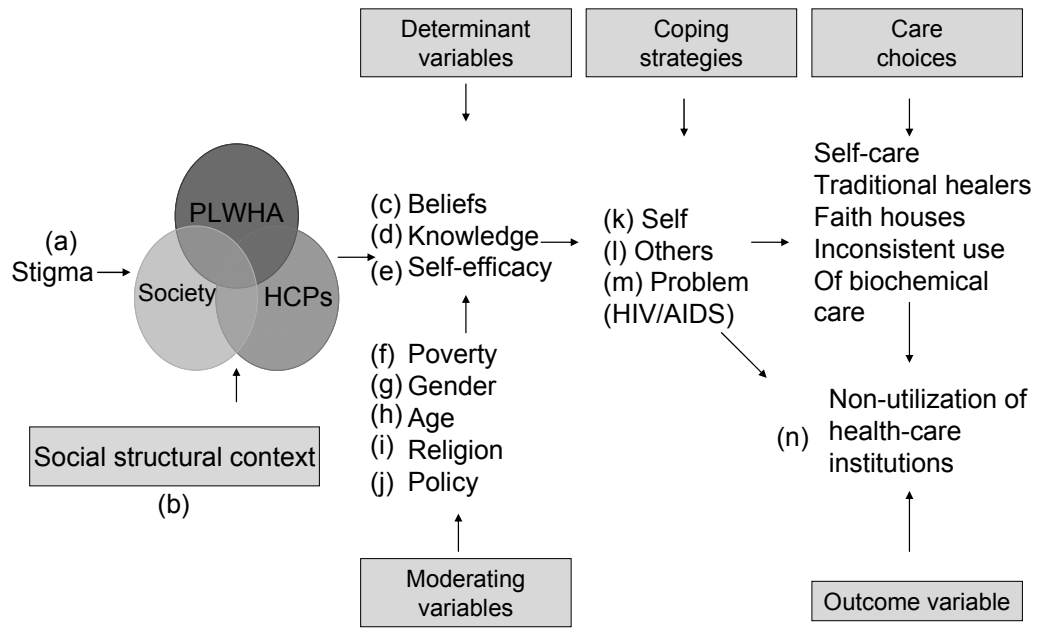

Figure 1: Explanatory model of role of stigma in care-seeking behaviour.

Mbonu, Van den Borne, \& De Vries, 2009 


\section{Social structural context}

HIV/AIDS stigma affects both HIV-infected people and people who care for PLWHA in a community. From this perspective, health caregivers of PLWHA are important in defining what shapes the care-seeking behaviour of PLWHA. Although health care professionals (HCPs) have a moral sense of duty towards their work by the various oaths taken, they are part of society and therefore are also inclined to show negative behavior to PLWHA. The subtle and overt expressions of disapproval and the moral sense of duty of the professionals may generate ambivalence about the worthiness of their work towards PLWHA (Shelp \& Sunderland, 1987). HCPs, though among the most knowledgeable about the disease in society, are not left out from fear of stigmatization. A study in Zambia among HCPs showed that, based on the beliefs and perceptions of HIV/AIDS shared with the community at large, $60 \%$ of the HCPs had chosen not to be tested because they would rather not know if they were infected by the virus (Chi, Chansa, Gardner, Sangi-Haghpeykar, Goldenberg, Sinkala, Muchimba \& Stringer, 2004). HCPs' fear of being tested for HIV/AIDS is a reflection of how worried they are, which explains why health-care institutions are a fertile ground for stigmatizing PLWHA. People in general, including health professionals, claim to have an absolute, moral right to protect themselves from contagion.

The fear that PLWHA may experience because of discrediting or judgemental attitudes both from health-care professionals (Bond, Chase, \& Aggleton, 2002; Valdiserri, 2002; Mwinituo \& Mill, 2006) and society at large can prevent them from not seeking care (Goffman, 1974). The risk of infection the professionals take in caring for these patients is perceived to be far higher than the benefit the patient will get from the care. Excuses and justifications bridge the gap between action and expectation (Scott \& Lyman, 1968). Excuses will generally attempt to provide an explanation and deflect responsibility (Alonzo, 1985). Health-care professionals may prefer to shift the responsibility for the HIV to the patients and their relatives. Therefore understanding the cultural complexity of this marginalization process is a vital step in changing the practice of exclusion (Whitehead, Carlisle, Watkins, \& Mason, 2001).

The long wait in the hospital can make PLWHA feel that people around them evaluate them negatively; hence they may resort to traditional healers as a psychologically more satisfying alternative (Muyinda, Seeley, Pickering, \& Barton, 1997). AIDS stigma is also found to correlate with risk reduction intentions (Kalichman, Simbayi, Cain, Jooste, Skinner \& Cherry, 2006). A study in a Nigerian teaching hospital showed that $95.4 \%$ of doctors interviewed were worried about occupational HIV infection (Owotade, Ogunbodede, \& Sowande, 2003). Similarly, results of studies carried out in three West African hospitals showed that $45.7 \%$ of the HCPs that participated in the study had at least one accidental blood exposure. Of these, $48.3 \%$ said the risk of occupational exposure by HIV/AIDS would influence their choice of future posting (Tarantola, Koumare, Rachline, Sow, 
Diallo, Doumbia, Aka, Ehui, Brucker, \& Bouvet, 2005). Part of the explanation may be due to the fact that they have families and friends and are part of the society which may be inclined to stigmatize them once they get HIV/AIDS. In this sense, stigma needs to be understood in relation to different variables that can affect PLWHA care-seeking behaviour.

\section{Determinant variables}

In our model, three variables - beliefs, knowledge, and self-efficacy - are particularly important because of their impact on coping strategies which PLWHA use and on the choices for health care they make.

Beliefs: A belief is a conviction that a phenomenon is true (Green \& Kreuter, 1999) which can lead to stigmatization of PLWHA. Beliefs that may have an impact on coping and care-seeking behaviour can be general beliefs about infection with HIV/AIDS or about persons with HIV/AIDS, beliefs about the reactions of others on care-seeking behaviour of persons with HIV/AIDS as well as specific beliefs about ways of coping. HIV/AIDS is most frequently contracted through sexual intercourse in Sub-Saharan Africa and since sex is widely believed to be a consensual act, responsibility is often attributed to PLWHA. A study carried out in Ghana shows that PLWHA are believed to be individuals being punished by supernatural forces for their promiscuous behaviour and therefore deserve to be stigmatized and avoided (Mwinituo \& Mill, 2006). This belief is often associated with societal reactions including from HCPs, which will deter PLWHA from seeking care and support from people around them or going to a health-care institution. A study carried out in Uganda also showed that there is a general belief that PLWHA maliciously spread HIV/AIDS through putting blood in tomatoes or passion fruit so that other people can get infected (Muyinda, et al., 1997). Such beliefs can become manifest as fear which is a powerful motivator; its combination with anxiety produces a flight response that expresses itself in negative behavioural responses such as stigmatizing PLWHA or caring for them which in turn affect care-seeking behaviour. Some beliefs can be internalized by PLWHA, e.g. linking HIV infection with sin, witchcraft, belief that the heterosexual route of transmission is the only route, and lead to negative reactions. This may make PLWHA go to traditional healers rather than to health facilities because they are believed to be able to cure illnesses caused by witchcraft. A study carried out among traditional healers in South Africa showed that $21 \%$ of them believed that there is a cure for AIDS (Peltzer, Mngqundaniso, \& Petros, 2006). Similarly in a study in Malawi, an ordinary villager claimed to have a herbal drink that cures AIDS (Lwanda, 2004) so PLWHA were seeking care from this man. Some other traditional healers have recommended that male PLWHA sleep with a virgin as a way of curing HIV/AIDS (Schoepf, 2004). Depending on the belief, PLWHA may end up combining visits to 
health-care institutions with visits to churches, healing houses, traditional healers or to retreat to self-care or not seek care at all.

Knowledge: Knowledge of HIV status and effective treatment is important for obtaining adequate care for PLWHA. Stigma also thrives in an environment of ignorance and half-truth (Valdiserri, 2002), which affects health-seeking behaviour. AIDS-related stigma was also found to correlate inversely with AIDS knowledge in a model of health behaviour change and AIDS stigma (Kalichman et al., 2006). Although general knowledge about HIV/AIDS has improved in Sub-Saharan Africa, accurate knowledge about risks, transmission modes and prevention is often a problem (Odujinrin \& Adebayo, 2001; James, Reddy, Taylor, \& Jinabhai, 2004; Hamra, Ross, Orrs, \& D'Agostinos, 2006). Similarly, inadequate knowledge of transmission routes will enhance stigma because people are afraid of having casual contact with PLWHA or being associated with immoral behaviour linked with HIV/AIDS, which affects PLWHA care-seeking behaviour and also care-giving by health-care professionals.

In a study carried out in Kenya, about $86 \%$ of the participants did not know that mother-to-child transmission can be a cause of HIV/AIDS in children; also $87 \%$ of the participants in the same study felt that mosquito bites could be a cause of transmission and $98 \%$ felt there is a high risk associated with touching or greeting an HIV/AIDS person (Hamra et al., 2006). Pregnant women living with HIV/AIDS who do not know that HIV/AIDS can be transmitted from mother to child, will not seek care to prevent the transmission and even the few that know may not seek care due to stigma. Prompt action requires persons who are infected to learn of their serostatus and subsequently gain access to care and therefore benefit from the available treatment options (Chesney \& Smith, 1999). Stigma affects the use of ART and adherence to the therapy because PLWHA may not want to be seen taking drugs regularly at home, leading to poor drug adherence, or going for an HIV/AIDS programme where they can get the knowledge they need.

Self-efficacy: Stigma lowers self-efficacy which is positively associated with protection behaviour (Kalichman et al., 2006). Self-efficacy refers to the confidence a person has in being able to perform a specific action such as finding the right health-care institution and health-care workers for treatment, being tested for HIV/AIDS or handling the situation if others know about their HIV-positive status, because it can affect their relationship with their families, friends and community. Similarly, high self-efficacy for caring enables families and health-care professionals to care for PLWHA while low self-efficacy caused by stigma can make care look tougher than it actually is. According to Bandura (1977, 1986), acquisition of high or low efficacy expectations depends on performance accomplishments, vicarious experience, verbal persuasion and state of emotional/psychological arousal. When people know that PLWHA get better with 
ART it may motivate them to work hard in caring for PLWHA and at the same time PLWHA can seek care if they know they will feel better.

How these three determinant variables influence coping and care-seeking choice may vary depending upon how they have been affected by modifying variables.

\section{Stigma-modifying variables}

Among the variables likely to modify PLWHA coping and care-seeking choice due to stigma are: gender, age, religion, policy and poverty.

Gender: HIV/AIDS stigma tends to be expressed locally against relatively powerless groups (Herek et al., 1998) such as women. Gender is one of the important cultural definitions that are crucial to the transmission of HIV/AIDS (Obbo, 1995) as well as to seeking health care. HIV/AIDS is believed to be mainly transmitted through the sexual route and people who engage in sexual behaviour are believed to get HIV/AIDS. In Sub-Saharan Africa, prostitution is generally thought to be something that women do (Schur, 1984), hence a female offence. What emerges from these beliefs is that any female with HIV/AIDS is labelled a prostitute, leading to scapegoating, victimization and double stigmatization. Female PLWHA are isolated more than their male counterparts. For instance, studies from Tanzania and Kenya have shown that women who share HIV test results with their partners may experience a range of reactions such as accusations, discrimination, physical violence and abandonment (Temmerman, Ndinya-Achola, Ambani, \& Piot, 1995; Maman, Mbwambo, Hogan, Kilonzo, \& Sweat, 2001; Maman, Mbwambo, Hogan, Kilonzo, Campbell, Weiss \& Sweat, 2002). The general adage that women should never be heard or seen contributes further to not seeking care. This culture of silence is symbolic because it translates to non-disclosure of serostatus. Female PLWHA tend to be scared of discussing their status since most of the time they will need the support of their partner financially and psychologically before seeking care. Some of the explanations for low uptake of voluntary counselling and testing (VCT) among pregnant women in Ouagadougou, Burkina Faso were: poor autonomy of women requiring male consent to accept a VCT proposal; social stigma; and fear of not having access to effective treatment (Pignatelli, Simpore, Pietra, Ouedraogo, Conombo, Saleri, Pizzocolo, Delaco, Tall, Ouiminga, Carosi \& Castelli, 2006). Most females living with HIV/AIDS prefer to care for their household rather than seeking health care because of stigma. Those who choose to take a test do so without their partner's consent and hence do not feel free to disclose their status afterwards which negatively affects their care.

"There is also a social pressure on women to prove their fertility" (Obbo, 1995, p. 83). This is significant in an environment where women with children are respected and women without child or barren women are pitied and looked down upon. This encourages a female person living with HIV/AIDS not to disclose her 
status since she has to fulfil the societal obligation of having children and avoid being alienated or stigmatized. Hence the female PLWHA may not access care if she feels family planning may be advised based on her seropositive status or ART may be initiated to prevent mother to child transmission. In a study carried out in South Africa $77 \%$ of the participants said they felt HIV-positive people should not have children (Myer, Morroni, \& Cooper, 2006). Yet limiting PLWHA from having children will impinge on their rights and can contribute to stigmatization, which will decrease their willingness to seek care. Men on the other hand are sexually active and demanding and wanting to prove their virility, no matter what their HIV status. This contributes to the pressure women are under to prove their fertility. It also enhances secrecy and denial of HIV/AIDS thereby preventing PLWHA seeking care.

Age: Studies show that young people and bachelors have more discriminatory attitudes towards PLWHA (Letamo, 2003; Hamra et al., 2006). Most young people are also not willing to go for voluntary counselling and testing or seek care related to HIV/AIDS due to stigma. Given their age, it seems plausible that young people feel that they have a lot of expectations in life yet to meet; hence they prefer to avoid anybody or anything that is linked to HIV/AIDS. They may avoid getting close to PLWHA and may not go for testing or to seek care for HIV/AIDS, even if they think they may be seropositive. This expectation was reiterated in a study carried out among South African youth. A male participant in the study said:

I have a dream of having five children in the future so if I go to a test, my dream will be shattered, because at the clinic maybe they will tell me that I am HIV-positive and that only could cause me to commit suicide. I would rather not test than to test (Macphail, Pettifor, Coates, \& Rees, 2006, p. 6).

Religion: Religion plays a major role in the lives of many Sub-Saharan Africans. People often use religion to deny AIDS as a problem (Petros, Airhihenbuwa, Simbayi, Ramlagan, \& Brown, 2006). Since God is perceived to be the dispenser of punishment, efforts to control or eliminate punishment are looked at as anti-God (Shelp \& Sunderland, 1987). HIV/AIDS is regarded as punishment from God for immoral behaviour, hence justifying the stigmatizing behaviour towards PLWHA. These factors may prevent PLWHA from getting the psychological support needed in church or seeking care in the health facility. The Church can also act as a motivator by communicating with PLWHA on the importance of seeking care in appropriate facilities and in good time. Some churches provide care for PLWHA. Since religious beliefs are diverse, PLWHA may utilize spiritual healing together with going to a health-care facility but at the same time it may prevent them from seeking care because they may believe that AIDS can be healed spiritually. In a study carried out in Gabon to find out factors contributing to the delay between the first HIV-related symptoms and diagnosis of HIV infection, it was found that resort 
to religious healing was among the risk factors contributing to the delay together with social stigma (Okome-Nkoumou, Okome-Miame, Kendjo, Obiang, Kouna, Essola-Biba, Bruno-Boguikouma, Mboussou \& Clevenbergh, 2005).

Policy: Policy considerations can influence care-seeking behaviour (Valdiserri, 2002) and can be stigmatizing. If policy does not encourage confidentiality as well as protection of the rights of the PLWHA, access to health care may be hindered. Policy involving placing the HIV/AIDS clinic separately from other hospital facilities can deter many PLWHA from seeking care. The physical separation also contributes to stigmatization. Location of the care facility or VCT centres is important in seeking care. A study carried out in rural Uganda showed that location of VCT sites in a visible environment, fear of stigmatization, inconvenience and emotional vulnerability after receiving results from public facilities contributed to reduced uptake of VCT (Wolff, Nyanzi, Katongole, Ssesanga, Ruberantwari \& Whitworth, 2005).

Poverty: HIV/AIDS stigma has been closely intertwined with poverty (Herek et al., 1998). The sense of insecurity suffered by PLWHA is worsened by financial problems. Lewis Oscar (1966) makes this point more explicitly when he writes that poverty itself has its own modalities and distinctive social and psychological consequences for those who suffer from it. User fees for health-care services make it unlikely that poor PLWHA will obtain adequate care (Schoepf, 1995). Stigma can lead to restriction of career opportunities and loss of employment (Herek et al., 1998). Unemployment is common in young adults (Shelp \& Sunderland, 1987) which also has economic implications. Lack of health insurance in many countries in Sub-Saharan Africa and low social economic status all contribute to stigmatization, while rich people are often not stigmatized even when they have HIV/AIDS since they are held in high esteem in society.

\section{Coping strategies}

Our model postulates that PLWHA may utilize three strategies to cope with HIV/AIDS stigma: first, coping with physical, emotional and cognitive problems; second, coping directed at others; and third, coping directed at problem-solving.

\section{Coping with self (physical appearance, emotional and cognitive problems)}

First, PLWHA may have internal coping strategies directed at their own physical, emotional and cognitive problems which may include denial, depression, blame, concealment, self-judgment, shame, self-doubt, etc. This strategy may involve hiding their identity. The feasibility of hiding their identity may depend on the stage of the illness, on prior knowledge of the disease status by the person himself or herself, and by people around the PLWHA. In the initial stage PLWHA may be able 
to conceal the illness when it is not visible, but when complications like skin diseases, e.g. kaposi's sarcoma or chronic diarrhoea with weight loss set in, this coping strategy may be put to the challenge. General negative beliefs about HIV/AIDS and linking it to immorality contribute to emotional consequences. Knowledge of and access to ART may have an impact on a person's intention to hide their condition. ART may allow PLWHA to regain their strength and prevent complications increasing the possibility of hiding their identity. The degree of their self-efficacy can influence to what extent they are able to confront the physical, emotional and cognitive consequences.

\section{Coping directed at others}

Second, the coping strategy of PLWHA aimed at reducing unfavourable reactions of others may include the same hiding tendencies but also social withdrawal because of fear of disclosure and feelings of guilt, etc. This strategy may also involve trying to influence the meaning other people attach to HIV/AIDS (Goffman, 1963). Since HIV/AIDS is linked to promiscuity, which is socially unacceptable, some PLWHA may prefer to alter other people's reactions by ascribing their condition to witchcraft or a curse from the gods. Some traditional healers and faith healers also ascribe HIV/AIDS to witchcraft or a curse from the gods, so PLWHA would prefer to use their services rather than seeking care in health-care institutions.

This strategy may also imply associating or comparing themselves to people with a similar problem. PLWHA may prefer to associate with another person with HIV/AIDS. The perception of similar persons in support groups can also motivate PLWHA to seek care. Similarly when health-care professionals and family members are willing to care for PLWHA it can encourage them to keep up with their hospital visits.

\section{Coping directed at problem-solving}

Third, PLWHA may apply strategies aimed at solving the direct or indirect problems with their disease (HIV/AIDS) which may include self-care, going to traditional healers or a faith house, self-exclusion from health services, etc. that may lead to delay or not seeking appropriate care. General beliefs about HIV/AIDS can lead PLWHA to take self-medication with a view of relieving immediate signs and symptoms. Similarly beliefs linked to spirits and witchcraft encourages them to go to traditional healers because they tell them what they want to hear. In a South African street intercept survey, $11 \%$ believed that AIDS is caused by spirits and the supernatural (Kalichman \& Simbayi, 2004). Some of the traditional healers may convince them that there is nothing like AIDS. Also the belief that God can make impossible things possible can lead them to taking the faith house as their first 
choice for care. When PLWHA have a high self-efficacy they will be able to find the right health-care institution.

\section{Conclusion}

PLWHA make different care-seeking choices as a result of self-stigma and stigmatization from others which may lead to non-utilization of health-care institutions. This paper sought to build an explanatory model aimed at systematically analysing the role of stigma in the care-seeking behaviour of PLWHA. The conceptual analysis of the problem started with a social assessment. A literature review indicated that stigma had a great impact on the psychosocial problems of PLWHA. Subsequently, three important determinants (beliefs, knowledge and self-efficacy) which influence the patient's coping and care-seeking behaviour were examined. Other variables such as gender, age, religion, policy and poverty were identified as moderators. Three strategies PLWHA may use for coping which affect care-seeking were analysed (coping with physical, emotional and cognitive problems, coping directed at others, and coping directed at problemsolving). More studies are needed to authenticate the precise coping strategies PLWHA employ in Sub-Saharan Africa. Social support from society can reduce tension and anxiety. PLWHA can deal better with their situation by comparing and contrasting personal feeling with others in similar circumstances through joining peer groups (Sosnowitz \& Kovacs, 1992) which makes it easier as the stigma is reduced and that alone is a powerful motivator for seeking care.

\section{References}

Adam, B. D. (1992) Sociology and people living with AIDS. In: Huber J. and Schneider B. E. eds. The social context of AIDS (pp. 3-18). London, Sage publications.

Alonzo, A. A. (1985). An analytic typology of disclaimers, excuses and justifications surrounding illness: a situational approach to health and illness. Social Science and Medicine, 21(2), pp. 153162.

Bandura, A. (1977). Self efficacy: Towards a unifying theory of behavioural change. Pschological review, 84(2), pp. 191-215.

Bandura, A. (1986). Social foundations of thought and Action: A social cognitive theory. Englewood Cliffs, NJ, Prentice Hall.

Bond, V., Chase, E. \& Aggleton P. (2002). Stigma, HIV/AIDS and prevention of mother-to-child transmission in Zambia. Evaluation and Program Planning, 25, pp. 347-356.

Camp, R. (2006). Antiretroviral pipeline 2006. In Huff, B. ed. What's in the pipeline: New drugs, vaccines, Microbicides, HCV and TB Therapies in Clinical Trials (pp. 2-20). New York, Treatment action group.

Chesney, M. A. \& Smith, A. W. (1999). Critical delays in HIV testing and care. The potential role of stigma. America behavioural scientist, 42, pp. 1162-1174. 
Chi, B. H., Chansa, K., Gardner, M. O., Sangi-Haghpeykar, H., Goldenberg, R.L., Sinkala, M., Muchimba, M. \& Stringer, J.S. (2004). Perceptions towards HIV, HIV screening and the use of anti retroviral medications: a survey of maternity based health care providers in Zambia. International Journal of STD and AIDS, 15(10), pp. 685-690.

Goffman, E. (1963). Behavior in public places. New York, The free Press.

Goffman, E. (1974). Stigma: notes on the management of spoiled identity. New York, Jason Aronson, Inc.

Green, L. W. \& Kreuter, M,W. (1999). Health promotion planning. An educational and ecological approach. United States of America, Mayfield publishing company.

Hamra, M., Ross, M. W., Orrs, M. \& D'Agostinos, D. (2006). Relationship between expressed HIV/AIDS related stigma and HIV beliefs/ knowledge and behaviour in families of HIV infected children in Kenya. Tropical Medicine and International health, 11(4), pp. 513-527.

Herek, G. \& Glunt, E. K. (1988). An epidemic of stigma: public reaction to AIDS. American Psychologist, 43(11), pp. 886-891.

Herek, G. M., Mitnick, L., Burris, S., Chesney, M., Devine, P., Fullilove, M. T., Fullilove, R., Gunther, H. C., Levi, J., Michaels, S., Novick, A., Pryor, J., Snyder, M. \& Sweeney, T. (1998). Workshop Report: AIDS and Stigma: A conceptual framework and Research Agenda. AIDS and Public Policy Journal, 13(1), pp. 36-47.

James, S., Reddy, S. P., Taylor, M. \& Jinabhai, C. C. (2004). Young people, HIV/AIDS/STIs and sexuality in South Africa: The gap between awareness and behaviour. Acta Paediatrica, 93(2), pp. 264-269.

Kalichman, S. C. \& Simbayi, L. (2004). Traditional beliefs about the cause of AIDS and AIDS related stigma in South Africa. AIDS Care, 16(5), pp. 572-80.

Kalichman, S. C., Simbayi, L. C., Cain, D., Jooste, S., Skinner, D. \& Cherry, C. (2006). Generalizing a model of health behaviour change and AIDS stigma for use with sexually transmitted infection clinic patients in Capetown, South Africa. AIDS Care, 18(3), pp. 178-82.

Letamo, G. (2003). Prevalence of and factors associated with HIV/AIDS-related stigma and discriminatory attituides in Botswana. Journal of Health Population and Nutrition, 21(4), pp. $347-357$.

Lewis O. (1966). The culture of poverty. Scientific American, 215(4), pp. 19-25.

Lwanda, J. L. (2004). Politics, culture and medicine: an unholy trinity? Historical continuities and ruptures in the HIV/AIDS story in Malawi. In Kalipeni, E., Craddock, S., Oppong, J. R., and Ghosh, J eds. HIV and AIDS in Africa. Beyond Epidemiology (pp. 29-42). UK, Blackwell publishing Ltd.

Macphail, C. L., Pettifor, A., Coates, T. \& Rees, H. (2006).You must do the test to know your status: Attitudes to HIV voluntary counseling and testing for adolescents among South African youth and parents. Health education and behaviour, (Epub ahead of print). PMID: 16870815.

Maman, S., Mbwambo, J., Hogan, N. M., Kilonzo, G. P. \& Sweat, M. (2001). Women's barriers to HIV-1 testing and disclosure: challenges for HIV-1 voluntary counseling and testing. AIDS Care, 13(5), pp. 595-603.

Maman, S., Mbwambo, J. K., Hogan, N. M., Kilonzo, G. P., Campbell, J. C., Weiss, E. \& Sweat M. D. (2002). HIV- positive women report more life time partner violence: findings from a voluntary counseling and testing clinic in Dar es salaam, Tanzania. American Journal of Public Health, 92(8), pp. 1331-1337.

Mann, J. (1988). Statement at an informal briefing on AIDS to the 42nd session of the United Nations General Assembly. Journal of the Royal Statistical Society, Series A (Statistics in Society). 151(1), pp. 131-136.

Muyinda, H., Seeley, J., Pickering, H. \& Barton, T. (1997). Social aspects of AIDS- related stigma in rural Uganda. Health and Place, 3(3), pp. 143-147.

Mwinituo, P. P. \& Mill, J. E. (2006). Stigma associated with Ghanaian caregivers of AIDS Patients. Western Journal of Nursing Research, 28(4), pp. 369-382. 
Myer, L., Morroni, C. \& Cooper, D. (2006). Community attitude towards sexual activity and child bearing by HIV positive people in South Africa. AIDS Care, 18(7), pp. 772-776.

Obbo, C. (1995). Gender, age and class: Discourses on HIV transmission and control in Uganda. In Brummelhuis, H. T and Herdt, G. eds. Culture and sexual risk. Anthropological perspectives on AIDS (pp.79-95). United States of America, Gordon and Breach publications.

Odujinrin, M. T. \& Adebayo, S. B. (2001). Social characteristics, HIV/AIDS knowledge, preventive practices and risk factors elicitation among prisoners in Lagos, Nigeria. West African Journal of Medicine, 20(3), pp. 191-198.

Okome-Nkoumou, M., Okome-Miame, F., Kendjo, E., Obiang, G.P., Kouna, p., Essola-Biba, O., Bruno Boguikouma, J., Mboussou, M. \& Clevenbergh, P. (2005). Delay between first HIV- related symptoms and diagnosis of HIV infection in patients attending the internal medicine department of the foundation Jeanne Ebori (FJE), Libreville, Gabon. HIV Clinical Trials, 6(1), pp. 38-42.

Owotade, F. J., Ogunbodede, E. O. \& Sowande, O. A. (2003). HIV/AIDS pandemic and surgical practice in a Nigerian teaching hospital. Tropical Doctor, 33(4), pp. 228-31.

Parker, R. \& Aggleton P. (2002). HIV and AIDS-related stigma and discrimination: a conceptual framework and implications for action. Brazil, Brazilian Interdisciplinary AIDS Association.

Peltzer, K., Mngqundaniso, N. \& Petros, G. (2006). HIV/AIDS/STI/TB knowledge, beliefs and practices of traditional healers in Kwazulu-Natal, South Africa. AIDS Care, 18(6), pp. 608-613.

Petros, G., Airhihenbuwa, C. O., Simbayi, L., Ramlagan, S. \& Brown, B. (2006). HIV/AIDS and 'othering' in South Africa. The blame goes on. Culture, Health and Sexuality, 8(1), pp. 67-77.

Pignatelli, S., Simpore, J., Pietra, V., Ouedraogo, L., Conombo, G., Saleri, N., Pizzocolo, C., Delaco, G, Tall, F., Ouiminga, A., Carosi, G. \& Castelli, F. (2006). Factors predicting uptake of voluntary counselling and testing in a real-life setting in a mother and child center in Ouagadougou, Burkina Faso. Tropical Medicine and International health, 11(3), pp. 350-357.

Rankin, W.W., Brennan, S., Schell, E., Laviwa, J. \& Rankin, S. H. (2005). The stigma of being HIVpositive in Africa. Plos Medicine, 2(8), pp. 0702-0704.

Schoepf, B. G. (1995). Culture, sex research and AIDS prevention in Africa. In Brummelhuis, H. T and Herdt, G. eds. Culture and sexual risk anthropological perspectives on AIDS (pp. 29-45). USA, Gordon and Breach publishers.

Schoepf, B. G. (2004). AIDS, history and struggles over meaning. InKalipeni, E., Graddock, S., Oppong, J. R and Ghosh, J. eds. HIV and AIDS in Africa, beyond epidemiology (pp.15-28). UK, Blackwell publishing ltd.

Schur, E. M. (1984). Labelling women deviant: gender, stigma and social control. USA, Temple University press Philadelphia.

Scott, M. B. \& Lyman, S. M. (1968). Accounts. American Sociological Review, 33(1), 46-62.

Shelp, E. E. \& Sunderland, R.H. (1987). AIDS and the church. USA, The Westminster press.

Sontag, S. (1991). Illness as metaphor: AIDS and its metaphors. London, Pengium.

Sosnowitz, B. G. \& Kovac, D. R. (1992). From burying to caring: Family AIDS support groups. In Huber, J \& Schneider, B. E. eds. The social context of AIDS (pp.131-144). London, Sage Publications.

Tarantola, A., Koumare, A., Rachline, A., Sow, P.S., Diallo, M.B., Doumbia, S., Aka, C., Ehui, E., Brucker, G. \& Bouvet, E: Groupe d'etude des risques d'exposition des soignants aux agents infectieux (GERES). (2005). A descriptive retrospective study of 567 accidental blood exposures in health care workers in three West African Countries. Journal of Hospital Infection, 60(3), pp. 276-282.

Temmerman, M., Ndinya-Achola, J., Ambani, J. \& Piot, P. (1995). The right not to know HIV test results. Lancet, 345(8955), pp. 969-970.

The Joint United Nations programme on HIV/AIDS (UNAIDS) AIDS epidemic update 2006 available at http://data.unaids.org/pub/epireport/2006/02-global_summary_2006_epiupdate_eng.pdf [Accessed 10 July 2007]. 
Valdiserri, R. O. (2002). HIV/AIDS stigma: An impediment to public health. American Journal of Public Health, 92(3), pp. 341-342.

Whitehead, E., Carlisle, C., Watkins, C. \& Mason T. (2001). The historical developments. In Mason, T., Carlisle, C., Watkins, C \& Whitehead, E. eds. HIV and Aids (pp. 117-125). New York, Routledge.

Wolff, B., Nyanzi, B., Katongole, G., Ssesanga, D., Ruberantwari, A. \& Whitworth, J. (2005). Evaluation of a home based voluntary counseling and testing intervention in rural Uganda. Health Policy Plan, 20(2), pp. 109-116. 


\section{Chapter Four}

\section{Societal beliefs and reactions about people living with HIV/AIDS}

\section{Submitted}

\section{Authors}

Ngozi. C. Mbonu

Bart van den Borne

Nanne K. De Vries 


\section{Abstract}

Objective: We sought to examine and understand societal beliefs and reactions about people living with HIV/AIDS (PLWHA).

Methods: We conducted in-depth semi-structured interviews among 40 people from the general public using street-intercept methodology in Port Harcourt, Nigeria. The Nvivo (QRS release 2.0) computer program was used to manage the data effectively. The analysis of the interviews enabled us to identify factors that cause society to stigmatize PLWHA.

Results: An explanatory model shows ten major determining factors that relate to processes and conditions that allow a manifestation of stigma. Four manifestations of stigma and also conditions that facilitate others to care for PLWHA were also found.

Conclusion: The study shows that there is an urgent need to increase HIV/AIDS information to dispel the various causal links and myths. Religious leaders should be made important stakeholders in the fight against stigmatization. Government should continue to play a leading role by not only creating policies that protect the rights of PLWHA but also ensuring that these policies are implemented. 


\section{Introduction}

Sub-Saharan Africa remains the region most heavily affected by HIV/AIDS, accounting for $67 \%$ of all people living with HIV/AIDS (PLWHA) and for $75 \%$ of AIDS deaths worldwide in 2007 (UNAIDS, 2008). In West Africa, Nigeria has the largest epidemic in absolute numbers (UNAIDS, 2008), with 2.6 million (2.0 million-3.2 million) people living with HIV and 170,000 (130,000-270,000) adult and child deaths from AIDS in 2007 (Epidemiological Factsheet, 2008). The HIV/AIDS prevalence rate in Nigeria remains uneven across different states (Utulu \& Lawoyin, 2007; UNAIDS, 2008). A retrospective study carried out between 2000 and 2004 among 10,032 pregnant women attending the antenatal clinic at the Braithwaite Memorial Hospital, Port Harcourt, Nigeria, showed that $5.93 \%$ of the women were HIV-positive patients (Obi, Iroagba \& Orjiakor, 2007). Another study carried out in the university teaching hospital at Port Harcourt, Nigeria, between 1999 and 2004 showed a paediatric prevalence rate of 25.8\% (Alikor \& Erhabor, 2005).

One of the many challenges associated with HIV/AIDS is stigma. Stigma is generally recognized as an 'attribute that is deeply discrediting' that reduces the bearer 'from a whole and usual person to a tainted, discounted one' (Goffman, 1963). Herek (2002) describes stigma as an enduring condition, status, or attribute that is negatively valued by a society and whose possession consequently discredits and disadvantages an individual (Herek, 2002). Steward and colleagues noted further that stigma is very much about the socially constructed meanings associated with the attribute or characteristic (Steward et al., 2008). Because AIDS or HIV infection is an enduring condition or characteristic that is negatively valued (Herek, 2002), AIDS-related stigma continues to be a barrier to caring for, and supporting, people whose HIV status is known in society (Campbell et al., 2007).

Stigma arises and stigmatization takes shape in specific contexts of culture and power (Parker \& Aggleton, 2003). Stigma is especially significant in many developing countries, such as those in Africa, where social networks and, therefore, societal values, are relatively strong (Greeff et al., 2008). The family and the community constitute vital aspects of the social structure that normally offers strength and support during times of need and crisis (Ajuwon et al., 1998; Hilhorst et al., 2006; Kipp et al., 2007). In this communal and social network, contact with someone afflicted with a disease regarded as a mysterious threat, inevitably, feels like a trespass or, worse, as violation of a taboo (Sontag, 1988).

Stigma influences all phases in the prevention, the detection of HIV/AIDS and care for PLWHA. It decreases turn-up for facilities for voluntary counselling and testing in hospitals (Weiser et al., 2006). Anticipated stigmatizing societal reactions may also decrease the tendency to disclose sero-status to the immediate social environment and, more importantly, to sexual partners. Specifically, a study carried 
out in Port Harcourt, Nigeria, showed that $77 \%$ of PLWHA had disclosed their HIV sero-status to one or more others, of which $22.3 \%$ disclosed their condition to their parents, $9.7 \%$ to their siblings, $27.8 \%$ to pastors, $6.3 \%$ to friends, $10.4 \%$ to their family members and $23.6 \%$ to their sexual partners (Akani \& Erhabor, 2006).

In a previous study, we reviewed the problems of PLWHA in Sub-Saharan Africa concerning care-seeking behavior, and argued that this is partly due to stigmatizing responses to PLWHA from health care professionals (HCPs) and society at large (Mbonu, Van den Borne, \& De Vries, 2009). Given the negative impact of stigma on care seeking and the selective disclosure of a positive HIVsero-status to close and trusted people, it is important to understand why HIV/AIDS attracts such a degree of negative reaction in society. In the present study, we focus further on a description and analysis of public beliefs and reactions towards PLWHA in a multi-street study conducted in Port Harcourt, Nigeria, to understand why society stigmatizes PLWHA and what causes the stigma. The paper concludes with recommendations that may help reduce the negative reaction towards PLWHA.

\section{Methodology}

A descriptive qualitative research design, using a convenient multi-venue streetintercept interview technique, was used to explore public beliefs and reactions towards PLWHA. The street-intercept methodology provides access to segments of the urban population that are hard to reach and has a high degree of validity and reliability (Green, 1995; Miller et al., 1997; Baseman et al., 1999; Fortenberry et al., 2001; Rotheram-Borus et al., 2001). It is also used frequently in studies of sensitive topics, such as drug use and sexual behavior (Hidaka et al., 2008). In our study, due to the sensitivity of the topic, and in order to encourage remarks about PLWHA, we talked not only about individual processes but also at a meta-level about social processes. Furthermore, participants sometimes gave examples of processes or perceptions based on hearsay while in other parts they talked about themselves and their own experiences, perceptions and thoughts.

Eligibility requirements included being an adult older than 18 years and residence or employment in Port Harcourt. Streets were selected from the Obio Akpor local government area of Port Harcourt. We recruited 40 participants for the interviews. Self-reported PLWHA were excluded. Port Harcourt is located in the southern part of Nigeria, specifically in the Eastern Niger Delta. The area is particularly rich in crude oil. Families have a median of six persons per household (Obinna et al., 2009). 


\section{Recruitment and consent of participants}

A convenience sample was used in this study. Interviewees were approached at the recruitment venues and interviews were held in workplaces, offices, restaurants, shops or on the street. An introductory sentence informed participants that the interviews were covering stigma towards PLWHA. Verbal consent was obtained from participants and total anonymity was guaranteed. We approached Forty-one persons, of whom 40 agreed to participate in the interviews. The one person who refused was too busy to grant an interview. No compensation was offered to participants. Interviews were conducted throughout the week. Interviews were conducted in the English language and were face to face. The interviews lasted between an hour and one and a half hours. Basic demographic data about participants were gathered before the interviews. Interviews continued until no new information emerged. All interviews were audio-taped and transcribed verbatim.

\section{Data analysis}

We used Nvivo (QRS release 2.0), a computer-assisted qualitative data analysis system, to aid analysis and reporting. The analysis of the interviews enabled us to identify causal relationships and, therefore, come up with a causal structure. We also used field notes and information from the literature review during the analysis. We examined emerging issues to identify related concepts, and we formed different factors from the emerging themes. We built a model to explore important relationships between concepts. We formed attributes to include important characteristics such as gender and work category, which were subsequently imported into Nvivo.

\section{Validity}

An independent researcher coded a random selection of data to look for new concepts. The independent researcher compared emerging themes with the coding by the authors. New meanings and discrepancies were checked by re-reading the transcripts and fine-tuning interpretations until unambiguous categories and themes were agreed. No important discrepancies were found.

\section{Results}

Demographic characteristics are presented in Table 1. Of the 40 interviewees, 24 persons were female and 21 persons were married. An explanatory model was organized in a causal structure based on the combined responses of the interviewees (Figure 1). The model shows that stigma by society is affected by ten different determining factors, all of which relate to processes and conditions that allow a manifestation of the stigma. These determining factors are; degree of knowledge, association with promiscuity, blame, societal reaction to care givers, media, 
poverty, fear, religion, gender, and role of government. Blame functions both as a determining factor that creates stigma and as a manifestations of stigma. Other manifestations of stigma are abandonment, isolation and harassment.

Table 1 shows Demographic Characteristics

\begin{tabular}{|c|c|c|c|c|}
\hline Participant & Gender & Marital Status & Types Of Work & Tribe \\
\hline 1 & Female & Single & Company Worker & Efik \\
\hline 2 & Male & Married & Police Officer & Kalabari \\
\hline 3 & Female & Married & Legal Practitioner & Efik \\
\hline 4 & Female & Married & Legal Practitioner & Ibo \\
\hline 5 & Female & Married & Sales Woman & Ibo \\
\hline 6 & Female & Married & Teacher & Yoruba \\
\hline 7 & Female & Married & Teacher & Ibo \\
\hline 8 & Male & Single & Company Worker & Yoruba \\
\hline 9 & Female & Single & Motor Company & Ibo \\
\hline 10 & Male & Married & Manager & Yoruba \\
\hline 11 & Female & Single & Manager & Efik \\
\hline 12 & Male & Married & Supervisor & Ibo \\
\hline 13 & Male & Single & Manager & Efik \\
\hline 14 & Female & Single & Office Secretary & Ibo \\
\hline 15 & Female & Single & Hair Dresser & Ibo \\
\hline 16 & Male & Single & Company Worker & Efik \\
\hline 17 & Female & Single & Company Worker & Efik \\
\hline 18 & Female & Single & Company Worker & Ibo \\
\hline 19 & Female & Single & Company Worker & Ibo \\
\hline 20 & Male & Single & Company Worker & Ibo \\
\hline 21 & Female & Married & Company Worker & Ibo \\
\hline 22 & Male & Married & Police Officer & Efik \\
\hline 23 & Female & Married & Legal Practitioner & Efik \\
\hline 24 & Female & Married & Manager & Yoruba \\
\hline 25 & Female & Married & Teacher & Ibibio \\
\hline 26 & Male & Married & Businessman & Ibo \\
\hline 27 & Male & Married & Manager & Yoruba \\
\hline 28 & Female & Single & Computer Analyst & Yoruba \\
\hline 29 & Female & Married & Shop Owner & Ibo \\
\hline 30 & Male & Married & Government Worker & Ibo \\
\hline 31 & Male & Married & Company Worker & Efik \\
\hline 32 & Male & Single & Restaurant Worker & Efik \\
\hline 33 & Male & Single & Company Worker & Ibo \\
\hline 34 & Female & Married & Insurance Worker & Ibo \\
\hline 35 & Female & Married & Motor Company Worker & Ibo \\
\hline 36 & Female & Single & Student & Ibo \\
\hline 37 & Female & Single & Student & Efik \\
\hline 38 & Male & Single & Student & Efik \\
\hline 39 & Male & Single & Student & Ibo \\
\hline 40 & Female & Married & Surveyor & Yoruba \\
\hline
\end{tabular}




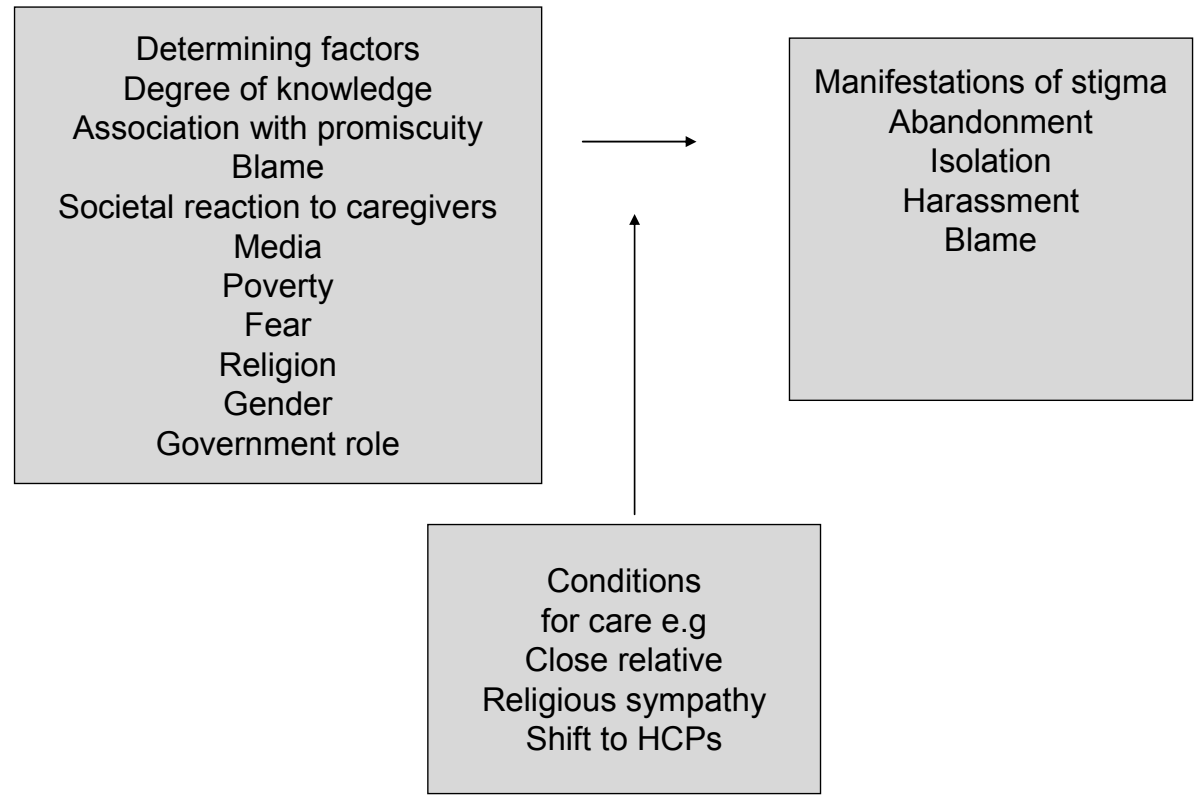

Figure 1 Showing determining factors, conditions of care and manifestations of stigma

The views of both men and women are combined. The following sections presents the ten determining factors. Subsequently, we describe different manifestations of stigma. Thirdly, we describe the conditions facilitating care, and finally, we discuss how these processes and conditions interrelate in the explanatory model. The described findings and interpretations offer a general insight, illustrated with verbatim excerpts.

\section{The determining factors}

We distinguished ten factors; degree of knowledge, association with promiscuity, blame, reactions to care givers, media, poverty, fear, religion, gender, and role of government.

\section{Degree of knowledge}

We found that inadequate knowledge about the transmission of HIV/AIDS and about HIV condition in general can influence how people react to PLWHA. Although public awareness on different ways of transmission of HIV may be increasing, still many people are not aware of accurate means of transmission of HIV virus. To some of the participants, people's lack of knowledge about HIV/AIDS infection contributes to reluctance to care for PLWHA, as the following quote illustrates: 
'Reaction depends on the education of the person involved, the mentality. Many people think if they touch the HIV person they will get it.' (Male, single)

PLWHA are especially ostracized when they show signs and symptoms of AIDS. Many participants based their judgement about HIV status on appearance, rather than on information, and a person's looks may determine how negative a reaction he or she receives. For instance, if a person with HIV has a normal body weight or is heavy weighted, people around them may not believe that the person has HIV. Conversely, if a person has a physical characteristics that are widely associated with $\mathrm{HIV}$, people begin to react negatively to the person, even if they are wrong about the diagnosis. Participants in our study described the appearance of a HIV-positive person as slim with skin rashes. They frequently mentioned loss of weight and being sick for a long time, as elaborated on in the following quote:

'The hair of people with HIV starts falling out, with boils all over the skin and they are slim.' (Female, single)

People felt confirmed in this judgement strategy, and looked for outward features of HIV/AIDS. Some participants, without knowing the exact illness of a person, assume the HIV status of that person and feel they are right if they see prototypical HIV/AIDS features. For instance, in the words of one interviewee:

I know someone has HIV when someone is real lean and before you know it the person is sick. When they take the person to the hospital, the doctor will examine and find out that the person is HIV positive.' (Male, single)

Association with promiscuity

According to the participants, people associate HIV/AIDS with promiscuity and perceive this as a barrier to caring for PLWHA. Many of them reported that HIV/AIDS is contracted from unprotected sexual intercourse. The general impression among our participants is that HIV/AIDS is acquired when the person has had much sexual activity with different persons. It was common for the participants in this study to depersonalize themselves from the belief of associating promiscuity with HIV/AIDS by shifting the belief to other people, for instance:

'Most people believe HIV is contracted through sexual transmission so immediately they see someone with HIV they automatically believe the person is promiscuous and goes around sleeping around but it can be got from different ways like blood transfusion.' (Male, married)

\section{Blame}

According to our respondents, a person with HIV/AIDS in society is frequently an object of blame. When people blame PLWHA for contracting the illness, it makes them stigmatize those people. Many of the participants said that society expects 
people to stick to their steady or wedded partners, as that is the way of avoiding contracting HIV/AIDS. Infected people deserved to be blamed, in their view for instance:

I think people blame HIV persons. Some people feel HIV persons get HIV because they are prostitutes or go about having sexual intercourse with men or flirting about. So if people find out someone has HIV, people will see the person as somebody who is not responsible. The society feels if the person has not been going from person to person sexually, why should they come in contact with such illness?' (Male, single)

Another participant put it this way:

If you are married to somebody, you are not supposed to go to another woman. You should stick to your wife. Then the single person has to be careful with their movement. People with HIV/AIDS should be blamed because they met someone; that is why they got HIV/AIDS.' (Male, single)

\section{Societal reaction to caregivers}

There was a consensus among participants that the reactions to people who care for PLWHA originate from their immediate environment, such as communal reactions, neighbors' influence and spousal reactions or from HCPs. One participant expressed the idea that people care for one another with the expectation of reciprocity, that is, that they themselves may have a need for the care of another person in the future. Unfortunately, caring for a person with HIV/AIDS may not fit into this method of care because they are regarded as people who will die soon. Many of the participants were also concerned about the way other people will react to them when caring for a person with HIV/AIDS. A female participant described what happened when she went to hospital to learn the result of a HIV/AIDS test of a relative who was visiting her, which turned out to be positive. She received this response in the hospital:

Laboratory worker: 'Oh madam, how long has this HIV person been staying with you in your house?

Woman: She has been staying for three months.

Laboratory worker: You have to bring all your children for a HIV test. No, no, infact any help you want to give her, let it be from a distance. She should be sent packing [sic- sent away] from your house.' (Female, married)

This exchange indicates the extent of stigmatizing reactions even from HCPs. In some cases, people fear that neighbors might spread the word that a family is caring for a person with HIV/AIDS, thereby affecting the possibilities of marriage of family members. One of the common procedures in marriage is that the family of the groom asks around for information about a potential bride before entering into a marriage. This implies that neighbors' judgements can be significant. Some 
participants felt that their desire for marriage and to have children overrides their desire to care for a person with HIV/AIDS. This concern was shown vividly in the following comment:

'Of course, caring for a person with HIV matters to me, because people around me can know about it or how else do people get husbands? They [potential suitors] can ask questions around about me where I live. I will not care for a person with HIV/AIDS even if she is my twin sister. Do you want me to get AIDS? I do mind as long as it is HIV/AIDS, or do you want me to die young? You know it is a very serious disease that has no cure. You can see I am not married. I am a single girl. I do not want anything that will stain my image.' (Female, single)

\section{Media}

According to some participants, the media have created an image that HIV/AIDS is contracted by people who have sex with multiple partners, or who visit sex workers. One participant had the following to say:

'People react to a person with HIV in the same way, no matter how you get it. The reason why it is like that is that the first awareness of HIV publicity said $H I V$ was for people sleeping around. The media always said stick to one partner, use a condom. This made people feel that once people stick to one partner, they will not get HIV, not realizing that it is possible the one partner already has HIV.' (Female, married)

Participants said that the information people get from radio and television is that HIV/AIDS can be guarded against. This helps in fuelling the negative public reaction people give to PLWHA by shifting the responsibility to the individual. The next participant was concerned by the way media send HIV/AIDS messages to the public using words like "obirinajocha" (which means "you end up in the white sand underground"), which can contribute to how people respond to HIV/AIDS:

'What is being chumed out in the media is also an issue. One begins to wonder whether they are out to create an undesired effect because we hear all over the media that this is an incurable disease and people should better attempt by any means not to pick it up. The media create an atmosphere of helplessness for HIV positive people, as well as their care givers.' (Male, married)

\section{Poverty}

Poverty is seen as an underlying factor in preventing care for PLWHA. Poor people are often looked down upon in society in any event. HIV/AIDS only contributes further to the stigmatization of such people. Economic difficulties complicate the situation for persons with HIV or for people who may be willing to care for them. Sometimes, even when relatives provide PLWHA with money for drugs, people 
caring for the person with HIV/AIDS divert the money for their own personal use, or for burial, because they feel the person is dying anyway, in addition to trying to avoid caring for the person. They regard it is a waste of scarce resources, as one interviewee noted:

'... when the HIV person was sick, his elder brother was given money by people to take care of the person with HIV for drugs,but he spent the money on him self. He believed his brother was going to die so there was no need of giving him that money for care.' (Female, single)

Fear

Many of the participants had a fear of HIV/AIDS infection, and felt they could make mistakes when caring for such a person. People feel that PLWHA are close to death and since people are afraid of death, they try to avoid anything that reminds them of their own mortality, for instance:

'People who know someone with HIV, the relationship with the person will change somehow because people are scared. Nobody wants to die. When we see someone (HIV person) like that we need to know how to deal with them.' (Male, single)

\section{Religion}

Our data revealed that religion may play both a detrimental and a supportive role. It is an important factor in the stigma of PLWHA, with some people placing faith in religion above medical treatment, causing much conflict in caring for PLWHA. Some of the participants believed it was possible to heal HIV/AIDS because there is nothing God cannot do. This merely reflects the notion that, if they contract HIV/AIDS, they may likely seek care in churches. This affects care-seeking behavior and, especially may cause delay in seeking care. One participant was convinced that HIV/AIDS can be cured in the church she attends:

'Many people with HIVIAIDS will fear to tell their pastor that they have AIDS so it is a problem because I know in my church they heal HIV/AIDS.' (Female, married)

However, another participant felt that the way the church approaches HIV/AIDS is wrong. Because people look up to pastors and hope to receive comfort from them, the clergy may misuse the power they have over people, as demonstrated by the following comment:

'There is segregation in the church. The church counselors give a paper to new couples to go for compulsory HIV screening and when the results turn positive, they give them back seats in the church. The church committee gossip around 
and people who have heard are not comfortable with the persons with HIV, so they feel segregated.' (Female, married)

Making PLWHA sit at the back seats of the church is possible because the clergy are able to use their power to give them whichever seat position they wish. Information about who has HIV also travels very fast in the church, as one participant noted:

I heard about the HIV couple in the church I attend. I did not know until people found out and started telling others. It was the pastor who found out through spiritual means and called them out. He asked them whether they are HIV positive and they said yes.' (Female, single)

Openly asking for persons with HIV/AIDS to come out in public has added implications because the whole church will become aware of the HIV status of those involved.

\section{Gender}

Our data show that women living with HIV experience more problems because their position is often marginal and inferior. Many of the participants expressed the concern that women encounter more problems because they are largely dependent on their husbands in almost every aspect: financially, emotionally, and in decisionmaking. Many of the participants said some women may be willing to care for a person with HIV/AIDS, but they need the approval of their husbands before they can do so. Chastity is expected of women, so when they contract HIV/AIDS, they are blamed to a larger extent than men, which may affect the willingness to care for them. The following illustrates a classic example of gender difference in blame:

'The person I know living with HIV is a girl. It will be different for a man because people will not think immediately of sex as a cause of the HIV. They will think he got it from the barber salon.' (Female, single)

When a woman is infected with HIV, she is easily labelled a prostitute, as one participant observed:

'Women seem to suffer in everything. You find out that when a lady is HIV positive, nobody wants to hear anything apart from the fact that she has been fornicating and moving from place to place. They say she deserves what happened to her..... but if it is a male it is different.' (Female, single)

This male participant showed concern that women have a possibility of spreading HIV/AIDS more deliberately than men, as the following illustrates:

'It is better to tell the government to take away a person with HIV, especially females, because if one does not take care she can spread it to other male 
people. Some of them know they will die one day so they start flirting about.' (Male, single)

\section{Role of government}

Many of the participants felt that government has a major role in providing care for PLWHA and increasing public knowledge about people about HIV/AIDS. Take the following quote, for example:

'Government should continue with public information. People are still not educated very well. Some people think that if you share a toilet with a HIV person you will get HIV.' (Female, married)

Participants also felt the government should be involved in the care of persons with $\mathrm{HIV}$, as shown by the following quote:

'Government should make antiretroviral therapy within the limit of individuals. Some should be helped if they cannot afford it because I read in the newspapers that ART is very expensive.' (Female, married)

\section{Manifestations of stigma}

As a result of these factors, there are changes in the relationship between the general public and PLWHA. The various external manifestations of stigmas, such as abandonment, isolation, harassment and blame are discussed below.

\section{Abandonment}

Participants in this study reported knowing PLWHA that are abandoned or they themselves would advocate abandoning PLWHA. People are suspicious that people with HIV/AIDS can purposely infect others by sharing household sharp objects or start flirting with them because they know they will die. Because of that, some participants wanted the government to restrict the movement of PLWHA. Other people felt that persons with HIV/AIDS have to accept their fate and need to learn to live with the fact that people will stigmatize them. Another participant preferred to shift the responsibility of care to HCPs:

'Why must a HIV person come to the house? They should stay back in the hospital.' (Female, married)

\section{Isolation}

Participants described how their relationship will change upon realizing that a person with HIV/AIDS, or a caregiver of such a person, is around. People avoid people with HIV/AIDS. This explains why PLWHA are reluctant and selective in disclosure, as a way of coping with HIV/AIDS stigma. People also feared that, once they care for someone with HIV/AIDS, word will spread around and from there on, 
people will isolate them. This participant talks about her experience of how PLWHA are cared for:

'Sometimes people with HIVIAIDS are locked up in the room and the care givers make a hole through which they give them food so that the caregivers do not come in contact with the person. Sometimes the caregivers do not even give the person food so that the person can die.' (Female, single)

A participant shared what happened when a person with HIV/AIDS living close to her came back home from hospital:

'They try to isolate the woman who is caring for her daughter. When she was discharged and came home to their house, people started peeping at them through the window. People will not want to go to the kitchen when she is cooking and they will not want to go near the bathroom until they finish using the bathroom. Everybody wants to keep away. People look at the care giver as someone who is not reasonable anymore.' (Female, single)

This is particularly significant for people living in shared accomodation and shared utilities such as bathroom or kitchen.

\section{Harassment}

We also found that harassment can be a manifestation of stigmatisation and can be shown in any form of unwelcome behavior. According to this participant, who tried to describe what will happen to someone caring for a person with HIV/AIDS:

'The care givers of HIV persons will have a problem because it will be the talk of the area. People will say there is a person with HIV/AIDS in that area. Some will not be relating to them because they are afraid.' (Male, single)

In addition, people gossip in the community. This participant gave an account of a person she knows and who has HIV/AIDS:

'People were running away, they always say they don't want to be involved, wherever she passes people will point at her and say, "look at that person with HIV”. Nobody wants to visit her. The ones that go just want to gossip.' (Female, single)

\section{Blame}

Our findings indicate that the society frequently assigns blame to PLWHA. Blame is another way used by the people to stigmatize persons with HIV, for example:

'People blame them because they feel a responsible person is supposed to live a rightful life so they cannot contract the disease.' (Male, married)

Consider also the following point: 
'You know, here in Nigeria, if you have such sickness, people will start blaming the person with HIV. They will tell her all sorts of things. They do not care how she got it. They will say the person got it from sexual intercourse.' (Female, single)

Despite these various effect factors manifesting as stigma, some participants set conditions for care, which will be discussed in the next section.

\section{Conditions for care}

The extent to which a person with HIV is discriminated against can sometimes depend on the closeness of the person who is rendering the care. Some of our participants felt that they will only care for a person with HIV who was close to them, as in the following instance:

'Caring for a HIV person depends on how close the person is. If it is my brother or sister I can manage, but if it is my house help I will be afraid.' (Female, single)

Some participants felt that some people will still care for persons with HIV/AIDS who have no other option based on religious sympathy:

'People will run away, though it may not be everybody. Some people, because of fear of God, will like to encourage that HIV person because there is no other way to do it. One cannot poison a person with HIV to die. One will prefer to take care of the person until God wants him or her.' (Male, single)

The way people discriminate those who care for PLWHA at home can be different from the way they react to health care professionals. Many of the participants in our study mentioned that the public may not react to health care professionals in the way they react to home care givers, because they feel they may have a need for a health care professional themselves. They are generally expected to be doing their work and their duty, which includes caring for PLWHA in a protective way. One participant, when asked whether healthcare professionals caring for PLWHA will be stigmatized like home caregivers, she responded by saying that their profession makes them different from home care givers:

'Look at the name you called them, professionals. Healthcare professionals know how to take care of themselves.' (Female, single)

The various factors, conditions and processes that give rise to external stigma, and the way they relate, will be discussed below. 


\section{Discussion}

This study offers a description and exploration of the various factors, conditions and processes that allow stigma to manifest itself. Our study indicates that people are still not very knowledgeable about HIV/AIDS, its mode of transmission and treatment possibilities. People react negatively towards PLWHA because they know little about the disease. Hence, they cannot handle PLWHA even when it is a close relative (Hilhorst et al., 2006). Lear (1998) argued that the problem of behavioural change is compounded by the persistence of myths concerning HIV/AIDS. Furthermore, as long as a disease such as HIV/AIDS is not well understood in an era in which medicine's central premise is that all diseases can be cured (Sontag, 1988), it will continue to evoke reactions from the society. Apart from our present data which show that society has negative reactions towards PLWHA, other studies in Sub-Saharan Africa, (Hilhorst et al., 2006; Campbell et al., 2007; Greeff et al., 2008) have also shown that those who care for PLWHA encounter negative reactions, putting the entire family at risk, and making HIV/AIDS a societal problem.

Our data show not only that people stigmatize those diagnosed with HIV/AIDS, but also they preoccupy themselves with the health diagnosis of other people, through creating ideas about the physical features associated with certain illnesses such as HIV/AIDS. People live in a society that is not only structured by communal interaction (Wood \& Lambert, 2008) but also intertwined with gossip and rumors. HIV/AIDS inspires much gossip, rumor and speculation. The images and the ideas associated with PLWHA are an expression of people's concern for social order and a sense of dissatisfaction from within society (Sontag, 1988). This has significant implications for PLWHA. It increases self-stigmatization, in addition to the stigmatization from society, when PLWHA have the physical features that are widely believed to indicate HIV/AIDS. It is perhaps not surprising that our study shows that PLWHA who are of normal body weight or heavy weighted may be exonerated because people do not believe they can have normal body weight or be heavy weighted and at the same time have HIV/AIDS, especially when they are on antiretroviral therapy (ART) and have less need for frequent hospitalization. This aspect of body politics was also reported by Greeff and colleagues (Greeff et al., 2008).

Our data emphasize that people link HIV/AIDS to promiscuity, which makes people stigmatize PLWHA because they are regarded as those who have gone against the societal values by having indiscriminate sex. Nigerian society has strong guiding morals and values (Campbell et al., 2007), and sex is considered a highly private issue not to be discussed in the open (Ajuwon et al., 1998; Stewart \& Richter, 1998). HIV/AIDS is also seen as a disease that flushes out the identity of a certain "risk group", a community of pariahs that might have remained hidden from neighbours, colleagues, family and friends because HIV/AIDS is considered as a 
calamity brought down upon oneself (Sontag, 1988). Our data shows that the association with promiscuity is what causes blame because of the assumed improper behavior. The linking of blame to immoral behaviour was also similarly reported in a multi-country study of Zimbabwe, South Africa, Tanzania and Thailand, in which participants from Tanzania and Zimbabwe felt that PLWHA deserved what they got in terms of being punished for their reckless behavior (Maman et al., 2009). In our study, participants often assigned blame to PLWHA without bothering to find out the cause of infection with HIV/AIDS of the person for that individual. It is noteworthy that our findings show that blame is both a cause of stigma and a manifestation of stigma. First, society acts as a social watchdog by linking moral judgments to people's assumed behavior. Secondly, the judgement meted out to PLWHA affects the willingness to give care; society is not ready to help someone whose illness arose from wilful social misbehavior thereby stigmatizing PLWHA. Moreover, due to societal judgement, PLWHA and the family caregivers may find it difficult to seek any financial help which they are likely to need since many people do not have health insurance. This finding, taken together with another study carried out in Nigeria, confirms the likelihood of people in Nigeira needing financial help (Hilhorst et al., 2006). The probability of being helped is reduced by the principle of reciprocity in society, which is of particular concern. Hilhorst and colleagues (2006) went on to say that social capital implies reciprocity that has to be built and maintained requiring investments and resources which PLWHA may not be able to meet with such obligations. Furthermore, society is a death-denying one, where the prospect of no future or the loss of independence is an abomination (Chateauvert, 1993). Our data show that, while some people may be willing to assist PLWHA because they feel they could end up in the same situation in the future, others stigmatize PLWHA by expecting the government to take them away or keep them in hospital. Those who choose to care for PLWHA often prefer to keep it a secret so that the stigma does not spread to the rest of the family. When people find out that someone close to them is HIV-positive, it can jeopardize the chances of marriage of their family members or their caregivers. This is particularly significant in Nigeria because of high value placed upon marriage and producing children (Ajuwon \& Shokunbi, 1998).

Findings from our study have shown that the churches in Port Harcourt do help PLWHA, but sometimes they can make their situation very difficult too. People are often obedient to the pastors and in the church, and the pastors were very influential, making their actions crucial. Aholou and colleagues further noted that the churches have strengths, credibility and are well grounded in communities (Aholou et al., 2009). Many PLWHA regard church as one of the places of protection from the negative reactions of society, but they end up being stigmatized by their fellow worshippers. In particular, according to our correspondents, if premarital HIV screening is required by the couple's church and there is a positive HIV test result, it means that the information may leak to other members of the 
church, since there is no standard guideline regarding the privacy and confidentiality of people. The future of the marriage is thereby jeopardized. Premarital HIV screening is becoming a prerequisite for marriage to be celebrated in many churches (Uneke, Alo \& Ogbu, 2007) and, since marriage is very important in society, many people thus end up knowing their status by necessity while being ill prepared for the negative reactions from the society. Sontag (1988) argues that any disease that is considered mysterious and acute enough to be feared will be felt to be morally, if not literally, contagious, in addition to the notion that cleanliness is next to godliness; thus, stigmatization is not unexpected for PLWHA even in the church. Lear (1998) shows that some Roman Catholic churches in Kenya and Uganda have used slogans such as "Love faithfully to avoid AIDS" to discourage usage of condoms. Other recent studies (e.g., Iwelunmor et al., 2006; Campbell et al., 2007; Neville \& Rubin, 2007) also reported both supportive and detrimental roles of churches. The belief in faith healing and miracles was also found in our study, which means that many who know of their status may choose faith healing as a first choice of care, or combine it with treatment from a health care institution.

With all these negative reactions towards PLWHA in general, our study also shows that societal reactions can differ depending on the person's gender. Nigerian society is constructed in such a way that it is a man's world, because decisions and actions are often dependent on men (Ajuwon \& Shokunbi, 1998). Society exonerates men with multiple partners (Ankra, 1994; Ajuwon et al., 1998; Hartwig et al., 2006; Utulu \& Lawoyin, 2007) as it reflects male virility. The sexual norm in Nigeria promotes sexual liberty for men and sexual purity for women (Ajuwon \& Shokunbi, 1998). Our study shows that when a man contracts HIV/AIDS he may be regarded as a victim and attract more sympathy. This is in keeping with other studies carried out in Nigeria, which show that male PLWHA are more accepted than female ones (Hilhorst et al., 2006; Babalola et al., 2009). A man is also often able to hide his HIV-positive status if he chooses, and may end up spreading the infection because he is the breadwinner and may have money to care for himself. A woman, on the other hand, is most likely to be financially dependent (Ajuwon et al., 1998; Hilhorst et al., 2006; Strebel et al., 2006), often finding it difficult to hide her status. The marginal position of women also means they will not be able to seek appropriate care, since they are often too embarrassed to attend a sexually transmitted infection (STI) clinic, making them resort to traditional healers or patent medicine dealers (Ajuwon \& Shokunbi, 1998).

Our data shows that, even when money is given for the care of PLWHA, family members may decide not to use it, since the person is regarded as dying and they may want to save it for the burial. This finding, taken together with other studies carried out in Sub-Saharan Africa (Plummer et al., 2006; Campbell et al., 2007) shows that poverty creates an additional burden to PLWHA and their carers. After death, the corpses of loved ones are valued and it costs money to be buried, with 
people more willing to offer help for funerals than during the period of actual illness (Hilhorst et al., 2006).

Our study also shows that the media has contributed to stigmatization because of the way it portrayed information about HIV/AIDS earlier in the epidemic. For example, in a Nigerian newspaper on 19 October 1987, HIV/AIDS was typified as "a self-inflicted scourge caused by reckless sexual extravaganza, and the person must be prepared to bear the consequence of their lustful indiscretion" (Lear, 1998). Such images conveyed by the media flourish and take a long time to be reversed.

\section{Limitations of the study}

A major weakness of this study is that the data cannot be generalized. We can conclude that these results are not representative of Port Harcourt city, but the study does aim to gather a broad perspective on stigma and societal reactions to PLWHA. The study was carried out in a city where people from different tribes live but nevertheless reflects only the ideas or culture of the people interviewed.

Another weakness of the present study is that it relied on verbal reports of participants. It was difficult for participants to admit to stigmatizing HIV persons because of considerations of social desirability, but when indirectly asked about others or spontaneously describing others' reactions, many of them expressed the view that stigmatization is still strong in society. Despite these limitations, this study illustrates the importance of not only knowing that stigma is still very much present, but also calls for more research in this area.

\section{Conclusion and recommendations}

The findings of our study may be valuable for developing interventions on stigma. The societal image of PLWHA can fuel the spread of HIV/AIDS because people continue to have unprotected sex based on their personal judgement about their partner's sero-status. Such judgement are based on the physical features typically associated with HIV/AIDS, because they believe a person with HIV/AIDS must be emaciated, without knowing that a well-cared-for person with HIV/AIDS can have a normal weight. Sometimes, the long-term nature of someone's illness can fuel suspicion of HIV/AIDS from the people around them, especially when the person is moved from one hospital to another or from a hospital in the city (back) to the village. Participants placed great emphasis on the power of faith-healing when the pastor prays, which may influence the way they care for PLWHA. At the same time, some other participants felt the clergy should use their position to teach people how to care for sufferers of HIV/AIDS. The churches should also use their position to protect the rights of PLWHA. Almost all the participants were of the opinion that care givers of people with HIV/AIDS should continue to care for them, mainly because they felt that they may find themselves in that position, as can 
anyone. The government should play a more active role in supporting PLWHA financially, especially the vulnerable ones, such as women and children, to help cover their basic needs and enable them to access HIV/AIDS programmes. When people are knowledgeable about HIV/AIDS they know the steps they may take to protect themselves. The government should also create policies that protect PLWHA in important areas, such as the workplace. HIV/AIDS is likely to stay for many years, and so society may benefit from learning to live with it and not discriminating against PLWHA. Emphasis on the proactive role that can be played by the media and faith-based institutions should be encouraged by the government.

Problems associated with HIV/AIDS are very real in society. The government needs to educate the entire population through radio, television, markets, churches and everywhere there is a possibility of people listening. Continuous education of people about HIV/AIDS, modes of transmission, and how people can protect themselves when caring for PLWHA is important. People should be fully aware that caring for a person with HIV/AIDS can be done without necessarily running the risk of contracting HIV/AIDS. A significant proportion of people in society have heard about HIV/AIDS and the kind of aggression with which the media initially provided information on HIV/AIDS, which enhanced discrimination, should now be turned towards giving HIV/AIDS a human face.

\section{References}

Aholou, T.M., Gale, J.E., \& Slater, L.M. (2009). African American clergy share perspectives on addressing sexual health and HIV prevention in premarital counseling: A pilot study. Journal of Religion and health, PMID: 19495984.

Ajuwon, A.J., Oladepo, O., Adeniyi, J.D., \& Brieger, W.R. (1998). Sexual practices that may favor the transmission of HIV in a rural community in Nigeria, In D. Buchanan and G Cernada (eds), Progress in preventing AIDS? Dogma, Dissent and Innovation, Global perspectives (pp21-33), Amityville, New York: Baywood publishing Company, Inc.

Ajuwon, A.J., \& Shokunbi, W. (1998). Women and the risk of HIV infection in Nigeria: Implications for control programs, In D. Buchanan and G Cernada (eds) (pp21-33), Progress in preventing AIDS? Dogma, Dissent and Innovation, Global perspectives, Amityville, New York: Baywood publishing Company, Inc.

Akani, C.I., \& Erhabor, O. (2006). Rate, pattern and barriers of HIV serostatus disclosure in a resource limited setting in the Niger delta of Nigeria. Tropical Doctor, 36 (2), 87-89.

Alikor, D.E., \& Erhabor, N.O. (2006). Trend of HIV- seropositivity among children in a tertiary health institution in the Niger Delta region of Nigeria. African Journal of Health Sciences, 13 (1-2), 8085.

Ankrah, E. M., \& Henry, K. (1994). Empowering women may retard HIV. Network, 15, 20-21.

Babalola, S., Fatusi, A., \& Anyanti, J. (2009). Media saturation, communication exposure and HIV stigma in Nigeria, Social Science and Medicine, 68 (8), 1513-1520.

Baseman, J., Ross, M., \& Williams, M. (1999). Sale of sex for drugs and drugs for sex: An economic context of sexual risk behaviour for STDs. Sexually Transmitted Diseases, 26 (8), 444-449.

Campbell, C., Nair, Y., Maimane, S., \& Nicholson, J. (2007). Dying twice: a multi-level model of the roots of AIDS stigma in two South African communities. Journal of Health Psychology, 12 (3), 403-416. 
Chateauvert, M. (1993). AIDS related stress in Canadian healthcare workers. In H. Van Dis and E Van Dongen, Burnout in HIV/AIDS Health Care and Support: Impact for professional and Volunteers, Amsterdam: University Press, Amsterdam.

Epidemiological fact sheet (2008). Retrieved 5 May 2009 from WHO website: www://apps.who.int/globalatlas/predefinedreports/efs2008/full/efs2008_ngpdf.

Fortenberry, J.D., Mcfarlane, M.M., Hennessy, M., Bull, S.S., Grimley, D.M., St Lawrence, J., Stone, B.P., \& Van Devanter, N. (2001). Relation of health literacy to gonorrhea related care. Sexually Transmitted Infection, 77 (3), 206-211.

Goffman, E. (1963). Stigma: Notes on the management of spoiled identity. New York: Simon and Schuster.

Greeff, M., Phetlhu, R., Makoae, L.N., Dlamini, P.S., Holzemer, W.L., Naidoo, J.R., Kohl, T.W, Uys, L.R., \& Chirwa, M.L. (2008). Disclosure of HIV status: experiences and perceptions of persons living with HIV/AIDS and nurses involved in their care in Africa. Qualitative Health Research, 18 (3), 311-324.

Green, G. (1995). Attitudes towards people with HIV: Are they as stigmatizing as people with HIV perceive them to be? Social Science and Medicine, 41 (4), 557.

Hartwig, K.A., Kissioki, S., \& Hartwig, C.D. (2006). Church leaders comfort HIV/AIDS and stigma: A case study from Tanzania. Journal of Community and Applied Social Psychology, 16, 492-497.

Herek, G. M. (2002). Thinking about AIDS and stigma: a psychologist's perspective. Journal of Law, Medicine and Ethics, 30(4), 594-607.

Hidaka, Y., Operario, D., Takenaka, M., Omori, S., Ichikawa, S., \& Shirasaka, T. (2008). Attempted suicide and associated risk factors among youth in urban Japan. Social Psychiatry and Psychiatric Epidemiology, 43 (9), 752-757.

Hilhorst, T., Van Liere, M.J., Ode, A.V., \& de Koning, K. (2006). Impact of AIDS on rural livelihoods in Benue state, Nigeria. Journal of Social Aspect of HIV/AIDS Research Alliance (SAHARA), 3(1), 382-393.

Iwelunmor, J., Airhihenbuwa, C.O., Okoror, T, A., Brown, D.C., \& Belue, R. (2006). Family systems and HIV/AIDS in South Africa. International Quarterly of Community Health Education, 27 (4), 321-325.

Kipp, W., Tindyebwa D., Rubaale, T., Karamagi, E., \& Bajenja E. (2007). Family caregivers in rural Uganda: the hidden reality. Health Care for Women International, 28 (10), 856-71.

Lear, D. (1998). AIDS in the African press. In D. Buchanan and G Cernada (eds) (pp. 215-226). Progress in preventing AIDS? Dogma, Dissent and Innovation, Global perspectives, Amityville, New York: Baywood publishing Company, Inc.

Maman, S., Abler, L., Parker, L., Lane, T., Chirowodza, A, Ntogwisangu, J., Srirak, N., Modiba, P., Murima, O., \& Fritz, K. (2009). A comparison of HIV stigma and discrimination in five international sites: The influence of care and treatment resources in high prevalence settings, Social Science and Medicine, DOI: 10.1016/J.socscimed.2009.04.002.

Mbonu, N.C., Van Den Borne, B., \& De Vries, N.K. (2009). A model for understanding the relationship between stigma and health care-seeking behaviour among people living with HIV/AIDS in SubSaharan Africa. African Journal of AIDS Research (AJAR), 8 (2), 201-212.

Miller, K.W., Wilder, L.B., Stillman, F.A., \& Becker, D.M. (1997). The feasibility of a street intercept survey method in an African-American community. American Journal of Public Health, 87 (4), 655-658.

Neville, M.A., \& Rubin, D.L. (2007). Factors leading to self-disclosure of a positive HIV diagnosis in Nairobi, Kenya: people living with HIV/AIDS in the Sub-Sahara. Qualitative Health Research, 17 (5), 586-98.

Obi, R.K., Iroagba, I.I., \& Orjiakor, O.A. (2007). Prevalence of human immunodeficiency virus (HIV) infection among pregnant women in an antenatal clinic in Port Harcourt, Nigeria. African Journal of Biotechnology, 6 (3), 263-266. 
Obinna, V., Owei, O., Ayodele, A., \& Okwakpam, I. (2009). Patterns and determinants of recreational behavior in Port Harcourt, Rivers State, Nigeria. Theoretical and Empirical Researches in Urban Management, 3 (12), 150-165.

Parker, R., \& Aggleton, P. (2003). HIV and AIDS-related stigma and discrimination: a conceptual framework and implications for action. Social Science and Medicine, 57 (1), 13-24.

Plummer, M.L., Mshana, G., Wamoyi, J., Shigongo, Z.S., Hayes, R.J., Ross, D.A., \& Wright, D. (2006). 'The man who believed he had AIDS was cured': AIDS and sexually transmitted infection treatment-seeking behaviour in rural Mwanza, Tanzania. AIDS Care, 18(5), 460-466.

Rotheram-Borus, M.J., Mann, T., Newman, P.A., Grusky, O., Frerichs, R.R., Wight, R.G., \& Kuklinski, M. (2001). A street intercept survey to assess HIV- testing attitudes and behaviors. Aids Education and Prevention, 13 (3), 229-238.

Sontag, S. (1988). Illness as metaphor and AIDS and its metaphors. New York: Doubleday publishers.

Steward, W.T., Herek, G.M., Ramakrishna, J., Bharat, S., Chandry, S., Wrubel, J., \& Ekstrand, M.L. (2008). HIV-related stigma: adapting a theoretical framework for use in India. Social Science and Medicine, 68 (8), 1225-1235.

Stewart, T.J., \& Richter, D.L. (1998). Perceived barriers to HIV prevention among University students in Sierra Leone, West Africa. In D. Buchanan and G Cernada (eds) (pp 35-46), Progress in preventing AIDS? Dogma, Dissent and Innovation, Global perspectives, Amityville, New York: Baywood publishing Company, Inc.

Strebel, A., Crawford, M., Shefer, T., Cloete, A., Henda, N., Kaufman, M., Simbayi, L., Magome, K., \& Kalichman, S. (2006). Social construction of gender roles, gender based violence and HIV/AIDS in two communities of the Western Cape, South Africa. Journal of Social Aspects of HIV/AIDS Research Alliance (SAHARA), 3 (3), 516-528.

The Joint United Nations Programme on HIV/AIDS (UNAIDS) (2008). Retrieved 5 May 2009 from UNAIDS

website: www://data.unaids.org/pub/report/2008/jc1526_epibriefs_subsaharanafrica_en.pdf.

Uneke, C.J., Alo, M., \& Ogbu, O. (2007). Mandatory premarital HIV testing in Nigeria: The public health and social implications. AIDS Care, 19 (1), 116-121.

Utulu, S.N., \& Lawoyin, T.O. (2007). Epidemiological features of HIV infection among pregnant women in makurdi, Benue state, Nigeria. Journal of Biosocial Science, 39 (3), 397-408.

Weiser, S.D., Heisler, M., Leiter, K., Percy-de Korte, F., Tlou, S., De Monner, S., Phaladze, N., Bangsberg, D.R., \& Lacopino, V. (2006). Routine HIV testing in Botswana: a population-based study on attitudes, practices and human rights concerns. PLoS Medicine, 3 (7), e261.

Wood, K., \& Lambert, H. (2008). Coded talk, scripted omissions: the micropolitics of AIDS talk in an affected community in South Africa. Medical Anthropology Quarterly, 22, 213-233. 


\section{Chapter Five}

\section{Professional health care delivery problems associated with HIV/AIDS}

\section{Submitted}

\section{Authors}

Ngozi. C. Mbonu

Bart van den Borne

Nanne K. De Vries 


\section{Abstract}

Aim: Previous research findings suggest that health care professionals (HCPs) stigmatize people living with HIV/AIDS (PLWHA). In this study, we tried to examine and understand HCPs' problems with care delivery and related factors associated with caring for PLWHA.

Method: In-depth semi-structured interviews, lasting 60-90 minutes, were conducted among a convenience sample of $40 \mathrm{HCPs}$ in government health facility and private hospitals in Port Harcourt, Nigeria. Interviews were tape-recorded and transcribed verbatim. The Nvivo 7 computer package was used to manage the data. The analysis of the interviews enabled us to identify factors that affect the care of PLWHA.

Result: Although there are differences between care in government and private hospitals, as well as differences between individual HCPs, six factors were identified that caused problems with delivering care: the degree of knowledge, policy, fear, protective functionality, patient-related problems and societal influence. In addition, effects on care were described in terms of; refusal to treat, conditions for treatment, quick referral, isolation and breach of human rights.

Conclusion: The study shows that there is a need to provide continuous training for HCPs with regard to HIV/AIDS. It is equally important to have policies that protect the HCPs in the workplace in case of accidental blood exposure. The provision and accessibility of protective materials will also reduce the fear HCPs have while caring for PLWHA. 


\section{Introduction}

The Human Immunodeficiency Virus/Acquired Immune Deficiency Syndrome (HIV/AIDS) poses a major challenge to health care professionals (HCPs) throughout the world, but especially in Sub-Saharan Africa. In addition to the medical aspects of the condition, this challenge is due partly to psychological, social and cultural aspects, which may affect the way people living with HIV/AIDS (PLWHA) are cared for in health care institutions.

Although policy issues concerning HIV/AIDS have been addressed in various government pronouncements in Nigeria and by professional bodies over a period of more than twenty years, a comprehensive policy addressing the specific problems arising from HIV infection and AIDS care in health care institutions remains fragmented (Adebamowo et al., 2002). Like many countries with limited resources (Li et al., 2007; Turan et al., 2008; Delobelle et al., 2009), managing HIV/AIDS in Nigeria is particularly complex because of the inadequate health infrastructure and the need for specialized HIV care facilities. HIV/AIDS places an additional burden on the Nigerian health care system, which is already overstretched by other preventable health conditions (Ajuwon \& Shokunbi, 1998; Ibrahim \& Alhassan, 2009). This paper sets out to present the problems in health-care delivery associated with caring for PLWHA from the perspective of health care workers.

Since HIV/AIDS has no cure yet, fear leads to unwanted forms of prevention behavior (Sontag, 1988), including by HCPs. HCPs are often caught between treating patients with HIV/AIDS, societal reactions and protecting themselves from occupational exposure. Occupational risk of exposure to blood-borne pathogens including HIV is a major concern to HCPs (Adebamowo et al., 2002; Tarantola et al., 2005). A study carried out in Ibadan, Nigeria, showed that $80 \%$ of resident doctors experienced moderate to major concerns about contracting HIV infections and $46-49 \%$ believed that refusing to take care of HIV/AIDS patients was not unethical (Olubuyide, 1996). A similar study carried out among nurses in South Africa showed that $72.1 \%$ of the respondents agreed with the statement "HIV/AIDS is highly contagious", while $90 \%$ agreed that the risk of occupational HIV/AIDS infection among HCPs is high (Delobelle et al., 2009). Many HCPs overestimate the risk of acquiring HIV infection following a needle-stick injury, or after exposure of mucocutaneous membranes and intact skin to infected blood and body fluids (Aisien \& Shobowale, 2005).

Experiences from throughout the world indicate that, when care and support are weak, people tend to conceal their HIV status (MacNeil \& Anderson, 1998) by not taking a HIV test, which is the first step to treatment. A study carried out in Sagamu, in the south-west of Nigeria, showed that the availability of proper treatment/care was found to form a crucial link to testing (Balls, 2002). It is, therefore, of great importance to know the barriers to HCPs delivering proper care. 
In Nigeria, there is still limited knowledge on the behavior of HCPs towards PLWHA (Reis et al., 2005; Oyeyemi et al., 2006). Studies suggest that HCPs in Nigeria may stigmatize PLWHA (Adebamowo et al., 2002; Aisien \& Shobowale, 2005; Obi et al., 2005; Oyeyemi et al., 2006; Adewuya et al., 2009; Morolake et al., 2009). Government hospitals, general practitioners in private settings and private specialized medical practitioners provide health care in Nigeria. The private health sector provides $65.7 \%$ of health care delivery in Nigeria (WHO, 2007). Patients have a right to go to any hospital (government or private) for treatment (Adeneye et al., 2007). However, health insurance is not widely available, leaving many of the patients obliged to pay for their own hospital bills and limiting their freedom of choice. It is also not uncommon for HCPs to work simultaneously in private and government hospitals (Ibrahim \& Alhassan, 2009), leaving room for differences in care. The present study involves HCPs working in both government hospitals and private hospitals. The research reported here is an attempt to contribute to the existing knowledge by revealing the various causal factors and experiences of HCPs towards caring for PLWHA.

\section{Methods}

This paper deals with problems HCPs experience in care delivery and related factors such as degree of knowledge, beliefs and other motivations underlying care for PLWHA in health care institutions. It is part of a larger study that aims to analyze the stigma PLWHA experience in society. The present investigation used qualitative methods. Qualitative researchers work with relatively small samples of people, nested in their context. Cases are studied in depth (Miles \& Huberman, 1994). This study focused on HCPs recruited from government and private hospitals in Port Harcourt, Rivers State, Nigeria. Participatory observation and indepth interviews were conducted.

\section{Study location}

Rivers State is located in the oil-rich Niger Delta basin of Nigeria. It has an estimated median HIV prevalence rate of $8 \%$ (Rivers State HIV/AIDS control programme, 2002). Port Harcourt is the capital of Rivers State, Nigeria, and has an officially-estimated population of 1,148,665 (Port Harcourt, 2007). Due to business activities in the region, there is a high rate of immigration of people from other parts of the country and beyond.

\section{Interviews}

A semi-structured interview guide was prepared based on a literature review and on a conceptual framework for the study. The face-to-face interviews were undertaken between January and April 2006. The interview guide covered: (1) the kind of 
patients the HCP would normally prefer to work with; (2) difficulties when caring for PLWHA; (3) family/societal considerations in care; (4) knowledge of HCP stigmatizing PLWHA. Prompts used were informed by background information and issues obtained from key informants from health services. We also collected information about the categorical of work level of each of the HCPs in the sample. The interview lasted between one hour and one and a half hours. Field notes were taken.

\section{Sample description}

The study used a convenience sample and was designed to be confidential, not mentioning the names of people or hospitals. A total of five private hospitals and one government hospital were used in the study. Table 1 shows the total number of 40 HCPs (20 doctors, 15 nurses and 5 laboratory scientists, 15 males and 25 females) that were interviewed. The HCPs in this study were all of economically productive age and were all working at the time of interview. Many of the HCPs interviewed were working concurrently in private and government hospitals.

\section{Data collection and analysis}

Rivers State Agency for Control of HIV/AIDS which acted as ethics committee approved the study. At the start of the interview, the study content and process were explained to the participants and verbal informed consent was solicited from each individually. The respondents were told that their participation was voluntary and they were free to withdraw at any time. They were encouraged to talk freely. The interviews were guided by a list with open-ended questions. Interviews were taperecorded with verbal permission from participants and later transcribed verbatim.

The software package Nvivo 7 was used to analyze the data and identify major themes. Emerging issues were identified and examined to identify related concepts. Different factors were formed from the emerging themes.

\section{Validity}

An independent researcher coded the data to look for new concepts. Emerging themes were compared, by the independent researcher, with the coding by the authors. New meanings and discrepancies were checked by re-reading the transcripts and fine-tuning interpretations until unambiguous categories and themes were agreed. 
Table 1 showing total number of health care professionals interviewed

\begin{tabular}{|c|c|c|c|}
\hline No & Gender & Marital Staus & Professional Category \\
\hline 1 & Male & Married & Medical Doctor \\
\hline 2 & Female & Married & Nurse \\
\hline 3 & Male & Single & Medical Doctor \\
\hline 4 & Female & Married & Medical Doctor \\
\hline 5 & Female & Married & Nurse \\
\hline 6 & Male & Married & Medical Doctor \\
\hline 7 & Male & Single & Medical Doctor \\
\hline 8 & Female & Single & Nurse \\
\hline 9 & Female & Married & Laboratory Scientist \\
\hline 10 & Male & Married & Medical Doctor \\
\hline 11 & Male & Married & Medical Doctor \\
\hline 12 & Female & Married & Medical Doctor \\
\hline 13 & Female & Married & Nurse \\
\hline 14 & Male & Married & Medical Doctor \\
\hline 15 & Female & Married & Medical Doctor \\
\hline 16 & Female & Married & Medical Doctor \\
\hline 17 & Female & Married & Nurse \\
\hline 18 & Male & Single & Medical Doctor \\
\hline 19 & Female & Married & Medical Doctor \\
\hline 20 & Female & Married & Medical Doctor \\
\hline 21 & Female & Married & Nurse \\
\hline 22 & Male & Married & Medical Doctor \\
\hline 23 & Female & Married & Nurse \\
\hline 24 & Female & Single & Medical Doctor \\
\hline 25 & Female & Married & Nurse \\
\hline 26 & Female & Single & Nurse \\
\hline 27 & Female & Married & Medical Doctor \\
\hline 28 & Male & Single & Nurse \\
\hline 29 & Male & Married & Nurse \\
\hline 30 & Male & Married & Nurse \\
\hline 31 & Female & Married & Laboratory Scientist \\
\hline 32 & Female & Single & Nurse \\
\hline 33 & Female & Married & Laboratory Scientist \\
\hline 34 & Male & Married & Medical Doctor \\
\hline 35 & Female & Married & Laboratory Scientist \\
\hline 36 & Female & Married & Nurse \\
\hline 37 & Male & Single & Medical Doctor \\
\hline 38 & Female & Single & Nurse \\
\hline 39 & Male & Single & Laboratory Scientist \\
\hline 40 & Female & Married & Medical Doctor \\
\hline
\end{tabular}




\section{Results}

In the interviews, HCPs described their experiences both in the government and private hospitals where they work. Because many HCPs work both in private and government hospitals, some of them change the way they give care depending on whether they work in the government or the private health care setting. Participants described a wide range of issues and experiences from their work in both private and government hospitals. Despite this wide range, six factors were revealed to contribute to HCPs' problems of caring for HIV patients in the hospital (see figure 1). These factors are; their degree of knowledge, policy, fear, protective functionality, patient-related problems and societal influence. In addition, effects on care such as refusal to treat, conditions for treatment, quick referral, isolation, and breach of human rights will be described below.
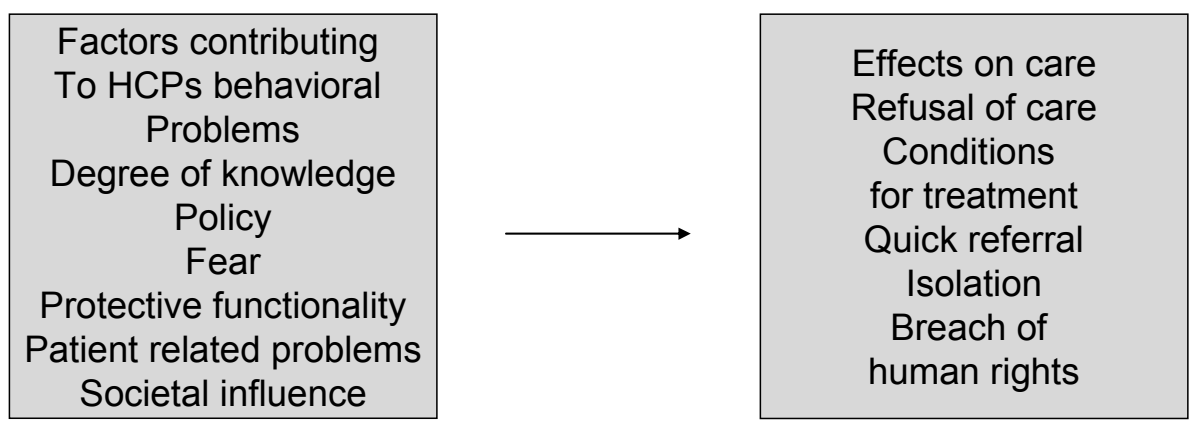

Figure 1 Showing factors contributing to HCPs behavioral problems and different care problems

Factors contributing to HCPs' care delivery problems

\section{Degree of knowledge}

Overall, the HCPs in our study identified knowledge of HIV/AIDS, its treatment and its care as very important to alter the meaning and perception of HIV/AIDS. Many of the HCPs accepted that they were more knowledgeable than the rest of society. Despite that, some HCPs think of only sexual means and end up blaming HIV patients for promiscuity because they do not seem to remember other modes of transmissions. As one HCP put it:

'Most of us, health care professionals...do not seem to remember other modes of transmission. We always think of sexual transmission as the only way, even though some people with HIV/AIDS may have got HIV from our own health mistakes, like instrumentation or blood transfusion.' (Doctor) 
In addition, reminders of risk associated with caring for HIV patients may further restrict care.

\section{Policy}

The need for a specific HIV/AIDS policy in the hospitals emerged as a concern. Some HCPs revealed that a lack of occupational hazard policies has a significant effect on the care of HIV/AIDS patients. For instance, one HCP stated:

'Hospital lack of policy encourages such negative attitudes. If one is a healthcare professional working here and one accidentally injures oneself in the work, the person would like to have anti-retroviral prophylaxis, but there is no laid-down policy for that. If this happens one has to bear the cost and consequences, so it reinforces the attitude. If the hospital cares about the health of the health-care professionals then health-care professionals will be willing to care for HIV patients, but when one is left alone, then it reinforces the attitude.' (Doctor)

Additionally, no policy of protecting HCPs from the possibility of employers relieving workers of their job (especially in private hospitals), should they become infected with HIV in the course of their work, was found to be a problem, as stated by this HCP:

'The employers find it difficult to keep a worker with HIV because they will find a way and dismiss the person from work.' (Nurse)

There are also some structural and material problems in the hospitals such as problems of space. Some HCPs stated that sometimes the staffing levels are insufficient, while others noted simply that they are too busy and also mentioned overwork as reasons why HCPs are unable to attend to the needs of PLWHA.

\section{Fear}

Fear was identified as a huge barrier to giving appropriate care to PLWHA. Many of the HCPs interviewed were scared specifically of a needle prick. One HCP expressed this opinion:

'Definitely I will not like to work with HIV/AIDS patients because of the possibility of contamination with blood. That is my own preference. You can never be so sure. Even with the gloves, there can be a needle prick. There is always the possibility.' (Doctor)

Similarly, another HCP cited the incurability of HIV as a reason:

'People are scared of HIV/AIDS. Initially people were scared of tuberculosis but since people found out there is a cure, they are no more scared but, honestly, health-care professionals are scared of HIV/AIDS. Every human being is scared of death.' (Nurse) 
Sometimes HCPs, who have to care for (clinically complicated) HIV/AIDS patients, have low expectations of success in addition to fear. This HCP explains further:

'Health care professionals stay away from HIV patients because of fear of contracting HIV. Health care professionals especially find it difficult to work with ones that have AIDS, tuberculosis and weight loss because they feel those will die soon. They do not get much care because it is like putting in effort and nothing is coming out.' (Doctor)

Other HCPs mentioned how the experience of having a colleague who contracted HIV/AIDS in the course of their professional work affects HCPs:

'Sometimes I understand the problem of health-care workers. I know one doctor who went to give a neighbor, who is a commercial sex worker, an injection because she complained of symptoms similar to malaria. The doctor gave an anti-malarial injection and accidentally had a needle prick. Four years later, the doctor came down with HIVIAIDS and died of HIV-associated nephropathy (kidney disease). So I will not say because health care professionals save lives they should expose themselves.' (Doctor)

Despite this insight, potential improvements in care were voiced by some HCPs:

I will just say things have improved a bit. Initially, with a diagnosis of HIV in a patient folder, everybody runs away. Health care professionals are scared. The patient tends to notice the sudden distance but things are a bit better though stigma is still there. There is a little element, like avoiding setting up an intravenous line.' (Doctor)

Other HCPs who care for HIV patients, do so because they are obliged to work.

\section{Protective functionality}

An important consideration for HCPs was the issue of protecting themselves in the course of their work. In practical terms, many HCPs complained about regular lack of appropriate protective materials. Sometimes gloves are not available or maybe disposable gloves will be available but not surgical gloves. One HCP stated:

If a health care professional is working in a place where there is a HIV patient, like in the labor ward, and one does not have gloves to protect oneself, you find out that the health care professional will not work freely with the HIV patient because the health care professional will not find it easy to work without protection materials.' (Nurse)

Other HCPs prefer to know the HIV status of patients, as they feel it makes them more cautious, rather than observing a general, universal precaution. Some HCPs go further and treat the patients without gloves, especially when they think based on 
clinical observation that the patient is unlikely to have HIV. One HCP described the advantage of having prior knowledge of a patient's HIV status in this way:

'When someone is identified as HIV positive even your subconscious mind will take precautions not just about any special precaution. You yourself will become worried and will like to take the precaution.' (Doctor)

This statement implies that some precautions are taken for some patients, especially those patients perceived, or known, to have HIV, while they are not taken for others. Many of the HCPs are worried about protection, but sometimes they routinely take risks with patients who they assume do not have HIV, for instance, patients with malaria, and overtly take precautions with patients who are confirmed HIV positive. This HCP went further to explain how knowledge of a patient's HIV status makes a difference:

'Normally when I want to take a blood sample I have to be careful, but when I am sure the person has HIV, I have to protect myself properly; properly as in consciously wearing the gloves and making sure nothing like a mistake happens, which is different from protection for preventive purposes. For a HIV patient, if I was to sit down to take the blood, I will stand up, get proper protective materials but when I am not sure the person is HIV positive, I can just use my other hand bare to hold the area I want to take the blood and do it carelessly, but when the person is confirmed HIV positive I have to sit up.' (Doctor)

With on-going and continuous anxiety about HIV/AIDS among HCPs, HIV test screening is sometimes done routinely for patients going for surgery. This HCP underlined the problem of routine HIV screening as they try to balance the pros and cons:

'The problem of routine HIV screening is that the fact that a patient is negative today does not mean in two weeks time he is not positive,so it makes the concept useless. Secondly, most often we let our guard loose for most patients we see daily that come with simple malaria, for example. We take blood and we do not take any of those precautions, but when we get a HIV positive patient, we get excited. You find out that the risk of contracting HIV is higher for regular simple health procedure on patients whom health care professionals assume to be HIV negative and in which health care professional do not bother to take precautions.' (Doctor)

This statement implies the potential of selective precautions amongst HCPs. In addition, sometimes the patient or the patient's relatives are asked to buy some of the protective materials, which results in the HCPs going ahead with treatment unprotected owing to time delays in procurement, or a desire to shift the patient to the next HCP on duty, thus leading to a delay in treatment. The delay in having protective materials procured by patients makes some HCPs take additional risks. 
Some HCPs accept their own responsibility in not taking precautions, such as this HCP:

'It is not always all the time we are in a position to take such precautions because sometimes unconsciously before you know it you are already with the patient and you find yourself using your bare hand.' (Nurse)

Selective precautionary measures imply that HCPs will always have a risk of contacting HIV/AIDS in the course of their work. A few HCPs reported resorting to faith in God for protection:

'God surpasses everything.... when one sees an unconscious patient who is dying, one just rushes there and one doesn't know what one is doing, until at the end, one sees oneself being rubbed with blood all over, so it is God that protects people not even the precautions we are taking. That is the way I see it.' (Nurse)

Such belief is significant because it makes HCPs less motivated actually to take precautions.

\section{Patient-related problems}

Many HCPs complained that patients report to the hospital very late thereby making their work very problematic. Since some clinics specialize in HIV, some HIV patients are discouraged because of the risk of identification and may not want to be seen around the clinic, so they stay away from treatment or start looking for alternative ways of getting medication:

'Some HIV patients do not want to go to the HIV clinic because they feel if someone sees them they will automatically assume they are HIV positive and they may have neighbors or friends who might see them. Due to this they are quiet or they try to sneak in and sneak out.' (Nurse)

Other HCPs cite belief in the faith of the blood of Jesus to heal as a reason why patients do not take anti-retroviral drugs, making them return to the hospital in a very bad condition. Having to cope with many tablets a day was also noted as affecting the drug adherence of the patient, because they need to take so many for the rest of their life. Other patients simply run away when their HIV status is revealed to them. In an effort to escape blame, stigma or misjudgement from HCPs, some of the patients deny that they have HIV even when they know they have it, and as a result, do not give a proper medical history to the HCPs. The following is illustrative of the way patients deny HIV/AIDS:

'Imagine someone that looks so emaciated, "When you ask when did your illness start?" he will answer: "Yesterday.I just woke up this morning and saw the problem". They say it is typhoid fever. Right now if I see someone that says, "I have typhoid fever or pneumonia" my mind goes first to HIV. Nobody will 
walk in here and say, "I have been diagnosed with HIV". Even if it was diagnosed right here in this hospital, they will still say it is typhoid fever.' (Doctor)

\section{Societal influence}

Despite HCPs' expression of a better understanding of HIV/AIDS, some HCPs attributed their concerns to moral judgement from society. The foremost concern is the societal reaction towards HCPs who care for PLWHA:

'The health care professionals think that if I get this illness I cannot be treated and people will say it is because I am promiscuous, largely because the society does not relate this issue of other means of transmission as a cause of HIV. The society still believes that promiscuity is the only method of transmission of HIV.' (Doctor)

This concern could be from their immediate family, but some HCPs try to continue with their work in a more careful way. Still, many HCPs find it difficult, as illustrated by this HCP whose wife is also a HCP:

'My personal experience is that I have a wife who initially believed no HIV patients should come to my clinic and my wife is also a health-care professional. Most health-care professionals' first reaction is to avoid as much as possible someone who is HIV positive. It is a general reaction coming from the society because people are afraid of the virus.' (Doctor)

For some HCPs in a private setting, there is an added dimension. This HCP talks about a problem with his clinic if neighbors knew that it is a referral clinic for HIV patients, and the efforts he makes to shield this information from people around:

I am aware of the tendency for people to label private clinics as treating HIV patients. Here as much as possible we try to keep our facts confidential....., I have a feeling that if neighbors and people know a clinic cares for HIV persons it might impact negatively,especially when you make it look like you are treating them.' (Doctor)

This HCP describes his futher efforts:

'Once or twice, people have come to my hospital to ask me that they heard so and so person is HIV positive and is in my hospital. My approach to this is to ask them to tell me who gave them the information. I tell them I do not know what they are talking about, [but] that if they tell me who told them of the HIV patient then I will be able to respond to them. Oftentimes they shy away after that.' (Doctor)

Sometimes, HCPs assume that HIV patients are vindictive and looking for a way to spread the disease and this affects the way they care for them. On the other hand, 
some other HCPs end up protecting patients from the negative reactions of society by helping them to keep their HIV status information secret, knowing what societal belief can be like. This makes concealment normal, because HCPs offer advice to patients not to reveal their status in order to live a normal life:

'I have a case of a woman who died of HIV and the husband came and said, "Please do not write HIV in her death certificate as the cause of her death", that it does not really speak well of the wife. Well, I thought that they have a right of confidentiality,so I wrote "immunosuppression" which is the same, only that it is someone in the medical field that will understand. Stigma and blame follows people and their family up to death because if the people around know that the wife was HIV positive before death, they will turn around and start suspecting the husband to be HIV positive too. This is a whole chain of problems that nobody can solve.' (Doctor)

\section{Effects on care}

As a result of all these factors, HCPs care towards PLWHA is not always standard. The substandard care exhibits itself through various forms of care problems that will be examined below: refusal to treat, conditions for treatment, quick referral, isolation and breach of human rights.

\section{Refusal to treat}

Refusal to treat can take the form of outright refusal or not giving the immediate treatment the patient needs. Sometimes, some private clinics refuse patients outright with the excuse that they do not have the facilities to manage HIV patients. Some HCPs admitted to refusing HIV patients in the past, but now the reception is better. It is important to know that in the government hospitals it is difficult to refuse admission to a HIV patient outright. There were also reports of HCPs refusing to give HIV patients medication or changing their medication from injectables to orals to avoid contact with blood, while others find it difficult to measure vital signs although that would not require any contact with blood. In some health care institutions special names are used when referring to HIV patients, either for confidentiality or easy communication among themselves, but sometimes from the way it is done it can be regarded as ridicule rather than information. Other times, this facilitates easy communication among HCPs:

'HIV patients are amongst other patients in the ward. The neighbors in the ward do not know they have HIV. Inside the folder we write HR (high risk) when they are diagnosed of HIV but health care professionals who handle the folder will know but others will not know. This is done so that health care professionals handle them with precaution.' (Doctor) 
Some private hospitals refuse to admit HIV patients based on the consideration that they do not want their hospital to be a place where patients die. This HCP explains the circumstances when they refuse HIV patients:

'We do refuse HIV patients. When the case is serious, maybe at the point of death, we refuse them. At times when you admit such patient, they may die at any time, so we do not want our hospital to be known as where patients always die.' (Nurse)

Similarly, another response by a HCP describes how others refuse HIV patients:

'Actually I have come in contact with health care professionals who have refused to treat HIV patients. Some health care professionals feel that HIV persons must die and feel what is the need of admitting them and after few days they die. It is better to let them go home and rest until they die instead of spending their money.' (Nurse)

\section{Conditions for treatment}

A significant care problem arises through specifying conditions for treatment. Some HCPs ask pregnant women to inform their husbands about their positive HIV status before they can continue to receive treatment. Sometimes, the concern is that the woman need her husband to provide financial support for her continued care management. For instance, this HCP stated:

'One of our reasons for asking them to inform their sexual partner is that, in this environment, husbands take lots of decisions and if the patient makes demands financially or otherwise on her husband, he may not understand why the doctor does one or two things both in pregnancy and labor. Without telling the husband the management becomes very difficult for us and I definitely object to that.' (Doctor)

An unpayable medical bill for medical treatment is sometimes used by some private hospitals as a way of discouraging PLWHA from udergoing treatment, or to make them go elsewhere for treatment. One HCP talks about his pregnant HIV patient who relocated to a different city for continued treatment:

'A HIV pregnant patient of mine who relocated had a problem of where to deliver because she was charged initially 300,000 naira (1800 euros) before the hospital finally settled for 180,000 naira (1000 euros). In effect, the delivery fee was so high because the woman was HIV positive. I do not know what the doctor had in mind. I do not think most doctors behave in that way. It is a bit unusual.' (Doctor)

Sometimes the patients are in a difficult situation, which is more psychologically painful and worse than outright refusal. One HCP gave an instance of his experience in one hospital he worked in with a HIV patient he met: 
'In one hospital I worked, I met a HIV positive patient who said she prefers to die at home rather than have people come and peep at her in the hospital. The health care professionals put her drug on the trolley and push the trolley for her bed to stop the trolley while she picks her drug up. That is not the kind of attitude anybody will like to see or adopt.' (Doctor)

\section{Quick referral}

Another common care problem is in the form of a quick referral elsewhere. Some HCPs are not willing to admit HIV patients on to a general ward with other patients, so they prefer to refer them to the government hospital to prevent other patients from seeing such patients. Owing to public fear and misunderstanding, some HCPs in private hospitals just refer out, as explained below:

'What I do is if a HIV positive patient is terminally ill and I get to know, I will suggest that they move the person to a government hospital because some of these HIV patients are really really bad. Do you know what terminally ill HIV is? We are almost talking of full-blown AIDS and their stay in the hospital frightens other patients especially if one has a small clinic like my own. Certainly people will ask what is wrong with this person that is looking like this. I do not want a scenario around my clinic and I do not want to frighten other patients to leave my clinic.' (Doctor)

Others argue that the government hospitals are better equipped than private hospitals as a way of presenting their referral in a positive way, whereas they know that care in a private hospital is more personal and could be better. This is an example from one HCP's experience in a private clinic:

'Initially, once we hear HIV, we just say: "Go to a government hospital, that is where they have antiretroviral drugs". We will say "go, go, go", but now we will treat them for malaria, for upper respiratory tract infection. We stabilize them before we them send to a government hospital because government hospital has no choice than to accept them.' (Doctor)

Sometimes there are instances of other colleagues exerting pressure for HIV patients to be referred on, so they will not have to care for them. When HIV patients come, and HCPs suspect that they have HIV, some HCPs refer them immediately to a government hospital without bothering to stabilize the patient:

'Stigma is a natural thing. Once or twice I have worked in a private clinic, they admit a patient but once the HIV status is known, the countenance changes immediately from doctors to nurses to ward maid. Most will immediately refer to a government hospital to start antiretroviral therapy. I think they do little or nothing for them in some private hospitals.' (Doctor) 


\section{Isolation}

Some private hospitals were reported to have different delivery rooms for HIV patients and mothers without HIV. The difference is important in a hospital where visiting relatives or other patients may be wondering why the other person is delivering in a different room:

'During delivery of HIV patients someone would think we are going to the moon, because we will wear double gloves, wear protection gown, boots, caps, goggles. We have two delivery rooms, one for HIV patients and one for non HIV patients. The hospital feels that way. We also have a different ward for them away from other patients.' (Doctor)

The materials used for HIV patients can be different. Different colors of bed sheets are used to differentiate HIV patients in some private hospitals. For example:

'Here in the hospital where I work we use different colors of bed sheet for HIV patients and non-HIV patients. Green color is for HIV patients while blue color is for non-HIV patients.' (Nurse)

\section{Breach of human rights}

In attempting to protect themselves from HIV/AIDS, HCPs sometimes perform HIV tests on patients without consent. This is a breach of human rights because every person deserves to know when their blood samples are taken to assess their HIV status. When screening is done without consent, it becomes likely that the patient is not informed of the HIV status result. This HCP explains how and why he took blood from a patient without consent:

'One time I had a needle prick while doing abdominal tap trying to tap blood. It was ectopic pregnancy and the patient was so septic. I was trying to remove the needle and gloves at the same time when I had a needle prick. Immediately I took the patient's blood and sent to lab for HIV test, luckily it was negative at the time and my mind came to rest. It is just for my personal knowledge because it is not as if I will tell the patient her result. I did it because if you ask someone, "I want to do HIV test", the person might disappear before I come back.' (Doctor)

\section{Discussion}

This data presents the problems associated with caring for PLWHA in health care institutions. This study also shows that there are differences between caring for PLWHA in government hospitals and in private hospitals. Although generally care in government hospitals is better than in private hospitals, owing to better human and material resources, including care facilities for PLWHA, our data reveals some 
vital problems involved in the care of PLWHA. The cost of treating patients in a private hospital is almost always different from the government hospitals. The fees Charged by private hospitals are not standardized or regulated. Our data shows that this provides an opportunity for private hospitals to come up with fee intended to discourage PLWHA that they do not want in their hospital presenting a hardly payable bill to the patient that is beyond their means to pay.

Our study shows that the idea of concealing a patient's HIV/AIDS status is sometimes encouraged by HCPs, who also reinforce concealment by writing a different diagnosis on patients' files or as the cause of death of a patient to avoid HIV-related stigma. Literature around the world shows as well that the communication of clinical diagnosis to patients (Sontag, 1988; Turan et al., 2008) and the accuracy of death certificates (Revakhah, 2006) have always been a challenge for HCPs, especially with regard to HIV/AIDS (King, 1989). Sontag (1988) goes on to say that the truth about communication of the clinical diagnosis is sometimes considered to be intolerable for patients (Sontag, 1988). Furthermore, studies have shown that there can be a loss of benefits to the surviving family members if AIDS appears on a death certificate, for example, insurance benefits or the placement of children in foster homes (King, 1989; Muula \& Mfutso-Bengo, 2005).

Our study revealed that many HCPs have fears about HIV/AIDS. These fears are due to a variety of reasons. First, HCPs feel there is always the possibility of a contagion from a needle prick. Second, HCPs feel they are helpless, with no policy on protective measures in place and the inability to protect themselves. Third, HCPs feel they would be isolated from society if they contract HIV/AIDS due to society's moral judgement, despite the true reason for their infection being their caring medical work. Similar findings have been reported from Kenya (Turan et al., 2008). Moreover, our data shows that this feeling aggravates HCPs' fear of contracting HIV from patients. This supports what other studies elsewhere around the world have concluded about fear as an important factor among HCPs (Ganczak, 2007; Varas-Diaz \& Marzan-Rodriguez, 2007; Turan et al., 2008; Delobelle et al., 2009) with regard to caring for PLWHA.

We also found that HCPs try to avoid the patient as soon as they know the patient's positive HIV status or even suspect it from the clinical outlook of the person. HCPs are mostly knowledgeable about the implications of the diagnosis and what risks are involved; therefore, they take precautionary steps to protect themselves. Furthermore, our data shows that some HCPs resort to diagnostic HIV testing, without consent from the patient, when they have a needle prick. The issue of routine HIV testing generated multiple perspectives in our study. Many participants prefer to screen patients for HIV before handling them, especially surgical patients, while others do not support compulsory HIV screening. Some HCPs in our study did not support routine screening, owing to the fact that tests may yield a false negative result in the window period. In their view, it is better to 
assume all patients may have the HIV antibody and use protective devices for every medical procedure.

Our data shows that HCPs sometimes have no choice other than to give care to PLWHA, but if given a choice they will not. This aspect was also reported in a study in Puerto Rico among HCPs where, if allowed their own preference, they would not attend to PLWHA (Varas-Diaz \& Marzan-Rodriguez, 2007). We also report that sometimes in an emergency situation, they are forced to attend to the patient without gloves because they are not available. Some also become carefree and go out of their way to attend to patients voluntarily without gloves. In one of the few similar studies, Adebamowo and colleagues found the unavailability of protective materials to be a problem in a survey of the knowledge, attitude and practice of Nigerian surgery trainees with regard to HIV-infected persons and AIDS. In this study, $86 \%$ of those who did not use the protective materials gave unavailability as a reason (Adebamowo et al., 2002).

The overall impression is that, although stigmatization among HCPs has reduced since the onset of the HIV epidemic, it is still present. Our result supports a previous study carried out among surgical residents in Nigeria, which showed that $58 \%$ and $78 \%$ would not perform elective surgery on HIV positive and AIDS patients respectively, while $14.4 \%$ and $31.7 \%$ would deny life-saving surgery to patients with HIV and AIDS respectively. Additionally, $43 \%$ would not perform surgery on HIV positive patients with a malignancy, while $55 \%$ would not do it in AIDS cases (Adebamowo et al., 2002).

We also found that some HCPs in private hospitals now stabilize patients before referring them out, while some HCPs are no longer scared of PLWHA as a result of improved knowledge and exposure. The use of special names to indicate HIV patients on the ward or written in the patient's folder is for ease of work and communication, it is just done for HCPs' convenience, and is not necessarily a representation of stigmatization (albeit it may be seen as such by others). These findings, taken together with other studies, suggest that levels of stigmatization are decreasing. For instance, a study carried out among pregnant women attending an antenatal clinic in Ogun State, Nigeria, showed that $78.5 \%$ thought their privacy was guaranteed and $80.8 \%$ felt that the staff were able to maintain the confidentiality of the patients (Adeneye et al., 2007).

Although there are programmes for PLWHA available in government hospitals, our data show that HCPs are still afraid, especially those who do not regularly work in areas where they have exposure to caring for HIV patients. Some HCPs report consideration of possible negative societal opinions and reactions to their care delivery, which makes them even more cautious in dealing with HIV/AIDS patients. The present evidence is also consistent with a larger body of literature from around the world (Bennett et al., 1993; Munjal, 1994; Hayter, 1999), which shows that HCPs are concerned about the reaction from people around them, such as their family. 


\section{Limitation}

Although purposive sampling has limitations, it is in keeping with qualitative sampling methods (Riley et al., 2008). This study cannot be generalized to reflect the behaviour of all HCPs because of the convenience selection of hospitals and HCPs used. Nevertheless, it gives an insight into the problems that they sometimes face in the course of handling PLWHA in the hospitals. Again, efforts were made to Preserve the anonymity of the respondents and the hospitals used for the study. Purposive sampling of the HCPs is also a problem and therefore the results cannot be reflected quantitatively.

\section{Conclusion}

Relationships between HCPs and PLWHA are sometimes fraught with anxiety and tension. There are differences in the way HIV patients are cared for in government and in private hospitals. The government hospitals are generally more accepting of HIV patients than the private hospitals. Some private hospitals try to observe standard procedures, although at the same time they may not want to keep HIV patients in their hospital. There are also differences between individual HCPs' approaches to caring for PLWHA. Caring for HIV patients is complex even from a clinical point of view. It requires long-term management with frequent complications. There has to be teamwork for the HIV patient to be well cared for. If a part is left out, quality of care is affected. HCPs perceive a dilemma between taking precautions against contracting HIV/AIDS themselves and caring for PLWHA. Perhaps the most significant complaint was the lack of protective materials. By being able to protect themselves, HCPs can offer better care than when they are not protecting themselves. Availability of gloves would improve the quality of care given to HIV patients.

Although fear is a natural response that will always be an issue among HCPs until a cure is finally found for HIV/AIDS, it could be argued that protective materials, more awareness and better education will improve the way HCPs deal with PLWHA. Medical education aimed specifically at reducing fears of infection in the workplace, as well as access to necessary equipment, is fundamental in ensuring that HCPs can manage the risk of workplace infection (Deacon \& Boulle, 2006). Furthermore, the government should enact and implement work policies that protect HCPs, such as continued employment, prophylactic treatment after accidental blood exposure and the care of any HCPs who contract HIV/AIDS.

Finally, although the safety of HCPs is important, care still has to be given to HIV patients and should in no way differ from the treatment of other patients with other illnesses. HCPs, therefore, should be compassionate towards their HIV-positive patients. 


\section{References}

Adebamowo, C.A., Ezeome, E.R., Ajuwon, J.A., \& Ogundiran, T.O. (2002). Survey of the knowledge, attitude and practice of Nigerian surgery trainees to HIV-infected persons and AIDS patients, BMC Surgery, 2, 7. (Doi: 10.1186/1471-2482-2-7).

Adeneye, A.K., Brieger, W.R., Mafe, M.A., Adeneye, A.A., Salami, K.K., Titiloye, M. A., Adewole, T.A., \& Agomo, P.U. (2007). Willingness to seek HIV testing and counseling among pregnant women attending antenatal clinics in Ogun State, Nigeria. International Quarterly of Community Health Education, 26 (4), 337-53.

Adewuya, A.O., Afolabi, M.O., Ola, B.A., Ogundele, O.A., Ajibare, A.O., Oladipo, B.F., \& Fakande, I. (2009). Post-traumatic stress disorder after stigma related events in HIV infected individuals in Nigeria, Social Psychiatry and Psychiatric Epidemiology, 44 (9), 761-766.

Aisien, A. O., \& Shobowale, M. O. (2005). Health care workers knowledge on HIV and AIDS: Universal precautions and attitudes towards PLWHA in Benin-city, Nigeria. Nigerian Journal of Clinical Practice, 8 (2), 74-82.

Ajuwon, A.J., \& Shokunbi, W. (1998).Women and the risk of HIV infection in Nigeria: Implications for control programs, In D. Buchanan and G Cernada (eds), Progress in preventing AIDS? Dogma, Dissent and Innovation, Global perspectives (pp 227-239), Amityville, New York: Baywood publishing Company.

Bennett, L., Ross, M., \& Kelaher, M. (1993). The impact of working with HIV/AIDS. In H. Van Dis and E Van Dongen (eds), Burnout in HIV/AIDS Health Care and Support: Impact for professional and Volunteers. Amsterdam: Amsterdam University Press.

Deacon, H., \& Boulle, A. (2006). Commentary: Factors affecting HIV/AIDS-related stigma and discrimination by medical professionals. International Journal of Epidemiology, 36, 185-186.

Delobelle, P., Rawlinson, J.L., Ntuli, S., Malatsi, I, Decock, R., \& Depoorter, A.M. (2009). HIV/AIDS knowledge, attitudes, practices and perceptions of rural nurses in South Africa. Journal of Advanced Nursing, 65 (5), 1061-1073.

Eke, N., Jamabo, R.S., Adotey, J.M., \& Jebbin, N.J. (2004). HIV positive patients and the surgeon. Nigerian Journal of Medicine, 13 (4), 366-71.

Ganczak, M. (2007). Stigma and discrimination for HIV/AIDS in the health sector: A Polish perspective. International Journal of Psychology, 41 (1), 57-66.

Hayter, M. (1999). Burnout and AIDS care-related factors in HIV community clinical nurse specialists in the North of England, Journal of Advanced Nursing, 29 (4), 984-993.

Ibrahim, H.J., \& Alhassan, A. (2009) Newspaper column, Daily trust, 24 January 2009. Medical doctors speak out: why health care is in a shambles Retrieved 14 May, 2009 from website: Http://www.dailytrust.com/index.php?option=com_content\&task=view\&id=3299

Li, L., Lin, C., Wu, Z., Wu, S., Rotheram-borus, M.J., Detels, R., \& Jia, M. (2007). Stigmatization and shame: consequences of caring for HIV/AIDS patients in China. AIDS Care, 19 (2), 258- 263.

Miles, M. B., \& Huberman, A.M. (1994). Qualitative data analysis: An expanded source book (second edition). Thousand Oaks: Sage Publications.

Morolake, O., Stephens, D., \& Welbourn, A. (2009). Greater involvement of people living with HIV in health care. Journal of International AIDS Society, 12 (1), 4.

Muula A. S., \& Mfutso-Bengo, J. M. (2005). When is public disclosure of HIV seropositivity acceptable? Nursing Ethics, 12, 288-295.

Munjal, Y.P. (1994). HIV infection and health care worker. Journal of the Indian Medical Association, $92(1), 31-32$.

Obi, S. N., Waboso, P., \& Ozumba, B.C. (2005). HIV/AIDS: occupational risk, attitude and behavior of surgeons in Southeast Nigeria. International Journal of STD and AIDS, 16 (5), 370-373.

Olubuyide, I.O. (1996). Doctors at risks of hepatitis B and HIV infections from patients in Nigeria. Journal of Royal Society of Health, 116 (3), 157-60. 
Oyeyemi, A., Oyeyemi, B., \& Bello, I. (2005). Caring for patients living with AIDS: Knowledge, attitude and global level of comfort. Journal of Advanced Nursing, 53 (2), 196-204.

Port Harcourt (2007). Population of Port Harcourt, Nigeria. Retrieved 4 July 2010 from: http://population.mongabay.com/population/nigeria/2324774/port-harcourt.

Reis, C., Amowitz, L. L., Heisler, M., Moreland, R. S., Mafeni, J. O., Anyamele, C., \& Lacopino, V. (2005). Discriminatory attitude of health care workers towards patients with HIV/AIDS in Nigeria. PLoS Medicine, 2, e246.

Revakhah, K. (2006). Death certificates are not reliable: revivification of the autopsy. Southern Medical Journal, 99 (7), 728-733.

Riley, T.A., Lewis, B.M., Lewis, M.P., \& Fava, J.L. (2008). Low-income HIV-infected women and the process of engaging in healthy behavior, The Journal of the Association Nurses in AIDS Care, 19 (1), 3-15.

Singh, M., Garg, S., Nath, A., \& Gupta, V. (2009). An assessment of felt needs and expectations of people living with HIV/AIDS seeking treatment at NGOs in Delhi, India. Asia-Pacific Journal of Public Health, PMID: 19443873.

Sontag, S. (1988). Illness as metaphor and AIDS and its metaphors. New York: Doubleday publishers.

Tarantola, A., Koumare, A., Rachline, A., Sow, P. S., Diallo., M.B., Doumbia, S., Aka, C., Ehui, E., Brucker, G, Bouvet, E \& the group des risques d'exposition des soignants aux agents infectiuesx (GERES) (2005). A descriptive retrospective study of 567 accidental blood exposues in health care workers in three West African countries. Journal of Hospital Infection, 60 (3), 276-282.

Turan, J.M., Bukusi, E.A., Cohen, R.C., Sande, J., \& Miller, S. (2008). Effects of HIV/AIDS on maternity care providers in Kenya. Journal of Obstetric Gynecology and Neonatal Nursing, 37 (5), 588-595.

Van Dis, H., \& Van Dongen, E. (1993). Introduction: burnout in HIV and AIDS care, In H. Van Dis and E Van Dongen (eds), Burnout in HIV/AIDS Health Care and Support: Impact for professional and Volunteers, Amsterdam: Amsterdam University Press.

Varas-Diaz, N., \& Marzan-Rodriguez, M. (2007). The emotional aspect of AIDS stigma among health professionals in Puerto-Rico. AIDS Care, 19 (10), 1247-1257. 



\section{Chapter Six}

The experiences and complexities of the care-seeking behavior of people living with HIV/AIDS in Port Harcourt Nigeria

Submitted

Authors

Ngozi C. Mbonu

Bart van den Borne

Nanne K. De Vries 


\section{Abstract}

Aim: This study aims to describe the stigmatizing experiences, coping mechanisms and care-seeking behavior of people living with HIV/AIDS (PLWHA) in Port Harcourt, Nigeria, while applying an explanatory model of the role of stigma in care-seeking behavior of PLWHA.

Method: In-depth semi-structured interviews, lasting 60-90 minutes, were conducted with 20 PLWHA in Port Harcourt, Nigeria. One focus group discussion was held. Interviews were tape-recorded and transcribed verbatim. The Nvivo 7 computer package was used to manage the data.

Results: Using the explanatory model for interpretation, we identified determining and moderating factors affecting PLWHA in seeking care. Poverty and religion were found to be important in coping with HIV/AIDS and making care choices which affect the utilization of health care institutions. Additionally, power differences in marital relations were found to play an important role at the time of HIV diagnosis and in coping with this diagnosis.

Conclusion: The study identified factors associated with care-seeking choices and coping mechanisms. The explanatory model relating stigma to these processes is useful in structuring the experiences of PLWHA. We discuss the policy implications and recommend continuing education of PLWHA and of society in general on HIV/AIDS, on options of ART-treatment, on HIV-related stigma and on possibilities for care and supporting networks. 


\section{Introduction}

In 2007, approximately 2.6 million people in Nigeria were living with HIV/AIDS. More than 170,000 deaths were caused by AIDS and 1.2 million AIDS orphans are now living in Nigeria (UNAIDS, 2008). The availability of anti-retroviral therapy (ART) implies that people living with HIV/AIDS (PLWHA) should be able to carry out daily activities like the rest of society. However, there are a number of hindrances to the utilization of care, leading to suboptimal effectiveness of available treatment (Hilhorst, Van Liere, Ode \& De Koning, 2006; Morolake, Stephens \& Welbourn, 2009). One of the factors seems to be stigma; PLWHA and their care givers have to cope with negative reactions from the people directly around them as well as from the wider community (Mwinituo \& Mill, 2006; Mitchell, Kelly, Potgieter \& Moon, 2007; Sabin et al., 2008; Adewuya et al., 2009; Hejoaka, 2009).

Not only does the discovery that one is infected with HIV lead to fear of progression into AIDS and fear of dying among PLWHA, it also creates an anticipation of negative social reactions among PLWHA. Sontag (1988) argues that it is not the suffering from the disease that is deeply feared, but the denigration that is suffered from having the disease that makes PLWHA vulnerable as individuals and within society (Sontag, 1988). People in the community have a negative attitude towards PLWHA because they attribute the characteristic of promiscuity to those who are infected (Campbell, Nair, Maimane \& Nicholson, 2007). Societal norms and values in Nigeria are restrictive and secretive, while discussion about sex is often private for cultural and religious reasons (Ajuwon, Oladepo, Adeniyi \& Brieger, 1998), making people who transgress these norms vulnerable to being condemned because norms are very strong and strict.

Several studies around the world (Amirkhanian, Kelly \& McAuliffe, 2003; Singh, Garg, Nath \& Gupta, 2009), including Africa, indicate that PLWHA are still discriminated against (Muyinda et al., 1997; Duffy, 2005; Muula \& Mfutso-Bengo, 2005; Shisana et al., 2005; Hilhorst et al., 2006; Liamputtong, Haritavorn \& Kiatying-Angsulee, 2009; Morolake et al., 2009), making them resort to varied ways of coping with their problems (Mbonu, Van Den Borne \& De Vries, 2009). Despite these studies indicating the presence of stigma, some published studies have equally acknowledged that one of the positive noticeable interventions in the fight against HIV/AIDS and stigma is giving HIV/AIDS a human face (Fokolade et al., 2009; Morolake et al., 2009). This implies, however, that PLWHA who are active in public HIV/AIDS programmes may have to cope with additional problems. A recent UNAIDS summary of literature on HIV-related stigma and discrimination recognizes the strengthening of networks of PLWHA that take the lead in addressing stigma and calls for more studies to evaluate stigma and discrimination programmes (UNAIDS, 2009). There is an urgent need for evidencebased research to meet the needs of those affected by HIV/AIDS (Doyal, 2009). 
Moreover, experiences of PLWHA who are members of an existing network will help in future HIV/AIDS policies that can be used in society and by health care institutions (Nyblade et al., 2009).

In this paper, we report results from a qualitative study that explores the stigmatization experiences, coping mechanisms and care-seeking choices of PLWHA who belong to an association network in Port Harcourt, Nigeria. We also explore the possible role of contextual factors related to these stigmatization experiences and the PLWHA's health care-seeking behavior as a consequence.

\section{Theoretical framework}

Following prior research on stigma in relation to HIV/AIDS (Mbonu, Van Den Borne \& De Vries, 2009), using an inductive approach from an extensive review of the literature on HIV/AIDS and stigma in Sub-Saharan Africa, we adapted the Precede portion of the Precede-Proceed model (Green \& Kreuter, 1999) as an explanatory model. The Precede-Proceed model provides a systematic approach for assessing quality-of-life of health and for designing, implementing, and evaluating health education and health promotion programs. Precede includes five phases. In phase 1, the quality of life or social problems and needs of a population are identified. Phase 2 includes an epidemiological analysis in which the relevant health problems are identified. Phase 3 involves an analysis of the behavioral and environmental determinants of a key health problem. In the fourth phase, the factors that predispose (beliefs, knowledge, self-efficacy, social norms, etc.), reinforce (e.g. social support), and enable (facilities etc.) the health behavior, are identified. In phase 5 , the focus is on the development of a health education or health promotion intervention that would encourage the desired behavior change, changes in the environment, and changes in the determinants of behavior and environmental factors. Proceed includes an implementation phase, an intervention process evaluation, an impact evaluation of changes in behavior or environment, and an outcome evaluation in which the impact on health and quality of life is assessed (Green \& Kreuter, 1999). Since models are constantly modified to fit the situation (Chiang, Huang \& Lu, 2003), we specified the model to the health care-seeking behaviour among PLWHA and used it to analyse people's coping strategies in dealing with stigma-related problems (Mbonu, Van Den Borne \& De Vries, 2009). The model proposes that a complex health problem, such as care-seeking behaviour of PLWHA, is a function of various factors and these factors have to be considered from a wider perspective of the social structural context.

The first component of the explanatory model is the analysis of the problem that is, care-seeking behaviour of PLWHA and how stigma influences it (see [a] in Figure 1) and how it may have an impact on the socio-structural context within which PLWHA, society and health care professionals (HCPs) are embedded. The second component of the model involves identifying the predisposing, reinforcing 
and enabling factors. The predisposing factors are represented as variables such as beliefs, knowledge about HIV transmission and self-efficacy. Reinforcing and enabling factors are represented as moderating variables, such as poverty, gender, age, religion and policy and how stigma may impact on the variables that determine individuals' care-seeking behaviour. The model finally specifies different coping strategies (coping with self, coping directed at others and comparison with others, coping with solving the problems of HIV/AIDS) that can lead to various careseeking choices, such as inappropriate self-care, inconsistent use of biochemical care or use of traditional healers and faith houses (e.g churches), which may result in failure to use health care institutions. In our explanatory model, non-utilisation of healthcare institutions is the outcome variable (see [n] in Figure 1).

In this study, while the interview was left open for interviewees to express a variety of issues, thoughts and feelings with respect to stigma and other concepts, we use the explanatory model as a general framework for identifying relevant categories of variables.

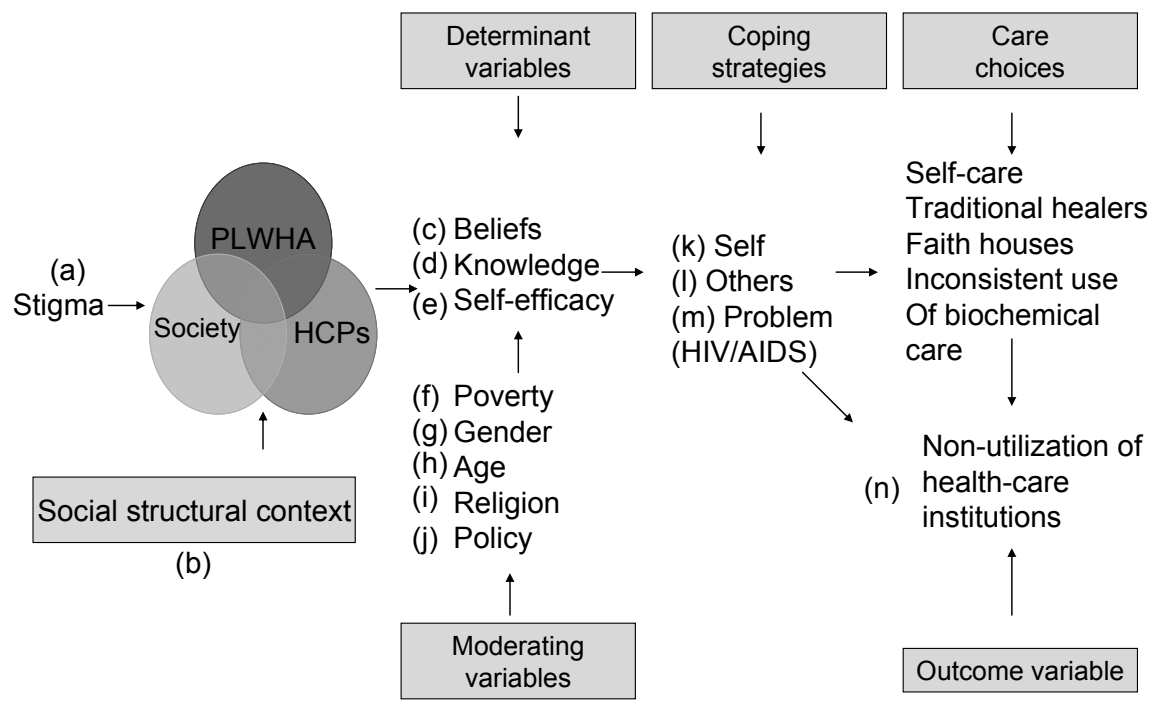

Figure 1: Explanatory model of role of stigma in care-seeking behaviour. Mbonu, Van den Borne, \& De Vries, 2009

\section{Methodology}

We conducted in-depth semi-structured interviews with a purposive sample of 20 adults (12 females and 8 males) living with HIV/AIDS who were receiving care from a resource centre in Port Harcourt, Nigeria. The participants are members of a network association of PLWHA and therefore were willing to be interviewed about 
their circumstances. All the persons approached agreed to participate. All the participants identified themselves as Christians and their ages ranged from 24 years to 48 years (Table 1). In addition, ten of these participants (six females and four males) participated in a focus group discussion which was conducted in the resource centre. The focus group discussion allowed the participants to exchange ideas and react to issues brought up by fellow participants. The resource centre was established to care for PLWHA and people with other sexually transmitted diseases. In addition, it provides pre- and post- HIV test counseling and nutritional advice for the PLWHA. Informed consent was obtained verbally from the persons who were interviewed and their anonymity was guaranteed. The aim of the study was explained to them before the interview took place. Interviews were conducted in the English language. Rivers State Agency for the control of HIV/AIDS which acts as ethics committee approved the study.

The interviews were held in the resource centre or, in three cases, in people's residences. The first author conducted the interviews and the focus group discussion. All the participants discussed freely the questions and issues covered in the study. The interviews were transcribed from audio tape and analyzed. The software package Nvivo 7 was used to analyze the data and identify major themes from Figure 1. Coding was done by the first author and subsequently validated by an independent researcher, who coded a random selection of data to look for new concepts. Emerging themes were compared by the independent researcher with the coding by the author. New entries and discrepancies were checked by re-reading the transcripts and fine-tuning interpretations until unambiguous categories and themes were agreed.

Table 1 showing the demographic characteristic of participants interviewed

\begin{tabular}{|c|c|c|c|c|c|c|}
\hline Nr. & Gender & Status & Job status & Reason for HIV test & Age & $\begin{array}{l}\text { Treatment } \\
\text { status }\end{array}$ \\
\hline 1 & Female & Widow & Government worker & $\begin{array}{l}\text { Went for test after the } \\
\text { Husband was sick with } \\
\text { HIV }\end{array}$ & 40 years & On ART \\
\hline 2 & Female & Widow & Government worker & $\begin{array}{l}\text { Went for test after the } \\
\text { Husband was sick with } \\
\text { HIV }\end{array}$ & 44 years & On ART \\
\hline 3 & Female & Single & $\begin{array}{l}\text { Office worker in company } \\
\text { now unemployed }\end{array}$ & $\begin{array}{l}\text { Was sick and went for } \\
\text { test afterwards }\end{array}$ & 24 years & $\begin{array}{l}\text { Not yet on ART } \\
\text { because of no } \\
\text { money }\end{array}$ \\
\hline 4 & Female & Single & Company worker & $\begin{array}{l}\text { Was sick and was sent } \\
\text { for testing }\end{array}$ & 39 years & On ART \\
\hline 5 & Female & Widow & Government worker & $\begin{array}{l}\text { Went for test after the } \\
\text { husband was dying From } \\
\text { HIV }\end{array}$ & 45 years & On ART \\
\hline
\end{tabular}




\begin{tabular}{|c|c|c|c|c|c|c|}
\hline Nr. & Gender & Status & Job status & Reason for HIV test & Age & $\begin{array}{l}\text { Treatment } \\
\text { status }\end{array}$ \\
\hline 6 & Male & Single & Private office worker & $\begin{array}{l}\text { Sent for test after being } \\
\text { sick }\end{array}$ & 35 years & $\begin{array}{l}\text { Take herbs, fruit, } \\
\text { and vegetable. } \\
\text { He stopped ART } \\
\text { Reacts to ART }\end{array}$ \\
\hline 7 & Female & Married & $\begin{array}{l}\text { Housewife } \\
\text { (husband lost job) }\end{array}$ & During delivery of baby & 29 years & On ART \\
\hline 8 & Female & Married & Housewife & During delivery of baby & 27 years & On ART \\
\hline 9 & Female & Widow & Petty trader & $\begin{array}{l}\text { Went for test after } \\
\text { husband died from } \\
\text { HIV/AIDS }\end{array}$ & 38 years & On ART \\
\hline 10 & Male & Separated & Government worker & $\begin{array}{l}\text { Sent for test after } \\
\text { sickness }\end{array}$ & 41 years & On ART \\
\hline 11 & Female & Married & Unemployed & $\begin{array}{l}\text { Went for test during } \\
\text { delivery }\end{array}$ & 29 years & On ART \\
\hline 12 & Female & Widow & Government worker & $\begin{array}{l}\text { Pre-operative test } \\
\text { screening }\end{array}$ & 45 years & On ART \\
\hline 13 & Female & Widow & Secretary (lost job) & Got sick and sent for test & 40 years & On ART \\
\hline 14 & Female & Married & Company worker & Got sick and sent for test & 48 years & On ART \\
\hline 15 & Male & Single & Banker & Got sick and sent for test & 40 years & On ART \\
\hline 16 & Male & Married & Government worker & Got sick and tested & 38 years & On ART \\
\hline 17 & Female & Widow & Petty trader & Husband was sick & 47 years & On ART \\
\hline 18 & Male & Single & Government worker & $\begin{array}{l}\text { Was sick and went for } \\
\text { test }\end{array}$ & 28 years & On ART \\
\hline 19 & Male & Single & $\begin{array}{l}\text { Company worker } \\
\text { (lost job) }\end{array}$ & Company screening & 35 years & On ART \\
\hline 20 & Male & Married & Unemployed & Was sick and tested & 29 years & On ART \\
\hline
\end{tabular}

\section{Results}

The results of this study are organized according to the components of the explanatory model in Figure 1. Some basic distinguishing characteristics of participants are provided after each quote.

\section{Stigma}

Participants indicated that negative reactions towards them were the major problems they had, affecting the way they cope with HIV/AIDS and leading to nonutilization of health care institutions. These negative reactions came from the community, including their close social networks, such as neighbors, family or 
spouse. A participant explained the reaction of her neighbors when they discovered the positive status of her and her husband:

'My neighbors found out in the church that my husband and I are HIV positive, they now pursued us [sic-sent us away] from the compound. The landlord and the neighbors drove us away from the compound we were living in because they said HIV will affect them. We live in an uncompleted building now.' (Female, 29 years, housewife, participant 7)

Some participants, even without revealing their HIV status to their partners, were abandoned because of suspicions of them being HIV-infected. Others lived with their spouses although these spouses knew they were HIV positive. But anticipated public reactions are apparently strong. A participant in the focus group discussion reported being abandoned by her partner when she went public with her positive status:

'I have lived with this man for five years. I have had HIV since then but he accepted it. He even was planning to marry me but then I went on a programme on the radio and his friends recognized my voice. They immediately called him and after that he left me because he said he was ready to live with the knowledge of my HIV alone but not to share it with others. I find it stupid because he has lived with me all this long.' (Female, single, company worker, FDG)

This reaction has implications for seeking care at health care institutions if a female with HIV needs her partner for financial support. Furthermore, some participants reported that HCPs also exhibit negative reactions towards PLWHA. The negative reactions from HCPs were enough to discourage them from going for treatment, leading to non-utilization of health care institutions, as illustrated by these quotes:

'Some health care professionals are not friendly when they come to find out that someone is HIV-positive. They tend to discard [sic] someone. They will not attend to me in the clinic and they ask me to wait by the corner while attending to others.' (Male, 41 years, separated, government worker, participant 10)

'Before, I had a problem with health-care professionals in the hospital where I delivered my baby, they were not nice. It was there I found out my HIV status. They started running and avoiding me.' (Female, 29 years, housewife, participant 11)

\section{Determinant variables}

The model also postulates that stigma has impact on three kinds of variables (beliefs, knowledge about HIV/AIDS, and self-efficacy) which are particularly important because of their impact on the coping strategies that PLWHA use and on 
the health care choices they make, which may lead to failure to utilize the health care facilities that are available.

\section{Beliefs}

Beliefs (see [c] in Figure 1) can either be general beliefs about HIV infection or about persons with HIV or AIDS, e.g the pathways of HIV infection. The following quotes illustrate this:

'I think HIV is a problem for everyone who has HIV because the society thinks you are loose [sic-promiscuous].' (Male, 35 years, single, company worker, participant 6)

'People will blame me for having HIV because they will say I am a prostitute.' (Female, 24 years, single, unemployed, participant 3)

The anticipation of reactions based on these popular beliefs cause PLWHA to refrain from seeking care. It can also be beliefs about the reactions of others to the care-seeking behaviour of persons with HIV or AIDS, or specific beliefs about the feasibility of coping. This can lead to the non-utilization of health care institutions and thereby render PLWHA unable to get the quality of care they need. Apparently, the expectation is that society will label every PLWHA as promiscuous and irresponsible. PLWHA are very aware of these societal beliefs. They expect to be blamed. As one participant said frankly to the interviewer:

'You should campaign more to people. You should tell people it is not only by sex that people have HIV, which is always the problem. When people change towards people with HIV then we can get better support and care at home and hospital.' (Female, 45 years, widow, government worker, participant 12)

\section{Knowledge}

This can be knowledge about HIV and AIDS (see [d] in Figure 1), HIV status, HIV transmission and about effective treatment, which are important for the utilization of health-care institutions. In our study, all of the participants were aware of their HIV status and the existence of antiretroviral therapy (ART) because they belonged to an association network. In the general population, knowledge is expected to be more limited. Furthermore, many of the participants felt that joining an association of people in the same situation helped them gain knowledge of HIV/AIDS and its care possibilities, for instance:

'Persons with HIV should join the association of people living with HIV and AIDS so they can get good information about the disease.' (Female, 40 years, widow, government worker, participant 1) 


\section{Self-efficacy}

Self-efficacy (see [e] in Figure 1) is the idea that one can carry out a task effectively, and it leads to problem-focused coping such as PLWHA finding the right health care institution and the right treatment from HCPs, going for HIV tests, or handling their condition and situation if others know about their HIV-positive status. Some of our participants had adequate self-efficacy in handling the situation when their HIV status was revealed to their relatives. For instance, a participant who is on ART described how he handled the situation with his brother when he disclosed his positive HIV status this way:

'My brother wanted to withdraw from me but when I talked to him, he understood .....I told him it can happen to even him, beside he has seen that I am not dying and I am still going on with my life.' (Male, 41 years, separated, government worker, participant 10)

A few others had low self-efficacy in handling their situation when others heard about their HIV status. Some participants who looked at HIV/AIDS as a chronic illness felt more confident in handling their situation of being drug-compliant and going for treatment at hospitals. One participant explained that normally in society, one is expected not to talk about one's illness and HIV/AIDS is no different, so, based on this expectation she decided to keep it a secret from others that she was taking her ART medications:

It is not only people with HIV that take drugs, hypertensive people take drugs, diabetes people take drugs and still these sicknesses do not go.' (Female, 40 years, widow, company worker, participant 13)

By implication, the strong stigma around HIV inhibits high self-efficacy. Some PLWHA seem to have come to regard HIV/AIDS as just another illness as a psychological means to increase their confidence in handling problems associated with HIV/AIDS and its care.

\section{Moderating variables}

The model also postulates that certain moderating variables (poverty, gender, age, religion and policy) have an impact on the coping and care-seeking behavior of PLWHA.

\section{Poverty}

Our participants reported that although many of them are aware of the benefits of ART, many are unable to utilize the health care institutions and take ART because they do not have the money to pay for ART or other medical and laboratory costs. Some, who do buy ART, are unable to take their medication routinely due to lack of money, since many of them lost their jobs after HIV diagnosis. Participants were 
also concerned about how their financial problems affect the whole family. For instance, a participant explained her dilemma in going for treatment:

'I have not gone for treatment because I do not have money. I need money. I am broke. I have to feed myself. Right now, my husband is admitted in the ward. Even I have a lab test to do but I have no money. I need money to buy food, drugs. My child is sick too with HIV.' (Female, 29 years, housewife, participant 7)

Further discussion showed the difficulty with utilization of health-care institutions:

'In our organization, people living with HIV/AIDS are facing a lot of problems. Most of them are not working. Some of them were working before but because of their HIV status they were laid off from their work. Many of them are jobless that is why treatment is difficult. We lose our members often.' (Male, 41 years, separated, government worker, participant 10)

\section{Gender}

Our study shows that due to the stigma associated with HIV/AIDS, male PLWHA are not willing to disclose their positive HIV status to their wives causing delay in seeking care. There seems to be a clear difference in the timing of HIV/AIDS diagnosis between male and female participants. Women find out much later after being infected. There are a number of reasons for this. First, society expects women to be conservative and faithful to their partners; such cautiousness, however, does not protect women from HIV if their partners have multiple partners and do not use protection during sexual intercourse. Moreover, even when women find out their HIV status, they have to disclose to their partners immediately if they want to secure financial support for treatment. On the contrary, society tolerates men with multiple partners. Men who are HIV positive may still be angry when they find out and blame women for their HIV infection. In this study, married women who contracted HIV from their partners felt very bad and betrayed when they discovered their positive HIV status. Two of the female participants in particular (participants 1 and 5) expressed anger towards their partners because of assumed infidelity resulting in infection:

'The thing [HIV/AIDS] pains me (very angry). I married him as a virgin, I never played life. The thing pains me. You know if I played life as a young girl, I would feel better but I tell you, the thing pains me.' (Female, 45 years, widow, company worker, participant 5)

Another said:

'I was very sad and confused. I now understand why my last three children died. When I was pregnant with them my pregnancy was not even up to nine months and they did not grow well like my first three children. They were 
always emaciated. They were premature and this man [her husband] knew he was HIV-positive and did not tell me. It is bad.' (Female, 40 years, widow, government worker, participant 1)

Second, men take decisions in the family and are breadwinners while women are mostly dependent. These differences are shown at the diagnostic phase and during illness. At the diagnostic phase, some women in this study were diagnosed as part of routine blood tests at pregnancy. This led to women discovering their HIV status without being previously informed by their spouses. At the illness phase, some women in this study were ill but needed their partners' support and approval before seeking care. Women who are tested during pregnancy find out earlier in contrast to women who present themselves to the hospital for a HIV-related illness. Apparently, the male control and lack of support hinders women from making early effective care choices such as voluntary counselling and testing (VCT). On the contrary, males cannot be diagnosed routinely because they are never pregnant. Male participants presented themselves with illness to the hospital before being sent for HIV test and did not need approval from their spouses before seeking care. An early diagnosis is important because when people find out their HIV status early, they are more likely to make an effective care choice, especially for those who know about ART. Female participants emphasized their frustration at the lack of knowledge of their spouses' HIV status. One female participant put it this way:

'Imagine how my husband hid his HIV status from me, so I now have HIVIAIDS from him. If I was a man, I would not be in this condition because I would know myself.' (Female, 40 years, widow, government worker, participant 1)

In summary, the gender issue is relevant in care seeking because it affects the time of diagnosis, societal blame and necessity of disclosure to partner.

Age

In our study, the younger participants emphasized a strong interest in marrying and having children. This was particularly important for them to fulfil their societal role. The emphasis on reproduction was demonstrated by this participant:

'Infact this baby issue has given me a lot of stress. You know, I have to think of the uncertainties.' (Male, 35 years, single, company worker, participant 6)

They believed that the ART will prevent their babies from being infected with HIV. This encouraged them to seek access to ART and health care despite the costs involved in accessing it:

I plan to have a baby because I do not have any. HIV will not affect my baby again provided I am taking my Anti retroviral therapy drugs.' (Female, 29 years, housewife, participant 11) 
I will like to have a baby. I am looking forward to marriage. My unborn baby maybe infected but we are told in the hospital that if you take your drugs effectively the baby may not be infected.' (Male, 41 years, separated, Government worker, participant 10)

On the contrary, due to fear of stigma, young people may not want to go for HIV testing. This enhances the spread of HIV/AIDS. This participant who disclosed his positive HIV status to his girl friend found it difficult to convince her to go for HIV testing:

'I tried to encourage my girlfriend to go for HIV test but she did not agree to go for the HIV test. I gave her some money but she will turn and ask me whether she is sick? Why should she go for a test? I told her it is important she goes for the test because I have the feeling that she has HIV because if she does not get it from me then she may get it from another person. She was angry with me that I am accusing her. At the end of the day she did not go for the test before we parted.' (Male, 28 years, single, government worker, participant 18)

\section{Religion}

Our data show that some participants received spiritual and psychological support from the pastors in their church; however, the church congregation is not free from stigmatizing reactions. Since the church is made up of members of society, who typically relish gossip, this participant indicated a lack of trust in people at his church:

In the church where I go, the moment they know my HIV status, they will start asking each other whether they have heard? It is even your closest friend that will give you away.' (Male, 48years, married, company worker, participant 14)

Such anticipations of the negative reactions of fellow church members can discourage PLWHA from utilizing health care institutions. This may also lead to them not looking for and not getting support from relevant others.

\section{Policy}

Discussion with participants revealed that many of them wanted free ART and wanted the government to implement a policy for protected work and a financial policy for PLWHA such as provision of micro-credits, which would enable them to pay for health care. A participant said this:

'Government should come to our aid. They should give us work because many of us whose HIV status is known have lost their job. They should give us micro credit.' (Female, 40 years, widow, government worker, participant 1)

At the time this study was conducted, the participants had access to subsidized ART, which means they still have to pay some expenses out of their own pocket 
which, some of them could not afford. All the participants in this study went for HIV diagnosis with a clear reason. Five women were tested after their husbands became sick or died from HIV/AIDS, three women were tested during antenatal care, four women and seven men were tested because of illness, and one man was tested at the behest of his employer. Further discussion revealed that some employers send people for compulsory HIV testing without informing them in advance about the HIV test; afterwards, they fire staff with a positive HIV diagnosis. A participant in the focus group discussion said this:

'What happens here is that immediately a company discovers one is HIV positive, they will not terminate the appointment based on HIV. It will not be written in one's letter. They may say because of so much labor they want to downsize the company. I lost my job. The whole company had to go through the $H I V$ screening test. All the staff was involved. After discovering that some of us were HIV-positive, they had to lay us off. They did not call it a HIV test, they called the test a different name because they know if they call it HIV test some people will not go for it. In the process some of us were affected and I am one of those people affected.' (FGD)

\section{Coping mechanisms}

In the following paragraphs, we report how PLWHA cope with HIV/AIDS and how different coping strategies affect PLWHA utilizing health care institutions.

\section{Coping with emotions because of HIV/AIDS}

As shown in (k) of Figure 1, PLWHA may use different internal coping strategies directed at their own emotional problems. Some of our participants showed some fearful emotional reactions after diagnosis, such as thoughts of suicide and feelings that society would not show them sympathy if people knew about their positive status. A male participant reacted to the diagnosis like this:

'Initially, I felt very bad when I knew of my HIV status. I thought of myself as finished in this world.' (Male, 41 years, separated, government worker, participant 10)

The reaction from another participant was more extreme:

'I was scared when I was told I have HIV/AIDS. I felt like killing myself.' (Female, 24 years, single, unemployed, participant 3)

The study's participants tried to cope with these emotional reactions through denial or by downplaying HIV/AIDS as a serious threat. They compared HIV/AIDS with other illnesses, denying that HIV/AIDS was any serious threat and that helped them to cope. Furthermore, they rather emphasized that HIV is not contracted from sex alone for example: 
'HIV/AIDS is a normal sickness and anybody can have it, it can come by sex, sickness or even the Hausa people [some people from Northern Nigeria] that move around doing pedicure for people.' (Female, 40 years, widow, company worker, participant 13)

\section{Coping directed at others and comparison with others}

Second, the coping strategy of PLWHA aimed at reducing the unfavorable reactions of others (see [1] in Figure 1) may include hiding tendencies, finding support from significant others or comparison with other people living with HIV/AIDS. This strategy may also involve trying to influence the meaning other people attach to HIV and AIDS (Goffman, 1963), such as attributing their HIV/AIDS to poisoning. Our study showed that the feasibility of hiding their HIV statuses depended on the stage of illness and use of ART. The concealment of their positive status enabled them to carry out their normal activities. In the focus group discussion, many participants explained why ART helped them cope with the physical features associated with HIV/AIDS. Many felt better with ART and did not have the look typical of AIDS patients, for instance:

Since I started taking antiretroviral therapy, people do not know I have HIV/AIDS. They cannot suspect.' (Female, married, company worker, FGD)

Another way of coping reported by the participants was to withdraw from people who they thought may suspect or know their diagnosis. They resolved not to tell anybody, as illustrated by the following quotes:

'I have not told any other person. I did not tell my friends, If I tell them, na dey same thing [sic] (the same thing), they will run away from me.' (Female, 29 years, housewife, participant 7)

'The society will not welcome me when they know my HIV status, so it is good keeping it to myself instead of people running away from me. That alone can cause emotional stress to me. It can cause more problems to me when I am rejected.' (Male, 48 years, married, company worker, participant 14)

Some of the participants chose to use selective disclosure. Selective disclosure was commonly made to people they trusted and who could support them:

I told my girlfriend who is also HIV positive but we did not know before we met. I told my doctor and my God. I told my doctor because I need his advice. HIV is something between the person, his or her doctor and God.' (Male, 35 years, single, company worker, participant 6)

'I told my husband, two of his sisters and one of my pastors. I told them because they are close to me.' (Female, 27 years, housewife, participant 8) 
Disclosure continues to be a huge problem. A few participants disclosed their status involuntarily out of necessity for financial support; while for some participants, people around them just ended up knowing. Some tried to deny it even when confronted. A participant who discussed his positive HIV status on TV still hides from his neighbors. He tries to deceive them into believing he is just working for an organization:

I do not keep my HIV status quiet but I tend to keep it quiet within my vicinity; but outside my vicinity I expose it because they used to call me out for programme. My neighbors used to say they saw me on the television but I always tell them, to confuse them, that we have an organization or I belong to an organization that take care of people with HIV and AIDS.' (Male, 41 years, separated, government worker, participant 10)

Others decided not to tell their colleagues because they did not want to lose their jobs. Concealment may be necessary for PLWHA to remain in employment and thus keep up with the financial obligations of utilizing health care facilities. This participant said the following when asked whether any of her colleagues knew about her positive status:

'Ah no... (Laughter). I have to tell you the truth, they [colleagues] will not mind to sum up one thing and that will be the reason for sending me out of the job. I will therefore tell nobody.' (Female, 40 years, widow, government worker, participant 1)

Disclosing HIV status to children was particularly difficult for female PLWHA due to what is widely believed to be the cause of HIV/AIDS and fear of losing the parents status as a role model. Sometimes, PLWHA preferred to wait until they were actually sick with HIV. Another problem that PLWHA tried to cope with was with significant others such as their partners. Some of them had got married without informing their partners until pregnancy, while others hoped their ART would help when they were married. This has implications for the spread of the virus, as well as for the process of seeking appropriate care at an early stage. Many PLWHA felt it was difficult to give an explanation for being unfit to have children. On the contrary, a female participant who was already married and believed she had contracted HIV through a blood transfusion during childbirth received positive support from her spouse. PLWHA may also prefer to associate with other people with HIV/AIDS by joining association networks as a way of coping with their illness. Others simply ascribe HIV/AIDS to another, more acceptable cause, such as attributing HIV/AIDS to poison, which may encourage them to use traditional healers and prevent them from utilizing health care institutions. For instance, the husband of this female participant, who was HIV-positive, said he was poisoned: 
'This man (my husband) knew he was HIV-positive and did not tell me. It is bad. He told me his village people (his kindred) gave him juju (African charm/poison).' (Female, 40 years, widow, government worker, participant 1)

\section{Coping directed at problem solving}

Third, to solve the problems related to HIV/AIDS, some participants reported strategies that excluded going to the hospital early and consistent use of ART (which is known to be effective). Instead, they preferred to try other options first rather than going to hospital for treatment with ART. Many of the participants mentioned using a combination of therapies; they went to faith houses such as churches, or traditional healers, or used herbs or combined them with attending a health care institution. This strategy may affect consistent utilization of health care institutions since some PLWHA may abandon utilization of health care when they feel better and then use traditional healers and faith houses. Furthermore, we asked the participants for their advice to other PLWHA. Their advice mostly was a reflection of what they practised themselves:

'Persons with HIV should pray to God for a miracle.' (Female, 24 years, single, unemployed, participant 3)

'My advice is that people with HIV should have hope in God.' (Female, 29 years, married, housewife, participant 7)

'HIV people have to trust in God and God can always change things.' (Male, 48 years, married, company worker, participant 14)

\section{Care choices}

Some participants made care choices which led them to refrain from treatment or stop their treatment after they had started. Others chose not to tell their pastors but opted for prayers alone. Many of the participants believed God could cure them of HIV and combined prayer with going to hospital for ART. It was also common for them to resort to religion early to solve problems, hence it was not unusual that visiting faith houses such as churches were the early choices participants made when managing their sickness:

I did not feel anything when I was told I had HIV because I know my God will heal me.' (Female, 47 years, widow, petty trader, participant 17)

\section{Discussion}

Our study focused on factors associated with PLWHA making care choices. Our participants are different from other PLWHA because they have tested themselves and sought care. Although they may not be representative for all PLWHA, they still 
gave insight into the stigma-related processes which affect utilization of health care institutions. Few participants in our study experienced positive support from their immediate family after disclosure of their positive HIV status. We found support for our main proposition that PLWHA still experience stigma in society including health care institutions, and in an effort to cope with stigma, they frequently utilize different care choices which can affect utilization of health care institutions. Our data revealed that poverty and religion were important in coping with HIV/AIDS as well as in making care choices, which affect utilization of health care institutions. Some PLWHA do not have money, while others lost their jobs based on their positive HIV status, which has implications for them when deciding to seek care in health institutions, especially since many people do not have health insurance or money to cover ART and care. A different study carried out in Russia also reported job losses by PLWHA (Amirkhanian et al., 2003) making securing of a living and finances an integral part of coping and utilizing health care institutions. Conversely, those participants who were still working and financially capable were able to cope and had less need to ask people for financial help, and hence, they successfully hid their status while utilizing health care facilities and taking ART.

Many of the participants went for HIV testing with a clear reason. This has implications for early HIV diagnosis and the use of ART, due to the subsequent delay in visiting health care institutions. In addition, early voluntary counseling and testing (VCT) will prepare people, give them knowledge and the self-efficacy needed to cope with and manage HIV/AIDS. This finding is consistent with a study carried out in Thailand, which showed that the majority of the men underwent HIV testing for health reasons, while the majority of women were tested following family events, such as a spouse's passing away or pregnancy (Le Coeur, Collins, Pannetier \& Lelievre, 2009). Fear of being identified as someone infected by HIV increases the likelihood of people avoiding VCT (Nyblade et al., 2009).

Our data showed that the discovery and disclosure of a positive HIV status may lead to family disharmony, generating a lot of suspicions. The findings show that concealment and disclosure remained an uphill task for PLWHA. The concealment affects their self-efficacy in seeking care, which in turn can lead to non-utilization of health care institutions because they will not want to be seen there. This study showed that some of the participants who disclosed, experienced negative consequences while others received support. Some of our participants had problems when they went on the radio programme as part of the PLWHA association activities because they revealed their positive HIV status and people who knew them recognized their voices. This shows the downside of PLWHA becoming active in HIV programmes and has implications for support from their partners which is necessary for them to be able to utilize health care institutions. Furthermore, non-disclosure contributes to the spread of HIV/AIDS when people have unprotected sex. 
Society can sometimes condemn PLWHA giving birth to children (Lekas, Siegel \& Schrimshaw, 2006; Valencia-Garcia, Starks, Strick \& Simoni, 2008), which affects their reproductive rights and self-efficacy of seeking early care. Our data shows that some unmarried and married participants did not plan to disclose their positive HIV status to their spouses but did want to have children. This is significant in Nigeria because high value is placed on bearing children (IsiugoAbanihe, 1994). Non-disclosure of positive HIV status to their spouses has implications for not seeking early treatment, as well as for the prevention of vertical transmission. Criminal prosecution for knowing transmission of HIV has already been applied in a few cases in the United Kingdom, where research showed that the majority of PLWHA in the study were against the criminalization of reckless HIV transmission, while a few felt it might be justified if it changed the behavior of PLWHA (Dodds \& Keogh, 2006). While the protection of individuals in society is important, the sexual rights, disclosure problems and further stigmatization of PLWHA remain a concern. Brown and colleagues noted that there are existing legislative tools to respond to actions that constitute criminally harmful behavior arguing that HIV-specific laws to punish PLWHA are unnecessary, counterproductive and jeopardizes the human rights of PLWHA (Brown, Hanefeld $\&$ Welsh, 2009). Furthermore, direct or indirect inclusion of criminalization of vertical transmission pose serious consequences for female PLWHA as well as undermine the success of vertical transmission programmes so far achieved (Csete, Pearshouse \& Symington, 2009).

The participants' coping strategies were highly determined by the anticipation of negative reactions from society and the link to non-monogamous heterosexual transmission. They utilized different coping strategies to hide their condition since they believed it would not be accepted in society. The ability to cope with HIV/AIDS further depended on their marital status. Sero-discordant partners found it more challenging to cope, because some were abandoned by their partners simply due to the suspicion of being HIV infected. Our data also showed that married people received support better. The route through which participants felt they contracted their HIV virus was related to their emotional reaction and the support they received. Literature has pointed out that many women living with HIV/AIDS consider themselves as innocent victims in order to escape moral judgment from society (Doyal, 2009).

Furthermore, our study showed that gender played a role in the knowledge of partner's HIV status, as some of the female participants did not know their partners were HIV-positive and could not seek care when they were infected with HIV/AIDS. Schur (1984) noted that the overall subordination of women can lead to a snowballing effect because of the difficulty for them to achieve desired goals, such as being tested for HIV. Women are often dependent on their husbands for finances and decisionmaking in the family, which is important when deciding to use the health care institutions. Also, this has implications for prevention of vertical 
transmission for pregnant women with HIV/AIDS since they will not seek early treatment to initiate necessary ART. Studies have shown that husbands' refusal to disclose their status contributes to the spread of HIV infection (Neves \& Gir, 2006; Chinkonde, Sundby \& Martinson, 2009).

Our findings demonstrate the use and role of combined care choices in the careseeking behavior of PLWHA such as visiting faith houses as well as taking ART from health care institutions. A combined care choice encourages opportunistic infections, ART drug resistance and complications that may result due to lack of drug adherence. This combination of treatments was also observed in health care seeking behavior for sexually transmitted infections in Zimbabwe (Pearson \& Makadzange, 2008), as well as in another study involving PLWHA in Ribeirao Preto, Brazil (Neves \& Gir, 2006), corroborating findings obtained elsewhere.

Limitations: Although the findings from this study are informative, they must be interpreted in the context of some methodological limitations. First, this is a small exploratory, qualitative study. Second, the findings were organized within the explanatory model which was based on a literature review of HIV-related stigma in Sub-Saharan Africa and so it is subject to the limitation of the search criteria used. Third, the findings cannot be generalized to the larger population. Fourth, the study was conducted with people who were open about their positive HIV status and belonged to a patient association. Finally, some of the participants were also on ART and enjoyed government, as well as social and company support.

\section{Conclusion}

In summary, the explanatory model applied in this study provided a framework for organizing the findings of this study. The model adapted from the Precede portion of the Precede-Proceed model (Green \& Kreuter, 1999) was helpful in understanding problems related to HIV stigma, coping mechanisms and careseeking behaviors of PLWHA, which can affect utilization of health care institutions. This study shows that certain determining and moderating variables are important for PLWHA, in order for them to cope with HIV/AIDS and to make care choices. The variables which are depicted in the model should be the target of context-specific interventions. The findings from this study can translate into practical issues if we understand how and why PLWHA seek care from health care institutions. Societal reactions, whether anticipated or real, continue to play a vital role in the way PLWHA cope and seek care from health care institutions. It also causes people not to disclose their HIV status, especially to their significant others such as their partners. This is because PLWHA believed that society blames them and perceives that it is only contracted through sex. Many PLWHA keep their HIV status quiet, but live with that burden to avoid societal judgement. PLWHA also try to compare HIV/AIDS- in terms of route of transmission, lifetime medication and 
prognosis - with other chronic illnesses as ways of coping, even though they know in reality that HIV/AIDS is different medically and in terms of societal impressions, beliefs and reactions. Altering these coping methods, societal impressions and beliefs about HIV/AIDS is necessary in order for PLWHA to seek appropriate care. It is important that HIV patients are supported so that they are able to go for HIV tests and access effective treatment. Proper counseling goes a long way to help PLWHA to accept their status and prepares them to live with HIV. Clearly, PLWHA need psychological, medical and material support. Access to antiretroviral drugs remains a very important step in the care of HIV patients because when people have access to drugs, their health greatly improves and they are less prone to complications so they can go to work, have normal relationships and interact fully with the people around them.

\section{Recommendations}

The government should, as suggested by some of the participants, support PLWHA whose positive HIV status is exposed through creating a protective work policy and providing them with free ART, as this will be a motivator for other people with positive HIV status to come forward for help. The government should help in providing micro credit for those trying to be self-employed and doing business. This is important for PLWHA who are poor and jobless to enable them pay their user fees, buy regular drugs, do laboratory investigations and take care of their families.

The government should continue with efforts to educate the population about HIV/AIDS-related stigma which, when reduced, will enable people to go for VCT and seek appropriate care in health care institutions in an early stage. Furthermore, education of people about the options of ART and possibilities of care will increase the self-efficacy of PLWHA.

The government should continue to involve and commit stakeholders such as the media, religious and community leaders in educating people about HIV/AIDS, stigma and HIV/AIDS care, as that will help people in making appropriate care choices. Policymakers should also involve PLWHA at all levels of consultation to ensure that all their needs are well represented. Special attention should go to youths through specially targeted HIV/AIDS programmes. In addition, effective gender-specific policies that protect women but include the role of men should be integrated into programmes to ensure full utilization and support, such as protection of women who find out their positive HIV status in antenatal care. Finally, the national HIV strategies should involve and support the members of vulnerable groups such as the association networks of PLWHA which are important to continue efforts of reducing the HIV stigma in society and health care institutions. 


\section{References}

Adewuya, A.O., Afolabi, M.O., Ola, B.A., Ogundele, O.A., Ajibare, A.O., Oladipo, B.F., \& Fakande, I. (2009). Post-traumatic stress disorder after stigma related events in HIV infected individuals in Nigeria, Social Psychiatry and Psychiatric epidemiology, 44 (9), 761-766.

Ajuwon, A.J., Oladepo, O., Adeniyi, J.D., \& Brieger, W.R. (1998). Sexual practices that may favor the transmission of HIV in a rural community in Nigeria, In D. Buchanan and G Cernada (eds) (pp 21-33), Progress in preventing AIDS? Dogma, Dissent and Innovation, Global perspectives, Amityville, New York: Baywood publishing Company, Inc.

Amirkhanian, Y.A., Kelly, J.A., \& McAuliffe, T.L. (2003). Psychosocial needs, mental health and HIV transmission risk behavior among people living with HIV/AIDS in St Petersburg, Russia. AIDS, 17 (16), 2367-2374.

Brown, W., Hanefeld, J., \& Welsh, J. (2009). Criminalising HIV transmission: punishment without protection. Reproductive Health Matters, 17 (34), 119-126.

Campbell, C., Nair, Y., Maimane, S., \& Nicholson, J. (2007). Dying twice: a multi-level model of the roots of AIDS stigma in two South African communities. Journal of Health Psychology, 12, 403 416.

Chiang, L.C., Huang, J.L., \& Lu, C.M. (2003). Educational diagnosis of self management behaviors of patients with asthmatic children by triangulation based on Precede-Proceed model in Taiwan. Patient Education and Counseling, 49 (1), 19-25.

Chinkonde, J.R., Sundby, J., \& Martinson, F. (2009). The prevention of mother-to-child HIV transmission programme in Lilongwe, Malawi: why do so many women drop out? Reproductive Health Matters, 17 (33), 143-155.

Csete, J., Pearshouse, R., \& Symington, A. (2009). Vertical HIV transmission should be excluded from criminal prosecution. Reproductive Health Matters, 17 (34), 154-162.

Dodds, C., \& Keogh, P. (2006). Criminal prosecution for HIV transmission: people living with HIV respond. International Journal of STD and AIDS, 17 (5), 315-318.

Doyal, L. (2009). Challenges in researching life with HIV/AIDS: an intersectional analysis of black African migrants in London. Culture, Health and Sex, 11 (2), 173-188.

Duffy, L. (2005). Suffering, shame and silence: The stigma of HIV/AIDS. Journal of the Association of Nurses in AIDS Care, 16(1), 13-20.

Fakolade, R., Adebayo, S.B., Anyanti, J., \& Ankomah, A. (2009). The impact of exposure to mass media campaigns and social support on levels and trends of HIV-related stigma and discrimination in Nigeria: Tools for enhancing effective HIV prevention programmes. Journal of Biosocial Science, 1-13, (PMID: 20018118).

Green, L.W., \& Kreuter, M.W. (1999). Health-Promotion Planning. An Educational and Ecological Approach. California, United States of America: Mayfield Publishing Company.

Hejoaka, F. (2009). Care and secrecy: Being a mother of children living with HIV in Burkina Faso. Social Science and Medicine, 69 (6), 869-876.

Hilhorst, T., Van Liere, M.J., Ode, A.V., \& de Koning, K. (2006). Impact of AIDS on rural livelihoods in Benue state, Nigeria. Journal of Social Aspects of HIV/AIDS Research Alliance (SAHARA), 3 (1), 382-393.

Isiugo-Abanihe, U.C. (1994). Reproductive motivation and family size preferences among Nigerian men. Studies in Family Planning, 25 (3), 149-161.

Le Coeur, S., Collins, J., Pannetier, J., \& Lelievre, E. (2009). Gender and access to HIV testing and antiretroviral treatments in Thailand: Why women have more and earlier access? Social Science and Medicine, 69 (6), 846-853.

Lekas, H.M., Siegel, K., \& Schrimshaw, E.W. (2006). Continuities and discontinuities in the experiences of felt and enacted stigma among women with HIV/AIDS. Qualitative Health Research, 16 (9), 1165-1190. 
Liamputtong, P., Haritavorn, N., \& Kiatying-Angsulee, N. (2009). HIV and AIDS, stigma and AIDS support groups: Perspectives from women living with HIV and AIDS in Central Thailand. Social Science and Medicine, 69 (6), 862-868.

The Joint United Nations Programme on HIV/AIDS (UNAIDS). Retrieved 11 May 2009 from UNAIDS website: www.unaids.org/en/countryresponses/countries/nigeria.asp.

The joint United Nations Programme on HIV/AIDS (UNAIDS), (2009). HIV-related stigma and discrimination: A summary of recent literature (Prepared by: Macquarrie, K., Eckhaus, T., Nyblade, L. et al., 2009): Retrieved 27 January 2010 from UNAIDS website: http://data.UNAIDS.org/pub/report/2009/20091130_stigmasummary_en.pdf.

Mitchell, S.K., Kelly, K.J.M., Potgieter, F.E., \& Moon, M.W. (2007). Assessing social preparedness for antiretroviral therapy in a generalised AIDS epidemic: a diffusion of innovation approach. AIDS and Behaviour, 13 (1), 76-84.

Mbonu, N.C., Van Den Borne, B., \& De Vries, N.K. (2009). A model for understanding the relationship between stigma and health care-seeking behaviour among people living with HIV/AIDS in SubSaharan Africa. African Journal of AIDS Research (AJAR), 8 (2), 201-212.

Morolake, O., Stephens, D., \& Welbourn, A. (2009). Greater involvement of people living with HIV in health care. Journal of International AIDS Society, 12 (1), 4.

Muula, A. S., \& Mfutso-Bengo, J. M. (2005). When is public disclosure of HIV seropositivity acceptable? Nursing Ethics, 12 (3), 288-295.

Muyinda, H., Seeley, J., Pickering, H., \& Barton, T. (1997). Social aspects of AIDS- related stigma in rural Uganda. Health and Place, 3, 143-147.

Mwinituo, P.P., \& Mill, J.E. (2006). Stigma associated with Ghanaian caregivers of AIDS patients. Western Journal of Nursing Research, 28(4), 369-382.

Neves, L.A., \& Gir, E. (2006). HIV positive mothers' beliefs about mother-to-child transmission, Revista Latino-Americana Enfermagem, 14 (5), 781-788.

Nyblade, L., Stangl, A., Weiss, E., \& Ashburn, K. (2009). Combating HIV stigma in health care setting: what works? Journal of International AIDS Society, 12(1), 15.

Pearson, S., \& Makadzange, P. (2008). Help-seeking behavior for sexual-health concerns: a qualitative study of men in Zimbabwe. Culture Health and Sex, 10 (4), 361-376.

Sabin, L.L., Desilva, M.B., Hamer, D.H., Keyi, X., Yue, Y., Wen, F., Tao, L., Heggenhougen, H.K., Seton, L., Wilson, I.B., \& Gill, C.J. (2008). Barriers to adherence to antiretroviral medications among patients living with HIV in Southern China: a qualitative study. AIDS Care, 20 (10), 12421250 .

Schur, E.M. (1984). Women and deviance: a social perspective, in: Labelling women deviant, gender, stigma, and social control. Philadelphia, USA: Temple university press.

Shisana, O., Rehle, T., Simbayi, L., Parker, W., Bhana, A., Zuma, K., et al. (2005). South African National HIV prevalence, incidence, behaviour and communication survey. Cape Town. Human sciences research council press.

Singh, M., Garg, S., Nath, A., \& Gupta, V. (2009). An assessment of felt needs and expectations of people living with HIV/AIDS seeking treatment at NGOs in Delhi, India, Asia Pacific Journal of Public Health, PMID: 19443873.

Sontag, S. (1988). Illness as metaphor and AIDS and its metaphors. New York: Doubleday publishers.

Valencia-Garcia, D., Starks, H., Strick, L., \& Simoni, J. M. (2008). After the fall from grace: negotiation of new identities among HIV-positive women in Peru. Culture, Health and Sex, 10 (7), 739-52. 



\section{Chapter Seven}

Gender-related power differences, beliefs and reactions towards people living with HIV/AIDS: An urban study in Nigeria

BMC Public health 2010, 10:334.

Authors

Ngozi C. Mbonu

Bart van den Borne

Nanne K. De Vries 


\begin{abstract}
Aim: Although there are an increasing number of studies on HIV-related stigma in Nigeria, very little research has focused on how power differences based on gender perpetuate the stigmatization of people living with HIV/AIDS (PLWHA) and how these gender differences affect the care that PLWHA receive in health care institutions. We explore gender-related beliefs and reactions of society, including health care professionals (HCPs), with regard to PLWHA, using Connell's theoretical framework of gender and power (1987). With Connell's structural theory of gender and power (financial inequality, authority and structure of social norms), we can describe gender differences in stigmatization of PLWHA.
\end{abstract}

Method: We conducted in-depth semi-structured interviews, lasting 60 to 90 minutes, with 100 persons (40 members of the general public, $40 \mathrm{HCPs}$, and 20 PLWHA) in Port Harcourt, Nigeria. The interviews were tape-recorded and transcribed verbatim. The Nvivo 7 computer package was used to analyze the data.

Results: There are similarities and differences between the general public and HCPs towards PLWHA in gender-related beliefs and reactions. For instance, although association with promiscuity and power differences were commonly acknowledged in both groups, there are differences in how these reactions are shown; such as HCPs asking the female PLWHA to inform their partners to ensure payment of hospital bills. Women with HIV/AIDS in particular are therefore in a disadvantaged position with regard to the care they receive.

Conclusion: Despite the fact that men and women with HIV/AIDS suffer the same illness, clear disparities are apparent in the negative reaction women and men living with HIV/AIDS experience in society. We show that women's generally low status in society contributes to the extreme negative reactions to which female PLWHA are subject. The government should create policies aimed at reducing the power differences in family, society and health care systems, which would be important to decrease the gender-related differences in stigma experienced by PLWHA. Interventions should be directed at the prevailing societal norms through appropriate legislation and advocacy at grassroots level with the support of men to counter laws that put women in a disadvantaged position. Furthermore, development of a policy that encourages equality in access to health care for all patients with HIV/AIDS by applying the same conditions to both men and women in health care institutions is recommended. There is a need to protect women's rights through implementing support policies including paying attention to gender in the training of HCPs. 


\section{Introduction}

Women and girls continue to be affected disproportionately by HIV in Sub-Saharan Africa (UNAIDS, 2009). In Nigeria, the HIV prevalence rate among females aged $15-24$ years was $2.3 \%$ in 2008 while the prevalence rate among males aged 15 24years was much lower at $0.8 \%$ (World Health Organisation, 2008). According to a united nation human development report on Nigeria, the burden of HIV infection in Nigeria is borne by young people, with more females affected than males (National Human Development Report, 2004). This means that females may be more vulnerable to the medical and social consequences associated with living with HIV/AIDS, such as experiencing more negative reactions than their male counterparts in society. Ever since stigmatization has been described as a discrediting attribute (Goffman, 1963), researchers have emphasized the importance of conceptualizing stigma in terms of power differences that feed on existing inequalities in the society, such as those found in gender (Link \& Phelan, 2001; Parker \& Aggleton, 2003). While sex can be defined as the biological distinction between men and women (Turmen, 2003), Schur (1984, p. 10) describes gender as "the socio cultural and psychological shaping, patterning and evaluation of male and female behaviour" (Schur, 1984). Butler (2004, p. 42) similarly noted that "gender is a mechanism by which notions of masculinity and femininity are produced and naturalized" (Butler, 2004). It is important to understand how society, including the health care system allows gender differences in behaviour towards PLWHA. In this context, theories founded on gender become critical.

Connell (1987) elaborated one of the most integrative theories of gender (Connell, 1987). This theory is important because it allows for an understanding of the complex interplay between gender and power beyond the individual perspective. A central emphasis of this theory is that the analysis of gender involves a three-part structural model involving sexual division of labour (e.g. financial inequality), sexual division of power (e.g. authority), and the structure of affective attachments (e.g. social norms). These three structural models are the major elements of any gender order and operate with a logical complexity. Furthermore, these structural models exist at different levels (e.g. family, societal and institutional) and are maintained by social mechanisms. Connell's theory of gender and power has been shown previously to explain the gender effects in the spread of HIV/AIDS infection (Wingwood \& Diclemente, 2000; Sa \& Larsen, 2008). Sa and Larsen applied this theory in their study in Moshi, Tanzania, using gender inequality to explain women's risk of HIV infection (Sa \& Larsen, 2008). In this study, we adopt Connell's theory of gender and power as a theoretical framework to explore and clarify the gender dimension in societal beliefs and reactions towards PLWHA and in particular within the family, society and health care system in Port Harcourt, Nigeria. 
In Nigeria, power differences exist that are based on gender inequality. Although a matriarchal system co-exists with the patriarchal system in Nigeria (ThomasEmegwali, 1994), often in juxtaposition in the form of matricentric structures (Amadiume, 1997), partriarchy remains the dominant ideology (Odimegwu \& Okemgbo, 2008). Furthermore, a recent United Nations Development report shows that gender inequality in Nigeria is fuelled by socio-cultural practices, patriarchy among other reasons (UNDP, 2009). The patriarchal system in Nigeria uses inheritance customs to place women at a relative disadvantage (Kolawale, 1997), while its structures and processes position women as men's property, perpetuating female subordination (Omorodion, 2007). These inequalities are associated with inheritance laws that restrict the transfer of property and wealth to males (Olunloyo, 1993). Women do not inherit land in many cultures in Nigeria (UNDP, 2009). The inheritance laws that favour men place women in economically disadvantaged positions, which make women more vulnerable to infection with HIV/AIDS and its problems. Research carried out among HIV-positive women in Abia state, Nigeria, showed that $86.7 \%$ of the women in the study were denied rights to family resources (Enwereji, 2008). It is also generally accepted that sons provide continuity of the family name in this patriarchal system (Olunloyo, 1993; IsiugoAbanihe, 1994; Ezumah, 2003). Men are cast as strong-willed and associated with power and leadership; sexual activity is represented as a central marker of masculinity, and is thus portrayed as normal and proper (Achebe, 1958; Izugbara, 2008). Conversely, women are expected to be soft, subservient and gentle (Ozumba, 2005). The gender roles in some cases are so well defined that if the males should go into areas meant for females, it is regarded as abomination (Ozumba, 2005). Amadiume (1997) argues that the traditional gender roles and systems in Nigeria, have been eroded with the changes over time (Amadiume, 1997), leaving poor women in even more vulnerable positions. While not all cultures have such clearly defined gender roles, many other societies, like those in the Middle East and North Africa, show tolerance of men having multiple partners while encouraging women to practise lifelong fidelity (Shawky, Soliman \& Sawires, 2009). Furthermore, a study carried out in Namibia shows that people consider men having more than one wife as a right and necessity while multiple sexual partners are part of the tradition (Brown, Sorrell \& Raffaelli, 2005). There is a need to understand socially constructed ideas of gender issues as they relate to sexual behaviour (Boileau et al., 2008) which may help to find solutions for prevention and for the care of PLWHA.

Despite the fact that studies show that there is discrimination against males living with HIV/AIDS (Pallikadavath, Garda, Apte, Freedman \& Stones, 2005), and especially against males who have sex with males (Liu \& Choi, 2006; Zhou, 2006; Okal et al., 2009), Schwartz and Rutter (1998) argue that the punishments for female sexual transgression are swifter, stronger, and more public compared with punishments for males (Schwartz \& Rutter, 1998). In a presentation given at the 2004 Bangkok XV International AIDS conference, a female person living with 
HIV/AIDS from South Africa poignantly highlighted issues of violence and abuse, among others, in her relationship with her partner, following disclosure of her positive HIV status (Mthembu, 2004). Another study carried out in Chennai, India, among female sex workers showed that they feared the adverse consequences of disclosure of their positive HIV statuses due to the stigma and discrimination associated with HIV and sex work (Chakrapani et al., 2009). Other studies (Strebel et al., 2006; Chan, Rungpueng \& Reidpath, 2009; Sandelowski, Barroso \& Voils, 2009; Subramanian, Gupte, Dorairaj, Periannan \& Mathai, 2009) have pointed out that gender and power differences affect the stigmatization of PLWHA. In Nigeria, there is a growing amount of literature on HIV/AIDS and gender (Smith, 2007; Desilva et al., 2009; Oyediran, Isiugo-Abanihe, Feyisetan \& Ishola, 2009); however, these studies have not considered the gender perspectives that become manifest in differential negative reactions towards PLWHA in society, including in the health care system. Therefore it is important to understand the implications of the dominant male gender norms in Nigerian society as they affect women with respect to HIV/AIDS.

In this paper, our principal objectives are twofold; first, we aim to identify the causes of gender-related differences in societal beliefs and reactions towards men and women living with HIV/AIDS in Port Harcourt, Nigeria. Second, we analyze the impact on the persistence of problems of HIV infection and care for PLWHA in society, including the health care system. To achieve these objectives, we draw on information from the general public, HCPs, and PLWHA and we use Connell's theory of gender and power (1987).

\section{Methods}

A total of 100 in-depth interviews were conducted with 40 people from the general public, 40 HCPs and 20 PLWHA in Port Harcourt, Rivers State, Nigeria. These three different populations coincide with Connell's gender and power theory, which explores gender-related differences at different levels: family level (PLWHA), societal level (the general public) and health care institution level (HCPs). We compared results obtained from the three groups. For the general public, a convenience sample of persons (16 males and 24 females) was used in a multivenue street-intercept interview technique. A purposive sample of 20 adults living with HIV/AIDS (8 males and 12 females) who were receiving care and counseling from a resource centre in Port Harcourt was also interviewed. The study also used a convenience purposive sample for HCPs. HCPs from five private hospitals and one government health facility participated in the study. A total of $40 \mathrm{HCPs}$ (20 doctors, 15 nurses, and 5 laboratory scientists; 15 males and 25 females) were interviewed. Table 1 (A,B,C) shows the data of the participants. Many of the HCPs interviewed were working concurrently in private and government hospitals, therefore there was some crossover information about their experiences. A semi-structured interview 
guide was developed on the basis of a literature review in the areas of gender issues, HIV/AIDS and stigma. The study was carried out in the English language. The study was approved by the Rivers State Agency for the control of HIV/AIDS which acted as ethics committee.

Table 1A showing data of the general public

\begin{tabular}{|c|c|c|c|c|}
\hline Participant & Gender & Marital Status & Types Of Work & Tribe \\
\hline 1 & Female & Single & Company Worker & Efik \\
\hline 2 & Male & Married & Police Officer & Kalabari \\
\hline 3 & Female & Married & Legal Practitioner & Efik \\
\hline 4 & Female & Married & Legal Practitioner & Ibo \\
\hline 5 & Female & Married & Sales Woman & Ibo \\
\hline 6 & Female & Married & Teacher & Yoruba \\
\hline 7 & Female & Married & Teacher & Ibo \\
\hline 8 & Male & Single & Company Worker & Yoruba \\
\hline 9 & Female & Single & Motor Company & Ibo \\
\hline 10 & Male & Married & Manager & Yoruba \\
\hline 11 & Female & Single & Manager & Efik \\
\hline 12 & Male & Married & Supervisor & Ibo \\
\hline 13 & Male & Single & Manager & Efik \\
\hline 14 & Female & Single & Office Secretary & Ibo \\
\hline 15 & Female & Single & Hair Dresser & Ibo \\
\hline 16 & Male & Single & Company Worker & Efik \\
\hline 17 & Female & Single & Company Worker & Efik \\
\hline 18 & Female & Single & Company Worker & Ibo \\
\hline 19 & Female & Single & Company Worker & Ibo \\
\hline 20 & Male & Single & Company Worker & Ibo \\
\hline 21 & Female & Married & Company Worker & Ibo \\
\hline 22 & Male & Married & Police Officer & Efik \\
\hline 23 & Female & Married & Legal Practitioner & Efik \\
\hline 24 & Female & Married & Manager & Yoruba \\
\hline 25 & Female & Married & Teacher & Ibibio \\
\hline 26 & Male & Married & Businessman & Ibo \\
\hline 27 & Male & Married & Manager & Yoruba \\
\hline 28 & Female & Single & Computer Analyst & Yoruba \\
\hline 29 & Female & Married & Shop Owner & Ibo \\
\hline 30 & Male & Married & Government Worker & Ibo \\
\hline 31 & Male & Married & Company Worker & Efik \\
\hline 32 & Male & Single & Restaurant Worker & Efik \\
\hline 33 & Male & Single & Company Worker & Ibo \\
\hline 34 & Female & Married & Insurance Worker & Ibo \\
\hline 35 & Female & Married & Motor Company Worker & Ibo \\
\hline 36 & Female & Single & Student & Ibo \\
\hline 37 & Female & Single & Student & Efik \\
\hline 38 & Male & Single & Student & Efik \\
\hline 39 & Male & Single & Student & Ibo \\
\hline 40 & Female & Married & Surveyor & Yoruba \\
\hline
\end{tabular}


Table 1B showing data of health care professionals

\begin{tabular}{|c|c|c|c|}
\hline Participant & Gender & Marital Status & Types Of Work \\
\hline 1 & Male & Married & Medical Doctor \\
\hline 2 & Female & Married & Nurse \\
\hline 3 & Male & Single & Medical Doctor \\
\hline 4 & Female & Married & Medical Doctor \\
\hline 5 & Female & Married & Nurse \\
\hline 6 & Male & Married & Medical Doctor \\
\hline 7 & Male & Single & Medical Doctor \\
\hline 8 & Female & Single & Nurse \\
\hline 9 & Female & Married & Laboratory Scientist \\
\hline 10 & Male & Married & Medical Doctor \\
\hline 11 & Male & Married & Medical Doctor \\
\hline 12 & Female & Married & Medical Doctor \\
\hline 13 & Female & Married & Nurse \\
\hline 14 & Male & Married & Medical Doctor \\
\hline 15 & Female & Married & Medical Doctor \\
\hline 16 & Female & Married & Medical Doctor \\
\hline 17 & Female & Married & Nurse \\
\hline 18 & Male & Single & Medical Doctor \\
\hline 19 & Female & Married & Medical Doctor \\
\hline 20 & Female & Married & Medical Doctor \\
\hline 21 & Female & Married & Nurse \\
\hline 22 & Male & Married & Medical Doctor \\
\hline 23 & Female & Married & Nurse \\
\hline 24 & Female & Single & Medical Doctor \\
\hline 25 & Female & Married & Nurse \\
\hline 26 & Female & Single & Nurse \\
\hline 27 & Female & Married & Medical Doctor \\
\hline 28 & Male & Single & Nurse \\
\hline 29 & Male & Married & Nurse \\
\hline 30 & Male & Married & Nurse \\
\hline 31 & Female & Married & Laboratory Scientist \\
\hline 32 & Female & Single & Nurse \\
\hline 33 & Female & Married & Laboratory Scientist \\
\hline 34 & Male & Married & Medical Doctor \\
\hline 35 & Female & Married & Laboratory Scientist \\
\hline 36 & Female & Married & Nurse \\
\hline 37 & Male & Single & Medical Doctor \\
\hline 38 & Female & Single & Nurse \\
\hline 39 & Male & Single & Laboratory Scientist \\
\hline 40 & Female & Married & Medical Doctor \\
\hline
\end{tabular}


Table 1C showing data of persons with HIV/AIDS

\begin{tabular}{|c|c|c|c|c|c|c|}
\hline Participant & Gender & & Types Of Work & HIV test & Age & ART status \\
\hline 1 & Female & Widow & $\begin{array}{l}\text { Government } \\
\text { Worker }\end{array}$ & $\begin{array}{l}\text { went for test after the } \\
\text { Husband was sick } \\
\text { with HIV }\end{array}$ & 40 years & On ART \\
\hline 2 & Female & Widow & $\begin{array}{l}\text { Government } \\
\text { Worker }\end{array}$ & $\begin{array}{l}\text { went for test after the } \\
\text { Husband was sick } \\
\text { with HIV }\end{array}$ & 44 years & On ART \\
\hline 3 & Female & Single & $\begin{array}{l}\text { Office Worker in } \\
\text { Company now } \\
\text { unemployed }\end{array}$ & $\begin{array}{l}\text { was sick and went for } \\
\text { test afterwards }\end{array}$ & 24 years & $\begin{array}{l}\text { Not yet on ART } \\
\text { because of no } \\
\text { Money }\end{array}$ \\
\hline 4 & Female & Single & Company Worker & $\begin{array}{l}\text { was sick and was sent } \\
\text { for testing }\end{array}$ & 39 years & On ART \\
\hline 5 & Female & Widow & $\begin{array}{l}\text { Government } \\
\text { Worker }\end{array}$ & $\begin{array}{l}\text { went for test after the } \\
\text { husband was dying } \\
\text { From HIV }\end{array}$ & 45 years & On ART \\
\hline 6 & Male & Single & $\begin{array}{l}\text { Private Office } \\
\text { Worker }\end{array}$ & $\begin{array}{l}\text { sent for test after } \\
\text { being sick }\end{array}$ & 35 years & $\begin{array}{l}\text { Take herbs, Fruits, } \\
\text { and Vegetables he } \\
\text { stopped ART } \\
\text { Reacts to ART }\end{array}$ \\
\hline 7 & Female & Married & $\begin{array}{l}\text { Housewife(husband } \\
\text { lost job) }\end{array}$ & $\begin{array}{l}\text { during delivery of } \\
\text { baby }\end{array}$ & 29 years & On ART \\
\hline 8 & Female & Married & Housewife & $\begin{array}{l}\text { during delivery of } \\
\text { baby }\end{array}$ & 27 years & On ART \\
\hline 9 & Female & Widow & Petty trader & $\begin{array}{l}\text { went for test after } \\
\text { husband died from } \\
\text { HIV/AIDS }\end{array}$ & 38 years & On ART \\
\hline 10 & Male & Separated & $\begin{array}{l}\text { Government } \\
\text { Worker }\end{array}$ & $\begin{array}{l}\text { sent for test after } \\
\text { sickness }\end{array}$ & 41 years & On ART \\
\hline 11 & Female & Married & Unemployed & $\begin{array}{l}\text { went for test during } \\
\text { delivery }\end{array}$ & 29 years & On ART \\
\hline 12 & Female & Widow & $\begin{array}{l}\text { Government } \\
\text { Worker }\end{array}$ & $\begin{array}{l}\text { Pre-operative test } \\
\text { screening }\end{array}$ & 45 years & On ART \\
\hline 13 & Female & Widow & Secretary (lost job) & $\begin{array}{l}\text { Got sick and sent for } \\
\text { test }\end{array}$ & 40 years & On ART \\
\hline 14 & Female & Married & Company worker & $\begin{array}{l}\text { Got sick and sent for } \\
\text { test }\end{array}$ & 48 years & On ART \\
\hline 15 & Male & Single & Banker & $\begin{array}{l}\text { Got sick and sent for } \\
\text { test }\end{array}$ & 40 years & On ART \\
\hline 16 & Male & Married & $\begin{array}{l}\text { Government } \\
\text { worker }\end{array}$ & Got sick and tested & 38 years & On ART \\
\hline 17 & Female & Widow & Petty trader & Husband was sick & 47 years & On ART \\
\hline 18 & Male & Single & $\begin{array}{l}\text { Government } \\
\text { worker }\end{array}$ & $\begin{array}{l}\text { Was sick and went } \\
\text { for test }\end{array}$ & 28 years & On ART \\
\hline 19 & Male & Single & $\begin{array}{l}\text { Company } \\
\text { worker(lost job) }\end{array}$ & Company screening & 35 years & On ART \\
\hline 20 & Male & Married & Unemployed & Was sick and tested & 29 years & On ART \\
\hline
\end{tabular}




\section{Data Analysis}

Interview data were analysed and interpreted using content analysis in which the main ideas were grouped into emerging themes. Nvivo software was used in the analysis. Coding was done by the first author. To check the reliability of coding, an independent researcher coded a random selection of data. When compared, the coding by the first author and the independent researcher showed only a few differences. The few new meanings and discrepancies were discussed and reanalysis of the transcript resulted in fine-tuning of coding and interpretations.

\section{Results}

To organise our findings, we grouped the categories of statements according to Connell's theory of gender and power (Connell, 1987). Figure 1 applies the threepart structural model to our study. The sexual division of labour, the sexual division of power and the structure of affective attachments are represented as financial inequality, authority and the structure of social norms respectively; these are causes of power differences, while the effects of these power differences are apparent at the level of family, society and health care systems. We will first examine the three structures (financial inequality, authority, and structure of social norms) as shown in Figure 1 and how they complement and interact with one another to create power differences that affect the care of and reactions towards male and female PLWHA. Subsequently, we explore the effect of the power differences in our domain of interest at the level of family, society and health care systems.

\section{Financial inequality}

As shown in [a] of Figure 1, one critical aspect of the structural theory regarding gender analysis deals with financial inequality. Financial inequality causes power differences. Our participants mentioned that women often depend on their husbands for money. Women's low financial status makes them even more vulnerable than men. In Nigeria, there are many women who depend on men for financial support and this makes women vulnerable to HIV infection. For instance, a participant from the general public explained about a HIV-positive woman she knows:

'People blame the woman I know with HIVIAIDS. I think the woman got her $H I V$ due to poverty because the woman was not having anybody to care for her, so I think she must have met other men to help her out.' (Female, married, business woman) 


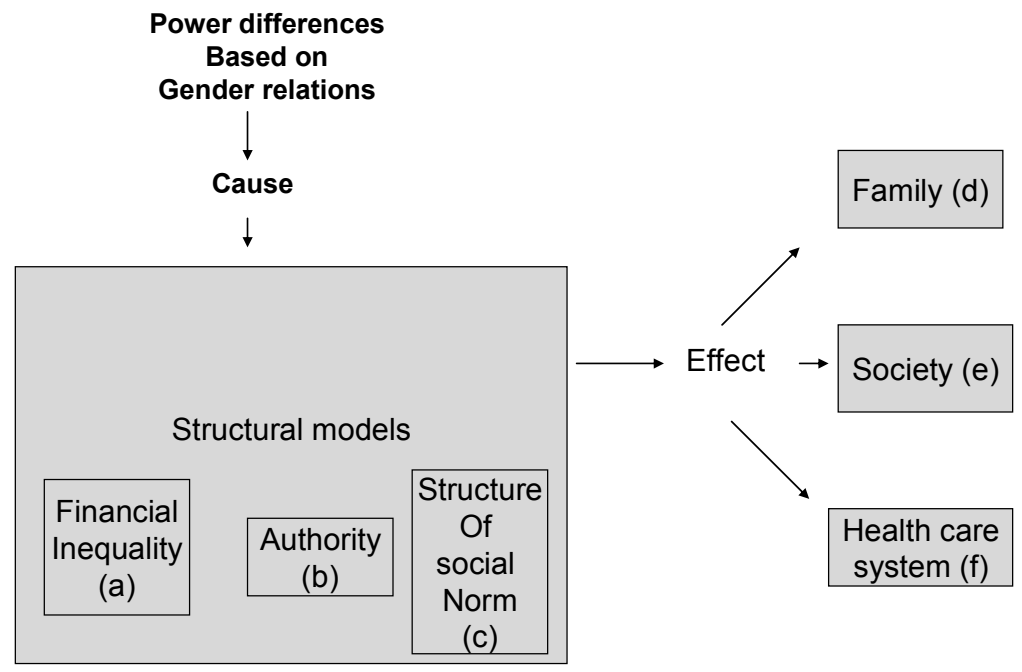

Figure 1 Showing Connell's theory of gender and power

Even after becoming infected with HIV, women are still more vulnerable because they lack proper financial means to pay for proper care. This vulnerability of women prevents them from questioning their husbands, for instance, when the men are going out with other women:

'Females are a lot more dependent. They depend on their husbands for money to buy drugs, so basically female patients are at a great disadvantage. Most of them are afraid of losing their husbands that are bringing in the money.' (Male, married, medical doctor)

A power difference due to the financial inequality between male and female PLWHA is therefore apparent.

\section{Authority}

Another fundamental part of the structural theory (see [b] in Figure 1) involves control in relationships and authority. There was a clear recognition by the participants that there are power differences in the exercise of authority between men and women in society. Many participants reported that, in Nigeria, men are placed higher than women and this contributes to the manner in which society treats male and female PLWHA. They mentioned that women are always marginalized in one way or another. Either as a cause or as a consequence of the power difference, men have a domineering attitude. Some participants said that a higher level of education and enlightenment reduces the domineering effect; it is worse among uneducated people or those of average education. Men's dominant authority also gives them greater ability to hide things, such as their HIV-positive status, from 
people - including their wives. In some cases, women who are pregnant find out about their HIV-positive status only when they go to hospital for routine antenatal care or delivery. There are a number of possible explanations why men are able to hide their HIV status. First, men take the decisions in the family and most of the time they do not need the support of their wives before seeking care. Second, wives cannot question men if the men choose not to disclose their HIV status. This participant, who is a female HIV-positive patient, was helpless after discovering her HIV-positive status long after her husband was dead:

'Imagine how my husband hid his HIV status from me so I now have HIV/AIDS from him. If I was a man, I would not be in this condition because I would know myself.' (Female, widow, government worker)

In contrast, a woman with HIV may not be able to hide her status because she needs the support of her husband. This has implications for women in terms of becoming infected, seeking early treatment, and their future care.

\section{Structure of the social norms}

Another basic part of the theory presented (see [c] in Figure 1) involves the structure of social norms. Power differences manifest themselves by the way the social norms are shaped. Our participants mentioned that the man is the head of the family and the woman is the caregiver. Women cook and give the best part of the food to their husbands, even when they are sick. Some participants mentioned that a woman's role is to care for the family and that she does so when her husband is admitted to hospital:

'Here you hardly find any wives who abandon their husbands. Look, here in the male wards, you see their wives by the bedside, but when you go to the female ward, it changes. You hardly see their husbands.' (Female, married, nurse)

The social norms prescribe men to go to work and therefore they are not expected to stay by the bedside. Most men need to continue providing for their families even when their wives are sick; in contrast, most married women are housewives, so they are expected to stay in the wards with their sick husbands. Women are observed "managing the situation" because many have no choice other than to stay within the family relation, since most of the time they are dependent on their husbands and like to support their husbands in all possible ways to enable them to recover fast and go back to work. Women protect the family by ensuring that difficult situations are managed. For example, one of the participants from the general public recounted the differences:

'The woman will have more problems at home. If a man has HIV, nobody may hear about it because when he comes home to stay, the wife will not open her mouth to talk about it. She will find a way of managing the situation, but if it is a woman that has it, the first thing the man will do will be to send the woman 
away from the house, unless it can be proved beyond reasonable doubt that the woman got it from her husband, otherwise there is no remedy for such situation.' (Female, married, legal practitioner)

The care-giving role of a woman in the family seems to be a priority concern for female PLWHA even when they are ill:

'It is not the same thing between man and woman with HIV/AIDS because, for instance, when I told this to my relative, the first thing she said was, "Oh, what if her husband hears about her HIV status? What about her children?" I do not think a man would react like that. I do not think a man would bother about what his wife's family will think about his HIV status.' (Female, married, legal practitioner)

The care-giving responsibilities of women in general sometimes conflict with their own health. For HIV-positive women, the care-giving role becomes complex because they struggle to continue with their role in the family and at the same time deal with problems associated with HIV/AIDS. This affects their ability to seek care in health-care institutions. Although female PLWHA try to care for their families, a medical doctor mentioned that male HIV/AIDS patients have a comparable fear about their social role, that they risk losing their responsibility to be sources of livelihood for the family. This problem was also observed by another health care worker:

'The problem is that some of the HIV patients who are family men care for their family, but their family scatter once they are admitted to hospital. There is now the problem of providing money for the family.' (Female, married, nurse)

Men are more concerned with providing income for their families, while women are concerned with efforts aimed at trying to avoid losing their partners. A woman may be sent away by her husband since the woman has left her own family's house to move into the man's family's house, so it is always possible for him to ask her to leave it.

Another important aspect of the structure of social norms, according to our participants, is the general beliefs about sexual roles in society. Men are allowed more sexual contacts while women are expected to be faithful. This creates a double standard because, on the one hand, society believes that PLWHA contracted HIV through sex and that therefore they must have been promiscuous, but on the other hand, society allows men more sexual indiscretions while expecting women to keep to one partner. Society also prescribes these female monogamous sexual roles and further accuses HIV-positive women of transgressing the rules and being promiscuous. Many participants expressed the view that females are often viewed as agents of HIV transmission, while men are seen as the victims. These participants from the general public tried to explain how women are looked on as vectors: 
I believe if a woman gets HIV/AIDS it will be worse. People will discriminate against her more than a man. In Nigeria, some people do not believe a man can carry HIV/AIDS; they say it is only women.' (Female, single, company worker)

'The person I know with HIV is a woman. It will be different from a man with $H I V$ because people will not think immediately of sex as a cause of the HIV; they will think he got it from the barber's salon.' (Female, single, company worker)

Furthermore, a HIV-positive participant mentioned the pressure she experiences with regard to the marriage issue:

'My husband has died from HIV/AIDS and his family and people do not know what killed him. After my husband died, people started asking me why I do not want to get another man. I said in my heart, if only they know what I have, they will not talk to me again.' (Female, widow, government worker)

Apparently, people feel that, since her husband is dead, she needs a man to continue giving her support. We will examine how these three structures in Figure 1, which create power differences for male and female PLWHA, affect family, societal and health care systems.

Family system

First, as shown in [d] of Figure 1, the effect of power differences manifests itself in the family. This means that women accept whatever situation they find themselves in at home in order to keep their men, who are the source of livelihood, while risking becoming infected with HIV/AIDS by their partners. Additionally, keeping their partners is important for women who are taking anti-retroviral therapy (ART) because they need money to buy the drugs. Other HIV-positive women simply cannot afford the ART:

'I have not started taking antiretroviral treatment because I have no money.' (Female, single, office worker)

Another participant who is an HCP mentioned his experience in practice of how a discovery of positive HIV status can affect marriage:

'The sex of the HIV person matters. The few patients I have with a woman HIVpositive and the man HIV-negative, it is hell for the woman, even if they have been sleeping together before the HIV test. As we were trying to console one woman who tested positive for HIV, we looked around for the man; he was gone through the window. They had been sleeping together since six months ago. I was shocked that he could not show a little sympathy.' (Male, single, medical doctor) 
Sometimes when a woman seems to be sure of herself in knowing that she has been faithful to her husband, she can react differently, as mentioned by this participant who is an HCP:

'Before we wanted to discharge a HIV woman, she said we can call her husband and tell her husband everything about her HIV status. Maybe in her mind she knew she has been faithful to her husband and there was no history of blood transfusion, and if she has that kind of disease, the husband must have given it to her.' (Female, married, medical doctor)

Such women emphasize their innocence to gain support from their spouses. Continuity of support from their spouses is very important. Furthermore, a participant who is HIV-positive attributes the negative behaviour towards her by her husband's family to the fact that her husband is not alive:

'They do not even come close to us (me and my children). I am living alone with my children; I am not happy that my husband's family behaved this way. I am suffering with the children-people are running away from us. If it was their brother living, his family may not behave that way.' (Female, widow, petty trader)

\section{Societal system}

At the societal level (see [e] in Figure 1), the effect of power differences can be found. Participants mentioned that the general belief in society is that PLWHA contracted HIV through sexual intercourse which contributes to differences in the way society treats male and female PLWHA. Many participants mentioned that women are expected to avoid premarital sex or remain faithful to their partners, so when they contract HIV, the negative reactions towards them are worse and therefore they are blamed for contracting HIV/AIDS. For instance, this participant who is HIV-positive knows this:

'People will blame me for having HIV because they will say I am a prostitute.' (Female, single, office worker)

HIV-positive women are more likely to be judged harshly by society. These participants from the general public share their own understanding of the differences:

'When a girl gets HIV, people think the girl is a flirt and got it through sexual intercourse with a man. If it is a man, the same thing, but most times they say he got it through a haircut. People will not blame the man too much, but for the woman, people blame her and say that she walks about, goes about meeting men. The difference is that they feel women are flirts.' (Female, single, company worker) 
It is better to tell government, especially for female people living with HIV and AIDS, because if you do not take care she can spread it to other male people. Some of them know they will die one day so they start flirting about; therefore government should restrict their movement.' (Male, married, company worker)

This is a manifestation of the way society shields the men under culturally acceptable excuses while justifying the difference in negative reaction towards PLWHA. Others try to prove their innocence when they contract HIV. There are instances where a female can avoid blame and accusation in the society, but she needs to prove beyond reasonable doubt her innocence in contracting HIV. A possibility of escaping accusation is demonstrated by this quote:

In very few cases the female is not blamed when the society looks at the person and feels that she is a real Christian and not the type that goes around...but if it is obvious the person got it from sex, the whole family will dump the person. Nobody will listen to her and they will not give the basic help.' (Female, married, nurse)

For married people, it is easier for the couple to protect themselves by hiding their HIV statuses, since once the society knows that one of them has HIV, it will automatically be assumed that the other partner has HIV as well. Some participants felt that even if both partners were positive, it was usually only the woman who was blamed by society:

'If a married couple is HIV-positive, the man is kept aside from blame. It is only the woman that will be blamed.' (Female, married, nurse)

This also reinforces the more negative reaction towards female PLWHA since society believes that the woman must have given it to the man. Furthermore, even when a man and a woman are both HIV positive, there is a feeling that the woman will experience more problems than the man due to the power difference.

\section{Health care system}

Third, at the level of the health care system, ([f] in Figure 1) power differences are also shown. The financial dependency of women makes them powerless and that can affect the way that female PLWHA are treated in the hospital by HCPs. This participant, who is an HCP, highlighted the importance of financial considerations when treating female HIV patients:

'One of our reasons for asking the female HIV patients to inform their sexual partner is that in this environment husbands take lots of decisions and if the patient makes demands financially or otherwise on her husband, he may not understand why the doctor does one or two things both in pregnancy and labour. Without telling the husband, the management becomes very difficult for us and I definitely object to that.' (Male, married, medical doctor) 
In Nigerian society, approval for treatment by female patients' husbands is important because of the assurance it gives to the HCPs that bills will be paid. However, this is a way of allowing gender differences to be perpetuated through the health care system. As a result, the manner in which HCPs approach female HIV patients is different from the way they treat male HIV patients. In general, male HIV patients are not obliged to inform their spouses in order to ensure payment of bills. HCPs enhance the lack of confidentiality in the hospitals for female PLWHA. This participant who is an HCP tried to give an explanation for why women cannot hide their HIV status in comparison with men:

'The woman is different because of societal pressure. If a man has HIV, people do not question him so much, so they can hide it because nobody pressures them to say anything, but when a woman gets HIV, the first thing people or a health care professional will say is, "You should tell your husband or relatives." (Male, married, medical doctor)

Furthermore, another participant, who is an HCP, emphasized the effect of decision making power of men:

'In Nigeria, this is a man's world. If a woman is HIV-positive, most times you find it difficult to get their husbands to be tested.' (Male, married, medical doctor)

These are classic examples of how gender differences are mediated through the health care system because female patients are pressured to inform their significant others, such as their partners. The expectation from society and HCPs for women to disclose to their significant others puts pressure on women, making them helpless and giving them less choice in deciding when to disclose their HIV status and to whom, while giving men the opportunity to decide when to disclose their HIV status and to whom. This also discourages women from seeking care because of their fear for disclosure.

\section{Discussion}

We have shown that Connell's theory of gender and power can explain genderrelated power differences, beliefs and reactions towards PLWHA in Port Harcourt Nigeria. Our results show how structures of financial inequality, authority relations and social norms cause power differences between male and female PLWHA. We show how the power differences perpetuate the gender differences in family, society and health care systems and highlight their impact on the persistence of HIV infection and the care of PLWHA. We show that there are similarities and differences in societal beliefs and reactions towards PLWHA between the general public, HCPs and PLWHA. In general, the association of PLWHA with promiscuity 
was common among the three groups of participants and accusations and blame were directed towards female PLWHA rather than their male counterparts.

Although the existence of power differences was commonly acknowledged among these three groups of participants and in the systems (family, societal and health care), there were, however, differences in the ways that they were shown. The general public mentioned that female PLWHA experienced more negative reactions from society than their male counterparts because the culture marginalises women, not letting them take decisions to prevent infection and to receive timely treatment and care. The HCPs persuade women to inform their partners or relatives of their HIV status, which is a type of difference in the care given to them compared with their male counterparts. For female PLWHA, disclosure of their positive HIV status to their partner or significant other has important implications. On the one hand, disclosure allows female PLWHA to get support from their partners, but on the other hand it may expose them to more risks, such as marital problems at home, especially when such disclosure is a prerequisite before treatment can be given. Moreover, our results already show that female PLWHA were worried about being expelled from the marriage once their husband knew of their HIV status. Power differences also caused some female PLWHA to be unaware of their HIV status until long after their husbands were dead, or until they were in hospital for pregnancy-related reasons. We also found differences between male and female PLWHA in the family system; the general public mentioned that female PLWHA were more concerned about their role in the family; the HCPs noted greater support by women for their husbands in the wards, while female PLWHA were worried about fulfilling this family role. Differences were also observed within marriage, where the general public mentioned that women were more likely to be blamed for contracting HIV when a couple were both HIV-positive.

Our study clearly illustrated how, in Nigerian society, gender power differences may explain why male PLWHA are in a favoured position over their female counterparts. Our findings also showed how power differences permeate in the family, society and health care system. For instance, in the health care system, our study showed that women who go to hospital are sometimes required to inform their husbands before treatment can be given to them, as a way of guaranteeing the payment of hospital bills. This has implications for the care and support that women receive in the hospitals. There are a number of possible reasons why HCPs need some guarantee of the payment bills before treatment can be started. First, there is no accessible universal health insurance that covers every Nigerian (such coverage would even be more important for women who are vulnerable). In addition, the financial contribution that even those with health insurance will have to make personally for their medical treatment is often unaffordable and thus hinders care. Second, HCPs are aware that many female PLWHA are housewives who are financially dependent on their husbands. In general, the poor economic situation with inequality, higher poverty prevalence for women, the fact that only $47 \%$ of 
women are employed compared with $86 \%$ of men and the fact that females in Nigeria have less access to micro credit and grants (UNDP, 2009) all contribute to the difference of care given to women compared with their male counterparts. Because health care institutions endeavour to make sure their bills will be paid, they place female PLWHA in vulnerable positions. The financial aspect is particularly important for private hospitals because they have a need to cover their overhead costs, including payment of staff. Although other research shows that women are increasingly taking active decisions on matters affecting their daily lives (Orubuloye, Oguntimehin \& Sadiq, 1997), men are still more domineering and take the main decisions in households (Isiugo-Abanihe, 1994; Remien, et al., 2009). In our study, we go further in reporting that men's domineering attitude is worse in families with low socio economic status, which impedes women's involvement in family decision-making that is relevant to their health. Other recent research also showed that gender inequalities in health are manifest in traditional practices which attribute women's difficulty in seeking and obtaining adequate care such as with lack of autonomy by women leading to lack of decision-making power (Remien et al., 2009).

Participants in our study reported that men who know they are HIV-positive may hide their status successfully because they do not need support from their wives to go for treatment. Non-disclosure of a positive HIV status has implications for the spread of HIV/AIDS when unprotected sex is practiced. Male PLWHAs' wives almost always protect them and help to prevent their husband's positive status becoming known to others. In contrast, if a woman is HIV-positive, her husband may choose to send her away, exposing the reason behind his actions through informing people of her HIV status.

Our participants emphasized that the link to promiscuity as well as blame comes up immediately once a woman's positive HIV status is disclosed, unlike for her male partner, whose HIV status may be linked to culturally acceptable causes, such as transmission at a barber's salon, allowing him to avoid blame. Our study and others show that HIV-positive women are more likely to be regarded as immoral and to be judged harshly by society (Sandelowski, Lambe \& Barroso, 2004; Lekas, Siegel, \& Schrimshaw, 2006; Chan, Rungpueng, \& Reidpath, 2009). The measure by which society judges these women who become infected remains outside the control of PLWHA, making them more helpless in defending themselves, especially for those who contracted HIV/AIDS through no fault of their own, such as from their partners. Moral stigma arising from the supposed relation to sex work, stigma tied to the assumption of knowingly infecting men, in addition to the general stigma related to gender, heightens the negative attitude female PLWHA experience (Infante, Aggleton \& Pridmore, 2009).

Women who are dependent are unable to seek care in the health care institutions or to procure the anti-retroviral treatment (ART) they need. Our data also show that women are unable to prevent their partners from having sexual relationships with 
other women since they are dependent on them for financial support. This is in line with a study carried out in Nigeria which shows that women's possibility to confront their husbands' infidelity or to insist on condom use is a highly charged issue (involving avoidance of pregnancy, counter-accusations and suspicions on both sides) which can threaten the marriage (Smith, 2007).

\section{Limitations}

This study provides important information on the complexities of gender-related power differences that manifests themselves in the family, society and health care institutions. However, there are a number of important limitations that should be considered when interpreting the results. An important limitation in this study is that we employed convenience samples. The street intercept method used for the general public has a disadvantage because it results in a purposeful rather than random sample, limiting external validity. PLWHA were also selectively recruited from a resource centre, where many of them had already exposed their positive HIV status. This implies that the information they gave may be different from PLWHA in the general population who are still secretive. Furthermore, we relied on participants' self-reported data. In general, the participants may not have felt free to discuss issues and therefore may have answered or discussed issues in a way they considered was socially desirable. The findings of this study cannot be generalized to other areas of the country, all health care institutions and to other populations but must be interpreted in the context in which the study was done.

\section{Conclusion}

Although both men and women suffer the same illness when they contract HIV/AIDS, there are obvious differences between men and women living with HIV/AIDS. We argue that society, including HCPs, helps to perpetuate the gender difference in reactions towards PLWHA. The gender difference is embedded in a gendered society which favours males and perpetuates power differences; these affect the care that female PLWHA receive, in family, society and health-care institutions. Although there have been social changes over time, with women gradually becoming more economically self-reliant, the majority are still very dependent on their partners. Women who are financially dependent have less power to take important decisions. They are also unable to seek HIV testing, prevention and early care, and they do not take important decisions that affect their health when they suspect they may be infected with HIV/AIDS. We further point out that health care institutions and HCPs are supposed to apply an egalitarian approach towards caring for PLWHA, but unfortunately they contribute to enhancing the gender difference because of their own need to secure their financial situation (getting paid). Gender-specific power relations and stigma clearly have a great 
impact on problems related to HIV/AIDS infection and on access to prevention and treatment, which need to be understood. More research is needed to identify the structural and systemic factors that allow gender differences to flourish in society and in the health care systems in order to develop proper policies and programmes for prevention and care.

\section{Recommendations}

This study has helped to understand gender-related power differences as conceptualized in Connell's theory of gender and power (1987). This understanding can be used for practical purposes in terms of interventions and recommendations. Any political measure that will ameliorate the social situation of women, such as the prevailing financial inequality, authority and social norms, will be beneficial. The government could increase the ability for women to pay for their drugs and increase accessibility of ART drugs free of charge. The government could help to reduce women's vulnerability to increased stigmatization in society by the development and implementation of policies that enhance and protect women's rights such as equal employment policies. The government should create more job opportunities for women through provision of access to soft loans and micro credit, that will help to reduce the financial inequality for women and thereby give them more power and authority. These policies will allow more women to be employed, improve their decision making power in the family and increase women's access to health care. Furthermore, although social norms are informal, specific steps can be taken to protect the vulnerable in society, including in health care institutions. Interventions should be directed at the prevailing societal norms which allow men to take decisions in the home. This can be achieved by appropriate legislation and advocacy at grassroots level with the support of men to counter laws that put women in a disadvantaged position. Problems female PLWHA face in health care institutions can be addressed by creating legislative measures that prevent HCPs from requiring female PLWHA to disclose their HIV status to significant others before starting treatment. It will also help to reduce the differences in reaction female PLWHA experience in health care institutions. Legislation should be enacted to protect women from some of the effects of social norms, such as the sexual roles in society that allow men to have multiple partners and expect a monogamous relationship from women. Legislation should further protect women who are sent away by their husbands in ensuring that fair assets are given to them. This will reduce the fear women have in losing their marriage and security. There should be development of a feasible health insurance policy that allows people access to health care and medication. Also, we suggest the government to develop a policy that encourages equality in access to health care for all patients with HIV/AIDS by applying the same conditions to both men and women, and not extending the prevailing social norms to the hospitals. Furthermore, attention 
should be paid to the training of HCPs to understand the culturally determinedgender differences in this respect in order to prevent stigmatizing behaviour and provide effective care for female and male patients with HIV/AIDS.

\section{References}

Amadiume, I. (1997). Reinventing Africa: matriachy, religion and culture. Zed Books: New York.

Boileau, C., Vissandjee, B., Nguyen, V.K., Rashed, S., Sylia, M., \& Zunzunegui, M.V. (2008). Gender dynamics and sexual norms among youth in Mali in the context of HIV/AIDS prevention. African Journal of Reproductive Health, 12 (3), 173-184.

Brown, J., Sorrell, J., \& Raffaelli, M. (2005). An exploratory study of constructions of masculinity, sexuality and HIV/AIDS in Namibia, Southern Africa. Culture Health and Sexuality, 7 (6), $585-$ 598.

Butler, J. (2004). Gender regulations in undoing gender. New York: Routledge.

Chakrapani, V., Newman, P.A., Shunmugam, M., Kurian, A.K., \& Dubro, R. (2009). Barriers to free antiretroviral treatment access for female sex workers in Chennai, India. AIDS Patients Care and STDs, 23 (11), 973-980.

Chan, K.Y., Rungpueng, A., \& Reidpath, D.D. (2009). AIDS and the stigma of sexual promiscuity: Thai nurses' risk perceptions of occupational exposure to HIV. Culture Health and Sexuality, 11 (4), 353-68.

Connell, R.W. (1987). Gender and power, society, the person and sexual politics. UK: Blackwell publishers.

Desilva, M.B., Merry, S.P., Fischer, P.R., Rohrer, J.E., Isichei, C.O., \& Cha, S. S. (2009). Youth, unemployment, and male gender predict mortality in AIDS patients started on HAART in Nigeria. AIDS Care, 21 (1), 70-77.

Enwereji, E. E. (2008). Sexual behavior and inheritance rights among HIV-positive women in Abia state, Nigeria. Tanzania Journal of Health Research, 10 (2), 73-78.

Ezumah, N.N. (2003). Gender issues in the prevention and control of STIs and HIV/AIDS: lessons from Awka and Agulu, Anambra State, Nigeria. African Journal of Reproductive Health, 7 (2), 89-99.

Goffman, E. (1963). Behavior in Public Places. New York: The Free Press.

Infante, C., Aggleton, P., \& Pridmore, P. (2009). Forms and determinants of migration and HIV/AIDS related stigma on the Mexican-Guatemalan border. Qualitative Health Research, 19, 1656-1668.

Isiugo-Abanihe, U.C. (1994). Reproductive motivation and family size preference among Nigerian men. Studies in Family Planning, 25 (3), 149-161.

Izugbara, C.O. (2008). Masculinity scripts and abstinence-related beliefs of rural Nigerian male youth. Journal of Sex Research, 45 (3), 262-276.

Kolawale, M.E.M. (1997). Womanism and African consciousness. In: The context of African women struggle, pg 3-43.

Lekas, H.M., Siegel, K., \& Schrimshaw, E.W. (2006). Continuities and discontinuities in the experiences of felt and enacted stigma among women with HIV/AIDS. Qualitative Health Research, 16 (9), 1165-1190.

Link, B.G., \& Phelan, J.C. (2001). Conceptualizing stigma. Annual Review of Sociology, 27, 363-385.

Liu, J. X., \& Choi, K. (2006). Experiences of social discrimination among men who have sex with men in Shanghai, China. Aids and Behavior, 10 (4), S25-33.

Mthembu, P. (2004). Bangkok 2004: Young women living with HIV/AIDS have rights too- a personal testimonial. HIV/AIDS Policy Law Review/Canadian HIV/AIDS Legal Netweork, 9, 72-74.

National Human Development Report (UNDP), (2004). National report. Retrieved 12 December, 2009 from UNDP website: www.hdr.undp.org/en/reports/nationalreports/africa/nigeria/nigeria_2004_en.pdf. 
Odimegwu, C., \& Okemgbo, C.N. (2008). Men's perceptions of masculinities and sexual health risks in Igboland, Nigeria. Retrieved 1 April 2010 from: http:/www.thefreelibrary.com/Men's+perceptions + of + masculinities + and + sexual + health + risks + in $+\ldots-$-a 0178535126

Okal, J., Luchters, S., Geibel, S., Chersich, M.F., Lango, D., \& Temmerman, M. (2009). Social context, sexual risk perceptions and stigma: HIV vulnerability among male sex workers in Mombasa, Kenya. Culture Health and Sexuality, 11 (8), 811-826.

Olunloyo, S. (1993). The girl child: a blessing or an abomination. Journal of Population Activities in Nigeria (Nigeria's Population), Oct-Dec, 41-42.

Orubuloye, I. O., Oguntimehin, F., \& Sadiq, T. (1997). Women's role in reproductive health decision making and vulnerability to STD and HIV/AIDS in Ekiti, Nigeria. Health Transition Review, 7, 329-336.

Oyediran, K., Isiugo-Abanihe, U.C., Feyisetan, B.J., \& Ishola, G.P. (2009). Prevalence of and factors associated with extramarital sex among Nigerian men. America Journal of Mens Health, PMID: 19477757

Parker, R., \& Aggleton, P. (2003). HIV and AIDS-related stigma and discrimination: a conceptual framework and implication for actions. Social Science and Medicine, 57 (1), 13-24.

Pallikadavath, S., Garda, L., Apte, H., Freedman, J., \& Stones, R.W. (2005). HIV/AIDS in rural India: context and health care needs. Journal of Biosocial Science, 37 (5), 641-655.

Remien, R.H., Chowdhury, J., Mokhbat, J.E., Soliman, C., Adawy, M.E., \& El-Sadr, W. (2009). Gender and care: access to HIV testing, care and treatment. Journal of Acquired Immune Deficiency Syndrome, 51 (3), S106-110.

Sa, Z., \& Larsen, U. (2008). Gender inequality increases women's risk of HIV infection in Moshi Tanzania. Journal of Biosocial Science, 40 (4), 505-525.

Sandelowski, M., Lambe, C., \& Barroso, J. (2004). Stigma in HIV-positive women. Journal of Nursing Scholarship, 36 (2), 122-128.

Sandelowski, M., Barroso, J., \& Voils, C.I. (2009). Gender, race, ethnicity and social class in research reports on stigma in HIV-positive women. Health Care Women International, 30 (4), 273-288.

Schur, E.M. (1984). Women and deviance: a social perspective. In: Labelling women deviant, gender, stigma, and social control. Philadelphia, USA: Temple university press.

Schwartz, P., \& Rutter, V. (1998). The gender of sexuality. USA: Pine Forge press.

Shawky, S., Soliman, C., \& Sawires, S. (2009). Gender and HIV in the Middle East and North Africa: lessons for low prevalence scenerios. Journal of Acquired Immune Deficiency Syndrome, 51(3), S73-S74.

Smith, D.J. (2007). Modern marriage, men's extramarital, sex, and HIV risk in South Eastern Nigeria. American Journal of Public Health, 97 (6), 997-1005.

Strebel, A., Crawford, M., Shefer, T., Cloete, A., Henda, N., Kaufman, M., Simbayi, L., Magome, K., \& Kalichman, S. (2006). Social constructions of gender roles, gender based violence and HIV/AIDS in two communities of the Western Cape, South Africa. Journal of Social Aspects of HIV/AIDS Research Alliance (SAHARA), 3 (3), 516-528.

Subramanian, T., Gupte, M.D., Dorairaj, V.S., Periannan, V., \& Mathai, A. K. (2009). Psycho-social impact and quality of life of people living with HIV/AIDS in South India. AIDS Care, 21 (4), 473-481.

The Joint United Nations Programme on HIV/AIDS (UNAIDS), (2009). HIV epidemic report. Retrieved 22 January 2010 from UNAIDS website: http://data.unaids.org/pub/Report/2009/Jc1700_Epi_Update_2009_en.pdf.

Thomas-Emegwali, G. (1994). Islam and gender: The Nigerian case. Retrieved 31 March 2010 from: http://www.hartford-hwp.com/archives/34a/007.html.

Turmen, T. (2003). Gender and HIV/AIDS. International Journal of Gynaecology and Obstetrics, 82 (3), 411-418. 
United Nations Development Programme (2009). 2008-2009 Nigerian report: Achieving growth with equity. Retrieved 6 April 2010 from: http://web.ng.undp.org/documents/NHDR2009/NHDR_SUMMARY_2008-2009.pdf.

Wingood, G.M., \& Diclemente, R.J. (2000). Application of the theory of gender and power to examine HIV-related exposures, risk factors and effective interventions for women. Health Education and Behaviour, 27(5), 539-565.

World Health Organisation (WHO), (2008). Nigeria epidemic report. Retrieved 12 December 2009 from WHO website: http://apps.who.int/globalatlas/predefinedreports/efs2008/full/efs2008_NG.pdf.

Zhou, Y.R. (2006). Homosexuality, seropositivity and family obligations: perspectives of HIV- infected men who have sex with men in China. Culture, Health and Sexuality, 8 (6), 487-500. 



\section{Chapter Eight}

\section{General discussion and conclusions}

Part published as abstracts

Journal of International Association of physicians in AIDS care (JIAPAC) 2010. (Abstract Nos: 63515, 60623, 63513, 63511) 
The assumption underlying the studies in this thesis is that one of the barriers to adequate care and support for people living with HIV/AIDS (PLWHA) in Nigeria is related to stigma. Although an increasing number of studies have appeared about HIV-related stigma in Nigeria (Reis et al., 2005; Babalola, 2007), these do not include the interrelationship between the different perspectives of the general public, the health care professionals (HCPs) and PLWHA themselves. This dissertation illustrates the problems of PLWHA, including stigma, from these three perspectives. The main aims of the research described in this thesis were, first, to investigate the problems of PLWHA associated with seeking and receiving care; second, to understand the role of stigma in care seeking and receiving care; and third, to explore how this affects the HCPs caring for PLWHA.

The research reported in this thesis showed that society endorses certain beliefs about HIV/AIDS and therefore people react negatively towards PLWHA which affects the quality of life of PLWHA. Our research showed that stigma discourages proper care-seeking behavior of PLWHA such as attending health-care institutions in Port Harcourt, Nigeria. Using a model to explain the role of stigma and careseeking behavior of PLWHA in Sub-Saharan Africa, we found that although both men and women suffer from HIV/AIDS, there are differences in reactions to PLWHA depending on their gender. HCPs are also not exempt from stigmatization towards PLWHA. In this chapter, we will put our main findings into perspective. Finally, we discuss methodological issues, public health implications, and implications for future research. We also make recommendations for health care practice and health policy. The main results discussed are structured by the specific research questions for this dissertation.

\section{Main results}

The research reported in this thesis showed that findings about HIV-related stigma in Port Harcourt, Nigeria, are similar to the findings from our review of the literature on Sub-Saharan Africa and similar to the findings from other parts of the world such as Australia (Korner, 2007), China (Hong et al., 2008; Li et al., 2008), the United States of America (Derlega et al., 2008; Darrow et al., 2009; Larios et al., 2009; Nanin et al., 2009; Wilson \& Moore, 2009) and Canada (Groft \& Robinson, 2007). This shows that stigmatization is a global phenomenon and is not restricted to any geographical region. Although our study indicates similar findings about HIV-related stigma to the findings from other parts of the world, we show in the context of Nigerian society how HIV-stigma processes develop, how HIV stigma impacts on PLWHA seeking care in healthcare institutions and how genderrelated power differences affect caring for PLWHA. A model that explains the relationship between stigma and health care-seeking behavior of PLWHA in SubSaharan Africa was built from one of the studies in this thesis and will be used to analyze the findings in this discussion. 


\section{Model}

In Chapter 3, we depicted and described a model (see Figure 1) for understanding the relationship between stigma and health care-seeking behavior of PLWHA in Sub-Saharan Africa. Although the model could not be empirically tested, it nevertheless emerged as functional for predictions to be derived. In this model, we hypothesized that care seeking behavior of PLWHA influenced by stigma is a function of various factors that should be considered from a wider social structural context including society, PLWHA and HCPs. The factors identified in the model include psychosocial determinant variables (beliefs, knowledge, and self-efficacy) and moderating variables (poverty, gender, age, religion and policy). Gender was particularly important in our study, therefore one of the research questions focused on gender. Below we will briefly discuss the research questions bringing evidence from different chapters, linking to the variables from the model.

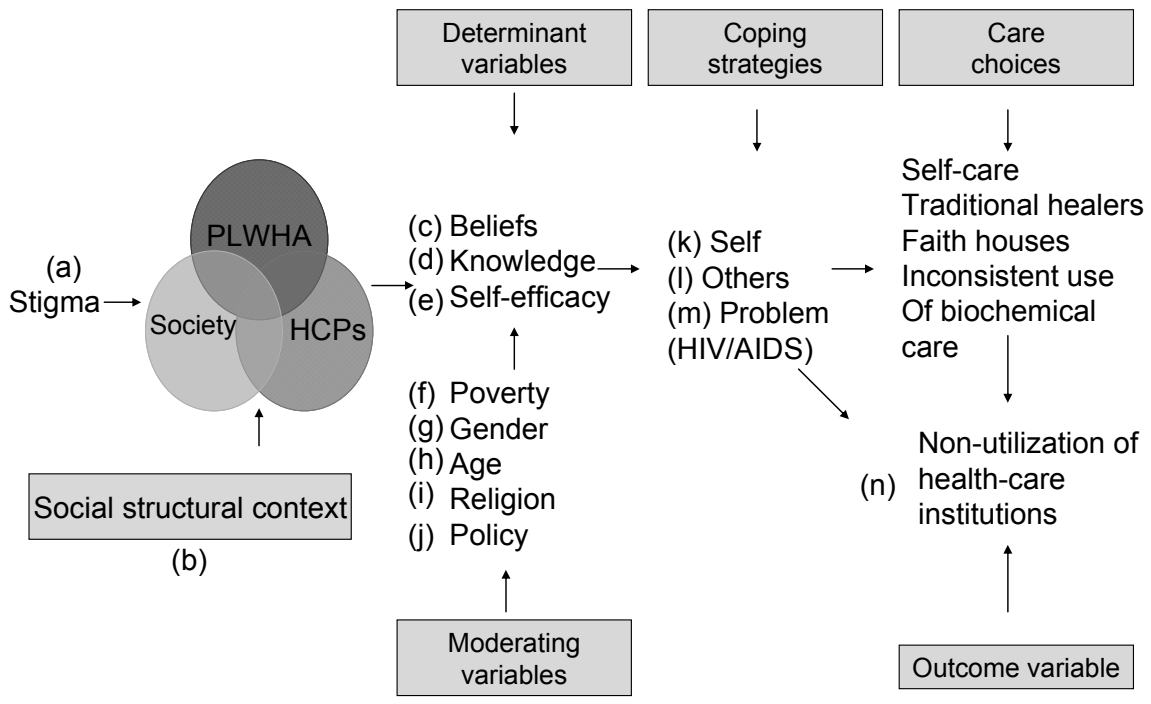

Figure 1: Explanatory model of role of stigma in care-seeking behaviour.

Mbonu, Van den Borne, \& De Vries, 2009

What are the underlying factors that allow stigma to occur in society?

There is a general idea about behavior of PLWHA in society (e.g. link to sexuality) that makes people feel that PLWHA, especially women, have transgressed the societal norm which leads to PLWHA being socially isolated. Our study clearly shows that PLWHA experience stigmatization in society and in health care institutions which affects care seeking. We will use the variables derived from the model in Chapter $\mathbf{3}$ to evaluate the factors that allow stigma to function in society. 
Beliefs: Our findings show that the beliefs about HIV infection, e.g., the cultural constructions of HIV based on contamination routes and the presumptions about the behavior of persons with HIV (e.g. sexuality) contribute to stigmatization in society. One major issue which was apparent in all our studies is the link that society including HCPs builds between stigmatization and unacceptable social behaviors such as prostitution or having indiscriminate sex. These popular beliefs make society blame PLWHA personally for their condition and therefore stigmatize them. These findings support findings from elsewhere. For instance, in a study carried out in Vietnam, stigma was found to be a result from linking HIV/AIDS to prostitution and illegal drug use (Gaudine et al., 2009). Similarly, a study carried out among inmates and staff in a state prison in the USA showed that negative attitudes towards drug use were positively correlated with AIDS stigma (Derlega et al., 2008). Likewise, studies have also shown the link between stigmatization and socially unaccepted behavior such as homosexuality (Terto, 1999; Anderson et al., 2008). Our study and these studies reflect the significance of culturally unacceptable behavior which is linked to stigmatization.

Knowledge: Lack of or inadequate knowledge about HIV and AIDS including the physical signs, HIV transmission and effective treatment contribute to stigmatization of PLWHA. For instance, we showed that knowledge of a person infected with HIV/AIDS based on information or physical body signs associated with HIV/AIDS, whether true or false, can generate negative reactions. People in society, including HCPs, make judgements based on images of PLWHA which allow stigma to function. For instance, PLWHA who are of normal weight or heavy-weighted or are on ART without any visible heuristic signs linked to HIV/AIDS, are often believed not to be HIV positive and therefore do not experience societal stigmatization (Chapter 3; Chapter 4, pg 68; Chapter 6, pg 119). The fact that many PLWHA disclose their positive HIV status only at the moment when they are dying (Maughan-Brown, 2010) reinforces the image that society has about PLWHA as a rapidly fatal disease and this encourages subjective judgment. Furthermore, some HCPs avoid the use of general universal precautions on patients they suspect (based on physical and clinical signs) are without HIV/AIDS (Chapter 5, pg 91; Chapter 5, pg 92). Selective universal precautionary measures imply that HCPs will always have a risk of contracting HIV in the course of their work.. It is also associated with difference in care given to patients with HIV and patients without HIV encouraging stigmatization. Similar results was also found in a study in Malawi which showed that health care workers are reluctant to use gloves when they assume the patient under their care is free from HIV virus thereby risking infection (Talashek et al., 2007).

Self-efficacy: People (partners and family) need high self-efficacy to avoid stigmatization of PLWHA which will enable them to continue care of PLWHA even if others know about it. On the other hand, having low self-efficacy implies that people are more likely to stigmatize PLWHA. Moreover, our study shows that 
some HCPs worry about their family when caring for a person with HIV/AIDS and this encourages stigmatization of PLWHA (Chapter 5, pg 94). Caregivers of PLWHA (professional or civil) need high self-efficacy to be able to give care despite stigmatization in society.

Poverty: Poverty only worsens the stigmatization of poor people who are often looked down upon in the society. For instance, funds allocated for the care of a person living with HIV/AIDS was diverted for personal use by the relatives, due to poverty in the family (Chapter 4, pg 70). Also the financial contribution that even those with health insurance will personally have to make for medical treatment hinders PLWHA from seeking care. Although in Nigeria, the communal networks for care and support are strong, the enormous discrepancy between the rich and poor in Nigeria implies that the financial aspects of having HIV mainly affect the poor. A study carried out among PLWHA in Plateau State, Nigeria receiving homebased care showed lack of money, food and transport to health care facilities as one of the major challenges PLWHA and their carers faced (Agbonyitor, 2009). Moreover, since there is no universal health insurance that is accessible to all in Nigeria, HCPs in health care institutions enhance the stigmatization of PLWHA by avoiding giving care to PLWHA who may not be able to afford the fees in hospitals (Chapter 5, pg 96). Castro and Farmer (2005) concluded that poverty, already representing universal stigma is one of the primary reasons that poor people living with HIV/AIDS suffer from greater AIDS-related stigma (Castro \& Farmer, 2005).

Age: Our findings suggest that young people especially stigmatize PLWHA. For instance, we show that young people who are looking forward to marriage may stigmatize PLWHA due to their fear of societal judgement and negative social reactions (Chapter 4, pg 69). These findings add to the results from South Africa which show that stigma increased among young adults in Cape Town between 2003 and 2006 (Maughan-Brown, 2010). The youths in that study reported instrumental stigma, such as avoiding touching a person with HIV/AIDS out of fear of contracting HIV.

Religion: Although our findings show the supportive role of religious institutions, the role of religion in stigmatization of PLWHA was equally apparent in our studies. We found, in different chapters, evidences linking religious institutions with stigmatization. For instance, we found that there is a compulsory HIV screening of couples who wish to be married in some churches, and subsequent relegation to the back seats in the church of couples whose HIV status turns out positive (Chapter 4, pg 71). Others are excommunicated based on their positive HIV status (Chapter 2, pg 36). Furthermore, there is no standard law for the protection of privacy in churches, giving room for the church committee and members to gossip about the results of HIV tests (Chapter 4, pg 72). A study carried out in Ghana among pastors, marriage counselors and members of Pentecostal churches showed that pastors expressed concern about the privacy and protection of confidentiality for members after positive HIV test results (Luginaah, 
Yiridoe \& Taabazuing, 2005). PLWHA who are members of churches are conscious of such gossip and so they take steps to protect themselves by hiding their HIV status (Chapter 6, pg 117).

Policy: Our findings indicate that the absence of an effective policy that covers institutions such as media and health care institutions contributes to the stigmatization of PLWHA. For instance, we found that there are still myths about the transmission of HIV in society, such as sharing toilet seats with PLWHA (Chapter 4 pg 73). This encourages stigmatization due to fear of contracting HIV. The negative image in the media, in which HIV/AIDS is linked to behavior that is unacceptable in society, encourages stigmatization. In addition, the way the media present HIV/AIDS messages was found to contribute to people stigmatizing PLWHA. For instance, messages such as that people can and should take precautions to guard against contracting HIV/AIDS shifts the responsibility for contracting the infection to the individual, making HIV/AIDS a disease of "others", further encouraging stigmatization. This result lends support to the findings in a study carried out in Vietnam, which shows that negative representation was fostered by a public health campaign in the media that used negative images of death and disease to try to scare people into avoiding high-risk behavior (Thi et al., 2008). Our findings and those of other studies point to the need for continual education of people about HIV/AIDS and its care.

What makes PLWHA refrain from seeking timely and proper care in health care institutions?

To address what inhibits PLWHA from seeking timely and proper care in health care institutions, the following specific questions will be discussed: What is the role of stigma in the care-seeking behavior of PLWHA? What are the determinants of care-seeking?

\section{What is the role of stigma in the care-seeking behavior of PLWHA?}

The model in Chapter 3 clearly illustrate that stigma plays a role in the relationship between PLWHA, on the one hand, and society, including HCPs on the other, leading to problems in seeking care. Importantly, besides society and HCPs stigmatizing PLWHA, PLWHA also stigmatize themselves which affects their careseeking behavior as well. This relationship became clear in different parts of our studies. We argue that, in addition to stigma, which plays a crucial role in careseeking behavior of PLWHA, other variables depicted in the model also affect PLWHA seeking care.

\section{What are the determinants of care-seeking?}

Beliefs: Our study shows that inaccurate beliefs about HIV/AIDS and its management affect care seeking. We found that the belief associating HIV/AIDS 
with improper sexual behavior is enough to deter PLWHA from seeking care. We also showed that common beliefs such as the belief in miracles may affect or delay seeking care (Chapter 3; Chapter 4, pg 71; Chapter 6, pg 121). This encourages families to take a relative with HIV/AIDS to the church, because a miracle is highly expected, rather than taking them to a health care institution. Furthermore, HCPs reported that the preference of PLWHA to go to faith houses such as churches first contributed to delay in them seeking care (Chapter 5, pg 93). The use of faith houses also prevents effective use and adherence of antiretroviral therapy (ART).

Knowledge: Our study showed that the knowledge about treatment options for HIV/AIDS is important for PLWHA to seek the right care. The lack of such knowledge, along with assumptions about cause (e.g poison) is associated with people believing that traditional healers can cure AIDS. In a study carried out in India, it was shown that some PLWHA turn to the traditional Indian system of medicine providers because they believed such practitioners offered a cure for HIV (Chomat, 2009). While we found that inaccurate knowledge of transmission of HIV by PLWHA affects care seeking, as well as prevention of vertical transmission, we also showed that societal lack of knowledge of HIV/AIDS and treatment options inhibits family caregivers from taking relatives for voluntary counseling and testing, or from taking HIV-positive relatives to health-care institutions. Furthermore, when people have knowledge about their HIV status, they could make appropriate choices for health care (Ikorok \& Akpabio, 2007); but people rather avoid such knowledge. Our research among HCPs illustrates that even some professionals may not have adequate knowledge about HIV/AIDS specialized care, which makes them react negatively to PLWHA; this discourages PLWHA from seeking care. Similar findings resulted from a study in Malawi among health workers which showed that although there have been HIV/AIDS workshops and training for some health workers especially those at the managerial levels, lack of HIV/AIDS training was especially common for lower level health workers which affects giving proper care to patients with HIV/AIDS (Talashek et al., 2007).

Self-efficacy: Our results make it likely that PLWHA with high self-efficacy are able to handle their HIV/AIDS and its problems including proper care seeking. Self-efficacy is also needed for PLWHA to handle their condition and situation if others know about their HIV-positive status. For instance, we found that PLWHA who have stated their positive HIV status publicly have high self-efficacy resulting from overcoming the shame and stigma, and enabling them to seek care (Chapter 3). Conversely, due to low self-efficacy, some PLWHA are not willing to disclose their HIV status to their relatives, including their children, preventing them from going for voluntary counseling and testing and waiting until they are sick. We found also that, despite the fact that many of the participants in our study among PLWHA in Port Harcourt, Nigeria were knowledgeable about HIV/AIDS (including the use of ART) due to their membership in the association of people living with HIV/AIDS, the stigmatizing responses of people around them inhibited 
the high self-efficacy which is important in consistent seeking of care (Chapter 6, pg 114). Moreover, low self-efficacy will prevent PLWHA from getting help from significant others. On the other hand, those PLWHA who regarded HIV as a chronic illness were more confident about going to hospital for treatment and they were more adherent to ART. Self-efficacy has been shown to affect the adherence to ART (Diiorio et al., 2009; Mo \& Mak, 2009; Rudy et al., 2009). PLWHA use comparison with other chronic illnesses as a psychological means to increase their self-efficacy.

Poverty: Our findings show that poverty greatly impeded care-seeking possibilities of PLWHA. For instance, some PLWHA did not have enough money even to pay for the subsidized ART and for laboratory tests, while some others lost their job due to their positive HIV status. PLWHA need to have a job to be able to seek care effectively. Problems associated with employment and incomes of PLWHA corroborate reports in previous studies. In a study carried out in China among PLWHA and their caregivers, even in the presence of heavily subsidized health services, the un-affordability of health care led to delays in care seeking until symptoms were severe (Xu et al., 2007). A qualitative study involving employers in Beijing, Hong Kong and Chicago showed that employers from all three cities are reluctant to hire PLWHA (Rao et al., 2008). Poverty is especially a problem among women, since they are dependent financially on men, which makes it more difficult for them to access care.

Age: With regard to age, we found that young people are reluctant to seek Voluntary Counseling and Testing (VCT) services due to societal reactions such as blame (Chapter 3). VCT is the first step to management of HIV/AIDS. Similarly, a study carried out in Nigeria on the knowledge and attitude of young adults to HIV/AIDS and to routine HIV screening showed that $58 \%$ of the respondents would not agree to routine HIV screening due to stigmatization, psychological trauma, fear of living with positive screening among other reasons (Omoigberale, Abiodun \& Famodu, 2006). We show also that young PLWHA may decide not to disclose their positive HIV status to their partners, which has implications for transmission for HIV/AIDS when they have unprotected sex. A study carried out in the USA among HIV-positive homeless young people showed that they were not willing to disclose their positive HIV status to their sexual partners (Ebner \& Laviage, 2003). We found also that, due to stigma, young people are less willing to care for a person with HIV/AIDS. Furthermore, despite the fact that young PLWHA have need for support from their families, our study shows that young people will not get this, because people generally believe that young people live a reckless life, such as having multiple partners further causing delay in seeking care (Chapter 3). A study carried out in South Africa among young people aged 15-24 years showed that one- third of the men reported multiple and/or concurrent sexual partners showing an important feature of young people's sexual behavior and risk concerning HIV (Harrison, Cleland \& Frohlich, 2008). 
Religion: Religious beliefs- for example, that HIV or AIDS can be cured spiritually- contribute to delay in seeking care or undermine consistent use of ART. Moreover, some PLWHA suggested that miracles can reverse a positive HIV status, which affects seeking care in health-care institutions (Chapter 6, pg 121). In a study carried out among African-born immigrants and refugees living with HIV in the USA, cultural and religious dilemmas, amongst other things, were barriers that affect seeking or remaining in care (Othieno, 2007). Our study also shows that some PLWHA received spiritual and psychological support from the church and used it together with ART. The adjuvant utilization of religious beliefs for spiritual and psychological support with other treatment options was also found in a study carried out in Tanzania among people who attend a church, which showed that $80.8 \%$ of them believed that prayer could cure HIV, but their religious belief did not influence the time they began ART (Zou et al., 2009), so care seeking is not postponed. Similarly, another study carried out among muslim and christian PLWHA in Tanzania showed that prayers gave them hope to live and supported their adherence to ART medications (Watt, Maman, Jacobson, Laiser \& John, 2009).

Policy: Policies that allow access to low-priced ART drugs, but still require financial contributions from PLWHA merely limits access to ART to financiallycapable people, further excluding many PLWHA from accessing care. Moreover, policies that do not protect working PLWHA from losing their jobs reduce the accessibility of care. For instance, loss of a job following compulsory HIV screening by the employer was noted in our study (Chapter 6, pg 118). A similar lack of a protective work policy was found in a study carried out in Vietnam, where there were cases of PLWHA who believed that their government employer would fire them if those responsible knew about their positive HIV status (Gaudine et al., 2009). In that study, some were required, like other employees, to have an annual medical examination, making it difficult for them to avoid disclosing their positive HIV status and to keep their employment. Furthermore, policies that create visibility by placing HIV/AIDS clinics or programmes separate from other hospital facilities prevent PLWHA seeking care due to fear of being identified (Chapter 3). In conclusion, the results presented in this thesis confirm the hypothesis that certain variables in addition to stigma prevent PLWHA from seeking care.

\section{What role does gender play with regard to stigmatization of PLWHA?}

As previously mentioned in the introduction (Chapter 1, Pg 12), 7\% of pregnant PLWHA in Nigeria had access to ART in 2007 indicating the vulnerability of women. Although our study clearly shows that PLWHA in general have problems seeking care, all our studies indicate that gender plays a role in stigmatization of PLWHA which affects care seeking. In Chapter 7, we compared data from the general public, society and HCPs. In addition, we used Connell's theory of gender and power (1987) to analyze the findings. We showed that one of the basic reasons 
why female PLWHA do not seek care and support is the powerlessness of women in society. The gender-related power differences are fundamentally based on financial inequality, authority and the structure of social norms. This finding is in line with a recent UNAIDS report, which argues that women and girls continue to be affected disproportionately by HIV in Sub-Saharan Africa due to social, legal and economic disadvantages (UNAIDS, 2009). We will further discuss how the variables depicted in the model described in Chapter 3 affect women in particular.

Beliefs: One important belief common in all our studies is the link society makes between HIV/AIDS and female PLWHA. Our study shows that society blames female PLWHA more than their male counterparts and believes that women are the carriers of HIV, which discourages female PLWHA from seeking care. For instance, a participant in our study suggested that the government should take female PLWHA away to avoid spreading HIV to other men (Chapter 4, pg 72). Moreover, even among a positive-HIV sero-concordant couple, the woman is blamed for making the man the victim. We also showed that male PLWHA are more likely assumed to have contracted HIV from a barber's salon, while female PLWHA are associated with prostitution (Chapter 7, pg 140). Since HIV/AIDS is linked to prostitution, which is thought to be associated only with women, women experience double stigmatization (Chapter 2, pg 37). Literature furthermore has demonstrated a gendered media effect, such as that found in a study carried out in Canada, which shows that the media disproportionately carries news about female PLWHA (Mensah et al., 2008).

Knowledge: Knowledge about HIV/AIDS, knowledge about one's HIV status and care information are important for female PLWHA to seek adequate care and support. Many female PLWHA are incapable of making health care decisions for themselves. Our findings show that women do not know about the HIV status of their partners because men feel there is no need to inform them (Chapter 6, pg 115; Chapter 7, pg 138). The weak societal position of women has implications for female PLWHA seeking care, since they are mostly dependent on their spouses. The financial dependency of female PLWHA inhibits them from receiving the health information on HIV/AIDS that is available from different programmes. Moreover, the pressure on women including female PLWHA, to bear children may discourage them from seeking care in health-care institutions especially when they suspect that the advice will be to use contraception as a means of avoiding HIV infection (Chapter 3). Women who do not produce children are devalued, and having children to produce descendants to keep family lineage is necessary to a woman's social security (Passador, 2009). The sexual rights of PLWHA continue to be a concern especially for female PLWHA.

Self-efficacy: People need a high self-efficacy to be able to go for HIV testing and to seek care following a positive HIV test result. High self-efficacy is particularly important for female PLWHA due to the double stigmatization women experience, which makes it much harder to overcome shame and stigma. Female 
PLWHA are more worried about others finding out their HIV status (Chapter $\mathbf{6}$ pg 120), which affects their confidence in seeking care. A recent study shows that female PLWHA experience higher rates of stress and anxiety than their male counterparts and receive less emotional support from partners and families (Gordillo et al., 2009). PLWHA also need a high self-efficacy to handle problems that may arise with disclosure of their HIV status. Our study shows that female PLWHA find it more difficult to disclose their positive HIV status. Non-disclosure or selective disclosure has implications for the support female PLWHA receive from people around them, especially the significant others who need to be aware of their need for the money to pay medical treatment. A study carried out in Nigeria among women attending an antenatal clinic shows that women wanted greater involvement of their partners in the counselling session to guard against stigma if they tested positive (Moses et al., 2009). Partner support following disclosure has been shown to increase the self-efficacy of female PLWHA, which is necessary for them to transit from learning their positive HIV status to seeking appropriate care (De Paoli, Manongi \& Klepp, 2004).

Poverty: Our study shows that female PLWHA are dependent on their partners for finance. This reduces their ability to seek care in health care institutions. Others remain in violent relationships as a result of economic dependency (Krishnan et al., 2008). We also found out that gender-related differences are manifest in health care institutions because HCPs request female PLWHA to inform their husbands of their positive HIV status before treating them as a way of ensuring that the hospital bill will be paid (see context Chapter 5, pg 96; Chapter 7, pg 144). This implies that female PLWHA must disclose their HIV status to their partners to be able to secure financial support. Disclosure problems aggravated by financial problems, especially for female PLWHA, are not new, nor are they particular to Sub-Saharan Africa. A study carried out in thirteen European countries, for example, shows that HIVpositive women who disclosed their positive HIV status and experienced more stigmatization, were more likely to be unemployed and experiencing financial difficulty (Gordillo et al., 2009). This shows the impact of financial power in reducing the effect of stigmatization and problems associated with disclosure.

Age: Although we did not find an age effect with regard to gender, we found generational problems such as sharing information with the children. Our study shows that female PLWHA find it very difficult to disclose their HIV status to their children and are not willing to take their young teenagers and children for VCT (Chapter 6, pg 120), which prevents the young people, including children, from receiving early care. Campbell and colleagues in a study carried out in South Africa, showed that parents denial of their children sexual activity affects their willingness to discuss HIV/AIDS with their teenage children (Campbell, Nair, Maimane \& Nicholson, 2007). Our result is also comparable to results found in a study of barriers to asymptomatic screening and other sexually transmitted disease (STD) services for adolescents and young adults conducted in North Carolina 
(USA), in which participants reported receiving little information from their parents about STDs (Tilson et al., 2004).

Religion: Our findings show that religious institutions contribute to the stigmatization of female PLWHA. For instance, conflicting information from religious leaders can have a negative impact, such as that HIV/AIDS is a punishment from God for immoral behavior (Chapter 2, pg 36). A recent study carried out in Nigeria on religious leaders' response to AIDS highlighted differences in messages between mainstream Christians, Pentecostal Christians and Muslims (Ucheaga \& Hartwig, 2010). In that study, Pentecostal churches tended to have more messages of punishment and condemnation for PLWHA. Abdulsalami \& Tekena (2004) noted that both Christian and Muslim religious leaders in Nigeria often view immoral behavior as the cause of the HIV/AIDS epidemic (Abdulsalami \& Tekena, 2004). Such messages of punishment and linking HIV to immorality further enhance the feminization of HIV/AIDS, since prostitutions are generally associated with women and women are believed to be carriers of the HIV virus. Behavior that is considered immoral will generate negative reactions, causing people to stigmatize female PLWHA more than their male counterparts. This is particularly significant because Nigeria is a very religious country. These messages will also prevent female PLWHA from disclosing to significant others to escape moral judgment and affect care seeking. A study carried out in Nigeria showed that married women may not disclose their positive HIV status as they risk their marriage, or they may experience other marital problems since they will be accused of prostitution (Ikorok \& Akpabio, 2007).

Policy: Societal customs and policies in Nigeria create an imbalance in the relationship between man and woman that make it easy for men to change partners. Furthermore, the patriarchical system regulates the transfer of wealth to men while excluding women (Chapter 7, pg 132). This enhances power differences between men and women, making female PLWHA more vulnerable in their homes, and to HIV/AIDS and its problems. For instance, our study shows that women who are HIV positive may be sent away from their husband's home and the steps they take to avoid this problem will affect their care-seeking behavior. Another study carried out in Mozambique, showed that female PLWHA are accused of being impure, and that expulsion of women with HIV from home appears to be a regular occurrence. This occurred to such an extent that expulsion from home of female PLWHA was made the target of official public health campaign discouraging the practice (Passador, 2009). Although social structure and norms are informal, specific steps can be taken to protect the vulnerable women in society. Jobson (2009) argues that involving men and masculine ideologies will help in closing the gap, given that women are less able to initiate conversations around sensitive issues. For future research, we suggest studying the perspectives of the partners of female PLWHA in understanding these gender-related differences that affect care seeking. 
What is the current situation of the care of HIV/AIDS patients in health care institutions?

We reported consistent findings with regard to the stigmatization of PLWHA in health-care institutions. However, our study among HCPs in Port Harcourt, Nigeria, suggests mixed or ambivalent stigmatization reactions to PLWHA, depending on whether they work in private or government hospitals. We will use the variables depicted in the model in Chapter 3 to discuss the current situation of professional care in health-care institutions.

Beliefs: Beliefs in society about HIV/AIDS (e.g sexuality) are also shared by HCPs working in health care institutions and affect their attitudes and behavior towards PLWHA. HCPs believe that there is a high risk of contracting HIV in the course of their work (Chapter 3; Chapter 5, pg 90, 91). This makes HCPs try to avoid contact with patients with HIV/AIDS to prevent the risk of contracting HIV. Similarly, a study carried out in Uganda on the knowledge and attitude of nurses caring for patients with HIV/AIDS showed that $47 \%$ of the participants ranked their fear of contracting HIV/AIDS from occupational practice at very high levels (Walusimbi \& Okonsky, 2004). Moreover, some HCPs who care for PLWHA, do diagnostic HIV testing without informing patients (Chapter 3; Chapter 5, pg 98). This they do out of fear of contracting HIV when they get a needle prick injury, which is a breach of the patients' rights. Furthermore, we found that the fear of negative social consequences (based on societal beliefs) discourages HCPs from going for VCT, which reflects why they take steps to avoid contact with PLWHA. HCPs believe that society will not regard their positive HIV status as a consequence of a professional hazard, but rather believe that they contracted HIV through indiscriminate sex (Chapter 5, pg 94). This encourages stigmatization in health care institutions, manifested in ways such as quick referral to a government health care institution. Our result is congruent with another study carried out in Yunnan, China among health care professionals (Chunqing, Li, Zunyou, Sheng \& Manhong, 2008). In that study, HCPs felt society will not believe their HIV infection to be from hospital work if they contract HIV infection from work.

Knowledge: Knowledge about HIV and AIDS, HIV transmission and effective treatment is important for HCPs to give proper care to PLWHA. Our findings indicate that, although HCPs are more knowledgeable about HIV/AIDS than the rest of the society, still many of them have inadequate knowledge about HIV/AIDS, its specialized care and management. We found that HCPs who have a good knowledge and experience of caring for patients with HIV/AIDS give better care to PLWHA. This is similar to a study carried out in Nigeria which showed that the more contact there is with patients with HIV/AIDS and the higher the knowledge about HIV/AIDS, the more HCPs are willing to care for PLWHA (Umeh et al., 2008).

Self-efficacy: HCPs need high self-efficacy to be able to give care to PLWHA. Conversely, low self-efficacy makes caring for PLWHA look tougher than it 
actually is. The fear associated with HIV/AIDS inhibits high self-efficacy. HCPs identified fear of HIV and its incurability as one of the problems that affect them giving proper care to PLWHA. We showed some private hospitals are afraid of being labeled as a hospital that treats PLWHA, which might drive other patients away (Chapter 5, pg 94). This makes them refuse HIV patients. Furthermore, we showed that lack of protective materials only worsens the fear HCPs have of PLWHA. The association between self-efficacy, fear and care of PLWHA is comparable with a study carried out in Ibadan, Nigeria, investigating attitudes towards caring for PLWHA among hospital workers, which showed a significant association between high self-efficacy and less fear of acquiring HIV, less sense of futility in providing care for PLWHA and higher willingness to provide such care (Olley, 2003). Godin and colleagues (1999) argue that to improve the motivation of HCPs to be able to cope with difficulties associated with caring for PLWHA, emphasis should be placed on self-efficacy (Godin et al., 1999).

Poverty: We found that due to financial obligations, the care given to PLWHA is different from that given to patients with other diseases. For instance, our findings indicate that a private hospital presented bills to pregnant person with HIV/AIDS that was different from the bills for pregnant patients without HIV (Chapter 5, pg 96). Such high bills exclude poor PLWHA from accessing health care. For future research it will be of interest to examine whether the ability to pay medical bills will result in better treatment for PLWHA by HCPs.

Age: Our findings show that due to stigma, both young and older adults are still shying away from VCT. For instance, young people fear that going for VCT may result in a positive HIV test result, which will affect future expectations about their life (Chapter 3). Use of VCT is particularly important for people of child- bearing age because of prevention of vertical transmission. In addition, avoidance of VCT has implications for the utilization of the HIV programmes that are available in health care institutions, meaning that PLWHA will miss out on these benefits.

Religion: Religious beliefs that are common in society affect the behaviour of some HCPs. For instance, some HCPs have faith that it is God who protects them at work, not the precautionary measures they take when carrying out their duties (Chapter 5, pg 93). This actually makes them less eager to take universal precautions, particularly in cases of emergencies. It also affects the consistent use of protective materials in health-care institutions. Furthermore, the general religious beliefs (e.g. immorality) shared in the community also make some HCPs react negatively to PLWHA.

Policy: Our study showed that a lack of effective HIV policy in hospitals, for example that would cover employment conditions and prophylactic treatment for health care workers, was one of the basic reasons why HCPs stigmatize PLWHA. Furthermore, HCPs feel they may lose their job if they contract HIV/AIDS, which only reinforces their negative attitudes. In another study carried out in four rural hospitals in Uganda, none of the hospitals in the study had a written policy to deal 
with HIV-positive staff (Dieleman, et al., 2007). At its core, stigmatization by HCPs is fundamentally a threat to PLWHA, since HCPs are trusted by society for care and in time of need. In conclusion, although there are differences between individual health care professionals and between private and government hospitals, the model allows the description and organization of results obtained among HCPs and PLWHA.

\section{What are the coping mechanisms that PLWHA use?}

The model in Chapter 3 explored the coping strategies of PLWHA and their effect on care-seeking. Our study shows that PLWHA utilize varied ways of coping with their stigmatization experiences in society and health care institutions. We hypothesized that, first, PLWHA cope by themselves with aspects like their physical appearance, emotional and cognitive problems; second, they try to cope with others, for example, by reducing the unfavorable reactions of others; and third, they try to solve the direct or indirect problems of the disease through self-care, traditional healers or visiting faith houses such as churches. We showed that some PLWHA received support from their family and relatives, while some did not. When PLWHA disclose their HIV-positive status, they may face negative consequences. On the other hand, when they choose silence, it leads to a burden they will live with for the rest of their lives.

In different studies, we showed that PLWHA use silence as a major strategy to cope with the problem of being infected with HIV/AIDS. Other studies have similarly shown a preference among PLWHA for keeping their positive HIV status secret (Emlet, 2008; Subramanian et al., 2009). We found evidence that many PLWHA try to cope with a HIV/AIDS problem through self-care, going to traditional healers, visiting faith houses and inconsistent use of or self-exclusion from health care institutions. Studies have reported self-care as one of the challenges that PLWHA face (Wong, 2003; Chou et al., 2004). Kalichman and colleagues (2003) showed that health-related internet use was associated with active coping in PLWHA (Kalichman et al., 2003). Our study also showed that PLWHA may utilize a combination of therapies (traditional healers, faith houses such as churches, health care institutions). This is similar to PLWHA in South Africa who see no conflict in seeking both allopathic and traditional African healing for illness (Peltzer, 2009), as well as similar to another study involving HIV-positive South African migrants living in London, in which $45 \%$ of the participants reported use of non-biochemical treatment before they had started ART and/or in combination with ART (Thomas, Aggleton, \& Anderson, 2010).

An important contribution of this study, which extends previously published data, was the construction of an explanatory model. The model allows for articulation of problems associated with healthcare-seeking behavior among PLWHA and an analysis of coping mechanisms in dealing with stigma-related problems. 


\section{Consequences of stigma in society}

We showed that stigma functions in society through its consequences; the negative interaction between PLWHA and society. Different parts of our study showed that attitudes of people, including HCPs, towards PLWHA potentially have negative consequences for seeking care. For instance, our results suggest that, due to stigma in society, PLWHA do not utilize prevention programmes and health services even when they were available. This finding adds to the current evidence found from a study in South Africa which shows that, despite the availability of ART, stigma still affects the prevention, treatment and care of HIV/AIDS (Maughan-Brown, 2010).

Another consequence of stigma is the denial of HIV/AIDS and its seriousness. For instance, our results indicate that euphemisms such as "died after a short illness" (or "...long illness") are frequently used in the obituary of someone who dies from HIV/AIDS in order to avoid stigmatization of the diseased and the surviving family. In addition, HCPs frequently write an indirect cause of death on death certificates, such as "immunosuppression" rather than HIV/AIDS to avoid stigmatization of the patients' relatives. HIV patients also tell HCPs that they have malaria or typhoid fever rather than HIV, even when they know their positive HIV status. PLWHA associate their HIV/AIDS status with culturally acceptable excuses such as witchcraft. In general, we showed that the denial of HIV/AIDS implies that people think HIV/AIDS is unacceptable in society, and so they use indirect terms rather than individualize HIV/AIDS to protect themselves from societal negative reactions. The use of indirect language for sensitive subjects, such as those associated with sexuality, is common and traditionally rooted in Sub-Saharan Africa. A study carried out in Malawi showed that, despite the knowledge and acceptance that HIV/AIDS exists, there is still a taboo surrounding HIV/AIDS that makes open discussion inappropriate within the community (Rosato et al., 2006). These findings demonstrate how societal denial is encouraged, underscoring the need for the cultural undertones that impact on HIV/AIDS stigma to be understood.

On the basis of the outcomes of this research, several conclusions can be drawn. HIV-related stigma is a critical problem because PLWHA are not able to seek care due to the negative societal reactions and caregivers (professional and civil) who are willing to care for them fear the wrath of society, including the negative reactions of people around them. This has an effect on the quality of life of PLWHA (on the family, social and societal obligations of PLWHA). PLWHA are unable to fulfil their family obligations, interact socially and be fit to go to work.

We demonstrated that the model in Chapter 3 identifying the factors that affect the care-seeking behaviour of PLWHA were relevant throughout the chapters and can be applied to PLWHA seeking care and receiving it, to gender-related differences in care seeking and receiving, as well as to the caregivers (professional and civil). The model enabled an understanding of the interaction processes involving PLWHA and caregivers (professional and civil) which inhibits PLWHA 
from seeking care. In doing so, we increased the likelihood of uncovering potential areas of intervention for improving the quality of life of PLWHA.

\section{Methodological Limitations}

\section{The literature review}

Two chapters in this thesis involved a literature review. Although the literature gave ample insight into the problems of PLWHA in Sub-Saharan Africa, using stringent search criteria meant that some important studies may have been left out. The model constructed in Chapter 3 was based on the results of this review and therefore is subject to this limitation. The search criteria used limited search sites. By inspecting reference lists, we tried to cover as much as possible, but still, important studies may have been left out.

\section{Qualitative research studies}

A basic flaw in the qualitative studies that were conducted in this thesis is that we employed convenience samples. The street intercept method used in the societal study has a disadvantage because it results in a purposeful rather than random sample, limiting external validity. Our sample from the general public lacked Muslim participants whose participation would have yielded additional information. Although our participants (PLWHA) were organized and belong to a network association of PLWHA, still they did not want their relatives to know about their HIV statuses. This prevented us from gathering important information from the direct family caregivers of PLWHA. Our findings relied strictly on participants' self-reported data. In general, the participants may not have felt free to discuss issues with the researcher and therefore may have answered or discussed issues in a way they considered socially desirable. One further limitation of the study was not interviewing stakeholders, such as community leaders and religious leaders. Future research should pay attention to this.

\section{Recruitment}

Access to PLWHA was difficult because of stigma; some of the coping strategies (negation, hiding) made it difficult to make contact with this group. In an attempt to overcome this problem, we chose a resource centre where PLWHA belonged to an association network and had already come out with their positive HIV status. However, this implies that the information they gave may have been different from PLWHA in the general population who are still more secretive about their positive HIV status. HCPs were one of the target populations for the study. We recruited HCPs working in both private and government hospitals, however, since many HCPs work in both systems this meant cross-over information from HCPs in both private and government hospitals. To get the public opinion about beliefs and 
reactions of society towards PLWHA, we recruited participants from the general public in the street. To ensure participants' privacy, identifying personal data was not collected.

\section{Public health implications}

This is the third decade of the global HIV/AIDS disease, yet the magnitude, longterm nature and severe impact of HIV/AIDS on societies are still indisputable and raise issues for public health. The core message of this thesis is that, due to stigma, PLWHA do not receive proper care and support in society and in health-care institutions as they should, which affects their quality of life. We have also argued that, on top of these shared problems of all PLWHA, the societal beliefs and reactions towards male and female PLWHA tend to be different. Gender stratification is reproduced at the societal and institutional level, such as health-care institutions, and in the power differences between male and female PLWHA. This perpetuates the growth of the HIV/AIDS epidemic. From this point of view, our findings are of public health relevance because international, government and nongovernmental organizations are continuously rolling out HIV/AIDS programmes that may be adapted in view of our findings. Policies and HIV programmes that are gender specific are important to protect female PLWHA. Governments can introduce policies that allow PLWHA to live freely in society and work with important stakeholders such as community and religious leaders. Furthermore, in Nigeria, health education interventions remain one of the most fundamental ways of reducing stigma and should continue to be given, not only to PLWHA, but to the rest of the society as well. By educating people about HIV/AIDS and its care, people gain more knowledge and power to move beyond the present stigma which allows stigmatization to remain and that prevents adequate care and support of PLWHA.

\section{Implications for future research}

This thesis has consistently shown that stigma plays a significant role in the problems PLWHA experience in society and in health-care institutions. Overall these problems have implications for people infected with and affected by HIV/AIDS, as well as for the effective development of interventions. While the results of this thesis provide additional information on HIV-related stigma and problems of PLWHA, there still is a lot more to be done also in terms of research. The points for attention for future studies include the following:

- Gender-related research that compares changes over time and their impact on HIV/AIDS care.

- Include PLWHA selected from the general population and see how they cope with their illness. 
- Religious institutions' governmental and health organizations' views and behavior towards PLWHA.

- Additional problems of HCPs should be studied in the presence of adequate protective materials.

- Updating research on determinants of stigmatizing behavior of HCPs.

- Research on the perspectives of partners of female PLWHA in understanding the gender-related differences that affect care seeking.

- Research on whether diagnostic HIV testing as a self-protection strategy among HCPs is advisable or not

- Research to find out whether the ability to pay treatment bills will result in better treatment for PLWHA by HCPs

- Research on development of policies to protect HCPs working in both government and private hospitals from the risks associated with contracting HIV in the course of their work

\section{Recommendations}

While the Nigerian government is involved in strategies towards providing better care for PLWHA, its efforts still fall short of the needs and expectations of PLWHA. We will outline steps that might ameliorate the problems of PLWHA as well as minimize the underlying problems from the negative reactions of society and HCPs. Based on our findings, which show that the needs of PLWHA are intertwined and dependent on certain variables, we suggest interventions covering these variables and focused on three broad areas; PLWHA, society and health care institutions:

\section{PLWHA}

- Education of PLWHA about HIV/AIDS, about the care that is available for PLWHA and about knowing their rights.

- Support of PLWHA to become self-reliant through the protection and creation of jobs and provision of financial support.

- Establishing special programmes to help PLWHA find employment.

- The government should work with employers and trade unions to ensure that the rights of PLWHA in the workplace are implemented.

- Incorporation of views of PLWHA in creating policies.

- Provision of health insurance that is accessible for all.

- Universal access to free ART for all PLWHA.

- Support of networks of PLWHA which is necessary to increase their selfefficacy.

- Establishing special programmes to target young PLWHA paying attention to safe sex and use of ART to prevent vertical transmission. 
- Establishing special programmes to target female PLWHA.

\section{Society}

- Prevention of HIV stigma by strengthening of messages in communities on the importance of care and support for PLWHA.

- Youth-adult partnerships and youth participation should be key elements of HIV-stigma prevention programmes.

- Review of efficacy of existing HIV policy to meet current needs.

- Effective HIV laws such as antidiscrimation laws backed up with policies that should be disseminated and accessible to everybody in society.

- Commitment of important stakeholders like religious leaders, HCPs and community leaders for providing practical information about HIV/AIDS and its care.

- Use of the media in a positive way to disseminate information.

- Empowerment of women and involvement of men to support the policies that address gender inequality which affects women.

- Link local action to national and global outcomes for continuous updating of programmes concerning HIV/AIDS and HIV-related stigma.

\section{Health care institutions}

- Training opportunities for HCPs with regard to increasing knowledge about HIV/AIDS and care, paying attention to cultural and religious beliefs that will increase the self-efficacy required to care for PLWHA.

- Programmes specifying the human rights of PLWHA in hospitals (privacy, counseling, HIV testing etc). Disclosure issues should be addressed in the context of protecting human rights.

- Creation of a policy that encourages equality in accessibility to health care.

- Policy protecting the job security and treatment of workers who contracted HIV.

- Policy that covers prophylactic treatment of HCPs.

- Allocation of more funds that are closely matched to needs, paying attention to adequate working materials such as sterile surgical hand gloves etc.

- Accurate detailed assessments on HIV spending need to be conducted regularly to facilitate more efficient allocation of funds.

- Integration of HIV programmes with the rest of the departments in hospitals, in order to comprehensively address needs including the prevention and treatment of co- morbidities such as tuberculosis.

- Incorporation of gender-related issues in the medical school curriculum to educate HCPs about need for equality in care service. 


\section{Concluding remarks}

The central focus of this research project was to investigate the problems that PLWHA face in society and in health-care institutions, using interrelated qualitative studies (PLWHA, the general public and HCPs). To date, qualitative research has been shown to be effective in exploring and understanding complex problems (Golafshani, 2003; Doyal, 2009). In this chapter and throughout the thesis, we have described some of the complexities of the interactions between PLWHA, society and HCPs that allow stigmatization to persist. Based on the results of the studies in this thesis, the evidence that stigmatization is still present is overwhelming. As was shown in the model depicted in Chapter 3, which was conceptually supported in subsequent chapters, these studies show that stigmatization arises out of multiple factors depicted as variables at individual level, institutional level and at societal level. PLWHA are not able to seek and receive care and support in society, including in health-care institutions, due to stigmatization and female PLWHA in particular are more vulnerable.

We have also shown that PLWHA face a number of challenges in trying to confront the problems of living with HIV/AIDS. They mainly choose complete silence or selective disclosure. This has huge implications for care seeking and the support they receive. Given this dilemma and the fact that the number of PLWHA is likely to increase, due to the effectiveness of current antiretroviral therapy and the perpetuation of the epidemic, it is necessary to ensure that they feel they are part of society. As we noted in Chapters 3 and 5, putting HIV/AIDS into the relational societal context, including the health care institutions, there is a need for collective action and responsibility. This means changing cultural values and symbols, which implies changes in individuals and institutions. Furthermore, despite the unease about HCPs' problems in treating PLWHA and the predicament of the high expectations in society of HCPs, and specifically by PLWHA, we have shown that certain measures such as provision of protective work policies, access to prophylactic treatment in case of accidental blood exposure and availability of appropriate protective work materials when taken will probably improve the care that PLWHA receive in hospitals.

While the problems of PLWHA remain complex, and while human and material resources in medical care are limited in many areas in Sub-Saharan Africa, including Nigeria, we have argued that the problems of PLWHA cannot be individualized but must involve all segments of society. Effective policies backed with practical multifaceted interventions are important. Despite the limitations of this study, we have identified some of the individual and interpersonal social dynamics that hinder the care and support of PLWHA as well as enhancing stigmatization. These specific problem areas, some of which are identified in the conceptual model (Chapter 3), are important areas for intervention for HIV/AIDS 
programmes including those targeting health care professionals in Nigeria and in Sub-Saharan Africa.

\section{References}

Abdulsalami, N., \& Tekena, O.H. (2004). The epidemiology of HIV/AIDS in Nigeria. Retrieved 12 March, 2010 from Harvard website: http://www.apin.harvard.edu/chapter2.pdf.

Agbonyitor, M. (2009). Home-based care for people living with HIV/AIDS in Plateau State, Nigeria: findings from qualitative study. Global Public Health, 4 (3), 303-312.

Anderson, M., Elam, G., Gerver, S., Solarin, I., Fenton, K., \& Easterbrook, P. (2008). HIV/AIDSrelated stigma and discrimination: accounts of HIV positive Caribbean people in the United Kingdom. Social Science and Medicine, 67 (5), 790-798.

Babalola, S. (2007). Readiness for HIV testing among young people in northern Nigeria: the roles of social norm and perceived stigma. AIDS and Behavior, 11 (5), 759-769.

Campbell, C., Nair, Y., Maimane, S., \& Nicholson, J. (2007). Dying twice: a multi-level model of the roots of AIDS stigma in two South African communities. Journal of Health Psychology, 12 (3), 403-416.

Castro, A., \& Farmer, P. (2005). Understanding and addressing AIDS-related stigma: from anthropological theory to clinical practice in Haiti. Amercian Journal of Public Health, 95 (1), 53 59.

Chomat, A.M., Wilson, I.B., Wanke, C.A., Selvakumar, A., John, K.R., \& Isaac, R. (2009). Knowledge, beliefs and health care practices relating to treatment of HIV in Vellore, India. AIDS Patient Care and STDs, 23 (6), 477-484.

Chou, F.Y., Holzemer, W.L., Portillo, C.J., \& Slaughter, R. (2004). Self-care strategies and sources of information for HIV/AIDS symptom management. Nursing Research, 53 (5), 332-339.

Chunqing, Lin., Li, Li., Zunyou, Wu., Sheng, Wu., \& Manhong, Jia. (2008). Occupational exposure to HIV among health care providers: a qualitative study in Yunnan, China. Journal of International Physicians in AIDS Care (Chic 111), 7 (1), 35-41.

Connell, R.W. (1987). Gender and power: society, the person and sexual politics. United Kingdom: Blackwell publishers.

Darrow, W. W., Montanea, J.E., \& Gladwin, H. (2009). AIDS-related stigma among black and Hispanic young adults. AIDS and Behavior, 13(6), 1178-1188.

De Paoli, M.M., Manongi, R., \& Klepp, K.I. (2004). Factors influencing acceptability of voluntary counseling and HIV-testing among pregnant women in Northern Tanzania. AIDS Care, 16 (4), 411-425.

Derlega, V.J., Winstead, B.A., \& Brockington, J. E. Jr. (2008). AIDS stigma among inmates and staff in a USA state prison. International Journal of STDs and AIDS, 19 (4), 259-263.

Dieleman, M., Bwete, V., Maniple, E., Bakker, M., Namaganda, G., Odaga, J., \& Van der Wilt, G.J. (2007). I believe that the staff have reduced their closeness to patients: an exploratory study on the impact of HIV/AIDS on staff in four rural hospitals in Uganda. BMC Health Service Research, 7, 205.

Diiorio, C., McCarty, F., Depadilla, L., Resnicow, K., Holstad, M.M., Yeager, K., Sharma, S.M., Morisky, D.E., \& Lundberg, B. (2009). Adherence to anti-retroviral medication regimens: a test of a psychosocial model. AIDS and Behavior, 13 (1), 10-22.

Doyal, L. (2009). Challenges in researching life with HIV/AIDS: an intersectional analysis of black African migrants in London, Culture Health and Sexuality, 11 (2),173-188.

Ebner, D.L., \& Laviage, M.M. (2003). The parallel universe of homeless and HIV positive youth. Seminars in Pediatric Infectious Diseases, 14 (1), 32-37.

Emlet, C.A. (2008). Truth and consequences: a qualitative exploration of HV disclosure in older adults. AIDS Care, 20 (6), 710-717. 
Gaudine, A., Gien, L., Thuan, T.T., \& Dung do, V. (2009). Perspectives of HIV-related stigma in a community in Vietnam: A qualitative study. International Journal Nursing Studies, 47(1), 38- 48.

Godin, G., Naccache, H., Brodeur, J.M., \& Alary, M. (1999). Understanding the intention of dentists to provide dental care to HIV positive and AIDS patients. Community Dentistry and Oral Epidemiology, 27 (3), 221-227.

Golafshani, N. (2003). Understanding reliability and validity in qualitative research, the qualitative report, 8(4), 597-607, Retrieved 27 January 2010: http://ace.upm.edu.my/lateef/handout\%20\%20dce\%205920/golafshani\%20-\%20reliability\%20and\%20va .

Gordillo, V., Fekete, E.M., Platteau, T., Antoni, M.H., Schneiderman, N., Nostlinger, C., \& The Eurosupport study group. (2009). Emotional support and gender in people living with HIV: effects on psychological well being. Journal of Behavioral Medicine, PMID: 19543823.

Groft, J.N., \& Robinson, V.A. (2007). Seeking serenity: living with HIV/AIDS in rural western Canada. Rural and Remote Health, 7 (2), 677.

Harrison, A., Cleland, J., \& Frohlich, J. (2008). Young people's sexual partnerships in Kwazulu- Natal, South Africa: patterns, contextual influences and HIV risk. Studies in Family Planning, 39 (4), 295-308.

Hong, Y., Li, X., Stanton, B., Fang, X., Lin, D., Wang, J., Mao, R., \& Yang, H (2008). Expressions of HIV- related stigma among rural-to-urban migrants in China. AIDS Patients Care and STDs, 22 (10), 823-831.

Ikorok, M.M., \& Akpabio, I.I. (2007). Women's choice of strategies for improving utilization of HIV/AIDS screening services. Health Care for Women International, 28 (8), 700-711.

Jobson, G. (2009). Changing masculinities: land use, family communication and prospects for working with older men towards gender equality in a livelihoods intervention. Culture Health and Sex, PMID: 19904648.

Kalichman, S.C., Benotsch, E.G., Weinhardt, L., Austin, J., Luke, W., \& Cherry, C. (2003). Healthrelated internet use, coping, social support, and health indicators in people living with HIV/AIDS: preliminary results from a community survey. Health Psychology, 22 (1), 111- 116.

Korner, H. (2007). Late HIV diagnosis of people from culturally and linguistically diverse backgrounds in Sydney: the role of culture and community. AIDS Care, 19 (2), 168-178.

Krishnan, S., Dunbar, M.S., Minnis, A.M., Medlin, C.A., Gerdts, C.E., \& Padian, N.S (2008). Poverty, gender inequities and women's risk of human immunodeficiency virus/AIDS. Annals of New York Academy of Sciences, 1136, 101-110.

Larios, S.E., Davis, J.N., Gallo, L.C., Heinrich, J., \& Talavera, G. (2009). Concerns about stigma, social support and quality of life in low-income HIV-positive Hispanics. Ethnicity and Disease, $19(1), 65-70$.

Li, L., Wu, Z., Wu, S., Jia, M., Lieber, E., \& Lu, Y (2008). Impacts of HIV/AIDS stigma on family identity and interactions in China. Families Systems and Health, 26 (4), 431-442.

Luginaah, I.N., Yiridoe, E.K., \& Taabazuing, M. M. (2005). From mandatory to voluntary testing:balancing human rights, religious and cultural values, and HIV/AIDS prevention in Ghana. Social Science and Medicine, 61 (8), 1689-1700.

Maughan-Brown, B. (2010). Stigma rises despite antiretroviral roll-out: A longitudinal analysis in South Africa. Social Science and Medicine, 70 (3), 368-374.

Mbonu, N.C., Van Den Borne, B., \& De Vries, N.K. (2009). A model for understanding the relationship between stigma and health care-seeking behaviour among people living with HIV/AIDS in SubSaharan Africa. African Journal of AIDS Research (AJAR), 8 (2), 201-212.

Mensah, M.N., Waugh, T., Lavoie, R., Dumas, J., Bernier, M., Garneau, M.J., Giroux, C., \& Otis, J (2008). The VHsibilite Project: HIV-positive people in the Quebec press and community responses. AIDS Care, 20 (5), 596-600.

Mo, P.K., \& Mak, W.W. (2009). Intentionality of medication non-adherence among individuals living with HIV/AIDS in Hong-Kong. AIDS Care, 21(6), 785-795. 
Moses, A.E., Chama, C., Udo, S.M., \& Omotora, B.A. (2009). Knowledge, attitude and practice of antenatal attendees towards prevention of mother to child transmission (PMTCT) of HIV infection in a tertiary health facility, Northeast-Nigeria. East African Journal of Public Health, 6 (2), 128-135.

Nanin, J., Osubu, T., Walker, J., Powell, B., Powell, D., \& Parsons, J. (2009). HIV is still real: perceptions of HIV testing and HIV prevention among black men who have sex with men in New York City. American Journal of Men's Health, 3 (2), 150-164.

Olley, B.O. (2003). Investigating attitudes towards caring for people with HIV/AIDS among hospital care workers in Ibadan, Nigeria: The role of self-efficacy. African Journal of AIDS Research (AJAR), 2 (1), 57-61.

Omoigberale, A. I., Abiodun, P.O., \& Famodun, A.A. (2006). Knowledge and attitude of youth (ages 15-25years) to HIV/AIDS and to routine HIV screening. Nigerian Journal of Clinical Practice, 9(1), 11-13.

Othieno, J. (2007). Understanding how contextual realities affect African born immigrants and refugees living with HIV in accessing care in the twin cities. Journal of Health Care for Poor and Underserved, 18 (3), 170-188.

Passador, L.H. (2009). 'Tradition', person, gender and STD/HIV/AIDS in southern Mozambique. Cadernos de Saude Publica, 25 (3), 687-693.

Peltzer, K. (2009). Traditional health practitioners in South Africa. Lancet, 374 (9694), 956-957.

Rao, D., Angell, B., Lam, C., \& Corrigan, P. (2008). Stigma in the workplace: employer attitudes about people with HIV in Beijing, Hong Kong and Chicago. Social Science and Medicine, 67 (10), 1541-1549.

Reis, C., Heisler, M., Amowitz, L.L., Moreland, R.S., Mafeni, J.O., Anyamele, C., \& Lacopino, V. (2005). Discriminatory attitudes and practices by health workers towards patients with HIV/AIDS in Nigeria. PLos Medicine, 2 (8), e246.

Rosato, M., Mwansambo, C.W., Kazembe, P.N., Phiri, T., Soko, Q.S., Lewycka, S., Kunyenge, B.E., Vergnano, S., Osrin, D., Newell, M.L., \& Costello, A.M. (2006). Women's groups perceptions of maternal health issues in rural Malawi, Lancet, 368 (9542), 1139-1140.

Rudy, B.J., Murphy, D.A., Harris, D.R., Muenz, L., Ellen, J., \& Adolescent trials network for HIV/AIDS interventions. (2009). Patient-related risks for non-adherence to antiretroviral therapy among HIV-infected youth in the United States: a study of prevalence and interactions. AIDS Patient Care and STDs, 23 (3), 185-194.

Subramanian, T., Gupte, M.D., Dorairaj, V.S., Periannan, V., \& Mathai, A.K. (2009). Psycho-social impact and quality of life of people living with HIV/AIDS in South India. AIDS Care, 21 (4), 473-481.

Talashek, M.L., Kaponda, C.P., Jere, D.L., Kafulafula, U., Mbeba, M.M., McCreary, L.L., \& Norr, K. (2007). Identifying what rural health workers in Malawi need to become HIV prevention leaders. The Journal of the Association of Nurses in AIDS Care, 18 (4), 41-50.

Terto, V., Jr. (1999). Seropositivity, homosexuality and identity politics in Brazil. Culture Health and Sex, 1 (4), 329-346.

The Joint United Aids (UNAIDS) (2009), Retrieved 22 January 2010: http://data.unaids.org/pub/Report/2009/Jc1700_Epi_Update_2009_en.pdf.

Thi, M.D., Brickley, D.B., Vinh, D.T., Colby, D.J., Sohn, A.H., Trung, N.Q., Giang Le, T.,

\& Mandel, J.S. (2008). A qualitative study of stigma and discrimination against people living with HIV in Ho Chi Minh city, Vietnam. AIDS and Behavior, 12 (4), S63-70.

Thomas, F., Aggleton, P., \& Anderson, J. (2010). Expert, partners, and fools: Exploring agency in HIV treatment seeking among African Migrants in London. Social Science and Medicine, 70(5), 736743.

Tilson, E.C., Sanchez, V., Ford, C.L., Smurzynski, M., Leone, P.A., Fox, K.K., Irwin, K., \& Miller, W.C. (2004). Barriers to asymptomatic screening and other STD services for adolescents and young adults: focus group discussions, BMC Public Health, 4, 21. 
Ucheaga, D.N. \& Hartwig, K.A. (2010). Religious leaders' response to AIDS in Nigeria. Global Public Health, PMID: 20155545.

Umeh, C.N., Essien, E.J., Ezechinachi, E.N., \& Ross, M.W. (2008). Knowledge, beliefs and attitudes about HIV/AIDS related issues and the sources of knowledge among health care professionals in Southern Nigeria. The Journal of the Royal Society for the Promotion of Health, 128 (5), 233-239.

Walusimbi, M., \& Okonsky, J.G. (2004). Knowledge and attitude of nurses caring for patients with HIV/AIDS in Uganda. Applied Nursing Research, 17(2), 92-99.

Watt, M.H., Maman, S., Jacobson, M., Laiser, D., \& John, M. (2009). Missed opportunities for religious organisations to support people living with HIV/AIDS: findings from Tanzania. AIDS Patients Care and STDs, 23 (5), 389-394.

Wilson, P.A., \& Moore, T.E. (2009). Public health responses to the HIV epidemic among black men who have sex with men: a qualitative study of US health departments and communities. American Journal of Public Health, 99 (6), 1013-1022.

Wong, W.C. (2003). Acceptability study of sex workers attending the HIV/AIDS clinic in Ruili, China. Asia- Pacific Journal of Public Health, 15 (1), 57-61.

Xu, J., Sullivan, S.G., Dou, Z., Wu, Z., \& China CIPRA project 2 Team. (2007). Economic stress and HIV-associated health care utilization in a rural region of China: a qualitative study. AIDS Patient Care and STDs, 21 (11), 787-798.

Zou, J., Yamanaka, Y., John, M., Watt, M., Ostermann, J., \& Thielman, N. (2009). Religion and HIV stigma, disclosure and treatment attitudes. BMC Public Health, 9, 75. 



\section{Summary}

People living with HIV/AIDS need care and support from the society as well as from professionals in healthcare institutions to preserve or enhance their quality of life. Finding the barriers to a good quality of life for people living with HIV/AIDS remains a challenge. One of these barriers is stigma. In general, this thesis seeks to understand origins and contents of this stigma, why people living with HIV/AIDS in Port Harcourt, Nigeria, do not seek and do not get proper care from people in society as well as from professionals in healthcare institutions. The first part of the studies was aimed at understanding the HIV-related stigma in Sub-Saharan Africa and the consequences of stigma for care seeking (Chapters 2 and 3). The second part aimed at understanding stigma and other problems people living with HIV/AIDS in Port Harcourt, Nigeria face in seeking care (Chapters 4, 5, 6). In addition, gender-related differences in stigma and in care given to PLWHA were also investigated (Chapter 7).

Chapter 1, the general introduction, provides an overview of epidemiological information on HIV/AIDS in Nigeria, information on the Nigerian government effort to combat HIV/AIDS, and a justification for the research reported in this thesis. In addition, the aims of the studies in the thesis, a general outline, and a brief description of the chapters are presented.

In Chapter 2, the literature on HIV-related stigma, processes of stigmatization and effects are described. A systematic review of 65 original papers revealed that beliefs, culture, religion and sexuality contribute to the stigmatization of people living with HIV/AIDS. In addition, the material was analyzed using Gilmore and Somerville's (1994) conceptualization of four processes of stigmatizing responses: the definition of the problem (HIV/AIDS), identification of people living with HIV/AIDS, linking HIV/AIDS to immorality and other negative characteristics, and finally behavioral consequences of stigma (distancing, isolation, discrimination in 
care). Stereotypes (ideas, words, images) about people living with HIV/AIDS were particularly important. Different expressions such as she is a 'walking corpse' or 'was caught in a trap' were used to describe people living with HIV/AIDS. These stereotypical expressions have an impact on people living with HIV/AIDS and may affect their use of HIV intervention programs as well as seeking health care.

In Chapter 3, a first step in a needs assessment using a review of literature of HIV/AIDS in Sub-Saharan Africa revealed stigma as a major problem for people living with HIV/AIDS. In this study, the relationship between stigma and health care seeking behavior among people living with HIV/AIDS in Sub-Saharan Africa was analyzed. An explanatory model was built inspired by the Green \& Kreuter (1999) PRECEDE-PROCEED model and on a systematic review of published studies. In this model, we hypothesized that three psychosocial determinant variables (beliefs, knowledge about HIV/AIDS and self-efficacy) are important because of their impact on the coping strategies that people living with HIV/AIDS use and on the healthcare choices they make. In addition, we argue that the ability of people living with HIV/AIDS to further cope with HIV/AIDS stigma and make care-seeking choices may vary depending on how they have been affected by certain modifying variables like poverty, gender, age, religion and policy. Finally, the model postulates that people living with HIV/AIDS may utilize any of three strategies to cope with HIV/AIDS. First, coping with self (physical appearance, emotional and cognitive problems), second, coping directed at others in the social environment, and third, coping directed at solving problems related to the HIV/AIDS disease. We concluded that the model is a useful representation of factors that affect non-utilization of healthcare institutions by people living with HIV/AIDS in Sub-Saharan Africa.

The second part of research in this thesis focused on people living with HIV/AIDS and involved a qualitative study in Port Harcourt, Nigeria (Chapters 4, $5,6 \& 7)$.

In Chapter 4, we investigated societal beliefs and reactions towards people living with HIV/AIDS using a street intercept survey. In this study, stigmatization was again found to be strongly present. The result of this study showed that certain factors such as identifying someone as having HIV based on physical appearance (whether true or false) or associating HIV/AIDS with promiscuity, allow stigma to occur. Some manifestations of stigma that were reported are locking a person with HIV/AIDS in a room, the caregivers passing food through a hole in a wall or door so as not to come in contact with the person with HIV/AIDS, and in an extreme case denying food to a person with HIV/AIDS to bring about quick death.

In Chapter 5, we explored the problems of health care professionals working both in private and government hospitals. In this study, different factors such as fear of contracting HIV infection in the course of their work and lack of regular availability of appropriate protective materials (e.g. sterile surgical gloves) inhibit proper care and encourage stigmatization of people living with HIV/AIDS in 
healthcare institutions. Effects of these factors on care such as refusal to treat, conditions for treatment (e.g. giving a high medical health bill), quick referral, isolation, and breach of human rights were presented. These results imply that certain steps such as effective HIV/AIDS work policy and availability of protective materials for health care professionals may improve the care of people living with HIV/AIDS in the health care institutions.

In Chapter 6, we focused on experiences of people living with HIV/AIDS in Port Harcourt, Nigeria by interviewing a convenience sample of members of a patient association. This chapter employed the same model as described in chapter 3 to analyze care seeking behavior of people living with HIV/AIDS. Although, the results generally supported findings in chapter 3, power differences in marital relations was found to play an important role at the time of HIV diagnosis and coping with this diagnosis. Some married women discovered their HIV status much later after being infected with HIV infection because their husbands did not disclose their HIV status affecting their ability to seek early care. In addition, many people living with HIV/AIDS utilized a combination of therapies like faith houses and healthcare institutions. Faith houses were also used for psychological support. The findings from this study illustrate the importance of getting the perspectives of people living with HIV/AIDS for the development of feasible interventions towards solving their problems.

In Chapter 7, we described the gender-related differences in societal beliefs and reactions toward people living with HIV/AIDS. Previous chapters have already described the stigmatization of people living with HIV/AIDS. In this chapter, we argue that, despite the fact that men and women with HIV/AIDS suffer the same illness, clear disparities remain in the negative reactions women and men living with HIV/AIDS experience in society. In order to highlight these differences, we compared data from the general public, health care professionals and people living with HIV/AIDS and we applied Connell's (1987) theory of gender and power. We show that women's general low status in society contributes to the extreme negative reactions female people living with HIV/AIDS experience. The gender perspectives in reactions towards people living with HIV/AIDS were shown to be based fundamentally on power differences (financial inequality, authority, structure of social norm) which subsequently influences care in the family, in health care systems and in the society in general. In the family, women accept whatever situation they find themselves in at home in order to keep their men and save their marriage while risking becoming infected with HIV/AIDS by their partners. In the health care system, health care professionals ask female HIV patients to inform their husbands about their HIV-positive status before they want to start treatment. This they do to ensure that payment of hospital bills are guaranteed. In the society, people associate female people living with HIV/AIDS to prostitution and link the infection of males with HIV/AIDS to cuts acquired in a hair salon. 
In Chapter 8, results of the studies were put in perspective by using the model in Chapter 3 and synthesizing the findings from all the studies in the different chapters. We demonstrated that the model identifying the factors that affect care seeking behavior of people living with HIV/AIDS was useful in uncovering the potential areas of intervention for improving the quality of life of people living with HIV/AIDS. Methodological considerations, implications for future research and recommendations for the provision of care were given. 


\section{Samenvatting}

Mensen die leven met HIV/AIDS hebben behoefte aan zorg en steun zowel vanuit de samenleving als van deskundigen in gezondheidsinstellingen om hun kwaliteit van leven te handhaven of te versterken. Het vaststellen van de factoren die de kwaliteit van leven van patiënten met HIV/AIDS bepalen, blijft moeilijk. Een van deze factoren is de stigmatisering van mensen die leven met HIV/AIDS. Het algemene doel van dit proefschrift is het begrijpen van de inhoud en de oorzaken van deze vorm van stigma, waarom mensen met HIV/AIDS in Port Harcourt, Nigeria geen zorg zoeken en geen zorg krijgen van mensen in de samenleving en evenmin van deskundigen in gezondheidszorginstellingen. Het eerste deel van de studies die zijn beschreven in dit proefschrift was gericht op het begrijpen van aan HIV gerelateerde stigma in Afrika beneden de Sahara en het vaststellen van de consequenties van stigma voor het zoeken van zorg (Hoofdstuk 2 en 3). Het tweede deel van de studies in dit proefschrift was gericht op het begrijpen van stigma en andere problemen die mensen die leven met HIV/AIDS in Port Harcourt, Nigeria tegen komen bij het zoeken van zorg (Hoofdstukken 4, 5, en 6). Bovendien werden geslachtsgebonden verschillen in stigma en in het geven van zorg aan personen die leven met HIV/AIDS onderzocht (Hoofdstuk 7).

In Hoofdstuk 1, de algemene inleiding, wordt een overzicht gegeven van epidemiologische informatie over HIV/AIDS in Nigeria, informatie over de pogingen van de Nigeriaanse overheid voor de bestrijding van HIV/AIDS en wordt een verantwoording gegeven voor het onderzoek dat in dit proefschrift is beschreven. Bovendien worden de doelstellingen voor de studies in het proefschrift beschreven en worden een algemeen overzicht en een korte beschrijving van de hoofdstukken gepresenteerd.

In Hoofdstuk 2 worden de literatuur met betrekking tot HIV en stigma, de processen van stigmatisering en de effecten daarvan beschreven. Een systematisch 
overzicht van 65 originele onderzoeken liet zien dat bepaalde beliefs en culturele, religieuze en aan seksualiteit gerelateerde factoren bijdragen aan de stigmatisering van mensen die leven met HIV/AIDS. Bovendien werd deze literatuur geanaliseerd waarbij gebruik werd gemaakt van de vier door Gilmore en Somerville (1994) geconceptualiseerde processen van stigmatiserende reacties: het definiëren van het probleem van HIV/AIDS, het identificeren van mensen die leven met HIV/AIDS, het verbinden van HIV/AIDS aan immoraliteiten en ander negatieve kenmerken, en de gedragsconsequenties van stigma ( afstand nemen, isolering, discriminatie in de zorg). Stereotypen (ideeën, woorden, beelden) over mensen die leven met HIV/AIDS waren in het bijzonder van belang. Verschillende uitdrukkingen zoals "ze is een wandelend geraamte" of "ze werd gevangen in een val" werden gebruikt om mensen die leven met HIV/AIDS te beschrijven. Deze stereotypische uitdrukkingen hebben een grote invloed op mensen die leven met HIV/AIDS en kunnen hun zoeken en gebruikmaken van interventieprogramma's of behandelingen voor HIV beïnvloeden.

In Hoofdstuk 3, waarin de eerste stap van een needs assessment wordt gezet met de beschrijving van de literatuur over HIV/AIDS in Afrika beneden de Sahara, blijkt dat stigma een groot probleem is voor mensen die leven met HIV/AIDS. In deze studie werd de relatie tussen stigma en het zoeken van zorg door mensen die leven met HIV/AIDS geanaliseerd. Geïnspireerd door het PRECEDE-PROCEED model van Green en Kreuter (1999) en op basis van een systematisch overzicht van gepubliceerd onderzoek, werd een verklaringsmodel gemaakt. In dit model is de hypothese vervat dat drie psychosociale determinanten, beliefs, kennis over HIV/AIDS en eigen-effectiviteit, van belang zijn vanwege hun invloed op de copingstrategieën die mensen die leven met HIV/AIDS gebruiken en op de keuzes die mensen maken voor hun gezondheidszorg. Bovendien veronderstellen we dat het kunnen omgaan van mensen die leven met HIV/AIDS met het stigma van HIV/AIDS en het maken van keuzes voor bepaalde zorg, kan afhangen van de mate waarin ze zijn beïnvloed door bepaalde modificerende variabelen zoals armoede, geslacht, leeftijd, religie en politiek. Tenslotte postuleert het model dat mensen die leven met HIV/AIDS ieder van de drie strategieën voor omgaan met HIV/AIDS kunnen toepassen. Ten eerste, omgaan met zichzelf (het fysieke uiterlijk, emotionele en cognitieve problemen), ten tweede, omgaan met anderen in de sociale omgeving, en ten derde, omgaan gericht op het oplossen van problemen die gerelateerd zijn aan de ziekte zelf. We concluderen dat het model bruikbaar is als een representatie van factoren die het niet gebruiken van gezondheidszorgvoorzieningen door mensen die leven met HIV/AIDS in Afrika beneden de Sahara, kunnen bepalen.

Het tweede deel van het onderzoek in dit proefschrift was gericht op de mensen die leven met HIV/AIDS en werd uitgevoerd in de vorm van kwalitatief onderzoek in Port Harcourt, Nigeria (Hoofdstukken 4, 5, 6 \& 7). 
In hoofdstuk 4 werden de beliefs en reacties ten aanzien van mensen die leven met HIV/AIDS onderzocht bij mensen in de samenleving die voor een interview op straat werden benaderd. In dit onderzoek werd vastgesteld dat stigmatisering veel voorkwam bij mensen in de samenleving. De resultaten van dit onderzoek lieten zien dat bepaalde factoren zoals het identificeren van mensen als zijnde besmet met HIV, werden gebaseerd op uiterlijke fysieke kenmerken (terecht of onterecht) en dat HIV/AIDS werd geassocieerd met promiscuiteit, resulterend in stigmatisering. Enkele uitingen van stigmatisering die werden gerapporteerd, betroffen het opsluiten van een persoon met HIV/AIDS in een kamer, het doorgeven van voedsel door een gat in de muur of deur zodat men niet in contact hoefde te komen met de persoon met HIV/AIDS en in een extreem geval het onthouden van voedsel aan een persoon met HIV/AIDS om een snelle dood te bevorderen.

In hoofdstuk 5 werden de problemen van deskundigen die werken in de private en openbare ziekenhuizen verkend. In dit onderzoek werden verschillende factoren geïdentificeerd zoals vrees voor de besmetting met HIV tijdens het werk en het gebrek aan de beschikbaarheid van beschermende materialen (bijvoorbeeld steriele operatiehandschoenen) die een goede zorg in de weg staan en die de stigmatisering van mensen die leven met HIV/AIDS in gezondheidsinstellingen versterken. Effecten van deze factoren op de zorg zoals weigering om te behandelen, condities stellen voor behandeling (bijvoorbeeld geven een hoge rekening voor de zorg), snel doorverwijzing, isoleren en schending van de vertrouwenspositie van de patiënt, werden vastgesteld. Deze bevindingen betekenen dat bepaalde stappen zoals een effectief HIV/AIDS beleid op het werk en de beschikbaarheid van beschermende materialen voor zorgverleners, de zorg voor mensen die leven met HIV/AIDS in gezondheidsinstellingen kunnen verbeteren.

Hoofdstuk 6 was gericht op een beschrijving van de ervaringen van mensen die leven met HIV/AIDS in Port Harcourt, Nigeria door interviews met een steekproef van beschikbare leden van een patiëntenorganisatie. In dit hoofdstuk werd hetzelfde model toegepast dat in hoofdstuk 3 is beschreven voor het zoeken van zorg door mensen die leven met HIV/AIDS. Hoewel de resultaten over het algemeen de bevindingen van hoofdstuk 3 ondersteunen, bleken met name de machtsverschillen in echtelijk relaties een belangrijke rol te spelen in de periode dat de HIV werd gediagnostiseerd en bij het omgaan met de diagnose. Sommige getrouwde vrouwen ontdekten hun positieve HIV-status pas veel later omdat hun echtgenoten hun positieve HIV-status niet bekend maakten, hetgeen van invloed was op hun mogelijkheden om vroegtijdige zorg te vragen. Bovendien gebruikten veel mensen die leven met HIV/AIDS een combinatie van therapieën zoals gebedsgenezing en zorg behandeling in gezondheidsinstellingen. Godsdienstinstellingen werden ook gebruikt voor psycho-sociale steun. De bevindingen van dit onderzoek illustreren het belang van de eigen perspectieven van mensen die leven met HIV/AIDS voor de ontwikkeling van haalbare interventies om hun problemen op te lossen. 
In Hoofdstuk 7 worden de geslachtsgerelateerde verschillen in maatschappelijke beliefs en reacties ten aanzien van mensen die leven met HIV/AIDS beschreven. In voorgaande hoofdstukken is de stigmatisering van mensen die leven met HIV/AIDS beschreven. In dit hoofdstuk laten we zien dat ondanks het feit dat mannen en vrouwen lijden aan dezelfde ziekte, er duidelijke verschillen bestaan in de negatieve reacties die vrouwen en mannen die leven met HIV/AIDS in de samenleving ontmoeten. Om deze verschillen naar voren te halen hebben we de gegevens die we hebben verkregen bij het algemene publiek, de gegevens van de werkers in de gezondheidszorg en die van de mensen die leven met HIV/AIDS met elkaar vergeleken waarbij we de theorie van Connell (1987) over geslacht en macht hebben gebruikt. We laten zien dat de over het algemeen relatief lage status van vrouwen in de samenleving bijdraagt aan de extreme negatieve reacties die vrouwen die leven met HIV/AIDS ervaren. De analyse van het geslachtsperspectief in de reacties tegenover mensen die leven met HIV/AIDS laat zien dat deze fundamenteel zijn gebaseerd op machtsverschillen (financiële ongelijkheid, autoriteit, structuur van sociale normen) die vervolgens de zorg in het gezin, in de gezondheidsinstellingen en de reacties van mensen in de samenleving beïnvloeden. In het gezin accepteren de vrouwen welke situatie dan ook om hun man te behouden en het huwelijk te redden waarbij ze het risico nemen geïnfecteerd te raken met HIV/AIDS door hun partners. In de gezondheidsinstellingen vragen de werkers in de gezondheidszorg hun vrouwelijke patiënten met HIV om hun echtgenoten te informeren over hun HIV-positieve status, voordat zij een behandeling willen beginnen. Dit doen zij om er van verzekerd te zijn dat de rekeningen voor de behandeling worden betaald. In de samenleving worden vrouwelijke patiënten die leven met HIV/AIDS geassocieerd met prostitutie terwijl de infectie met HIV/AIDS bij mannen in verband wordt gebracht met bijvoorbeeld snijwonden opgelopen bij een kapper.

In Hoofdstuk 8 worden de resultaten in een breder perspectief geplaatst waarbij gebruikt is gemaakt van het model dat is samengesteld in hoofdstuk 3 en waarbij de bevindingen van de verschillende hoofdstukken worden geïntegreerd. We laten zien dat het model voor het identificeren van factoren die het zoeken van zorg door mensen die leven met HIV/AIDS bepalen, bruikbaar was voor het verhelderen van de mogelijkheden voor interventies gericht op het verbeteren van de kwaliteit van leven van mensen die leven met HIV/AIDS. Eveneens worden hier methodologische kanttekeningen bij het onderzoek geplaatst, ideeën voor verder onderzoek gegeven en worden aanbevelingen voor de zorg gegeven. 


\section{Appendix}

\section{Questionnaire}

\section{Qualitative research}

\section{Semi-structured Interview questions}

\section{Health care professionals}

- What kind of patients do you like to work with most? Why?

- What kind of patients don't you like to work with? Why?

- What of tuberculosis and HIV patients, do you treat them? Yes or No, why?

- Is it compared to other patients more problematic to work with these patients? Why?

- How do you deal with those problems? Is it easy to deal with these problems? Explain

- Do you think the HIV patients are blamed in any way for getting HIV? By whom? Why? Do you imagine they blame these patients?

- Does this influence the way you care for them?

- Do you think other professionals find it tough to work with this kind of patients? Why?

- How do you think they deal with the problems? Is it easy for them to tackle the problems? Do you agree with the way they deal with those problems? Can you explain that?

- Are any special precautions taken in your hospitals when taking care of these patients?

- Which? Why? (medical technical precautions, keeping the exact nature of your work secret, others?)

- Are you always in a position to take these precautions? When not? What do you do in those cases? Are any other precautions necessary?

- Do your neighbours know you work with HIV patients? Yes or No, Do you think is a problem if they know you work with HIV patients. Why? 
- Does your family feel anyhow when you let them know you work with HIV patients, yes or No, why?

- Do you take your family/neighbours feelings/opinions about it into consideration? Why? How? Does this have influence on your work?

- Are there HIV infected persons admitted to your ward? Has any been refused? why? Are they referred them out more often than other patients? Why?

- Do you know some professionals who did refuse to treat such patients? What do you feel about that? Can you understand that? Explain

- What would be the proper way to care for these people? By whom? Where

- Do you think these people should be cared for in the hospital? Yes or No, explain

- Do you think the sex of the patient matters in any way? Is it more or less problematic to care for male or female HIV patients?

- Who will encounter more problems, a male or a female HIV patient? At home? At the hospital, why?

- Are there any moral dilemmas involved in working with these patients?

- Do you have any advise to other professionals who (will have to ) work with HIV patients?

\section{Society}

- Do you know anyone who has HIV? Male or female? How do you know the person has HIV? How does one recognize a person with HIV?

- Do you think people blame this person for getting HIV? Explain? Do you agree with those people? Explain

- Do you think it affected (will affect) this persons relationship with others? (Neighbours, friends, colleagues, classmates, relatives). Why? In what way?

- The HIV person you know is (wo) man. Would it be different for a man (or vice versa)? Why? In what way?

- Do you still have contact with him/her?

- Has your relationship with the person changed?

- Who is taking care of this HIV person you know? Do you know anyone who is taking care of people with HIV/AIDS? (a professional or a relative)

- How do people usually react to these care takers?

- Do you agree with that? Why?

- Would you care for a HIV person assuming your close relative gets it?

- How would your neighbours/colleagues/classmates etc react to knowing you take care of HIV infected person? Explain.

- Would that matter to you? Would you take these reactions into consideration? Why?

- Would it be wise to keep your care taking activities secret? Why (not)?

- Would it be risky in any way to take care of such a patient? Why? Explain how

- What could be done to avoid this risk?

- What could be done to avoid neighbours reaction? 
- How do you think people get this HIV infection?

- Do you know professionals who work with these patients?

- Do you have contact with that professional? Explain

- Do you think a professional work is more difficult if he/she also treats HIV patients? Why?

- How would a professional, relative, neighbours, friends, react when finding out he/she is taking care of HIV patients? Do you think it would make a difference? How? Why?

- Can or would you imagine such a reaction? Would it matter for your relationship with a person if you know this person takes care of a HIV patient?

- Would you advise such a professional to keep her work a secret?

- What would be proper care for such patients? Where, by whom? How could one reduce the risk of infection?

- Are there any measures that such a professional should take? Explain?

- Do you have advises for people who are suffering from HIV?

- And for those who are taking care of them?

- What do you expect the government/church to do for these people?

\section{HIV persons (Different interview for man and woman)}

- What is your age?

- How did you find out about your status?

- How do you feel when you were told of your status?

- Have you told anyone you have HIV?

- Whom? Why?

- Whom did you not tell? Why not?

- Is it possible to keep it quiet? Have you tried?

- Would advise someone who just found out to keep it quiet?

- Has your relationship with your partner, family, friends, neighbours, colleagues etc changed since they know you have HIV?

- Is anyone taking care of you? Who?

- Was this person willing to take care of you? Why (not)?

- Do you think it was difficult for this person to make that decision?

- Do you have a good relationship with this person? Explain

- Is your care taker the person whom you prefer to be your caretaker? Why? (Or: who would be the best person? And why is this person not able to do it)

- Do you think this person is at risk in any way? (of infections, of becoming an outcast)

- What do you think other people feel about your falling ill?

- Do you think they blame you for it?

- Do they show their feelings 
- Does it matter to you?

- Do you do anything about it? What?

- Do you still go to church after getting HIV

- Does any body in the church know?

- Could they find out? How?

- Have they offered help to you?

- Do you still go to work; has it affected your work in anyway?

- Do your colleagues know? And your boss?

- How did they react? Did they offer help?

- Are you married or single

- Does your partner know?

- Do you still have sexual relationship with your partner(s) without protection?

- Do they know their status?

- Where have you gone for treatment?

- Have you had any problem going and receiving treatment

- Were the professionals nice to you?

- Do you think your status mattered to them?

- Do you think they treat patients with HIV differently?

- What would be the kind of care you need?

- Is it available to you?

- Do you plan to have a baby and do you think this baby will be affected in anyway

- You are a wo(man). Do you think things would be different had you been of the opposite sex? Explain

- Do you have any advices for people who are in the same position as you are? 


\section{Curriculum vitae}

Ngozi C. Mbonu was born on the 6 March 1972 in Enugu, Nigeria. In 1997, she graduated with a Bachelors degree of Medicine and Bachelors degree of Surgery from the University of Nigeria, Nsukka, Nigeria. She did her internship with the University of Port Harcourt teaching hospital, Nigeria. She did a one-year youth service with the developmental health department of the Shell Petroleum Development Company (SPDC), Port Harcourt, Nigeria. She worked for half a year in Adanta Children's Hospital, Port Harcourt, Nigeria.

In the year 2002, she obtained a Masters Degree in Public Health from Maastricht University, The Netherlands. Her professional career included preclinical research training in the Faculty of Medicine, University of Ancona, Italy under Professor Castellucci; clinical and drug trials training in the Kriger Research Institute, Canada; Laser Therapy training in the Department of Dermatology, Phlebology and Laser Therapy, Medical Center Maastricht, The Netherlands; and pursuit of a Doctorate Degree in Public Health, culminating in the thesis reported in this book from the Faculty of Health, Medicine and Life Sciences, Maastricht University, The Netherlands.

She is a Fellow of the Royal Institute of Public Health (FRIPH), a member of the International Association of Physicians in AIDS care, a member of the International AIDS Society, and a member of the Association of Clinical Research Professionals.

She works as a Doctor in Clinical Research in the Department of Dermatology, Phlebology and Laser Therapy, Medical Center Maastricht, The Netherlands. In addition, she is working towards a Clinical Specialization in Internal Medicine.

She has been married to Okey since 1997 and together they have two children, Makua (1999) and Netochi (2004).

Ngozi C. Mbonu

ngozicmbonu@yahoo.com

Maastricht, The Netherlands 



\section{List of publications}

\section{Full papers}

C.A Schroeter, N. Mbonu, T. Reineke, H.A.M Neumann (2006). Blonde hair epilation using electro-optical synergy. Published in Journal of Cosmetic and Laser Therapy. 8 (2), 1476-4172.

Ngozi Mbonu, Elmar Weiler and Careen Schroeter (2008). Electroencephalogram changes caused by mobile phones: a protective device. In: Lecture notes in electrical engineering by Ronald Waynant and Darrell, B. Tata (Eds.). Published as a Chapter in Proceedings of Light-Activated Tissue Regeneration and Therapy Conference, New York: Springer Publishers.

Ngozi C. Mbonu, Careen. A. Schroeter. (2008). Clinical trials in hair and alopecia: management modalities. Published in International Biopharmaceutical Association (IBPA) Publications, Dec 2008 issue.

Ngozi. C. Mbonu, Bart Van Den Borne, Nanne K. De Vries (2009). HIV/AIDS stigma in Africa: Literature review and overview, Published in Journal of Tropical Medicine, doi: 10.1155/2009/145891.

Ngozi. C. Mbonu, Bart Van Den Borne, Nanne K. De Vries (2009). A model for understanding the relationship between stigma and health care seeking behavior among people living with HIV/AIDS in sub-Saharan Africa, Published in African Journal of AIDS Research (AJAR), 8 (2), 201-212.

Ngozi C. Mbonu, Bart Van Den Borne, Nanne K. De Vries (2010). Gender-related power differences, beliefs and reactions towards people living with HIV/AIDS: An urban study in Nigeria, Published in BMC Public health 2010, 10:334.

Ngozi. C. Mbonu, Bart Van Den Borne, Nanne K. De Vries (2010). Living with HIV/AIDS: Experiences and complexities in Port-Harcourt, Nigeria. (Submitted for publication). 
Ngozi. C. Mbonu, Bart Van Den Borne, Nanne K. De Vries (2010). Professional health care delivery problems associated with HIV/AIDS: A Nigerian city situation study (Submitted for publication).

Ngozi. C. Mbonu, Bart Van Den Borne, Nanne K. De Vries (2010). Societal reactions and beliefs about people living with HIV/AIDS: A qualitative study (Submitted for publication).

Schroeter CA, Mbonu N, Reineke T, Neumann, HA

Long term hair reduction achieved using a combination of optical energy and radiofrequency with ELOS. Submitted J Derm Surg.

\section{Abstracts}

C.A. Schroeter, Ngozi C. Mbonu. Transforming growth factor $\beta$ stimulation ELOS An experimental study: histological and statistical results of long term hair removal Barcelona, Spain. $25^{\text {th }}$ annual meeting of the EADV 2005.

C.A. Schroeter, Ngozi C. Mbonu. Effect of mobile phone on EEG: A reversal effect. Tomar Portugal. Presented in Congress on Light activated tissue regeneration and therapy $11.25^{\text {th }}$ June $-29^{\text {th }}$ June 2007 .

Ngozi. C. Mbonu. Health and Disability, African union in Diaspora congress Paris, 11-12 $2^{\text {th }}$ September 2007.

C.A.Schroeter, Ngozi.C.Mbonu. Effect of cell phones on the brain: a protective device. World Congress of anti-aging, Paris, France, $12^{\text {th }}$ April, 2008.

C.A. Schroeter, Ngozi. C. Mbonu Effect of mobile phone on EEG: A reversal effect. Presented in Congress of the Spanish Society of Anti-aging Medicine and Longevity, Semal Valencia, $2^{\text {nd }}$ October- $5^{\text {th }}$ October 2008.

Ngozi. C. Mbonu, Bart Van Den Borne, Nanne, K. De Vries. What makes people living with HIV/AIDS refrain from seeking timely and proper care in health care institutions in Port Harcourt, Nigeria? Journal of International association in Physicians in AIDS care (JIAPAC) Abstract No: 63513. Oral presentation. $5^{\text {th }}$ International conference on HIV Treatment Adherence, Maimi, USA. May 23-25, 2010.

Ngozi. C. Mbonu, Bart Van Den Borne, Nanne, K. De Vries. Professional health care delivery problems associated with HIV/AIDS. Journal of International of Physicians in AIDS Care (JAIPAC). Abstract No. 60623. Poster presentation. $5^{\text {th }}$ 
International conference on HIV Treatment Adherence, Maimi, USA. May 23-25, 2010 .

Ngozi. C. Mbonu, Bart Van Den Borne, Nanne, K. De Vries. Coping mechanisms that people living with HIV/AIDS use: Qualitative study in Port Harcourt, Nigeria. Journal of international association of Physicians in AIDS Care (JIAPAC). Abstract No: 63515. Poster presentation. $5^{\text {th }}$ International conference on HIV Treatment Adherence, Maimi, USA. May 23-25, 2010.

Ngozi. C. Mbonu, Bart Van Den Borne, Nanne, K. De Vries. A model for understanding the relationship between stigma and health care seeking behavior among people living with HIV/AIDS in Sub-Saharan Africa. Journal of International Association of Physicians in AIDS Care (JIAPAC). Abstract No 63511. Poster presentation. $5^{\text {th }}$ International conference on HIV Treatment Adherence, Maimi, USA. May 23-25, 2010.

Ngozi. C. Mbonu, Bart Van Den Borne, Nanne K. De Vries. Current situation of care of HIV/AIDS patients in health care institutions and its impact on treatment adherence: an urban study in Nigeria. Oral presentation World congress of virus and infection Busan, Republic of Korea. 31 July-3 August, 2010.

Ngozi. C. Mbonu, Bart Van Den Borne, Nanne K. De Vries. Using model to understand factors that allow stigma to occur in society and its impact on treatment adherence. Poster presentation World congress of virus and infection Busan, Republic of Korea. 31 July-3 August, 2010.

Ngozi. C. Mbonu, Bart Van Den Borne, Nanne K. De Vries. Consequences of stigma and how it affects people living with HIV. Oral presentation World congress of virus and infection Busan, Republic of Korea. 31 July-3 August, 2010.

\section{Clinical trials participations}

Project on phase 11 study of efficacy of the lowering effect of (unnamed substance) on blood concentrations of low density lipoprotein cholesterol (LDL-C) in patients with normal and elevated blood concentrations of LDL-C (randomized comparative method, multi center study).

Project on phase 11 study of the efficacy of the healing effect of (unnamed substance) on diabetic foot ulcers (randomized comparative method, multi-center study). 
Project on phase 1 study of the efficacy and dose determination of (unnamed substance) for bladder cancer, melanoma and colon cancer (open label, controlled phase 1 study, randomized comparative method, multi center study). 